\title{
ENSAMBLES DE PEQUEÑOS CARNÍVOROS (CARNIVORA: MUSTELIDAE Y MEPHITIDAE) EN PATAGONIA: TAXONOMÍA, DISTRIBUCIÓN Y REPARTICIÓN TRÓFICA.
}

Mauro Ignacio Schiaffini

Directores: Francisco Juan Prevosti y Gabriel Mario Martin

Trabajo de Tesis para optar al título de Doctor en Ciencias Naturales Facultad de Ciencias Naturales y Museo Universidad Nacional de La Plata 


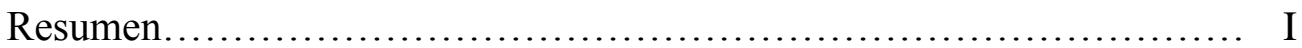

Abstract.............................................................. IV

Agradecimientos................................................ VIII

1. Introducción................................................. 1

1.1. El gremio de los pequeños carnívoros de Patagonia............... 2

1.2. Distribución y variaciones geográficas.......................... 8

1.3. Segregación trófica...................................... 10

2. Objetivos................................................. 12

3. Materiales y Métodos.......................................... 13

3.1. Área de estudio............................................. 13

3.2. Instituciones visitadas...................................... 14

3.3. Morfometría................................................. 16

3.3.1. Morfometría geométrica............................. 16

3.3.2. Morfometría tradicional................................. 18

3.4. Taxonomía de las especies de Conepatus....................... 20

3.5. Distribución de las especies................................. 22

3.5.1. Modelos de distribución potencial........................... 23

3.5.1.a. Distribución de Lyncodon patagonicus...................... 25

3.5.2. Distribución y riqueza................................... 26

3.6. Análisis de segregación trófica............................... 27

3.6.1. Métodos de ordenamiento................................ 27

3.6.1.a. Morfometría geométrica............................. 27

3.6.1.b. Morfometría tradicional................................. 28 
3.6.2. Filogenia y ambientes

3.6.3. Forma y dieta.......................................... 29

3.6.4. Patrones de ordenamiento en el morfoespacio.................. 30

3.7. Variaciones geográficas.................................. 30

3.7.1. Variables climáticas....................................... 31

3.7.2. Autocorrelación espacial................................... 31

3.7.3. Variaciones geográficas de tamaño............................ 33

3.7.3.a. Análisis de regresiones simples.......................... 33

3.7.3.b. Análisis de regresiones múltiples....................... 33

3.7.3.c. Análisis de redundancia................................. 34

3.7.4. Variaciones geográficas de morfología...................... 35

3.7.4.a. Análisis de regresiones multivariadas..................... 35

3.7.4.b. Análisis de redundancia................................. 36

4. Resultados..................................................... 37

4.1. Taxonomía de Conepatus.................................. 37

4.1.1. Análisis de componentes principales..................... 37

4.1.2. Análisis discriminantes................................. 40

4.1.3. Alometría.............................................. 41

4.2. Análisis de distribución................................... 42

4.2.1. Galictis cuja.......................................... 42

4.2.2. Lyncodon patagonicus.................................... 44

4.2.3. Lontra provocax...................................... 47

4.2.4. Neovison vison .......................................... 48

4.2.5. Conepatus chinga...................................... 50

4.2.6. Distribución y riqueza.................................. 52 
4.3.1. Métodos de ordenamiento............................... 53

4.3.1.a. Morfometría geométrica.............................. 53

4.3.1.b. Morfometría tradicional................................ 55

4.3.2. Filogenia y ambientes................................. 56

4.3.3. Forma y dieta.......................................... 58

4.3.4. Patrones de ordenamiento en el morfoespacio................ 59

4.4. Variaciones geográficas.................................. 59

4.4.1. Galictis cuja........................................... 59

4.4.1.1. Variaciones geográficas de tamaño..................... 59

4.4.1.1.a. Análisis de regresiones simples...................... 59

4.4.1.1.b. Análisis de regresiones múltiples...................... 60

4.4.1.1.c. Análisis de redundancia............................... 61

4.4.1.2. Variaciones geográficas de forma....................... 61

4.4.1.2.a. Análisis de regresiones multivariadas................... 61

4.4.1.2.b. Análisis de redundancia............................ 62

4.4.2. Conepatus chinga..................................... 62

4.4.2.1. Variaciones geográficas de tamaño.................... 62

4.4.2.1.a. Análisis de regresiones simples...................... 62

4.4.2.1.b. Análisis de regresiones múltiples...................... 63

4.4.2.1.c. Análisis de redundancia.............................. 64

4.4.2.2. Variaciones geográficas de forma....................... 65

4.4.2.2.a. Análisis de regresiones multivariadas................... 65

4.4.2.2.b. Análisis de redundancia............................. 65

4.4.3. Lyncodon patagonicus.................................. 66 
5. Discusión.

5.1. Taxonomía de Conepatus.................................... 67

5.2. Análisis de distribución..................................... 69

5.2.1. Galictis cuja......................................... 71

5.2.2. Lyncodon patagonicus................................. 74

5.2.3. Lontra provocax...................................... 77

5.2.4. Neovison vison ......................................... 80

5.2.5. Conepatus chinga...................................... 82

5.3. Segregación trófica...................................... 85

5.4. Variaciones geográficas................................ 90

6. Conclusiones............................................... 95

Referencias bibliográficas....................................... 100

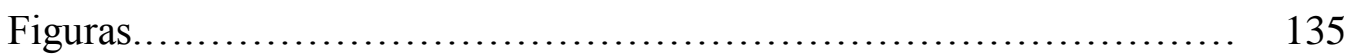

Tablas........................................................... 188

Apéndices.................................................. 252 


\section{Resumen}

Los musteloideos comprenden cerca del $30 \%$ de las especies vivientes del orden Carnivora, con 57 especies reconocidas en 22 géneros en la familia Mustelidae y 12 especies en cuatro géneros en la familia Mephitidae. En Argentina, la diversidad se reduce a nueve especies de mustélidos y dos de mefítidos. Particularmente en Patagonia habitan cinco especies de mustélidos, de los cuales se estudiaron cuatro y dos especies de mefítidos, ambas estudiadas en esta Tesis. De los mustélidos estudiados tres son nativos: Galictis cuja, Lontra provocax, Lyncodon patagonicus y uno introducido, Neovison vison; mientras que los dos mefítidos son nativos: Conepatus chinga y Conepatus humboldtii. El hurón menor (G. cuja) posee una de las distribuciones más amplias de las especies estudiadas, extendiéndose desde el sur de Perú y Brasil, hasta el sur de Argentina y Chile. El huroncito patagónico (L. patagonicus) en contraste, es uno de los carnívoros menos conocidos de Sudamérica, caracterizado como un predador especializado en roedores fosoriales y restringido a áreas xéricas de Argentina. El huillín (L. provocax) posee una de las distribuciones más restringidas entre las nutrias y se lo ha catalogado a su vez, como una especie "amenazada"; con algunas contribuciones estudiando su posible interacción con el visón ( $N$. vison) desde un punto de vista ecológico. La introducción de los visones data de mediados del siglo XX en el noroeste de Patagonia, desde donde ha invadido diversos ambientes patagónicos. Las dos especies de zorrinos comúnmente reconocidas (C. chinga y $C$. humboldtii) han sido descriptas sobre la base de caracteres externos (i.e., coloración del pelaje) y diferencias de tamaño; rasgos actualmente reconocidos como muy variables. Asimismo, un gran número de especies de Conepatus han sido descriptas en los siglos XIX y principios del $\mathrm{XX}$, las cuales fueron posteriormente sinonimizadas sin usar un criterio morfológico claro. El objetivo de la presente Tesis fue estudiar los ensambles de pequeños 
carnívoros patagónicos, centrándose en determinar el estado taxonómico de las especies de zorrinos actuales, dilucidar los patrones de distribución de las mencionadas especies y evaluar su segregación trófica a partir del tamaño y la anatomía craneodentaria. Para ello se visitaron diversas colecciones mastozoológicas, se tomaron datos morfométricos cráneo/mandibulares y dentarios y se registraron las localidades de colección de cada espécimen. Se utilizaron técnicas de morfometría geométrica en dos dimensiones, estudiándose las vistas de cráneo ventral, dorsal, lateral y de mandíbula en vista superior y lateral. Se relevaron todas las localidades de registro, asignándose coordenadas geográficas e integrando la información en diversos Sistemas de Información Geográficos (SIG). Se utilizaron diversos análisis multivariados (e.g., Análisis de Componentes Principales, Análisis Discriminantes, Análisis Multivariado de la Varianza) para estudiar la taxonomía de las especies de Conepatus, y para estudiar los patrones de segregación trófica derivados del morfoespacio generado. Se realizaron análisis de distribución potencial con el software MaxEnt y se evaluó la distribución geográfica en función de un esquema biogeográfico. Asimismo, se analizaron las variaciones geográficas en forma y tamaño de algunas de las especies estudiadas. No se observaron diferencias entre las dos especies de zorrinos analizadas, para ninguna de las vistas de cráneo o mandíbula utilizadas. Aún más, el holotipo de $C$. humboldtii se ubicó dentro del rango de variación morfológica de $C$. chinga en el morfoespacio generado. No se observaron diferencias de tamaño entre las medias de las dos especies, para un $\mathrm{P}<0,01$. Se observaron algunos patrones en común entre los modelos de distribución potencial generados, observando distintas áreas particularmente aptas para la presencia de todas las especies, como el noroeste de Patagonia, que se sitúa en una zona de transición (ecotono) entre las ecorregiones de Bosques Valdivianos y Estepa Patagónica. Se identificó a la Diagonal Árida como una de las principales barreras 
biogeográficas que limita o divide la distribución de los carnívoros estudiados. En cuanto a la segregación trófica, se identificaron los principales patrones morfológicos que agrupan o separan a las especies en distintas funciones ecológicas. L. provocax y $C$. chinga fueron las especies "hipocarnívoras" del gremio, mientras que G. cuja, L. patagonicus y N. vison fueron las tres especies más "hipercarnívoras", mostrando cierto solapamiento en el morfoespacio. Por último, se observaron algunos patrones de variación morfológica y de tamaño de $C$. chinga a escala regional. Tanto $C$. chinga como G. cuja mostraron patrones de variación en tamaño que no se corresponden con una variación latitudinal, siendo claramente opuestos a la regla de Bergmann. Se propone sinonimizar a las dos especies de zorrinos actualmente reconocidas para el sur de Sudamérica bajo el nombre de Conepatus chinga, debido a que es el que presenta la fecha más antigua de descripción. Se caracteriza a C. chinga y G. cuja como dos especies generalistas en cuanto a sus preferencias de hábitat, extendiéndose por una gran superficie del continente sudamericano. Se presentaron los patrones de distribución de L. patagonicus, comprobando que es un habitante típico de zonas áridas y frías, analizando los cambios en su distribución desde el Último Máximo Glaciar. Asimismo, se definieron las principales zonas habitables para L. provocax, identificándolo como un habitante típico de los Bosques Valdivianos, y de manera aislada y/o casual de los ríos de Estepa Patagónica; mientras que N. vison habitó ambientes con condiciones climáticas y de vegetación muy variadas, desde ríos y lagos de Bosques Valdivianos, a ríos de Estepa Patagónica, como el río Chubut y/o el río Senguer. En cuanto a la segregación trófica, el solapamiento de la dieta del huillín y el visón tendería a ser nulo, debido a la morfología "hipocarnívora" del primero (i.e., grandes áreas de trituración en sus molares) e "hipercarnívora" del segundo (i.e., trigónido desarrollado, con talónido muy reducido). El visón se solapó en el morfoespacio con otras dos especies nativas, el 
hurón menor y el huroncito patagónico, aunque en estos casos existirían diferencias notorias en cuanto al uso de hábitat. Estas últimas dos son a su vez, las de mayor similitud en cuanto a morfología y uso de hábitat, pero existieron diferencias notables en su tamaño, lo que podría causar una diferenciación ecológica en cuanto al tipo de presas consumida. Los factores históricos (i.e., cladogénesis) fueron responsables de una gran proporción de la variación en tamaño y morfología. Las variaciones en tamaño y morfología de $C$. chinga se relacionaron principalmente con la productividad ambiental, validando la regla del Recurso, mientras que se rechazó la regla de Bergmann.

\section{Abstract}

Musteloidea comprise $30 \%$ of all Carnivora species, with 57 species in 22 genera within Mustelidae, and 12 species in four genera within Mephitidae. Diversity decreases to nine mustelids and two mephitids in Argentina, and to five mustelids and two mephitids particularly in Patagonia. In this work, four of these mustelids were studied, three native: Galictis cuja, Lontra provocax and Lyncodon patagonicus, and one exotic: Neovison vison; plus the two mephitids species: Conepatus chinga and Conepatus humboldtii. The lesser grison (G. cuja) has one of the widest geographic distributions, ranging from southern Peru and Brazil, to southern Argentina and Chile. The patagonian weasel (L. patagonicus) in contrast, is one of the most poorly known small carnivorans from South America, commonly characterized as a predator specialized in fossorial rodents, and as a typical inhabitant of xeric areas. The huillín $(L$. provocax) is an endangered species that presents one of the most restricted distributions of all otters, with a few studies addressing its possible interespecific interactions with the exotic vison ( $N$. vison) from an ecological perspective. The latter is an exotic species 
introduced at the beginning of the XX century in southern South America, whence it has colonized several patagonic environments. Both commonly recognized skunk species (C. chinga and C. humboldtii) had been described on the basis of external characters (i.e., pelage coloration patterns) and size variation; which are not considered as reliable characters on taxonomical grounds, due to their great variation. Likewise, several Conepatus species were recognized in XIX and XX centuries, and then synonymized without a clear morphological basis. The main goal of this work was to study small carnivoran patagonian assemblages, focusing on taxonomical determination of skunks, elucidating distributional patterns and evaluating their trophic segregation through the study of size differences and craniodental anatomy. Major scientific collections were visited, in order to take morphometric data (crania/mandibles and dental) and record localities of each deposited specimen. Geometric morphometric techniques were used by taking digital photographs of skull in ventral, lateral and dorsal views, and mandibles in superior and lateral views. All record localities were analyzed, assigning geographical coordinates and integrating the information in Geographic Information Systems (GIS). Several multivariate approaches (e.g., Principal Component Analysis, Discriminant Function Analysis, Multivariate Analysis of Variance) were used to review the taxonomical status of Conepatus, and to evaluated trophic segregation in the morphometric space generated. Environmental niche modeling was performed with MaxEnt software, and geographic distribution was analyzed in the context of a biogeographic scheme. Likewise, geographic variation in size and shape was studied for some of the species. There were not morphological differences observed between the two skunks analyzed, using several views from skull and mandibles. Even more, the holotype of $C$. humboldtii falls within the variation range of $C$. chinga, in the generated morphospace. There were not significant differences between the means of both species, 
for a $P<0.01$. Certain patterns were observed between potential distribution models, with some geographic areas being particularly suitable for containing all studied species, such as northwestern Patagonia. This area is located between Valdivian Temperate Forests and Patagonian Steppe ecoregions, in a transitional zone. The South American Dry Diagonal was identified as one of the mains ecological barriers for small carnivorans distribution. As to trophic segregation, the main morphological patterns that groups or divide the guild species according to their ecological function were identified. L. provocax and C. chinga were the "hypocarnivorous" species of the guild, while $G$. cuja, L. patagonicus and N. vison were the "hypercanivorous", showing certain degree of overlap in morphospace. Lastly, some morphological and size variation patterns at regional scale were observed in $C$. chinga. Both the latter and the lesser grison shows size variation patterns that do not agree with a latitudinal pattern, conflicting with Bergmann's rule. I propose to sinonymize both currently recognized skunk species as Conepatus chinga, due to its previous publication date. Both C. chinga as G. cuja were the generalist species of the guild, according to their habitat preferences, extending over a wide continental area. Distribution patterns of $L$. patagonicus confirm its preferences for cold and dry areas, identifying its main changes from Last Glacial Maximum. $L$. provocax was characterized as a typical inhabitant of Valdivian Forests, considering historical localities in Patagonian Steppe as casual or isolated records; while N. vison was distributed in highly variable habitats regarding climatic and vegetation conditions, from lakes and rivers in Valdivian Forests to rivers in Patagonian Steppe, such as Chubut and Senguer basins. As to trophic segregation, I proposed that ecological overlap between huillín and vison is not likely to occur, given the "hypocarnivorous" morphotype of the first, (i.e., large crushing surfaces in its molars) and the "hypercarnivorous" morphotype of the latter (i.e., large trigonids and reduced talonids). 
The vison however, showed morphological overlap with two other native species, the lesser grison and the patagonian weasel, although habitat use differences are expected. These last two, are the most closely related species regarding morphology and habitat use, but there are great size differences between them, which might cause an ecological differentiation pattern, related to the prey type consumed. Historical factos (i.e., cladogenesis) were responsible for a great amount of size and morphological variation between studied species. Regarding specific size and morphological variation of $C$. chinga, they were primarily related to environmental productivity, validating the Resource rule and rejecting Bergmann's rule. 


\section{Agradecimientos}

A mi director Pancho Prevosti, por su guía, su interés y por compartir de manera desinteresada sus enormes conocimientos en todos estos años.

A mi otro director Gabo Martin, por abrirme las puertas del LIEB cuando aún era estudiante, por acompañarme en mi desarrollo profesional e incentivarme a mejorar cada día.

A los encargados y colaboradores de las colecciones visitadas, por permitirme el acceso a los materiales a su cuidado: B. Bender y R. Ojeda (CMI); S. Bogan (FHN); R. Barquez y M. Díaz (IML); D. Flores, S. Lucero y V. Segura (MACN); E. González (MHNM); F. Lagiglia (MHNSR); D. Verzi e I. Olivares (MLP); D. Romero (MMP); E. Casanave y D. Castillo (UNS). A P. Jenkins y M. Portela Miguez por enviarme fotografías de los holotipos depositados en el BMNH.

A Adriana Ruggiero, por toda la ayuda brindada en los temas de Macroecología.

\section{$\mathcal{A}$ Analía por acompañarme siempre y por el apoyo} incondicional. Más allá de las palabras, la compañera de mi vida...

$\mathcal{A}$ mis viejos, responsables en gran medida de mi formación como persona. Un privílegio tener su guía y su ejemplo.

$\mathcal{A}$ los amígos de todos estos años, en particular Guille, Lety y Lucho por compartir los altíbajos propios de esos momentos. 


\section{Introducción}

El Orden Carnivora contiene alrededor de 286 especies vivientes, distribuidas de manera natural en todo el mundo, exceptuando Australia, Nueva Zelanda, Nueva Guinea, Antártida y algunas islas oceánicas (Nowak, 1991; Wozencraft, 2005). El Orden se identifica a partir de la presencia de una "cuchilla carnicera", formada por el cuarto premolar superior $(\mathrm{P} 4)$ y el primer molar inferior $(\mathrm{m} 1)$. Otras de las principales sinapomorfías de los Carnivora, son la fusión de los huesos escafoide y lunar en la muñeca (formando el hueso escafolunar), la pérdida del tercer molar superior (M3), una caja craneal expandida con la sutura fronto-parietal localizada anteriormente, y el borde lateral del basioccipital bien desarrollado (Flynn y Wesley-Hunt, 2005).

El Orden se separa en dos grupos principales, Caniformia y Feliformia (Flynn y Wesley-Hunt, 2005; Goswami, 2010). Las diferencias básicas entre ambos grupos se refieren a la presencia de una bula auditiva compuesta por un solo hueso y no dividida en los primeros, y a una bula auditiva de dos cámaras unidas por un septo en los segundos (Vaughan et al., 2011). Caniformia incluye nueve familias: Canidae, Ursidae, Otariidae, Odobenidae y Phocidae; más cuatro familias dentro de la superfamilia Musteloidea, Ailuridae, Procyonidae, Mephitidae y Mustelidae (Vaughan et al., 2011). A pesar de numerosos esfuerzos, cierta controversia aún persiste en cuanto a la historia evolutiva del Orden (véase Dragoo y Honeycutt, 1997; Bininda-Emonds et al., 1999; Yu et al., 2004; Flynn et al., 2005; Koepfli et al., 2008; Eizirik et al., 2010; Nyakatura y Bininda-Emonds, 2012; Sato et al., 2012). La monofilia de la superfamilia Musteloidea ha sido demostrada en diversos estudios filogenéticos, así como también se han elucidado muchas de sus relaciones internas (véase Sato et al., 2012 y referencias allí citadas). Musteloidea comprende casi el 30\% de las especies vivientes de Carnivora, con 84 especies vivientes agrupadas en 33 géneros. De estas, 57 especies con 22 
géneros se reconocen en la familia Mustelidae y 12 especies con cuatro géneros en Mephitidae (Wilson y Mittermeier, 2009). Los mustélidos en general son de pequeño tamaño, poseen miembros cortos, cuerpo alargado y de forma tubular. Generalmente, presentan una larga caja craneana, con rostro corto, el proceso postglenoideo puede abarcar la fosa glenoidea, brindando una fuerte unión cráneo-mandibular, sin movimientos rotatorios y mínimos movimientos laterales (Vaughan et al., 2011). Los mefítidos también son de pequeño tamaño, y suelen presentar morfologías adaptadas para cavar, con fuertes y cortos miembros delanteros con largas uñas (Vaughan et al., 2011). Ambas familias son prácticamente cosmopolitas, abarcando un amplio rango de condiciones climáticas y un gran espectro de hábitats (Sato et al., 2012). En Argentina, existen actualmente nueve especies de mustélidos y dos de mefítidos (Díaz y Lucherini, 2006). Particularmente en Patagonia (sensu lato) el número disminuye a cinco especies de mustélidos, con cuatro nativas: Galictis cuja (Molina, 1782), Lontra provocax (Thomas, 1908), Lontra felina (Molina, 1782) y Lyncodon patagonicus (Blainville, 1842); y una introducida: Neovison vison (Schreber, 1777). Además, existen dos especies de zorrinos: Conepatus chinga (Molina, 1782) y Conepatus humboldtii Gray, 1837 (Wozencraft, 2005; Díaz y Lucherini, 2006).

\subsection{El gremio de los pequeños carnívoros de Patagonia}

El hurón menor, Galictis cuja, posee la distribución más extensa de los mustélidos presentes en Patagonia, registrándose desde el sur del Perú hasta el sur de Argentina, incluyendo Bolivia, Paraguay, Uruguay y Chile (Yensen y Tarifa, 2003a; Bornholdt et al., 2013). Se lo encuentra en ambientes tan diversos como el Chaco Seco, el Bosque Tropical y la Estepa Patagónica (Prevosti y Travaini, 2005). Si bien es posible que habite en las cercanías de cuerpos de agua (Mares et al, 1989) y 
considerando que posee miembros palmeados (Yensen y Tarifa, 2003a), se ha sugerido la posibilidad de que exista competencia con el "visón norteamericano" Neovison vison. Delibes et al. (2003) demostraron que existe separación de nichos en cuanto a sus presas, ya que el primero se alimentaría principalmente de roedores nativos y lagomorfos introducidos y se ha sugerido que el segundo depende de presas acuáticas. Los conocimientos sobre esta especie se han incrementado en los últimos años, incorporándose información y una evaluación sobre su estado taxonómico (Bornholdt et al., 2013), morfología y funcionalidad de a musculatura y sus implicaciones filogenéticas (Ercoli et al., 2012), distribución a diferentes escalas (Carrera et al., 2012; Bornholdt et al., 2013).

El huroncito patagónico, Lyncodon patagonicus, es uno de los carnívoros menos conocidos de Sudamérica (Prevosti y Pardiñas, 2001). En Argentina, habita estepas herbáceo-arbustivas y áreas xéricas desde Salta hasta Santa Cruz, a lo largo del límite con Chile (Osgood, 1943; Prevosti y Pardiñas, 2001). La escasa información disponible lo caracteriza como un animal nocturno, que preda fundamentalmente sobre roedores fosoriales (Cabrera y Yepes, 1940; Redford y Eisenberg, 1992). Es una especie enigmática (Harris, 2008) y debido a la falta de información ha sido clasificada como “casi amenazada” por el Libro Rojo de los Mamíferos de Argentina (Díaz Isenrath et al., 2012). La corología de este pequeño carnívoro ha sido estudiada por Prevosti y Pardiñas (2001), quienes destacaron la existencia de cambios en su área de distribución asociado a diversos cambios climáticos, en particular precipitaciones. Un reciente análisis ubica a esta especie como el taxón hermano de Galictis, conformando la tribu Lyncodontini con un origen cercano a los 2.6-2.9 Mya (millones de años), dentro de la subfamilia Ictonychinae (Sato et al., 2012). 
El huillín, Lontra provocax, probablemente posea el área de distribución geográfica más restringida de todas las nutrias (Chehébar, 1986), estando sólo presente en el suroeste de Argentina y Chile, entre $\operatorname{los} 36^{\circ} \mathrm{S}$ y $\operatorname{los} 52^{\circ} \mathrm{S}$, y en la Isla de los Estados (Chehébar et al, 1986). Es una especie que habita principalmente ambientes de agua dulce y, secundariamente, el litoral marino (Larivière, 1999a). Prefiere los cuerpos de agua con litorales rocosos y una franja de vegetación que le permita un acceso imperceptible al agua (Sielfeld y Castilla, 1999). En Argentina, esta especie estaría restringida al oeste de las provincias de Neuquén y Río Negro, y potencialmente en Chubut y Santa Cruz, con algunas incursiones en la estepa patagónica, pero poco frecuentes (Chébez, 2008). Se alimenta principalmente de crustáceos y peces, con gran predominio de los primeros (Sielfeld y Castilla, 1999); además, su dentición exhibe una tendencia hacia la especialización para la trituración (van Zyll de Jong, 1972). Las poblaciones de huillín han disminuido notablemente desde principios de siglo $\mathrm{XX}$, ya sea por la cacería desmedida o por la destrucción y fragmentación de su hábitat (Larivière, 1999a). Es una especie considerada vulnerable por la IUCN (International Union for Conservation of Nature), “en peligro" por el Libro Rojo de Mamíferos Amenazados de Argentina (Valenzuela et al., 2012a) y amenazada por el Libro Rojo de los Vertebrados de Chile (Porro y Chehébar, 1995). Las contribuciones al estudio de esta especie son escasas y datan de años recientes, destacándose estudios ecológicos en los cuales se evalúa la posible competencia interespecífica con Neovison vison (Fasola et al., 2009; Valenzuela et al., 2012b) y un estudio filogeográfico en el cual se evalúan diversas hipótesis sobre la existencia de refugios durante el Último Máximo Glacial (UMG; Vianna et al., 2011). La segunda especie del género, L. felina, habita principalmente ambientes marinos en la costa del océano Pacífico (Vianna et al., 2010) 
y se encuentra restringida a la provincia de Tierra del Fuego en Argentina, por lo cual no fue evaluada en el presente estudio.

El visón americano, Neovison vison, es un mustélido Holártico que fue introducido en Patagonia en repetidas ocasiones desde mediados de la década de 1940 hasta la de 1970 (Pagnoni et al., 1986). Su introducción se originó debido a la instalación de criaderos para el comercio de su piel, pero el cierre de dichos criaderos y los sucesivos escapes lo han hecho un mamífero común en los ambientes patagónicos. Debido a que habita ambientes similares a Lontra provocax, podría esperarse algún tipo de competencia interespecífica. Diversos estudios destacan la existencia de una separación ecológica a nivel trófico, siendo que $N$. vison se alimenta principalmente de peces, pequeños mamíferos, aves e invertebrados (Larivière, 1999b); mientras que en la dieta de L. provocax predominan los crustáceos (Sielfeld y Castilla, 1999). Fasola et al. (2009) no detectaron cambios en la dieta del huillín comparándola con un período previo a la introducción del visón. Más recientemente, se ha identificado la segregación trófica como el proceso que permitiría la coexistencia de ambas especies en Tierra del Fuego (Valenzuela et al., 2012b). Tradicionalmente incluido en el género Mustela, revisiones taxonómicas (morfológicas y moleculares) recientes, justifican su separación como la única especie viviente dentro del género Neovison (Baryshnikov y Abramov, 1997; Abramov, 2000; Sato et al., 2012).

El zorrino patagónico, Conepatus humboldtii, es uno de los dos representantes de la familia Mephitidae en el extremo sur de Patagonia, extendiéndose por las provincias de Río Negro, Chubut y Santa Cruz, además de regiones adyacentes en Chile (Osgood, 1943). El género Conepatus ha sido pobremente estudiado en la región Neotropical (Donadio et al., 2001) y la mayoría de los estudios se realizaron con Conepatus chinga, especie que se encuentra registrada hasta la provincia del Neuquén. 
Sin embargo, debido a la relativa homogeneidad de la estepa patagónica, quizás pueda encontrarse en localidades más australes. A la carencia de estudios sobre distribución en las especies de este género, se debe sumar la controversia general existente sobre el número de especies y la variación geográfica de sus caracteres morfológicos (Dragoo et al., 2003). De hecho, la familia ha sido objeto de recientes investigaciones ya que tradicionalmente fue incluida dentro de la familia Mustelidae, fundamentado en la presencia de algunos caracteres con un alto grado de homoplasia (e.g., grandes glándulas anales, pérdida del segundo molar superior y la falta de una “muesca" en el cuarto premolar superior; Wilson y Mittermeier, 2009). En base a un análisis de ADN mitocondrial y ARN ribosomal, se propuso elevar a categoría de familia la subfamilia Mephitinae, constituyendo la familia Mephitidae, incluyendo a las especies de los géneros Mydaus, Mephitis, Spilogale y Conepatus (Dragoo y Honeycutt, 1997). Este arreglo sistemático ha sido aceptado y seguido en diversas revisiones sistemáticas (véase Wozencraft, 2005; Wilson y Mittermeir, 2009). Asimismo, la compleja historia taxonómica de las especies de Conepatus de Argentina es aún incierta, con varias especies descriptas durante los siglos XIX y XX que fueron sinonimizadas posteriormente (Cabrera, 1958). Utilizando patrones de coloración del pelo y el tamaño, Cabrera y Yepes (1940) reconocieron cinco especies para Argentina: C. suffocans (Illiger, 1881), C. castaneus (d'Orbigny y Gervais, 1847), C. humboldtii, C. chinga y C. rex Thomas, 1898. Posteriormente, Cabrera (1958) reconoció sólo cuatro especies, indicando que $C$. suffocans sería un sinónimo de $C$. chinga. Este autor también incluye C. budini Thomas, 1919 y C. gibsoni Thomas, 1910 dentro de C. chinga; y comenta que C. castaneus podría representar una población de $C$. humboldtii con una ubicación más septentrional (Cabrera, 1958). Un estudio sistemático de las especies de Conepatus de Argentina, utilizando caracteres cuantitativos sobre una muestra de pieles (Kipp, 1965) 
propuso incluir a $C$. rex dentro de $C$. chinga, y a $C$. castaneus dentro de $C$. humboldtii. La separación de $C$. chinga y $C$. humboldtii se fundamentó en la coloración de las bandas blancas en el dorso, y a la presencia/ausencia de pelos bicolores en la cola, respectivamente. El trabajo de Kipp (1965) reitera un patrón identificado 70 años antes por Milne-Edwards et al. (1891), quienes plantearon que las pequeñas diferencias entre C. castaneus y $C$. humboldtii no justificaban la existencia de dos especies plenas. Van Gelder (1968) estudió una población de zorrinos de Uruguay identificando una gran variabilidad en la coloración del pelo en $C$. chinga, incluso en zorrinos provenientes de una misma localidad, implicando que este carácter debería ser usado con muchísima precaución (o ser directamente eliminado) al momento de asignar la pertenencia de individuos a una determinada categoría taxonómica. Varios autores (Van Gelder, 1968; Honacki et al., 1982; Wozencraft, 2005; Wilson y Mittermeier, 2009) siguieron el arreglo sistemático propuesto por Kipp (1965) en algunos aspectos pero no en otros (e.g., incluyendo C. castaneus en C. humboldtii, no incluyendo C. suffocans, C. gibsoni y C. mendosus Thomas, 1921 en $C$. humboldtii, respectivamente).

De esta manera, las dos especies de zorrinos de Argentina fueron descriptas sobre la base de caracteres externos, tal como el tamaño y los patrones de coloración del pelaje, como se observa en la descripción original de $C$. humboldtii: “... black, with some rather shining hairs, with a broad white band along each side of the back...." (Gray, 1837). Sin embargo, varios autores describieron una extensa variabilidad de los caracteres externos (Van Gelder, 1968; véase también Yepes, 1936; Cabrera y Yepes, 1940; Cabrera, 1958; Kipp, 1965; Dragoo et al., 2003; Dragoo y Sheffield, 2009). La ausencia de caracteres diagnósticos genera una situación confusa en la delimitación de estas especies y una circularidad, debido a que los especímenes son identificados basándose solamente en su localidad de colecta (i.e., Patagonia $=C$. humboldtii, resto de 
Argentina, Chile y Uruguay $=C$. chinga . Varios autores han destacado la necesidad de una revisión sistemática de estas especies de zorrino (e.g., Galliari et al., 1996; Forasiepi, 2003; Wang y Carranza-Castañeda, 2008). Una revisión reciente de los zorrinos de América del Norte, C. leuconotus y C. mesoleucus, demostró que se trata de una sola especie (Dragoo et al., 2003). Quizás una una situación similar esté ocurriendo entre $C$. chinga y $C$. humboldtii en América del Sur. La falta de conocimientos sobre estas especies presenta un serio riesgo para su conservación, dado que $C$. humboldtii se incluye en el apéndice II del CITES (Emmons y Helgen, 2008), aunque no así $C$. chinga.

\subsection{Distribución y variaciones geográficas}

Los patrones de distribución no han sido estudiados de igual manera para estas seis especies, con algunas contribuciones explorando aspectos particulares y a diferentes escalas, a saber: 1) se ha demostrado que G. cuja habita desde el extremo sur de Perú, sur de Bolivia y noreste de Brasil hasta el extremo sur de Argentina y Chile (Bornhold et al., 2013); 2) un análisis filogeográfico de L. provocax obtuvo diversas hipótesis sobre la presencia de refugios durante el UMG, pero no se analizan particularmente las áreas habitadas o susceptibles de serlo (Vianna et al., 2011); 3) diferentes análisis sobre aspectos corológicos en L. patagonicus, incluyendo la distribución de especímenes fósiles, han demostrando la importancia de cambios en su distribución relacionados con las precipitaciones (Prevosti y Pardiñas, 2001; Prevosti et al., 2009; Schiaffini et al., 2013a).

El estudio de los patrones de distribución y variaciones geográficas resulta interesante en estas especies que habitan el sur de América del Sur, debido a que esta zona presenta una gran diversidad de condiciones climáticas, incluyendo áreas 
tropicales, subtropicales y extratropicales (Garreaud et al., 2009), representando un área de particular interés que permite la existencia de condiciones particulares y fuertes gradientes ambientales (Morello, 1985). A su vez, una alta heterogeneidad ambiental podría estar relacionada con la aparición de clinas (Meiri et al., 2007), con importancia en patrones macroecológicos. Asimismo, es importante para los planes de manejo de diversidad a largo plazo, conocer las relaciones entre una determinada especie y el área que habita. Debido a que las especies en estudio son las representantes más australes de las familias, los análisis de distribución también aportarán información acerca de los procesos de colonización en el sur del continente.

El estudio de la variación del tamaño corporal a gran escala (i.e., continental), es uno de los desafíos más importantes de la macroecología (Olalla-Tárraga et al., 2006). Aunque la variación en tamaño ha sido estudiada para mamíferos del hemisferio norte (e.g., McNab 1971; Ochosinska y Taylor, 2003; Blackburn y Hawkins, 2004), los de Sudamérica han recibido menos atención (véase Kurtén, 1973; Lucherini et al., 2006; Martínez et al., 2013). Como los carnívoros en general presentan grandes rangos geográficos en su distribución, han sido utilizados frecuentemente para estudiar patrones macroecológicos (Meiri et al., 2004). Las variaciones en tamaño en general han sido relacionadas a la existencia de un gradiente, desde especímenes de mayor tamaño en altas latitudes, hacia especímenes de menor tamaño a bajas latitudes, la consabida "regla de Bergmann" (Bergmann, 1847). Sin embargo, cierta controversia existe respecto a la utilización de la regla de Bergmann para estudios intra o interespecíficos (véase Geist, 1987; Meiri y Dayan, 2003; Meiri et al., 2004; Rodríguez et al., 2006; Yom-Tov y Geffen, 2006; Blackburn et al., 1999). Recientemente, se ha introducido una nueva "regla" según la cual las variaciones espaciales en tamaño podrían ser explicadas por la disponibilidad y las características del recurso consumido 
("regla del recurso", McNab, 2010). En cuanto a las variaciones geográficas de forma, existe un vacío de conocimiento aún mayor que para el caso del tamaño. La importancia de conocer dichas variaciones no radica solamente en la interpretación de los patrones macroecológicos antes mencionados, sino que también aporta las bases para entender los patrones de variaciones morfológicas, aplicables a futuros análisis taxonómicos de especies relacionadas (actuales o fósiles).

\subsection{Segregación trófica}

Diversos estudios han destacado la importancia de interpretar la morfología dentaria y su relación con el tamaño en carnívoros, relacionándolo directamente con sus preferencias dietarias (Dayan et al., 1989; Van Valkenburgh, 2007) y determinando morfotipos que pueden ser descriptos como "hipercarnívoros" (o adaptados a una alimentación con más del 70\% de vertebrados) "hipocarnívoros" (o adaptados a una alimentación con más del 70\% de no-vertebrados; Ewer, 1973, Van Valkenburgh, 2007). Es posible que estas adaptaciones hayan evolucionado como una respuesta a la competencia por el alimento (Van Valkenburgh, 1995), que a su vez es una de las mayores fuerzas que estructura los ecosistemas (Dayan y Simberloff, 1998). En este sentido, se espera que los miembros de un gremio (“guild” sensu Root, 1967) sean potenciales competidores, o que hayan evolucionado de tal manera que eviten la competencia en zonas de simpatría. Una partición en el recurso relacionada al tamaño de la presa fue detectada para mustélidos de Gran Bretaña e Irlanda (Dayan y Simberloff, 1994); aunque otro estudio encontró que el tamaño de la presa no aumenta con el tamaño del depredador para las mismas especies (McDonald, 2002). Davies et al. (2007) proponen que la co-ocurrencia de las especies puede ser explicada por tres alternativas diferentes: 1) especies simpátricas tienden a tener ecomorfotipos similares, 
debido a que se encuentran adaptadas al mismo ambiente; 2) especies simpátricas presentan distintos ecomorfotipos, para evitar interacciones competitivas; o 3) la ecomorfología de especies simpátricas no está relacionada.

Para las especies aquí estudiadas, existen muy pocas referencias en cuanto a la posible competencia o segregación trófica; los estudios realizados han estado centrados principalmente, en la relación entre Lontra provocax (nativa) y Neovison vison (introducida) por ocupar ambientes similares (véase Fasola et al., 2009; Valenzuela et al., 2012b). Zapata et al. (2008), estudiaron la posición trófica relativa dentro de un gremio que incluía, entre otras especies, a C. chinga y G. cuja, identificando las adaptaciones que caracterizan a cada tipo de predador. Los estudios anatómicos y/o morfométricos podrían ayudar a identificar patrones de segregación trófica entre especies simpátricas de diferente manera, permitiendo identificar la presencia de procesos competitivos entre especies, contribuyendo a un mejor entendimiento de cómo se estructura un gremio, y cómo dieta, filogenia y hábitat se relacionan con la forma del cráneo y mandíbulas, en estos pequeños carnívoros. 


\section{Objetivos}

\subsection{Objetivo general}

$\checkmark$ Estudiar los ensambles de pequeños carnívoros (Carnivora, Musteloidea) de Patagonia, utilizando la morfología funcional como herramienta primaria para determinar los diferentes roles de cada especie en la comunidad (e.g., repartición de recursos tróficos) y evaluando su distribución a escala regional.

\subsection{Objetivos particulares}

$\checkmark$ Esclarecer el estatus sistemático de las especies de Conepatus de Argentina.

$\checkmark$ Precisar la distribución de estos pequeños mustélidos en Patagonia y su relación con distintos parámetros climáticos y ambientales.

$\checkmark$ Analizar la composición taxonómica de los ensambles de pequeños mustélidos en distintas áreas de Patagonia.

$\checkmark \quad$ Inferir la diversidad trófica de las especies presentes a partir del análisis de caracteres craneomandibulares y dentarios.

$\checkmark$ Evaluar la superposición de nichos entre las distintas especies, la existencia de desplazamientos competitivos y su relación con sus atributos morfológicos (e.g., tamaño corporal, morfología del aparato trófico).

$\checkmark$ Investigar las posibles interacciones entre los mustélidos nativos y exóticos (i. e., Neovison vison). 


\section{Materiales y Métodos}

\section{1. Área de estudio}

Se consideraron dos escalas espaciales distintas, en función de los objetivos planteados. Tanto para el análisis taxonómico de las especies de Conepatus de Argentina como para los análisis de distribución, se trabajó a escala continental (i.e., América del Sur, principalmente Argentina, Chile y Uruguay); mientras que para los análisis de segregación trófica se analizó particularmente el cono sur de América del Sur (centro-sur de Argentina).

Los patrones climáticos en América del Sur son altamente dependientes de la cordillera de los Andes, que se ubica al oeste de Sudamérica desde el norte del ecuador hasta $\operatorname{los} 55^{\circ}$ de latitud sur, con elevaciones variables y actuando como una "pared climática" (Garreaud et al., 2009). La circulación de los vientos sobre la porción subtropical está bajo la influencia de dos anticiclones semi-permanentes, el anticiclón del pacífico sur, que determina una alta variabilidad en las precipitaciones al oeste del continente; y el anticiclón subtropical atlántico, que transporta abundante humedad hacia las regiones centrales del continente, al este de los Andes (Mancini et al., 2005). Esto resulta en un arreglo muy diverso de condiciones climáticas en la parte sur del continente (Morello, 1985), que a su vez determina la distribución de diversos sistemas vegetales (Eva et al., 2004). Siguiendo el esquema biogeográfico ecorregional de Olson et al. (2001), el área de estudio incluye básicamente una diagonal árida desde el NO al SE de Argentina, que incluye las ecorregiones denominadas Monte Bajo (Low Monte) y Estepa Patagónica (Patagonian Steppe), que puede considerarse como un límite climático real entre áreas más húmedas (Bruniard, 1982); áreas abiertas y productivas en Argentina y Uruguay (Pampas Húmedas y Sabana Uruguaya); y un bosque lluvioso y 
frío en el sur de Argentina y Chile (Bosques Valdivianos; Morello, 1985; Burkart et al., 1999; Olson et al., 2001); entre otros (véase Figura 1).

\subsection{Instituciones visitadas}

Se visitaron las siguientes instituciones científicas (con sus acrónimos correspondientes), para analizar los especímenes depositados de las especies en estudio:

- CMI, Colección de Mamíferos del IADIZA, Mendoza, República Argentina.

- FHN, Fundación de Historia Natural Félix de Azara, Ciudad Autónoma de Buenos Aires, República Argentina.

- IML, Instituto Miguel Lillo, San Miguel de Tucumán, República Argentina.

- LIEB, Laboratorio de Investigaciones en Evolución y Biodiversidad, Esquel, República Argentina.

- MACN, Museo Argentino de Ciencias Naturales "Bernardino Rivadavia", CABA, República Argentina.

- MHNM, Museo de Historia Natural de Montevideo, Montevideo, República Oriental del Uruguay.

- MHNSR, Museo de Historia Natural de San Rafael. San Rafael, República Argentina.

- MLP, Museo de La Plata, La Plata, República Argentina.

- MMP, Museo Municipal de Mar del Plata "Lorenzo Scaglia”, Mar del Plata, República Argentina.

- UNS, Universidad Nacional del Sur, Bahía Blanca, República Argentina. Asimismo, se procedió a recolectar individuos encontrados muertos, a lo largo de rutas y caminos. Los mismos fueron procesados en la Facultad de Ciencias Naturales, Universidad Nacional de la Patagonia "San Juan Bosco", sede Esquel, y 
depositados en la colección mastozoológica del LIEB. También se analizaron algunos especímenes de instituciones científicas visitadas por mi director, enviadas por el personal correspondiente, o presentes en sus bases de datos:

- $\mathrm{AMNH}$, American Museum of Natural History, Nueva York, Estados Unidos de América.

- BMNH, British Museum of Natural History, Londres, Reino Unido.

- FMNH, Field Museum of Natural History, Chicago, Estados Unidos de América.

- IZP, Instituto Zoológico de la Patagonia, Punta Arenas, República de Chile.

- MHNN, Muséum National d'Histoire Naturelle, París, República de Francia.

- MNHNS, Museo Nacional de Historia Natural de Santiago, República de Chile.

- MSF. Museo de Santa Fe, República Argentina.

- NMW, Naturhistorischen Museum Wien - Mammalogy. Viena, República de Austria.

- SMNS, Staatliches Museum für Naturkunde Sttutgart - Mammalogy. Sttutgart, República Federal de Alemania.

- SNMNH, Smithsonian Museum of Natural History, Washington, Estados Unidos de América.

La lista completa de especímenes analizados por especie, se detalla en el Apéndice I.

Se tomaron los siguientes datos de cada uno de los especímenes estudiados: fecha y localidad de colecta (localidad, provincia, país), sexo y edad, siguiéndose para esto último a Van Gelder (1968), y clasificándose a los individuos en tres categorías: juvenil, con la dentición definitiva no completamente erupcionada; subadulto, con la dentición definitiva presente, pero con la sutura basioccipital-basiesfenoide visible; y 
adulto, con dentición permanente y sin suturas visibles. Además, se tomaron diversos datos morfométricos que se detallan en las secciones siguientes.

La nomenclatura de la morfología craneana/mandibular se definió siguiendo a Van Gelder (1968) y Forasiepi (2003), mientras que la dentaria siguiendo a Popowics (2003) y Szuma (2004). La dentición superior se definió con letras mayúsculas y la inferior con minúsculas (e.g., M1 para el primer molar superior, p4 para el cuarto premolar inferior).

Si las localidades de colecta/captura no contaban con coordenadas geográficas, estas le fueron asignadas con la ayuda de gaceteros (www.fallingrain.com) y mapas de referencia (e.g., departamentos, caminos). A un alto número de especímenes analizados no fue posible asignarle coordenadas geográficas específicas, ya que no se contaba con información suficiente (e.g., los únicos datos de colecta del espécimen Conepatus sp. MLP 1274 se refieren a "Pcia. Buenos Aires").

\subsection{Morfometría}

Se utilizaron diversas técnicas de morfometría geométrica y morfometría tradicional, las cuales sirvieron para el análisis taxonómico de las especies de Conepatus, para los análisis de segregación trófica, y para el estudio de variación geográfica intraespecífica. A continuación, en las secciones 3.3.1 y 3.3.2, se detalla el proceso general utilizado en las técnicas morfométricas, especificándose en las secciones siguientes el tipo de análisis morfométrico utilizado.

\subsubsection{Morfometría Geométrica}

Se tomaron fotografías digitales en dos dimensiones de las especies en estudio, para aplicar técnicas de morfometría geométrica. Se utilizaron vistas del cráneo en 
posición ventral, lateral y dorsal, y de mandíbula lateral y superior. Los cráneos y mandíbulas fueron orientados de manera paralela al plano de la mesa de trabajo y la cámara fotográfica, utilizando el paladar, los arcos cigomáticos y el plano sagital de la rama horizontal de la mandíbula. La cámara fotográfica (Sony DSC-HX1) fue colocada con un trípode sobre la mesa, y su orientación (paralela) se determinó mediante la utilización de un nivel “ojo de buey”. Todos los especímenes fueron fotografiados ubicándolos en el centro de la imagen, para evitar los efectos de deformación de los bordes de las fotografías producidos por las lentes.

Se utilizaron landmarks de tipo I, II y de tipo III (o semilandmarks) sensu Bookstein (1991). Para un correcto posicionamiento de los semilandmarks, se utilizó el software MakeFan 6 (Sheets, 2002), que permite dibujar líneas a lo largo de superficies curvas en la cuales no es posible la colocación de landmarks de tipo I y II. Para compilar las imágenes, se utilizó el software tpsUtil v. 1.40 (Rohlf, 2008a) y para colocar los landmarks se utilizó el software tpsDig 2.12 (Rohlf, 2008b). Se realizó Análisis Generalizado de Procrustes (GPA por sus siglas en inglés, Generalized Procrustes Analysis; Goodall, 1991; Rohlf, 1999), minimizando la suma de las distancias al cuadrado entre landmarks homólogos, rotando, reflejando, trasladando y escalando a la unidad, a cada una de las configuraciones de landmarks, utilizando el software tpsRelw v 1.35 (Rohlf, 2003). Los semilandmarks se trataron con la función TPS (Thin-Plate Splines; Bookstein, 1989, 1991), según la cual se minimiza la “energía de deformación" (bending energy) entre una forma de referencia y una forma objetivo (target) (Gunz y Mitteroecker, 2013). De esta forma, se obtiene un conjunto de datos representando la forma del objeto de estudio (coordenadas de Procrustes), de manera independiente del tamaño. Como estimador de tamaño, se utilizó el tamaño del centroide (Cs por sus siglas en inglés para Centroid size), definido como la raíz 
cuadrada de la suma de las distancias al cuadrado de cada landmark al centroide de la forma (Zelditch et al., 2004). Para algunos análisis posteriormente detallados, se utilizó también el software MorphoJ v 1.03c (Klingenberg, 2011).

La elección de los landmarks en los diferentes análisis respondió a obtener una buena representación de la anatomía del cráneo, las mandíbulas y la dentición. Elecciones similares de landmarks y semilandmarks pueden verse en Auffray et al. (1996); Marcus et al. (2000); Christiansen (2008); Prevosti et al. (2012); Segura et al. (2013) entre otros.

\subsubsection{Morfometría tradicional}

Se tomaron 37 medidas craneodentarias (Figura 2) con calibre digital con precisión de 0,01mm; extraídas o modificadas de Van Gelder (1968) y Zapata (2008). A continuación se detallan las medidas tomadas:

\section{$\underline{\text { Craneanas }}$}

Longitud cóndilobasal (LCB): desde los cóndilos occipitales hasta el borde anterior de los incisivos.

Largo total (LT): desde el inion hasta el borde anterior de los premaxilares.

Largo cóndilo-orbital (LCO): largo desde los cóndilos occipitales hasta el borde anterior de la órbita.

Largo del Paladar (LP): desde el borde anterior de los incisivos hasta el torus palatino. Ancho máximo del paladar (AmaxP): ancho máximo del paladar entre el P4 y el M1, tomado en el borde labial.

Ancho intercanino (AiC): ancho máximo entre los caninos. 
Ancho interorbitario mínimo (AiOmin): ancho interorbitario, tomado en el borde anterior de las órbitas.

Constricción postorbitaria $(\mathbf{C p O})$ : ancho de la constricción postorbitaria.

Ancho craneal (AC): ancho de la caja craneana (sin los procesos mastoideos).

Ancho mastoideo (AM): ancho máximo incluyendo los procesos mastoideos.

Largo de la bula (LB): tomada entre el proceso mastoideo y el borde anterior de la bula. $\underline{\text { Serie dentaria superior }}$

Serie dentaria superior (SDsup): desde el borde anterior del canino hasta el borde distal de M1.

Ancho de la serie incisiva superior (ASIsup): entre los bordes distales de I3.

Largo máximo del canino (LC).

Ancho máximo del canino (AC).

Largo máximo del tercer premolar (LP3).

Ancho máximo del tercer premolar (AP3).

Largo máximo del cuarto premolar (LP4).

Ancho máximo del cuarto premolar (AP4).

Largo labial del primer molar (LlabM1).

Largo lingual del primer molar (LlingM1).

Ancho máximo del primer molar (AM1).

\section{$\underline{\text { Mandibulares }}$}

Largo de la mandíbula (LM): desde el cóndilo hasta el borde anterior de la sínfisis.

Alto del proceso coronoideo (APC): desde el borde inferior del proceso angular hasta el borde superior del proceso coronoideo. 
Alto del cóndilo al proceso angular (ACPA): desde el borde superior del cóndilo mandibular hasta la base del proceso angular.

Largo del cóndilo al surco del carnicero (LCSC): distancia entre el cóndilo mandibular y el surco carnicero (del trigónido) del m1.

Altura de la rama horizontal (ARH): desde la base hasta la línea alveolar (en la unión del m1 y el p4).

\section{$\underline{\text { Serie dentaria inferior }}$}

Serie dentaria inferior (SDinf): desde el borde anterior del canino hasta el borde distal del $\mathrm{m} 2$.

Largo máximo del canino (Lc).

Ancho máximo del canino (Ac).

Largo máximo del premolar 4 (Lp4).

Ancho máximo del premolar 4 (Amaxp4).

Largo máximo del molar 1 (Lm1).

Largo máximo del trigónido del molar 1 (Ltrigm1).

Ancho máximo del talónido del molar 1 (Atalm1).

Largo máximo del molar 2 (Lm2).

Ancho máximo del molar 2 (Am2).

\subsection{Taxonomía de las especies de Conepatus}

Se analizaron más de 245 especímenes de Conepatus sp. de Argentina, Chile y Uruguay, incluyendo holotipos de $C$. rex, C. proteus Thomas, 1902b, C. gibsoni, $C$. budini, C. calurus Thomas, 1919, C. castaneus y C. humboldtii. 
Se utilizaron 29 landmarks para el cráneo en vista ventral, 16 para la vista lateral, 11 para la vista dorsal, 26 para la mandíbula en vista lateral y 13 para la mandíbula en vista superior (Figura 3 y Tabla 1), siguiendo la metodología descripta más arriba (sección 3.3.1). Debido a que los holotipos de $C$. castaneus y $C$. humboldtii están rotos, no se pudo ubicar los mismos landmarks en estos cráneos, por lo que se generaron dos conjuntos de datos complementarios del cráneo en vista ventral, con un número reducido de landmarks para incluirlos en los análisis.

Se exploraron las diferencias entre $C$. chinga y $C$. humboldtii según la demarcación geográfica de Osgood (1943), Redford y Eisenberg (1992), Parera (2002), Díaz y Lucherini (2006) y Emmons y Helgen (2008), que es coincidente y la más aceptada, según la cual $C$. chinga se encuentra desde el norte de la provincia de Río Negro hasta Perú, y C. humboldtii en el sur de las provincias de Río Negro, Chubut, Santa Cruz y áreas adyacentes en Chile (Figura 4A). Además se evaluaron las diferencias entre las dos especies siguiendo el arreglo de Kipp (1965), según el cual $C$. chinga se extiende desde el sur de Chile hasta el sur de Bolivia y Perú, incluyendo el noroeste argentino, mientras que $C$. humboldtii se extiende desde Patagonia (sensu lato) hasta el noreste de Argentina, incluyendo las regiones limítrofes con Uruguay y Paraguay (Figura 4B).

Se evaluaron las diferencias de forma y tamaño entre subadultos y adultos utilizando análisis multivariado de la varianza de una vía (MANOVA por sus siglas en inglés, Multivariate Analysis of Variance) y $t$-test, respectivamente. Debido a la presencia de diferencias significativas en forma (MANOVA, $F=4.87, P<0.0001$ ), pero no en tamaño ( $t$-test, $T=0.49, P=0.6259)$, sólo se analizaron individuos adultos.

También se evaluó la presencia de dimorfismo sexual utilizando los mismos análisis, y debido a la ausencia de dimorfismo en forma (MANOVA, $F=0.93, P=$ 
0.5553 ) y tamaño ( $t$-test, $T=0.98, P=0.3373$ ), la muestra fue agrupada independientemente del sexo. Estos test se llevaron a cabo con los software InfoStat v.2010 (Di Rienzo et al., 2010) y R v.2.15.3 (R Development Core Team, 2013).

Se exploraron las diferencias entre las dos especies utilizando análisis de componentes principales (PCA por sus siglas en inglés, Principal Component Analysis) en todas las vistas, y análisis discriminante (DFA por sus siglas en inglés, Discriminant Function Analysis) del cráneo en vista ventral y mandíbula en vista lateral, con validación cruzada (para calcular porcentajes de reclasificación de cada grupo) y 10.000 permutaciones para evaluar la significancia de las distancias de Procrustes, usando el software MorphoJ v.1.03c (Klingenberg, 2011). Los cambios de tamaño entre las especies fueron analizados con $U$-test de Mann-Whitney en R v.2.15.3 (R Development Core Team, 2013). Por último, se analizó la relación entre forma y tamaño (alometría) de las dos vistas antes mencionadas, utilizando regresión multivariada con 10.000 permutaciones, mediante el software MorphoJ v.1.03c (Klingenberg, 2011).

\subsection{Distribución de las especies}

Se realizaron diversos análisis en base a registros provenientes de dos fuentes: localidades de especímenes depositados en las colecciones visitadas y localidades de registro provenientes de referencias bibliográficas. Las localidades fueron analizadas en función de las ecorregiones de Olson et al. (2001) y además se realizaron modelos de distribución potencial (ver abajo).

Asimismo, se extrajeron los valores climáticos de altitud, temperatura media anual, isotermalidad, precipitación anual y estacionalidad de las precipitaciones, de todas las localidades georeferenciadas, por especie, a partir de la base de datos Worldclim (véase sección 3.5.1 para detalles, Hijmans et al., 2005a). Con estos valores 
se construyeron diversos gráficos por especie, con el fin de categorizar las condiciones climáticas generales de los ambientes para cada especie.

\subsubsection{Modelos de distribución potencial}

Se generaron modelos de distribución potencial de las especies mediante el software MaxEnt v3.3.3e (Phillips et al., 2004), el cual ha sido probado como el de mejor performance frente a otras alternativas (e.g., GARP, DOMAIN, BIOCLIM), utilizando sólo datos de presencia (Elith et al., 2006; Hernández et al., 2006; Townsend Peterson et al., 2007). Este software, además, provee curvas de respuesta para cada variable ambiental, representando cómo la predicción de MaxEnt es afectada por cada variable de manera individual (Moratelli et al., 2011). Ejemplos recientes de la utilización de este software pueden verse en Martin (2010a, 2011), Torres y Jayat (2010) y Moratelli et al. (2011).

Se utilizó un set de variables ambientales representando las condiciones climáticas desde los años 1950-2000, con una resolución espacial de 30 arc-s (arcosegundo) ó $1 \mathrm{Km}^{2}$ (Hijmans et al., 2005a; www.worldclim.org). Este dataset contiene información de elevación (altitud), temperaturas medias, mínimas y máximas de cada mes, precipitación promedio mensual, y 19 variables "bioclimáticas" (Hijmans et al., 2005a; Apéndice II).

Debido a que el dataset climático presenta datos para un período de tiempo restringido entre 1950-2000, se generaron dos modelos para cada especie (con la excepción de Lyncodon patagonicus, ver punto 3.5.1.a): uno conteniendo todas las localidades actuales, anteriores y posteriores al año 1950 (de aquí en adelante modelo “Actual”), y otro con las localidades con fecha de colecta posterior al año 1950 (de aquí en adelante, modelo “1950”). 
Se generaron diez réplicas para cada modelo, utilizando el $25 \%$ de las localidades como training data, 500 iteraciones y random seed. De esta manera, el 25\% de las localidades se utilizaron como puntos aleatorios para validar el modelo, mientras que la opción random seed garantiza que en cada réplica, el 25\% de los datos sea tomado al azar (Phillips, 2005). El número de background points fue distinto para las especies analizadas debido a que para especies ampliamente distribuidas, el objetivo del estudio no fue extrapolar a nuevas áreas potencialmente habitables, sino determinar las variables que mejor explican su distribución conocida, de modo que para $G$. cuja y $C$. chinga se utilizaron 100 background points, mientras que para especies restringidas geográficamente como L. provocax, L. patagonicus y $N$. vison se utilizaron 10000, con el objetivo de extrapolar a áreas no habitadas (Merow et al., 2013). Sin embargo, debido a que el valor AUC (Area Under Curve, véase más abajo) depende del número de background points, se espera que los modelos con menor cantidad, presenten un AUC más bajo (Merow et al., 2013). Se eligió la salida cumulativa en lugar de las otras posibles (raw o cruda que representa el modelo exponencial de MaxEnt per se, y logística que representa una posterior transformación del valor crudo, Phillips, 2005), asignándose valores de probabilidad representados por los siguientes colores: 100-51 (rojo), 50-26 (naranja), 25-11 (amarillo), 10-2 (verde) y 1-0 (blanco). La contribución de cada variable se analizó a través de test de Jackknife. La predicción del modelo se analizó de dos maneras diferentes: analizando los $P$-valores a distintos valores umbrales de 1, 5 y 10 (prueba "umbral-dependiente"), y analizando el área bajo la curva o "prueba umbral-independiente" (AUC por sus siglas en inglés, Area Under Curve; Phillips et al., 2004; 2006). El AUC cuantifica la probabilidad de que el modelo ordene (o distinga) correctamente entre una localidad de presencia, y un background point al azar (Radosavljevic y Anderson, 2014), tomando valores entre 0 y 1 y siendo una 
medida de la performance del modelo (i.e., un AUC de 0.5 indica un modelo que no se desempeña mejor que un modelo aleatorio; mientras que un valor de 1 indica un modelo que explica la distribución de manera perfecta; véase Hernández et al., 2006 y referencias allí citadas). Finalmente, todos los datos fueron integrados en un SIG (Sistema de Información Geográfico) utilizando el software DIVA-GIS v5.4 (Hijmans et al., 2005b) y ArcView® 3.3 (ESRI, 2002).

El listado de localidades para el hurón menor se presenta en la Tabla 2; para el huroncito patagónico en las Tablas 3 y 4 (pero véase sección 3.5.1.a); para el huillín en la Tabla 5; para el visón en la Tabla 6 (no se tuvieron en cuenta localidades provenientes de criaderos); y para el zorrino común en la Tabla 7 (en base a los resultados observados en la sección 4.1, no se realizaron análisis de distribución para $C$. humboldtii). Se generaron dos modelos de distribución potencial para cada una de las especies, con la excepción del huroncito patagónico para el cual se generaron cuatro (véase sección 3.5.1.a); y para el visón, para el cual sólo se generó uno debido a que todas las localidades son posteriores al año 1950.

\subsection{1.a. Distribución de Lyncodon patagonicus}

Para esta especie, además de los modelos de distribución actual, se generaron dos modelos de distribución utilizando localidades de especímenes fósiles provenientes de referencias bibliográficas (Prevosti y Pardiñas, 2001; Prevosti et al., 2009). Los mismos se realizaron utilizando una base de datos con información del Último Máximo Glacial (UMG), basada en el community climate system model (Collins et al., 2004), con una resolución espacial de 2.5 arc-min ó $20 \mathrm{Km}^{2}$. Este dataset contiene las mismas 19 variables bioclimáticas que la base Worldclim, derivadas del Paleoclimate Modelling Intercomparison Project Phase II (Collins et al., 2004). Además de los modelos Actual 
y 1950, se generaron dos modelos: el primero incluyendo localidades fósiles provenientes del Pleistoceno-Holoceno (de aquí en adelante modelo "PleistocenoHoloceno"), y el segundo incluyendo localidades sólo provenientes del Holoceno (de aquí en adelante, modelo "Holoceno"). Estos dos modelos se generaron de la misma manera que los anteriores. Así, se analizó la distribución de L. patagonicus tomando en cuenta los cambios desde el UMG. El listado de localidades actuales se presenta en la Tabla 3, y el de localidades fósiles en la Tabla 4. Cabe destacar que esta metodología se aplicó solamente para L. patagonicus debido a la existencia de referencias bibliográficas sobre registros fósiles y con su procedencia cronológica detallada (no contándose con esta información para las restantes especies).

Para validar los modelos fósiles se extrajeron los valores de las variables bioclimáticas de las localidades históricas (i.e., no fósiles) usando la base climática actual (Hijmans et al., 2005a), y también se extrajeron los valores de las variables bioclimáticas de las localidades fósiles de la base de datos del UMG (Collins et al., 2004). Luego se calculó el promedio para cada variable para todos los puntos (i.e., localidades) y se graficaron en las Figuras 5A y 5B. Se observó el mismo patrón en las variables actuales y fósiles, indicando que son las mismas variables las que afectan la distribución de Lyncodon patagonicus.

\subsubsection{Distribución y riqueza}

A partir del número de localidades total, sin duplicados $(\mathrm{n}=790)$ para todas las especies, se realizó un mapeo de riqueza específica, utilizando la función point to grid del software DIVA-GIS v.5.4 (Hijmans et al., 2005b), según el cual se divide el área de estudio en grillas de $1^{\circ}$ x $1^{\circ}$, y se analiza en función de un índice (e.g., riqueza específica, diversidad), con un desvío estándar de $2^{\circ}$. Se asignaron colores a las grillas 
en función de la cantidad de especies presentes en ellas: 5 especies (rojo), 4 especies (naranja), 3 especies (amarillo), 2 especies (verde oscuro), 1 especie (verde claro) y ausencia (blanco). Una metodología similar ha sido utilizada en Martin (2010b).

\subsection{Análisis de segregación trófica}

Como se mencionó previamente, estos análisis se llevaron a cabo en el cono sur de América del Sur, principalmente sur y centro de Argentina. Esta área se seleccionó para analizar la estructura del gremio entre las especies en estudio, evitando áreas conflictivas (Uruguay y norte de Argentina) donde otras especies que no fueron incluidas pudieran estar presentes (e.g., Pteronura brasiliensis (Gmelin, 1788), Eira barbara (Linnaeus, 1758) o Galictis vittata (Schreber, 1776), véase Díaz y Lucherini, 2006; Canevari y Vaccaro, 2007).

Se analizaron solamente especímenes adultos (véase más arriba, sección 3.2), con localidad de colecta conocida.

\subsubsection{Métodos de ordenamiento}

\subsection{1.a. Morfometría Geométrica}

Se incluyeron 133 cráneos en vista ventral, de los cuales 84 fueron de C. chinga, 27 de G. cuja, ocho de L. patagonicus, tres de L. provocax y 11 de N. vison. Asimismo, se analizaron 114 mandíbulas en vista lateral, de los cuales 68 fueron de $C$. chinga, 25 de G. cuja, seis de L. patagonicus, tres de L. provocax y 12 de N. vison (Figura 6). Los ejemplares se estudiaron mediante técnicas de morfometría geométrica como se describe en la sección 3.3.1, utilizándose 22 landmarks para cráneos en vista ventral y 25 para mandíbulas en vista lateral (Figura 7 y Tabla 8). 
Las diferencias en forma se analizaron mediante PCA con los software MorphoJ v.1.03c (Klingenberg, 2011) y tpsRelw v. 1.35 (Rohlf, 2003). Se realizó un análisis de variables canónicas (CVA por sus siglas en inglés, Canonical Variate Analysis), para encontrar las diferencias que mejor distinguen las especies en estudio. Su significancia estadística se evaluó mediante un test de permutación con 10.000 remuestreos en MorphoJ v.1.03c (Klingenberg, 2011). Las diferencias en tamaño se analizaron con $t$ test, utilizando la corrección de Bonferroni para muestras independientes, en el software R 2.15.3 (R Development Core Team, 2013).

\subsection{1.b. Morfometría Tradicional}

Se analizaron 103 individuos adultos, de los cuales 65 correspondieron $C$. chinga, 20 a G. cuja, cuatro a L. patagonicus, tres a L. provocax y 11 a N. vison. La diferencia en el $n$ respecto de los individuos analizados con morfometría geométrica se debe a que varios especímenes se encuentran rotos y no permiten la toma de todas las medidas lineales. Para garantizar que varios especímenes de todas las especies en estudio se incluyeran en el análisis, se seleccionaron las siguientes variables craneodentarias (ver abreviaturas en sección 3.3.2): LCB, LT, LCO, LP, AmaxP, AiC, Aiomin, CpO, AC, AM, Sdsup, LP4, AP4, LlabM1, LlingM1, AM1, LM, APC, ACPA, ARH, Sdinf. Se realizó un PCA en base a una matriz de correlación entre las variables estandarizadas, en el software InfoStat v. 2010 (Di Rienzo et al., 2010).

\subsubsection{Filogenia y ambientes}

Para evaluar la importancia que presenta la filogenia en explicar los patrones morfofuncionales observados en los PCA y CVA de la sección 3.6.1.a, se utilizó el método de ordenamiento filogenético canónico (CPO por sus siglas en inglés, 
Canonical Phylogenetic Ordination; Giannini, 2003), utilizando el software CANOCO v.4.5 (ter Braak y Šmilauer, 2002). Como variables de forma, se utilizaron las coordenadas de Procrustes derivadas de los análisis de morfometría geométrica y como variables filogenéticas se utilizó una matriz externa, conteniendo variables binarias $(1=$ taxones incluidos en ese nodo; $0=$ taxones no incluidos en ese nodo) para cada nodo (véase Giannini, 2003) en un árbol filogenético "recortado" (prunned). Este árbol se derivó de Sato et al. (2012) y puede observarse en la figura 8.

Asimismo, se analizó la importancia de las variaciones geográficas para explicar los patrones morfofuncionales observados, tanto de manera conjunta con la filogenia, como de manera independiente de esta (i.e., utilizando la filogenia como covariable), mediante CPO parcial con el software CANOCO v.4.5 (ter Braak y Šmilauer, 2002). Como variable ambiental se utilizó una matriz conteniendo la pertenencia de cada localidad a las ecorregiones de Olson et al. (2001). Esta asignación se realizó mediante el software ArcView 3.3 (ESRI, 2002), representada por un set de variables binarias ("1" y "0") indicando pertenencia/ausencia de cada localidad de registro en función de una ecorregión. Una metodología similar fue utilizada en Morales y Giannini (2010). Los mismos test se realizaron para analizar la asociación entre tamaño (Cs), filogenia y variaciones geográficas.

\subsubsection{Forma y dieta}

Para estudiar la asociación entre forma y dieta se caracterizó la dieta de cada especie con los porcentajes aproximados de vertebrados, invertebrados y vegetales consumidos. La información se obtuvo de referencias bibliográficas relevantes (e.g., Medina, 1998; Delibes et al., 2003; Donadio et al., 2004; Zapata et al., 2005; Ibarra et al., 2009; Medina et al., 2009; Valenzuela et al., 2013). Una metodología similar fue 
utilizada por Goswami (2006). Posteriormente, se realizó un análisis de correlaciones canónicas (CCA por sus siglas en inglés, Canonical Correlation Analysis) entre la dieta y forma (coordenadas de Procrustes), y CPO parcial, para explorar la interacción entre forma y dieta, tomando en cuenta los factores filogenéticos. Estos análisis se realizaron en R 2.15.3 (R Development Core Team, 2013) y CANOCO v 4.5 (ter Braak y Šmilauer, 2002).

\subsubsection{Patrones de ordenamiento en el morfoespacio}

Para evaluar los patrones de ordenamiento del ensamble de pequeños carnívoros en el espacio generado analizando forma (PCA), tamaño (Cs) y tamaño+forma, se calculó el índice de Clark-Evans (CEI por sus siglas en inglés, Clark-Evans Index) en R 2.15.3 (R Development Core Team, 2013). Este índice mide el grado por el cual la distribución de los individuos se aparta de una distribución al azar, con la distancia entre un individuo a su vecino más cercano utilizada como una medida de "espaciamiento" (Clark y Evans, 1954). El CEI toma valores entre 0 y 2,15; con una distribución conjunta, de máxima agregación (o clustered) tomando valores cercanos a 0 , una distribución al azar tomando valores cercanos a 1 y una distribución sistemática (individuos equidistantes) tomando valores cercanos a 2,15 (Clark y Evans, 1954).

\subsection{Variaciones geográficas}

Se analizaron las variaciones geográficas en forma y tamaño de Galictis cuja y Conepatus chinga, utilizando morfometría geométrica, y de Lyncodon patagonicus, utilizando morfometría tradicional. No se analizaron las variaciones geográficas de Lontra provocax y Neovison vison debido al escaso número de especímenes disponibles. 


\subsubsection{Variables climáticas}

Como se mencionó previamente, cada localidad fue georreferenciada con la mayor precisión posible y asignada a una ecorregión siguiendo el esquema de Olson et al. (2001). Posteriormente, se le asignó a cada localidad de registro el valor de las 19 variables bioclimáticas y la altitud, tomados de la base de datos Worldclim (Hijmans et al, 2005a). Se utilizó a su vez, una variable indicadora de la disponibilidad de recursos para consumidores primarios: producción primaria neta (NPP por sus siglas en inglés, Net Primary Productivity); y una variable que representa la energía disponible en un ecosistema: evapotranspiración potencial (PET por sus siglas en inglés, Potential Evapotranspiration; véase Ruggiero y Kitzberger, 2004). NPP (Foley et al., 1996; Kucharik et al., 2000) y PET (Willmott y Matsuura, 2001) fueron descargadas de http://sage.wisc.edu. NPP se encuentra disponible a una resolución de dos grados y se expresa como Kg-Carbón por metro cuadrado por año; mientras que PET se encuentra disponible a una resolución de 0,5 grados y representa la cantidad de agua que se removería de la superficie de una grilla por evaporación y transpiración, si la cantidad de agua presente en la grilla no fuera un factor limitante (Willmott y Matsuura, 2001).

\subsubsection{Autocorrelación espacial}

A lo largo de la presente sección, se analizó la existencia de autocorrelación espacial (SA por sus siglas en inglés para Spatial Autocorrelation) en los datos mediante correlogramas basados en el coeficiente I de Moran, usando el software SAM v.4.0 (Rangel et al., 2010). La SA causa que los datos de localidades cercanas sean más similares que lo esperado según el azar (Legendre, 1993, Kissling y Carl, 2007), resultando en una pérdida de información que limita el entendimiento del proceso en estudio (Hawkins, 2008) y perturbando la significancia de las técnicas estadísticas 
estándar (Diniz-Filho et al., 2009). Pueden verse detalladas explicaciones sobre la SA en Sokal y Oden (1978), Legendre (1993), Diniz-Filho et al. (2009) y algunos ejemplos en Diniz-Filho y Bini (2005), Diniz-Filho et al. (2007), Bernal et al. (2009) y Pérez et al. (2011).

Para incorporar la estructura espacial en los posteriores análisis (véase sección 3.7.3) se utilizó el mapeo espacial de eigenvectores (SEVM por sus siglas en inglés, Spatial Eigenvector Mapping; Diniz-Filho y Bini, 2005; Kühn y Dormann, 2012) en SAM v.4.0 (Rangel et al., 2010). Esta técnica incorpora "el espacio" a los modelos, al extraer eigenvectores de una matriz que expresa las relaciones espaciales entre poblaciones (Diniz-Filho et al., 2009). Si bien existen diversos métodos para tratar la SA de los datos, se seleccionó el SEVM debido a que los métodos que incorporan la SA directamente en los modelos parecieran obtener mejores resultados que aquellos que incorporan la SA en los residuales de los modelos (Diniz-Filho et al., 2009). Además, el módulo SEVM del SAM v 4.0 (Rangel et al., 2010) permite seleccionar y exportar los eigenvectores hacia otros software, permitiendo el análisis de SA tanto para el tamaño (variable respuesta univariada) como para la forma (variable respuesta multivariada) de las especies en estudio.

El SEVM resulta en predictores espaciales que pueden combinarse con las variables climáticas (o explicativas) en modelos espaciales, mientras se evita la introducción de multicolinearidad (Kühn y Dormann, 2012). Para esto, no se utilizaron los eigenvectores directamente seleccionados sobre la variable respuesta, sino que se utilizaron aquellos eigenvectores que resultaron estadísticamente significativos, calculados sobre los residuales de los modelos de regresión entre la variable respuesta (tamaño o forma) sobre las variables explicativas (climáticas). Este procedimiento se llevó a cabo para evitar la multicolinearidad entre los eigenvectores y las variables 
explicativas (véase Kühn y Dormann, 2012). Un esquema explicando esta metodología se presenta en la Figura 9.

Se utilizó el factor de inflado de la varianza (VIF por sus siglas en inglés, Variance Inflation Factor) como una medida del grado de multicolinearidad presente en los datos (VIF<10, véase Chatterjee y Hadi, 2006; Dormann et al., 2013).

\subsubsection{Variaciones geográficas de tamaño}

\subsection{3.a. Análisis de regresiones simples}

Se evaluó la relación entre el tamaño del cráneo y las mandíbulas con latitud, longitud, las 19 variables bioclimáticas, altitud, NPP y PET con regresiones simples en SAM v.4.0 (Rangel et al., 2010). En primera instancia, los análisis se realizaron de manera separada para cada variable ambiental, usando análisis de regresión simple (OLS por sus siglas en inglés, Ordinary Least Squared). Posteriormente, se evaluó el grado de SA que quedaba en los residuales luego de ajustar el modelo, y de ser necesario, el análisis se repitió utilizando SEVM de la manera antes descripta (i.e., incorporando al modelo los eigenvectores no colineares con la variable predictora). Como estimador de tamaño, se utilizó el tamaño de centroide de cráneos y mandíbulas para C. chinga y G. cuja, y la longitud cóndilobasal (LCB) para L. patagonicus (esta diferenca se debió a la cantidad de especímenes disponibles para las distintas técnicas morfométricas empleadas).

\subsection{3.b. Análisis de regresiones múltiples}

Se realizaron análisis de regresión múltiple para evaluar la asociación entre tamaño con cada predictor, en presencia de los otros predictores. Sin embargo, para evitar la multicolinearidad se calcularon los coeficientes de correlación $(r)$ entre las 
variables predictoras en R 2.15.3 (R Development Core Team, 2013) y aquellas que presentaran una asociación $r>0,7$ fueron eliminadas (Dormann et al., 2013). Este procedimiento se realizó de manera independiente para G. cuja, L. patagonicus, y C. chinga, dado que las localidades de colecta difieren notablemente.

Posteriormente se utilizó el módulo de inferencia de selección de multi-modelos (Mult-Model Selection Inference), basado en el criterio de Akaike (AIC por sus siglas en inglés, Akaike Information Criterion; Akaike, 1973) para identificar el modelo mejor soportado por la información, entre varios candidatos (Johnson y Omland, 2004; DinizFilho et al., 2008). El AIC se utiliza para medir el ajuste del modelo (Diniz-Filho et al., 2008) y estima la pérdida de información de Kullback-Leibler (Kullback y Leibler, 1951) al utilizar un modelo para aproximarse a la información observada o "realidad", permitiendo la identificación de hipótesis. En el caso de que varias hipótesis tuvieran soporte equivalente (identificado por un $\triangle \mathrm{AIC}>2$; véase Burnham y Anderson, 2002;

Diniz-Filho et al., 2008), se utilizó el modelo promedio (Model Average; Johnson y Omland, 2004). Se ha comprobado que esta técnica es muy robusta y permite interpretar la importancia relativa de cada variable (sumando los pesos de Akaike o Akaike weights -AICw- de una variable en todos los modelos en los cuales está presente). Estos análisis se realizaron tanto para la vista ventral de cráneos como para la vista lateral de mandíbulas en SAM v.4.0 (Rangel et al., 2010).

\subsection{3.c. Análisis de Redundancia}

Se realizaron análisis de redundancia parcial (RDA por sus siglas en inglés, Redundancy Analysis) para explorar la variación en tamaño explicada exclusivamente por las ecorregiones de Olson et al. (2001), utilizando los dos primeros eigenvectores (o SFs por sus siglas en inglés, Spatial Filters, provenientes del SEVM) como covariables 
para incluir la SA en los análisis. Los dos primeros SFs presentan los mayores eigenvalues y se relacionan con patrones espaciales a gran escala (Diniz-Filho y Bini, 2005), lo que resulta adecuado para análisis de tamaño a escala continental.

El RDA se llevó a cabo utilizando Cs como medida de tamaño y un set de variables binarias que representan la pertenencia de cada localidad a una ecorregión (de igual manera que en la sección 3.6.2). Se realizaron dos análisis: uno incluyendo todas las ecorregiones, y otro seleccionando aquellas ecorregiones con un $P<0,01$, a través de un test de Monte Carlo con 4999 permutaciones. En ambos análisis se utilizaron los dos primeros SFs como covariables, según se explicó más arriba. Los RDA se realizaron

con el software CANOCO v.4.5 (ter Braak y Šmilauer, 2002) para C. chinga y G. cuja.

\subsubsection{Variaciones geográficas de morfología}

Estos análisis se realizaron para Conepatus chinga y Galictis cuja. No se analizaron los cambios de forma de Lyncodon patagonicus debido al escaso número de especímenes disponibles.

\subsection{4.a. Análisis de regresiones multivariadas}

Se realizaron análisis de regresión multivariada en MorphoJ v $1.03 \mathrm{c}$ (Klingenberg, 2011), utilizando las coordenadas de Procrustes como variables respuesta y las variables predictoras seleccionadas (para evitar multicolinearidad, como se mencionó previamente en la sección 3.7.3.b.), con 10.000 iteraciones para testear la hipótesis nula de independencia entre los datasets. 


\subsection{4.b. Análisis de redundancia}

Finalmente, se realizó RDA parcial para explorar la variación morfofuncional explicada por las ecorregiones de Olson et al. (2001), utilizando los dos primeros SFs como covariables para incluir la SA en CANOCO v4.5 (ter Braak and Šmilauer, 2002). 


\section{Resultados}

\subsection{Taxonomía de Conepatus}

\subsubsection{Análisis de Componentes Principales}

El primer ACP de cráneo ventral se llevó a cabo con 132 especímenes, incluyendo holotipos de C. proteus, C. budini, C. rex, C. gibsoni y C. calurus, todos sinónimos junior de $C$. chinga o $C$. humboldtii. No se observó ninguna separación entre C. chinga y $C$. humboldtii en cuanto a la forma del cráneo, siguiendo el esquema de clasificación de Redford y Eisenberg (1992). El primer y segundo eje del cráneo en vista ventral, explicaron 22,39 y 9,49\% de la variación, respectivamente. En el extremo positivo del CP1 se ubicaron los especímenes con cráneos angostos, fosa temporal pequeña, P4 y M1 localizados más anteriormente, foramen magnum de mayor tamaño, y procesos mastoideo y paracondilar desplazados posteriormente (se observó el patrón opuesto en el extremo negativo del CP1; Figura 10). A lo largo del extremo positivo del CP2 se ubicaron los especímenes con cráneos alargados, cavidad glenoidea pequeña, bula timpánica, proceso mastoideo, borde posterior del paladar y P4 y M1 grandes y localizados más posteriormente (se observó el patrón opuesto en el extremo negativo del CP2, Figura 10). El tercer y cuarto eje explicaron 9,27 y 6,32\% de la variación, pero los cambios morfológicos fueron menos aparentes en las grillas de deformación. Los especímenes localizados en el extremo positivo del CP3 presentan arcos cigomáticos más comprimidos (i.e., menos redondeados) y paladares más cortos (Figura 11); mientras que aquellos situados en el extremo positivo del CP4 presentaron bulas timpánicas proporcionalmente más anchas (ambos patrones opuestos se observaron en los extremos positivos del CP3 y CP4, Figura 11). Los mismos análisis, pero siguiendo el esquema de clasificación de Kipp (1965), arrojaron resultados similares. No se observó ninguna separación entre C. chinga y C. humboldtii en el morfoespacio 
generado (Figura 12). De aquí en adelante para los PCA se presentan los resultados siguiendo el esquema de Redford y Eisenberg (1992).

El segundo ACP de cráneo en vista ventral, con un conjunto de datos complementario utilizando 22 landmarks, 133 especímenes e incluyendo el holotipo de C. castaneus, puede observarse en la Figura 13. Los primeros CP explican 15,47 y 11,30\% de la variación, y los cambios morfológicos son consistentes con el análisis anterior, ya que no se observó separación entre $C$. chinga y $C$. humboldtii.

El tercer ACP del cráneo en vista ventral, con un dataset complementario utilizando 14 landmarks, 134 especímenes e incluyendo el holotipo de C. humboldtii, puede observarse en la Figura 14. Los primeros CP explican 22,35 y 10,66\% de la variación, y los cambios morfológicos son consistentes con el análisis anterior, ya que no se observó separación entre $C$. chinga y $C$. humboldtii.

El ACP de cráneo lateral se realizó con 113 individuos, donde tampoco se observó separación en el morfoespacio entre ambas especies (Figura 15). El primer y segundo eje explicaron $34,95 \%$ y $18,08 \%$ de la variación, respectivamente. En el extremo positivo del CP1 se ubicaron aquellos especímenes con cráneos proporcionalmente más angostos y largos, con el patrón opuesto en su extremo negativo. En cuanto al CP2, ubicó a aquellos individuos con cráneos bajos en su extremo positivo (Figura 15).

El ACP de cráneo dorsal se realizó con 124 individuos, donde tampoco se observaron diferencias entre las dos especies de Conepatus analizadas (Figura 16). A lo largo del extremo positivo del CP1 (que explicó 33,14\%) se ubicaron los especímenes con los nasales más cortos y un cráneo proporcionalmente más angosto. En cuanto al CP2 (que explicó 21,65\%), se observó que los especímenes ubicados en su extremo 
positivo presentaron arcos cigomáticos más rectos y un basicráneo más ancho (Figura 16).

En cuanto al ACP de la mandíbula en vista lateral, en el que se usaron 101 especímenes, no mostró ninguna separación entre $C$. chinga y $C$. humboldtii en el morfoespacio. El primer y segundo eje explicaron 31,75 y 12,99\% de la variación. En el extremo positivo del CP1 se observaron los especímenes con mandíbulas más largas y robustas y un proceso coronoideo ubicado en una posición vertical. Aquellos ubicados en el extremo negativo presentaron mandíbulas más delgadas, con un proceso coronoideo inclinado posteriormente (Figura 17). En cuanto al CP2, separó en su extremo positivo a aquellos individuos con un proceso coronoideo bajo y cuerpo mandibular fuerte, con el patrón opuesto en el extremo negativo (Figura 17). El tercer y cuarto eje explicaron 11,81 y $8,12 \%$ de la variación, pero los cambios morfológicos en las grillas de deformación fueron menos evidentes. En el extremo positivo del CP3 se ubicaron los especímenes con el cóndilo mandibular desplazado ventralmente, m1 y m2 de mayor altura. El CP4 ordenó a los especímenes con una dentición localizada en una posición más anterior y un proceso coronoideo más angosto (el patrón opuesto se observó en los extremos negativos del CP3 y CP4, Figura 18).

El ACP de la mandíbula en vista superior se llevó a cabo con 86 especímenes, donde tampoco se observaron diferencias entre las dos especies analizadas. El primer eje explicó 27,33\% de la variación, con especímenes con m1 de menor tamaño y situado en una posición más anterior, junto con el p3 y c1 en posición más posterior (Figura 19). El segundo eje explicó el 14,03\% de la variación morfológica y ubicó en su extremo positivo a aquellos individuos con el talónido del $\mathrm{m} 1$ proporcionalmente más ancho y cuerpo mandibular más curvado (i.e., menos recto, Figura 19). 


\subsubsection{Análisis Discriminantes}

El DFA siguiendo el esquema de Redford y Eisenberg (1992) mostró diferencias significativas $(P<0,0001)$ en los análisis del cráneo en vista ventral, en las distancias de Procrustes $(0,0173)$ y Mahalanobis $(3,493)$ entre las medias de distintos grupos. El porcentaje de reclasificación fue de $83,33 \%$. El mismo análisis siguiendo el esquema de Kipp (1965) también arrojó distancias significativas $(P<0,001)$ entre las medias de distintos grupos en las distancias de Procrustes $(0,010)$ y Mahalanobis $(2,741)$, con un porcentaje de reclasificación de $72,44 \%$. El DFA de la mandíbula en vista lateral siguiendo el esquema de Redford y Eisenberg (1992), mostró diferencias significativas $(P<0,0003)$ en las distancias de Procrustes $(0,019)$ y Mahalanobis $(3,387)$, con un porcentaje de reclasificación de 71,62\%. El mismo análisis con el esquema de Kipp (1965), también arrojó diferencias significativas $(P<0,0072)$ en las distancias de Procrustes $(0,0137)$ y Mahalanobis $(3,035)$, entre las medias de ambos grupos. El porcentaje de reclasificación fue de 76,62\%.

Para evaluar si las diferencias significativas encontradas en los DFA fueron resultado de variaciones geográficas en forma, los mismos análisis se repitieron luego de extraer la variación geográfica, representada por latitud y longitud. Para esto se llevó a cabo un análisis de regresión multivariada entre la forma (coordenadas de Procrustes) y latitud-longitud en MorphoJ v.1.03c (Klingenberg, 2011); y los DFA se rehicieron con los residuales de dicho análisis de regresión. El primer DFA de cráneo ventral (luego de la regresión multivariada) siguiendo el esquema de Redford y Eisenberg (1992), no mostró diferencias significativas $(P=0.99)$ en las distancias de Procrustes $(0,0065)$ y Mahalanobis (1,213). Asimismo, el porcentaje de reclasificación disminuyó al 44,11\%. El mismo DFA siguiendo el esquema de Kipp (1965) tampoco mostró diferencias 
significativas $(P>0,99)$ en las distancias de Procrustes $(0,0048)$ y Mahalanobis $(1,099)$, con un porcentaje de reclasificación de 59,18\%.

En cuanto al DFA de mandíbula en vista lateral, siguiendo el esquema de Redford y Eisenberg (1992), tampoco mostró diferencias significativas $(P>0,99)$ en las distancias de Procrustes $(0,009)$ y Mahalanobis $(1,05)$, con un porcentaje de reclasificación que disminuyó al 33,78\%. El DFA de la mandíbula en vista lateral, siguiendo el esquema de Kipp (1965), tampoco mostró diferencias significativas $(P>0,99)$ en las distancias de Procrustes $(0,005)$ y Mahalanobis $(1,137)$, con un porcentaje de reclasificación de 58,44\%.

\subsubsection{Alometría}

La forma del cráneo mostró una correlación positiva con el tamaño de manera significativa $(P<0,0001)$. El porcentaje de variación explicada por el tamaño fue de 3,7\%. Los especímenes de mayor tamaño presentaron P4 y M1, foramen magnum y bulas timpánicas proporcionalmente más pequeños, fosa temporal de mayor tamaño, paladares más angostos (en la parte posterior al M1) y extendidos posteriormente. Los especímenes de menor tamaño presentaron el patrón opuesto (i.e., bulas timpánicas grandes, fosa temporal de menor tamaño; Figura 20).

La forma de las mandíbulas también mostró una correlación positiva con el tamaño $(P<0,05)$, con el 3,64\% de la variación explicada. Los especímenes de mayor tamaño presentaron cuerpos mandibulares más altos (especialmente debajo de los premolares y canino), y un proceso coronoideo más inclinado posteriormente; mientras que los especímenes de menor tamaño presentaron cuerpos mandibulares más delgados y proceso coronoideo en posición más vertical (Figura 21). 
El test $U$ de Mann-Whitney indicó que no existen diferencias significativas $(P=$ 0.111) entre $C$. chinga $(1031,975)$ y $C$. humboldtii $(1017,536)$, siguiendo el esquema de clasificación de Redford y Eisenberg (1992). El mismo test con el esquema de clasificación de Kipp (1965), indicó diferencias significativas para un $P<0,05$ entre las medias de tamaño de $C$. chinga $(992,1068)$ y $C$. humboldtii $(1033,9681)$.

\subsection{Análisis de distribución}

\subsubsection{Galictis cuja}

Se relevaron 180 localidades del hurón menor, provenientes de colecciones nacionales y diversas referencias bibliográficas (Tabla 2). La localidad ubicada más al norte proviene de Borhnoldt et al. (2013) y no se le ha asignado un nombre en particular, tratándose de una localidad ubicada unos $50 \mathrm{Km}$ al sur del pueblo de Juatama, Brasil; La localidad más austral es Península Brunswick (Prevosti y Travaini, 2005); la localidad ubicada más al oeste, se encuentra situada unos $4 \mathrm{Km}$ al norte de Valdivia, Chile; y la ubicada más al este se trata de una localidad ubicada $1 \mathrm{Km}$ al este de São Lourenço da Mata, Brasil, también proveniente de Bornholdt et al. (2013). De esta manera, G. cuja se distribuye desde los $5^{\circ} 29^{\prime} \mathrm{S}$ hasta los $53^{\circ} 30^{\prime} \mathrm{S}$ y desde $35^{\circ} 2^{\prime}$ O hasta $\operatorname{los} 73^{\circ} 13^{\prime} \mathrm{O}$. El mayor porcentaje de localidades provienen de la Ecorregión Estepa Patagónica (Patagonian steppe, 14,44\%), seguido por Sabana Uruguaya (Uruguayan Savanna, 13,33\%) y Pampas Húmedas (Humid Pampas, 11,67\%, sensu Olson et al., 2001). La altitud promedio de las localidades fue de 357 m.s.n.m. (0-3130 m.s.n.m.); la temperatura media de $16,3^{\circ} \mathrm{C} \pm 3,7^{\circ} \mathrm{C}\left(3,4-27,3^{\circ} \mathrm{C}\right)$; y la precipitación anual de 902mm (115-2451mm; Figura 22).

Los modelos de distribución potencial se presentan en la Figura 23. El modelo “Actual” presentó una distribución fundamentalmente concentrada en Uruguay, 
Argentina y Chile, sumado a dos áreas en el sur y noreste de Brasil. Estas últimas se corresponden con los estados de Paraíba, Pernambuco y Alagoas al noreste (elipse "a" en Figura 23A), y Minas Gerais y Sao Paulo al este de Brasil (elipse "b” en Figura 23A), separadas por una distancia de unos $1500 \mathrm{Km}$ entre ellas, entre las cuales se observan algunas localidades de registro. Estas áreas se corresponden con las ecorregiones Caatinga al noreste de Brasil, y con los Bosques Atlánticos (Alto Parana Atlantic forest) y una pequeña porción al este del Cerrado (sensu Olson et al., 2001). Asimismo, un tercer área se extiende a la parte sur de Brasil (estado Rio Grande do Sul, elipse "c" en Figura 23A) desde Uruguay, donde se observaron altos valores de predicción, correspondiéndose con la Sabana Uruguaya. El área con altos valores de predicción en Chile (elipse “d” en Figura 23A), se encuentra en su región central, extendiéndose por las Regiones de Valparaíso, Metropolitana, Libertador, Maule, Biobío hasta la Región de la Araucanía, abarcando fundamentalmente el Matorral Chileno (Chilean Matorral, sensu Olson et al., 2001). Otro núcleo de altos valores de predicción se extendió desde el sur de Bolivia en sentido norte-sur, hacia las provincias argentinas de Jujuy, Salta, Tucumán (elipse "e" en Figura 23A), y extendiéndose de manera discontinua hasta el norte de San Luis y Córdoba. Esta área se corresponde fundamentalmente con las Yungas Andinas (Southern Andean Yungas) y una porción al oeste del Chaco Seco (Dry Chaco, sensu Olson et al., 2001). Una última área con altos valores de predicción se observó en Patagonia sensu lato, fundamentalmente localizada en la Estepa Patagónica. Todas las áreas con altos valores se encuentran separadas entre sí por áreas de predicción con valores medios a bajos (1-25\%).

El modelo de distribución con localidades posteriores a 1950 presentó un patrón similar al anterior, pero con una marcada reducción areal en todas las categorías de predicción (Figura 23B). Se identificaron los mismos núcleos con altos valores, a 
excepción del presente en el noreste de Brasil. La distribución en Patagonia sensu lato se restringió hacia el sur, mientras que la zona centro y norte de Argentina presentó valores bajos de predicción. Asimismo, tampoco se observaron altos valores de predicción en el centro de Chile.

La contribución de las variables a los modelos se presenta en la Tabla 9. En ambos modelos la variable con mayor contribución fue la estacionalidad de la temperatura (34,1\% en Actual y 52,9\% en 1950, respectivamente). Otras variables importantes para explicar el modelo "Actual" se relacionaron con temperaturas máximas de meses fríos y altitud; mientras que para el modelo "1950” fueron la altitud, isotermalidad y temperaturas máximas de los meses fríos. Las variables con información más útil para explicar ambos modelos fueron la estacionalidad de la temperatura (Actual) y la isotermalidad (1950), y las variables con información no contenida en el resto (i.e., más única) fueron la altitud (Actual) y la isotermalidad (1950; Tabla 9).

Ambos modelos se desempeñaron mejor que modelos aleatorios: $\mathrm{AUC}=0,660 \pm$ 0,025 (Actual) y 0,811 $\pm 0,034$ (1950). Las pruebas umbral-dependiente se presentan en la Tabla 10, donde se observan valores significativos para umbrales de 1, 5 y 10.

\subsubsection{Lyncodon patagonicus}

Se relevaron 55 localidades actuales del huroncito patagónico, una de ellas (i.e., 2000m al E. de Pto. Pirámides) no pudo ser asignada a ninguna edad en particular, ya que carecía de procedencia estratigráfica, por lo cual no se incluyó en los análisis (véase localidad “38” en Tabla 3). La localidad ubicada más al norte es Alemanía, Salta, Argentina (Olrog, 1976); la más austral y más al oeste es Puerto Prat, Magallanes, Chile (Wolfsohn, 1921); y la más al este Azul, Buenos Aires, Argentina (Burmeister, 1879). 
De esta manera, L. patagonicus se distribuye desde los $25^{\circ} 38^{\prime} \mathrm{S}$ hasta los $50^{\circ} 01^{\prime} \mathrm{S}$ y desde $62^{\circ} 15^{\prime} \mathrm{O}$ hasta los $72^{\circ} 38^{\prime} \mathrm{O}$. El mayor porcentaje de localidades provienen de la ecorregión Estepa Patagónica (44,44\%) sensu Olson et al. (2001), seguido por Monte Alto (High Monte), Chaco Seco, y Monte Bajo (Low Monte) con iguales porcentajes (11,11\%). La altitud promedio de las localidades fue de 727 m.s.n.m., (3-1906 m.s.n.m.); la temperatura media de $12,4^{\circ} \mathrm{C} \pm 4,8^{\circ} \mathrm{C}\left(5,9-20,2^{\circ} \mathrm{C}\right)$, y la precipitación anual de 380mm (121-1175mm; Figura 24).

Los modelos de distribución potencial, con localidades fósiles, se presentan en la Figura 25. Tanto el modelo "Pleistoceno-Holoceno" $(n=20)$ como el modelo "Holoceno" ( $n=15)$, mostraron un área con altos valores de predicción que cubre la mayoría de las provincias de La Pampa, Neuquén, Río Negro y Chubut, el oeste de Mendoza y este de Santa Cruz. Esta área se extiende hacia el norte de Chile a través de una región al oeste de San Juan, La Rioja y Catamarca. Asimismo, incluye gran parte de la plataforma continental que actualmente se encuentra sumergida, pero que probablemente estuvo emergida durante el UMG (Rabassa et al. 2005; Figura 25 A y B). Desde el modelo "Pleistoceno-Holoceno" al "Holoceno", se observa una marcada reducción en los niveles de predicción en el centro y sur de Buenos Aires y oeste de Córdoba (ver flechas en Figura 25B).

Los modelos “Actual” ( $n=54)$ y “1950” ( $n=37)$ mostraron un patrón similar al anterior, con una reducción del área total en todos los niveles de predicción (Figura 26 A y B). Se identificó un área con altos valores de predicción $(<50 \%)$, concentrada en el oeste de Patagonia y la Meseta de Somuncurá en Chubut y Río Negro, rodeada de un área de valores medios (25-50\%) que se extiende sobre la mayoría de Patagonia sensu lato. Separadas de esta área, se observaron varios pequeños núcleos de altos valores de predicción en el sur y oeste de Mendoza, sur de Buenos Aires, centro de Chile y un área 
medianamente continua desde el centro de Salta hasta el centro de San Juan (Figura 26 A y B).

La contribución de las variables para todos los modelos se observa en la Tabla 11. En ambos modelos fósiles, la variable con mayor contribución fue la temperatura media del trimestre más frío (64,1 y 60,3\% para "Pleistoceno-Holoceno" y "Holoceno", respectivamente). Para los modelos “Actual” y "1950" la variable más importante fue la estacionalidad de la temperatura (55,1 y 48,3\%, respectivamente). Otras variables con menores contribuciones se relacionaron con temperaturas mínimas de meses fríos y estacionalidad de las precipitaciones (modelos fósiles), altitud y precipitaciones de primavera (modelos actuales, Tabla 11). La variable con información más útil para explicar ambos modelos fósiles fue la temperatura mínima del mes más frío, mientras que la variable con información no contenida en el resto (i.e., más única), fue la temperatura media del trimestre más seco para el modelo Pleistoceno-Holoceno y la estacionalidad de las precipitaciones para el modelo Holoceno, respectivamente. Para ambos modelos actuales, la información más útil fue la temperatura mínima de Julio, mientras que la variable con más información no contenida en el resto (i.e., más única) fue la altitud (Tabla 11).

Los cuatro modelos se desempeñaron mejor que modelos aleatorios, con altos valores de AUC: 0,948 — 0,055 (Pleistoceno-Holoceno); 0,973 \pm 0,013 (Holoceno); $0,949 \pm 0,009$ (Actual); 0,959 $\pm 0,018$ (1950). Las pruebas umbral-dependiente se presentan en la Tabla 12, observándose valores significativos para umbrales de 1, 5 y 10. 


\subsubsection{Lontra provocax}

Se relevaron 65 localidades para el huillín (Tabla 5). La localidad ubicada más al norte proviene es Temuco, Chile (AMNH 33295); mientras que la localidad más austral es Isla de los Estados, Argentina (Pine et al., 1978); la localidad más al este es “cerca de la boca del Río Negro, justo S” (SNMNH 171959) y la localidad más al oeste es Isla Madre de Dios, Magallanes, Chile (Vianna et al. 2011). De esta manera, L. provocax se distribuye desde los $38^{\circ} 48^{\prime} \mathrm{S}$ hasta los $54^{\circ} 52^{\prime} \mathrm{S}$, y desde los $62^{\circ} 52^{\prime} \mathrm{O}$ hasta los $75^{\circ}$ 09’ O. El mayor porcentaje de localidades proviene de la ecorregión Bosques Valdivianos (Valdivian Temperate Forests, 80\%), seguido por Bosques Magallánicos (Magellanic Subpolar Forests, 7,69\%) y Matorral Chileno (6,15\%) sensu Olson et al. (2001). La altitud promedio de las localidades fue de 514m.s.n.m. (0-1285m.s.n.m.), la temperatura media de $9,01^{\circ} \mathrm{C} \pm 3,58^{\circ} \mathrm{C}\left(1-13,8^{\circ} \mathrm{C}\right)$, y la precipitación anual de $1655 \mathrm{~mm}$ (163-5724mm; Figura 27).

Los modelos de distribución potencial se presentan en la Figura 28. Ambos modelos (“Actual” $n=65$; “1950” $n=59$ ) resultaron similares, presentando altos valores de predicción en el centro-sur de Chile, principalmente en las regiones de la Araucanía y de los Lagos, con altos valores observados también en la isla de Chiloé (elipse "a" en Figura 28A, véase también Figura 28B). Separado de esta zona, se observaron altos valores de predicción al sur de la región de Aysén, en Isla Prat (elipse "b" en Figura 28A). La distribución potencial en Argentina se limitó principalmente al suroeste de la provincia del Neuquén y al noroeste de Río Negro, presentando altos valores de predicción en el área correspondiente al P.N. (Parque Nacional) Nahuel Huapi. Otras cuencas similares como la del P.N. Los Alerces en el noroeste del Chubut, presentaron valores medios de predicción. Desde el modelo Actual al de 1950, se observó una marcada disminución en los valores altos de predicción $(<50 \%)$ en las regiones de la 
Araucanía y Los Lagos y en el sur de la provincia de Aysén, en la Isla Prat (Chile). Asimismo, también se observó una disminución en los valores medios de predicción en el noroeste del Chubut, y a lo largo de Patagonia sensu lato. Esta última en ambos modelos, presentó valores muy bajos de predicción (1-10\%) pese a presentar algunas localidades de registro en el modelo Actual, bordeando los límites de la Estepa Patagónica, presentando los valores más bajos (0-1\%) a partir del Monte Bajo y hacia el norte de Argentina.

La contribución de las variables a ambos modelos se presenta en la Tabla 13. Para los modelos “Actual” y “1950”, las variables con mayor contribución fueron la temperatura media del trimestre más húmedo $(43,7$ y 41,4\%) y la precipitación de Julio (32,7 y 36,8\%), respectivamente. Otras variables con menores contribuciones se relacionaron fundamentalmente a la altitud, la estacionalidad de las precipitaciones y la temperatura (Tabla 13). La variable con información más útil para explicar ambos modelos fue la temperatura media del trimestre más húmedo, mientras que la variable con información no contenida en el resto (i.e., más única) fue la altitud.

Ambos modelos se desempeñaron mejor que modelos aleatorios, con altos valores AUC: 0,983 \pm 0,009 (Actual), 0,992 $\pm 0,004$ (1950). Las pruebas umbraldependiente se presentan en la Tabla 14, donde se observaron valores significativos para umbrales de 1,5 y 10 .

\subsubsection{Neovison vison}

Se relevaron 215 localidades para el visón, de las cuales tres (con ocho individuos) provenían de criaderos y no fueron tenidas en cuenta para los análisis de distribución (véase registros $N^{\circ}$ 206; 214 y 215 en Tabla 6). La localidad más al norte registrada es "Lago Panguipuli”, Araucania, Chile (Medina, 1997), mientras que la más 
austral es "Parque Etnobotánico Omora”, Magallanes, Chile (Rozzi y Sherriffs, 2003); la localidad más al oeste es "Río Petrohué”, Región de Los Lagos, Chile (Medina, 1997); mientras que la más al este es "Río Ewan”, Tierra del Fuego, Argentina (Valenzuela et al., 2013). De esta manera en Argentina y Chile N. vison se distribuye desde los $39^{\circ} 42^{\prime} \mathrm{S}$ hasta los $54^{\circ} 57^{\prime} \mathrm{S}$, y desde $67^{\circ} 12^{\prime} \mathrm{O}$ hasta los $72^{\circ} 19^{\prime} \mathrm{O}$. El mayor porcentaje de localidades provienen de la ecorregión Estepa Patagónica $(61,97 \%)$ seguido por Bosques Valdivianos (30,52\%) y Bosques Magallánicos (7,51\%, sensu Olson et al., 2001). La altitud promedio de las localidades fue de 638m.s.n.m. (21908 m.s.n.m.), la temperatura media de $8,19^{\circ} \mathrm{C} \pm 4,3^{\circ} \mathrm{C}\left(1,2-16,3^{\circ} \mathrm{C}\right)$, y la precipitación anual de 536mm (137-3130mm; Figura 29).

El modelo de distribución potencial indicó una distribución concentrada en el oeste de Patagonia sensu lato, con altos valores de predicción en el suroeste de la provincia del Neuquén, oeste de Río Negro y Chubut (Figura 30). En esta última provincia se observaron altos valores de predicción hasta lo $69^{\circ} \mathrm{O}$, ingresando en la Estepa Patagónica y siguiendo los cursos de los ríos Chubut y Senguer. En cuanto a la ecorregión de Bosques Valdivianos, se observaron altos valores en varias de sus cuencas, como las del P.N. Nahuel Huapi y Los Alerces. Asimismo, se observó que el modelo de distribución potencial predijo zonas potencialmente habitables, situadas exclusivamente a lo largo de la región Andina (sensu Morrone 2001; 2006). Tanto hacia el este como al norte de Patagonia sensu lato, los valores de predicción disminuyen gradualmente hasta llegar a los más bajos en el límite con el Monte Bajo (sensu Olson et al., 2001). En el sur de Argentina (i.e., Tierra del Fuego) se observaron valores medios de predicción, pese a existir varios registros de localidades. Además, también se observaron valores medios de predicción en el centro-sur de Chile, en la Región de Los Lagos, y en la de Aysén. 
La contribución de las variables al modelo se detalla en la Tabla 15. Las variables con mayor contribución fueron la temperatura media del trimestre más húmedo (55,4\%, al igual que para los modelos del huillín) y la temperatura de Agosto $(16 \%)$. Otras variables con menor contribución se relacionaron con la isotermalidad y la estacionalidad de las precipitaciones. La variable con información más útil en sí misma fue la temperatura media del trimestre más húmedo, mientras que la variable con más información no contenida en el resto (i.e., más única) fue la isotermalidad.

El modelo se desempeñó mejor que un modelo aleatorio, con altos valores AUC: $0,987 \pm 0,002$. Las pruebas umbral-dependiente se presentan en la Tabla 16, y se observaron valores significativos para umbrales de 1,5 y 10.

\subsubsection{Conepatus chinga}

Se relevaron 276 localidades para el zorrino común (Tabla 7). La localidad más al norte y más al oeste es Chachapoyas, Perú (localidad tipo $C$. inca taxinus Thomas, 1924); mientras que la más austral es Punta Arenas, Magallanes, Chile (AMNH 130049); y la localidad más al este se trata de "Bom Retiro", Santa Catarina, Brasil (Cherem et al., 2007). De esta manera, $C$. chinga se distribuye desde los $6^{\circ} 13^{\prime} \mathrm{S}$ hasta $\operatorname{los} 53^{\circ} 9^{\prime} \mathrm{S}$, y desde los $49^{\circ} 28^{\prime} \mathrm{O}$ hasta los $77^{\circ} 52^{\prime} \mathrm{O}$. El mayor porcentaje de localidades provienen de la ecorregión Estepa Patagónica (17,39\%), seguido por Sabana Uruguaya (16,30\%), Pampas Húmedas (13,04\%) y Chaco Seco (10,14\%), sensu Olson et al. (2001). La altitud promedio de las localidades fue de 753m.s.n.m. (04652 m.s.n.m.), la temperatura media de $14,68^{\circ} \mathrm{C} \pm 4.21^{\circ} \mathrm{C}\left(3,5-23,1^{\circ} \mathrm{C}\right)$, y la precipitación anual de 758mm (12-2203mm; Figura 31).

Los modelos de distribución potencial se presentan en la Figura 32. En el modelo de distribución "Actual” $(n=276)$ se observaron tres áreas con altos valores de 
predicción $(<50 \%)$. El primero se extiende de manera casi continua desde el sur del Perú y oeste de Bolivia, hasta el norte de la provincia argentina de San Luis (elipse "a" en Figura 32A). En Perú y Bolivia, se observaron zonas con altos valores de predicción hacia el oeste de la ecorregión Puna Central (Centran Andean Puna), mientras que en Argentina hacia el oeste en Chaco Seco y a lo largo de Yungas Andinas (sensu Olson et al., 2001). Separado de esta área por valores bajos y medios (10-25\%) a lo largo del Espinal, se observó otra área con altos valores de predicción, en la provincia de Buenos Aires, Uruguay, y sur de Brasil (elipse "b” en Figura 32A). Separado de estas dos áreas por valores medios y bajos a lo largo del Monte Bajo, se observaron altos valores de predicción en Patagonia sensu lato, incluyendo la Estepa Patagónica y los Bosques Valdivianos (elipse “c” en Figura 32A).

El modelo de distribución potencial "1950” $(n=162)$ resultó similar al “Actual”, con una reducción en los valores altos de predicción en las mismas áreas antes mencionadas. Sin embargo, el área con altos valores que se extiende desde el sur del Perú se observó en este modelo hasta la provincia argentina del Neuquén, ocupando sólo una pequeña porción al oeste del Monte Bajo. Asimismo, en Buenos Aires, Uruguay y sur de Brasil se observó una reducción en los valores altos de predicción. Cambios notorios se observaron también en el sur de Patagonia, donde la distribución del zorrino común pareciera desplazarse hacia el este, concentrándose en la Estepa Patagónica y alejándose de los Bosques Valdivianos (Figura 32B).

La contribución de las variables a los modelos se detalla en la Tabla 17. Las variables con mayor contribución para el modelo "Actual” fueron las temperaturas mínimas de Julio y Agosto (35,3 y 25,2\%, respectivamente), mientras que para el modelo “1950” fueron la temperatura máxima de Mayo y la temperatura media del trimestre más frío (15,1 y 12,5\%, respectivamente). Las variables más útiles para 
explicar los modelos fueron la temperatura mínima de Agosto para el modelo "Actual" y la temperatura media de Agosto para el modelo “1950". Las variables con información no contenida en el resto (i.e., más única) fueron la estacionalidad de las precipitaciones para el modelo “Actual” y la altitud para el modelo “1950”, respectivamente (Tabla 17).

Ambos modelos se desempeñaron mejor que modelos aleatorios, con valores AUC: 0,637 $\pm 0,026$ (Actual), 0,676 $\pm 0,032$ (1950). Las pruebas umbral-dependiente se presentan en la Tabla 18, y se observaron valores significativos para umbrales de 1, 5 y 10.

\subsubsection{Distribución y riqueza}

El mapa de riqueza generado se presenta en la Figura 33. Se observó una mayor diversidad en el noroeste de Patagonia, particularmente en el oeste de las provincias de Río Negro, Neuquén y noroeste del Chubut, donde se registraron las cinco especies estudiadas (grillas rojas en Figura 33). Hacia el este de Patagonia, en la provincia del Chubut, la riqueza disminuye a cuatro especies, debido a la ausencia de Lontra provocax (grillas naranjas en Figura 33); mientras que hacia el este de Río Negro la riqueza disminuye debido a la ausencia de $L$. provocax y $N$. vison. En la provincia de Santa Cruz, región pampeana de Buenos Aires y en el noroeste de Argentina, también se observaron valores medios a bajos de riqueza (grillas amarillas y verdes en Figura 33), debido a la ausencia de L. provocax y Neovison vison. Se observaron valores bajos a nulos (grillas verdes y blancas) a lo largo de la Diagonal Árida (sensu Bruniard, 1982), y en noreste de Argentina, debido a la ausencia de $L$. provocax, $N$. vison y $L$. patagonicus. 


\subsection{Análisis de segregación trófica}

\subsubsection{Métodos de ordenamiento}

\subsection{1.a. Morfometría Geométrica}

El ACP del cráneo mostró una clara segregación de los morfotipos hipo e hipercarnívoros, con el primer CP explicando $64 \%$ de la variación total y ubicando a $G$. cuja, L. patagonicus y N. vison en el extremo derecho del eje (valores positivos, especies hipercarnívoras). Morfológicamente, estas especies comparten un M1 reducido, una porción lingual del P4 reducido, un paladar largo y delgado que se extiende más allá del M1 y un basicráneo más largo. El patrón opuesto, con una tendencia hacia la hipocarnivoría, se observó en el extremo negativo del eje donde se ubicó C. chinga. Lontra provocax mostró una posición intermedia a lo largo del CP1 y no se solapó (o no solapándose) con ninguna especie (Figura 34). El segundo eje del ACP explicó $10 \%$ de la variación total, con aquellas especies con arcos cigomáticos redondeados, amplia cavidad glenoidea y dentición postcanina localizada más posteriormente ubicadas en su extremo positivo, con el patrón morfológico opuesto para valores negativos (Figura 34). Conepatus chinga se segregó del resto por su amplia superficie de trituración en los carniceros, un paladar corto y arcos cigomáticos redondeados o rectos. Los morfotipos hipercarnívoros incluyeron a G. cuja, $L$. patagonicus y $N$. vison, que mostraron cierto grado de superposición en el morfoespacio, debido principalmente a la importancia de los bordes cortantes en sus carniceros, reducción del M1 y otros cambios morfológicos relacionados con altos valores del CP1. Lontra provocax no se solapó con ninguna especie, presentando un cráneo ampliamente redondeado y robusto.

El CP1 de las mandíbulas explicó 67\% de la variación total, mostrando especímenes con grandes trigónidos y reducidos talónidos, procesos coronoideos rectos 
(delgados en la punta, pero amplios en su base), cóndilos mandibulares desplazados ventralmente y cuerpos mandibulares robustos (especialmente en su parte anterior), ubicados en su extremo negativo (Figura 35). El patrón morfológico opuesto se observó en su extremo negativo. El CP2 explicó sólo 6\% de la variación total, con especímenes con cóndilo mandibular menos expandido posteriormente, proceso coronoideo inclinado posteriormente y cuerpos mandibulares más rectos y robustos ubicados en su extremo positivo (Figura 35). De la misma manera que en el análisis del cráneo, C. chinga se segregó del resto, principalmente por la amplia superficie de trituración en sus carniceros inferiores; mientras que se observó cierta superposición en el morfoespacio de los morfotipos hipercarnívoros, especialmente G. cuja, L. patagonicus y N. vison. Lontra provocax presentó un patrón similar al del ACP del cráneo, ocupando una posición intermedia pero solapada, en este caso, con G. cuja. Asimismo, L. patagonicus y $N$. vison se encuentran separados a lo largo del CP2, pero se ubican dentro del rango de variación mandibular de G. cuja.

En cuanto al CVA de cráneo en vista ventral, se observó que el CV1 explicó $81 \%$ de la variación total, con los especímenes ubicados en su extremo positivo con grandes bordes cortantes en sus carniceros, M1 reducidos y paladares y basicráneos largos; mientras el patrón opuesto se observó en sus valores negativos (Figura 36). El CV2 explicó casi 8\% de la variación, separando claramente aquellos especímenes con dentición postcanina en una posición más anterior, proceso paracondilar más posterior, paladares un poco más anchos y basicráneos anchos (Figura 36). Los primeros dos CVs separaron claramente cuatro morfotipos: $C$. chinga, L. provocax, $N$. vison y un cuarto que incluyó a G. cuja y L. patagonicus, que presentaron cierto solapamiento. Sin embargo, se observaron diferencias significativas $(P<0,01)$ en las distancias de Procrustes entre todos los pares (Tabla 19). 
En el CVA de mandíbulas, se observó que el CV1 explicó 90\% de la variación total, con especímenes con grandes talónidos y reducidos trigónidos en $\mathrm{m} 1$ y proceso coronoideo corto e inclinado posteriormente, ubicados en su extremo positivo (Figura 37). El CV2 explicó solo 5\% de la variación, separando especímenes con dentición en posición más posterior y cuerpos mandibulares más delgados en su extremo positivo (Figura 37). Al igual que en el CVA del cráneo, se identificaron los mismos cuatro morfotipos y se observaron diferencias significativas $(P<0,01)$ en las distancias de Procrustes entre todos los pares (Tabla 20).

El análisis de tamaño del cráneo en vista ventral mostró diferencias significativas $(P<0,01)$ entre todos los pares, exceptuando $C$. chinga- $N$. vison (Tabla 21). El análisis de tamaño de la mandíbula en vista lateral, mostró diferencias significativas $(P<0,01)$ entre todos los pares, exceptuando C. chinga-G. cuja (Tabla 22). En la Figura 38 se presentan los valores de tamaño de centroide de cráneo para todas las especies.

\subsection{1.b. Morfometría tradicional}

Los primeros tres CP explicaron 94\% de la variación total, con el CP1 explicando 72\%, el CP2 19\% y el CP3 4\%. El CP1 separó a las especies en función del tamaño, ubicándose L. provocax en su extremo positivo y L. patagonicus en su extremo negativo; con G. cuja, C. chinga y N. vison con valores intermedios entre los extremos (Figuras 39 y 40). Las variables con mayores autovectores asociados de manera positiva al CP1 se relacionaron con el largo y el ancho del cráneo (LT; AC y AmaxP, respectivamente). El CP2 separó a las especies en función de su morfología dentaria, ubicándose $C$. chinga en sus valores más positivos, L. provocax en una posición intermedia y las tres restantes especies con los menores valores (Figuras 39 y 41). Las 
variables con mayores autovectores asociados al $\mathrm{CP} 2$ de manera positiva se relacionaron con la presencia de molares con mayores superficies de trituración (LlabM1, LlingM1, AM1). Por último, el PC3 separó a las especies en función de su CpO, ubicándose G. cuja en su extremo positivo, L. provocax en una posición intermedia y las tres restantes especies en su extremo negativo (Figuras 40 y 41).

\subsubsection{Filogenia y ambientes}

El CPO parcial del cráneo (i.e., forma explicada por ambientes, de manera independiente de la filogenia y utilizándola como covariable) indicó que sólo un pequeño porcentaje de la variación (1\%) fue explicado por patrones geográficos, con Estepa Patagónica (sensu Olson et al., 2001) como la única ecorregión con un $P<0,01$. El segundo CPO (i.e., forma explicada por la filogenia de manera independiente de patrones geográficos, utilizando la matriz de ambientes como covariable) indicó que la mayoría de la variación morfológica (61\%) se explicó por tres nodos, de manera significativa $(P<0,01)$. El nodo 2 (véase Figura 8 ) separa mustélidos de mefítidos y explicó 54,6\% de la variación; los nodos 3 (Lutrinae + Ictonychinae) y 4 (Ictonychinae) explicaron sólo 2,5\% y 3,6\% de la variación, respectivamente. Un tercer CPO (i.e., forma explicada por filogenia) explicó $67 \%$ de la variación morfológica debida a factores históricos, con los mismos tres nodos arriba mencionados explicando, de manera significativa, porcentajes similares.

El CPO de las mandíbulas (i.e., forma explicada por ambientes, de manera independiente de la filogenia y utilizándola como covariable), indicó que ninguna ecorregión explicó de manera significativa un porcentaje de la variación morfológica. El segundo CPO de la mandíbula (i.e., forma explicada por filogenia de manera independiente de patrones geográficos), indicó que un alto porcentaje de la variación 
morfológica $(58 \%)$ se explicó por tres nodos de manera significativa $(P<0,01)$. El nodo 2 (véase Figura 8), separa mustélidos de mefítidos y explica 54\% de la variación; los nodos 3 (Lutrinae + Ictonychinae) y 4 (Ictonychinae) explican sólo 3\% y 1\% de la variación, respectivamente. Un tercer CPO (i.e., forma explicada por filogenia) explicó $67 \%$ de la variación morfológica debida a factores históricos, con los mismos tres nodos arriba mencionados explicando, de manera significativa, porcentajes similares.

El CPO parcial de tamaño del cráneo (i.e., tamaño explicado por ambientes, de manera independiente de la filogenia y utilizando la matriz filogenética como covariable), indicó que $10 \%$ de la variación fue explicada por patrones geográficos, con Matorral Chileno y Monte Bajo explicando significativamente $(P<0,01)$ una porción de la variación. El segundo CPO de tamaño del cráneo (i.e., tamaño explicado por filogenia de manera independiente de ambientes y utilizando la matriz de ambientes como covariable), indicó que 27,4\% de la variación fue explicada por dos nodos. El nodo 4 (Ictonychinae) y el 3 (Lutrinae + Ichonychinae) explicaron 17,5\% y 9,9\% de la variación total, respectivamente. El tercer CPO (i.e., tamaño explicado por filogenia), indicó que $48 \%$ de la variación en tamaño fue explicada por factores históricos, con los mismos nodos explicando similares porcentajes de manera significativa.

El CPO parcial de tamaño de mandíbulas (i.e., tamaño explicado por ambientes de manera independiente de la filogenia y utilizando la matriz filogenética como covariable), indicó que solamente 2,5\% de la variación en tamaño fue explicada por patrones geográficos, con Pampas Húmedas como la única ecorregión con un $P<0,01$. El segundo CPO (i.e., tamaño explicado por filogenia de manera independiente de ambientes y utilizando la matriz de ambientes como covariable), indicó que 37\% de la variación en tamaño fue explicada por la filogenia, con el nodo 3 (Lutrinae + Ichonychinae) como el único nodo con un $P<0,01$. Por último, el tercer CPO parcial 
(i.e., tamaño explicado por filogenia), indicó que ningún nodo explicó de manera significativa $(P<0,01)$ una porción significativa de la variación en tamaño de las especies.

\subsubsection{Forma y dieta}

Se encontró una asociación significativa entre la forma y la dieta en el Análisis de Correlaciones Canónicas (CCA), con la forma del cráneo explicando 67\% de la variación en la dieta. La primera combinación de variables se relacionó a una alimentación en base a vertebrados en sus coeficientes positivos, a invertebrados y material vegetal en sus valores negativos (Figura 42). La segunda combinación de variables lineares se relacionó a vertebrados y material vegetal en sus valores positivos, y a invertebrados en sus valores negativos. La tercera combinación de variables presentó valores negativos para las tres categorías de alimentación. El CPO parcial (i.e., dieta explicada por forma, de manera independiente de la filogenia), indicó sólo un $2 \%$ de asociación con vertebrados como la única categoría estadísticamente significativa $(P<0,01)$.

Asimismo, también se encontró una asociación significativa entre la forma de las mandíbulas y la dieta en el CCA, con la forma de las mandíbulas explicando 66\% de la variación en la dieta. La primera combinación de variables lineales se relacionó con una alimentación en base a invertebrados y material vegetal en sus coeficientes positivos y vertebrados en sus coeficientes negativos (Figura 43). La segunda combinación de variables lineares se relacionó con vertebrados en sus coeficientes positivos, e invertebrados y material vegetal en sus coeficientes negativos. El CPO parcial (i.e., dieta explicada por forma, de manera independiente de la filogenia), indicó sólo un 
1,5\% de asociación con vertebrados como la única categoría estadísticamente significativa $(P<0,01)$.

\subsubsection{Patrones de ordenamiento en el morfoespacio}

El índice de Clark Evans para tamaño de cráneos mostró una distribución de los puntos al azar $(C E=0,037, P<0,3986)$, mientras que para forma y forma + tamaño se observó un patrón sistemático $(C E=1,68, P<0,0079 ; C E=1,87, P<0,0014$, respectivamente). Para tamaño de mandíbulas también se observó un patrón al azar $(C E=0,04, P<0,2698)$; mientras que para forma y tamaño + forma se observó un patrón sistemático pero no significativo $(C E=1,73, P<0,066, C E=1,92, P<0,056$, respectivamente).

\subsection{Variaciones geográficas}

\subsubsection{Galictis cuja}

\subsubsection{Variaciones geográficas de tamaño}

Los individuos de mayor tamaño fueron los de Pampas Húmedas, seguidos por los de Espinal y Sabana Uruguaya, mientras que los de menor tamaño pertenecieron a Yungas Andinas y Monte Bajo (sensu Olson et al., 2001, Figura 44).

\subsubsection{1.a. Análisis de regresiones simples}

Los resultados principales de las OLS para G. cuja se presentan en la Tabla 23 para cráneos y Tabla 24 para mandíbulas. No se observó SA en los residuales de ninguna OLS, por lo que no se utilizaron SFs. No se encontró asociación significativa $(P<0,01)$ entre el tamaño del centroide y latitud, longitud, o ninguna de las variables ambientales, tanto para cráneos como para mandíbulas. 


\subsubsection{1.b. Análisis de regresiones múltiples}

Los análisis de regresión múltiple para G. cuja se llevaron a cabo con altitud, temperatura media anual, estacionalidad de la temperatura, temperatura media del trimestre más seco y precipitación anual. Se encontraron nueve modelos con iguales probabilidades de explicar la variación en tamaño de cráneo de 31 posibles, con un $\Delta \mathrm{AIC}<2$ desde el modelo con menor AIC $(475,893)$, que incluyó solamente la altitud. El modelo promedio $(\mathrm{AIC}=482,148)$, indicó que $10,3 \%$ de la variación en tamaño fue explicada por las variables incluidas, con precipitación anual y altitud como las más importantes (Tabla 25). Asimismo, altitud, temperatura media anual y temperatura media del trimestre más seco presentaron coeficientes negativos (menor tamaño del centroide a mayores valores de estas variables) y las tres restantes coeficientes positivos. Los valores VIF fueron menores a 10, y el correlograma indicó que la SA se redujo luego del ajuste del modelo. Los valores estimados de esta regresión indicaron que los individuos de mayor tamaño de G. cuja se encuentran en las provincias argentinas de Buenos Aires y Entre Ríos, mientras que los más pequeños se encontrarían en el noroeste y centro del país, y también a lo largo de la Diagonal Árida.

En cuanto a las mandíbulas, se encontraron ocho modelos con iguales probabilidades de explicar la variación en tamaño de 31 posibles, con un $\Delta \mathrm{AIC}<2$ desde el modelo con menor AIC $(463,23)$, que incluyó solamente a la precipitación anual y explicó 4,4\% de la variación. El modelo promedio (AIC=471,204) indicó que sólo 3,2\% de la variación en tamaño de mandíbulas fue explicada por todas las variables, con la precipitación anual como la más importante (Tabla 26). Solamente la temperatura media anual presentó coeficiente negativo (menor valor de tamaño de centroide a mayores valores de esta variable). Los valores VIF fueron menores a 10 y el correlograma indicó 
que la SA fue tenida en cuenta por el modelo. Los valores estimados de esta regresión indicaron el mismo patrón de variación en tamaño arriba explicado.

\subsubsection{1.c. Análisis de redundancia}

El RDA utilizando todas las ecorregiones indicó que 23,9\% de la variación en tamaño de cráneos se explicó por éstas, aunque ninguna ecorregión presentó valores significativos para un $P<0,01$. De igual manera, el RDA de mandíbulas indicó que 30,6\% de su variación en tamaño se explicó por ecorregiones, pero ninguna presentó valores significativos $(P<0,01)$.

\subsubsection{Variaciones geográficas de forma}

\subsubsection{2.a. Análisis de regresiones multivariadas}

La regresión multivariada de forma del cráneo indicó que 11,19\% de la variación fue explicada por las variables ambientales, pero de manera no significativa $(P=$ 0,4975). La regresión multivariada de forma de las mandíbulas indicó que 15,47\% de la variación fue explicada por las variables ambientales, pero de manera no significativa $(P=0,1382)$.

Una porción significativa $(P<0,05)$ de la variación en forma de cráneo $(3,56 \%)$ fue explicada por el tamaño (alometría). Los especímenes de G. cuja de mayor tamaño presentaron paladares más largos, dentición postcanina en una posición más anterior, arcos cigomáticos más rectos y menores tamaños en el forámen magnum y la bula timpánica; con el patrón opuesto en los individuos más pequeños (Figura 45).

Asimismo, 7,3\% de la variación en forma de las mandíbulas se explicó por el tamaño de manera significativa $(P<0,05)$. Los individuos de mayor tamaño presentaron cuerpos mandibulares más robustos y cortos, $\mathrm{m} 1$ de menor tamaño y proceso 
coronoideo más ancho y en posición más recta; el patrón opuesto se observó en los individuos más pequeños (Figura 46).

\subsubsection{2.b. Análisis de redundancia}

El RDA del cráneo indicó que 22,7\% de la variación en forma se explicó por las ecorregiones, aunque ninguna presentó valores significativos $(P<0,01)$. En cuanto al RDA de forma de las mandíbulas, el 31,1\% de la variación se explicó por las ecorregiones, con Pampas Húmedas como la única que explicó de manera significativa $(P<0,01)$ solamente $1,8 \%$ de la variación.

\subsubsection{Conepatus chinga}

Del total de individuos analizados para tamaño y forma, $25 \%$ provinieron de Pampas Húmedas, 14\% de Chaco Seco y Sabana Uruguaya, seguido por 13\% de Estepa Patagónica, y en menores porcentajes Espinal, Monte Bajo, Puna Central, Monte Alto, Yungas Andinas, Chaco Húmedo y Estepa Andina (sensu Olson et al., 2001).

\subsubsection{Variaciones geográficas de tamaño}

Los individuos de C. chinga de mayor tamaño fueron los de Sabana Uruguaya y Puna Central, mientras que los más pequeños fueron los de Monte Bajo y Chaco Seco (Figura 47).

\subsubsection{1.a. Análisis de regresiones simples}

Los resultados principales de OLS se presentan en la Tabla 27 para cráneos y Tabla 28 para mandíbulas. No se encontró asociación significativa $(P<0,01)$ entre tamaño y latitud, o entre tamaño y temperatura para cráneos o mandíbulas. La 
productividad primaria neta (NPP) explicó significativamente 32,8\% de la variación en tamaño de cráneo, evidenciando una falta de autocorrelación espacial (SA) en los residuales de OLS. Las variables estacionalidad de la temperatura, precipitación del trimestre más seco y precipitación del trimestre más frio explicaron significativamente una porción de la variación (entre 25 y 27\%) en tamaño de cráneos y mandíbulas (Tablas 27 y 28).

\subsubsection{1.b. Análisis de regresiones múltiples}

Los análisis de regresión múltiple para $C$. chinga se llevaron a cabo con Altitud, isotermalidad, estacionalidad de la temperatura, estacionalidad de las precipitaciones, precipitación del trimestre más cálido, NPP y evapotranspiración potencial (PET).

Se encontraron ocho modelos con iguales probabilidades de explicar la variación en tamaño del cráneo de un total de 255 posibles, con un $\triangle \mathrm{AIC}<2$ desde el modelo con menor AIC (1349,785), que incluyó solamente altitud y NPP y explicó 42,6\% de la variación en tamaño. El modelo promedio (Model Averaging, AIC= 1362,429) indicó que $40,1 \%$ de la variación en tamaño fue explicada por todas las variables incluidas, con NPP y altitud como las más importantes (Tabla 29). Solamente la precipitación del trimestre más cálido y PET presentaron coeficientes negativos (i.e., menor tamaño del centroide a mayores valores de estas variables); mientras que las restantes variables presentaron coeficientes positivos. Los valores VIF fueron menores a 10, y el correlograma indicó que la SA se redujo luego del ajuste del modelo (Figura 48). Los valores estimados de esta regresión indicaron que los especímenes más chicos de $C$. chinga se encontraron a lo largo de la Diagonal Árida, desde el noroeste al sudeste de Argentina, y los individuos más grandes en Uruguay, las provincias argentinas de Corrientes, Entre Ríos y Jujuy (Figura 49A). 
En cuanto a mandíbulas, se encontraron cinco modelos con iguales probabilidades de explicar la variación en tamaño de 255 posibles, con un $\Delta \mathrm{AIC}<2$ desde el modelo con menor AIC (990,833), que incluyó altitud, estacionalidad de la temperatura, temperatura media del trimestre más seco y NPP, y explicó 36,8\% de la variación. El modelo promedio (AIC=1000,939) indicó que 32,3\% de la variación en tamaño de mandíbulas fue explicada por todas las variables, con altitud y NPP como las más importantes (Tabla 30). Las variables estacionalidad de las precipitaciones, precipitación del trimestre más cálido y PET presentaron coeficientes negativos, mientras que las restantes variables presentaron coeficientes positivos. Los valores VIF fueron menores a 10 y el correlograma indicó que la autocorrelación espacial se redujo luego del ajuste del modelo. Los valores estimados de esta regresión, indicaron el mismo patrón de variación en tamaño arriba explicado (Figura 49B).

\subsubsection{1.c. Análisis de redundancia}

El RDA utilizando todas las ecorregiones explicó $23.9 \%$ de la variación en tamaño del cráneo, con Puna Central y Monte Bajo explicando significativamente $(P<0,01) 13,3 \%$ y $4,8 \%$, respectivamente, (y $18 \%$ tomadas juntas en el segundo análisis). El RDA de mandíbulas indicó que 21,5\% de la variación en tamaño se explicó por las ecorregiones, con Chaco Seco y Monte Bajo explicando significativamente $(P<0,01) 6,8 \%$ y $5,6 \%$ de la variación en tamaño $(12,4 \%$ tomadas juntas en el segundo modelo) 


\subsubsection{Variaciones geográficas de forma}

\subsubsection{2.a. Análisis de regresiones multivariadas}

La regresión multivariada del cráneo indicó que 15,4\% de la variación en forma fue explicada, de manera significativa $(P<0,01)$, por las variables ambientales. Los diagramas de dispersión de cada variable incluida se observan en la Figura 50. Los cambios de forma más importantes se relacionaron con NPP y PET, con individuos ubicados en el extremo positivo del primero, que incluye hábitats más productivos, presentando P4 y M1 relativamente más pequeños, cavidad glenoidea más pequeña y foramen magnum más pequeño y en una posición más anterior; con el patrón morfológico opuesto en hábitats menos productivos. Aquellos especímenes de hábitats con más energía disponible (i.e., mayores valores de PET) presentaron dentición postcanina ubicada más anteriormente, arcos cigomáticos más rectos y mayor tamaño del foramen magnum (o un foramen magnum de mayor tamaño). El correlograma de los residuales indicó que la SA fue tenida en cuenta por las variables predictoras.

La regresión multivariada de las mandíbulas indicó que 16,6\% de la variación en forma fue explicada, de manera significativa $(P<0,01)$, por las variables predictoras. Los diagramas de dispersión de cada variable incluida se observan en la Figura 51. Los cambios de forma más importantes se relacionaron principalmente con NPP, ubicándose en su extremo positivo los especímenes con una mandíbula más robusta, la rama horizontal alta, amplio proceso coronoideo y m1 de menor tamaño y desplazado anteriormente (Figura 51).

\subsubsection{2.b. Análisis de redundancia}

El RDA utilizando todas las ecoregiones, explicó 11,9\% de la variación en forma del cráneo de C. chinga, con Estepa Patagónica y Sabana Uruguaya como las 
únicas ecorregiones que explicaron significativamente $(P<0,01)$ una parte de la variación (3,2\% y 2,2\%, y solamente $5.4 \%$ en conjunto). El RDA de mandíbulas, indicó que $14,1 \%$ de la variación en forma, fue explicado por todas las ecorregiones, con Sabana Uruguaya como la única ecoregión que explicó 2,4\% de manera significativa $(P<0,01)$.

\subsubsection{Lyncodon patagonicus}

De los especímenes analizados, el de mayor tamaño provino de las Yungas Andinas, mientras que los del Monte Bajo, Estepa Patagónica y Chaco Seco presentaron valores similares, y aquellos provenientes del Espinal fueron los de menor tamaño (Figura 52).

No se presentan los análisis de regresión, ya que no fue posible eliminar la presencia de SA en los residuales mediante SEVM. 


\section{Discusión}

\subsection{Taxonomía de Conepatus}

Durante el siglo XIX y la primera mitad del XX, se describieron muchas especies del género Conepatus, basadas en caracteres externos, tales como el tamaño y la coloración del pelaje. Así para Sudamérica, Oldfield Thomas describió varias especies, incluyendo C. rex (1898), C. arequipae (1900b), C. chorensis (1902a), C. gibsoni (1910), C. ajax (1913), y dos especies provenientes de una misma localidad, $C$. budini y C. calurus (1919) de Otro Cerro, Catamarca (véase Pardiñas et al., 2007). Resulta sorprendente notar que el mismo autor en el año 1902 (referencia en Thomas 1920) había señalado "the difficulty of a proper determination of the members of Conepatus, and the probability that most of the forms grade into each other" y que "... each character varies individually...". A pesar de estas consideraciones, Cabrera y Yepes (1940), Cabrera (1958) y Kipp (1965), propusieron el pase a sinonimia de varias de las mencionadas especies basándose exclusivamente en caracteres externos. Resulta llamativo que varias de estas propuestas hayan sido seguidas hasta la actualidad (véase Canevari y Vaccaro, 2007), teniendo en cuenta las marcadas variaciones intraespecíficas en el pelaje de los zorrinos, incluso dentro de una misma población (véase Van Gelder, 1968). La ausencia de caracteres diagnósticos claros para discriminar entre estas especies, a menudo resultó en la asignación específica basándose exclusivamente en su localidad de colecta, o en la utilización de mapas de distribución, en lugar de caracteres morfológicos diagnósticos. Esto introducía ambigüedad en las asignaciones taxonómicas previas y una complicación en la evaluación de la validez de las especies del género.

En los Análisis de Componentes Principales realizados en todas las vistas, se observó una clara superposición de las dos especies actualmente reconocidas, 
incluyendo los análisis que contenían el holotipo de $C$. humboldtii y otros sinónimos junior. Estos resultados se obtuvieron tanto para el esquema de Redford y Eisenberg (1992), como para el esquema de Kipp (1965), indicando que las variaciones morfológicas craneodentarias no se condicen con los esquemas taxonómicos propuestos en base a caracteres externos y al tamaño. Contrario a los resultados de los ACP, los DFA indicaron diferencias significativas en las distancias de Mahalanobis y Procrustes. Sin embargo, algunos puntos indican cierta cautela a considerar estos resultados (véase Kovarovic et al., 2011), ya que los especímenes fueron asignados a $C$. chinga y $C$. humboldtii de acuerdo a su procedencia geográfica, sin una justificación morfológica clara, lo que resulta un problema dada la necesidad de una clasificación inequívoca para el DFA (véase Davis, 1986; Legendre y Legendre, 1998). Esto puede resultar en un problema en el caso de existir un patrón geográfico de variación morfológica, dado que si la muestra se separa en dos categorías basándose solamente en su procedencia geográfica (e.g., patagonia vs. al norte de patagonia), es esperable obtener diferencias significativas. Esto se confirmó al extraer la porción de la variación craneodentaria explicada por la distribución de los especímenes (representada por la latitud y la longitud) antes de realizar el DFA, con lo que se observó que las distancias de Mahalanobis y Procrustes no fueron significativas y los porcentajes de reclasificación cayeron al 30-40\% (peor que lo esperado según el azar: 50\%), indicando la presencia de un patrón geográfico de variación morfológica. También es importante destacar que los mismos DFA, pero con el esquema de Kipp (1965) sin excluir la variación geográfica, arrojaron diferencias significativas entre las dos especies, lo que conlleva un resultado claramente contradictorio, dadas las diferencias en la delimitación de las especies entre las propuestas de Redford y Eisenberg (1992) y Kipp (1965). 
Un análisis reciente que incluyó variaciones en la coloración del pelaje y genes mitocondriales arrojó los mismos resultados que los observados en estos análisis morfométricos (Schiaffini et al., 2013b), confirmando que $C$. chinga y C. humboldtii pertenecen en realidad a una misma especie. Por ende, debido a lo variable de los caracteres utilizados en sus descripciones, y a la falta de diferencias morfológicas claras, se propone sinonimizar ambas especies y $C$. chinga sería el nombre válido por tener prioridad sobre otros nombres de acuerdo a su fecha de publicación. Estos resultados indican que sólo existiría una especie de zorrino en el sur de América del Sur.

\subsection{Análisis de distribución}

Como se mencionó previamente, los estudios de distribución sobre estos pequeños carnívoros son escasos, y a excepción de Lyncodon patagonicus (Prevosti y Pardiñas, 2001; Schiaffini et al., 2013a), se desconoce su relación con las variables climáticas más determinantes y cuáles son las principales áreas habitadas en el sur de Sudamérica. Ciertos patrones en común y algunas diferencias se observaron en los resultados presentados. Ambos hurones (Galictis cuja y L. patagonicus) habitan tanto zonas bajas como medias (hasta 2000m.s.n.m.) y zonas frías y templadas, aunque al hurón menor también se lo encuentra en zonas templadas a cálidas y de hecho pareciera concentrarse en ellas (i.e., la mayoría de las localidades se encuentran en zonas templadas-cálidas). Asimismo, este último se encuentra tanto en zonas secas como lluviosas, mientras que el huroncito patagónico habita preferentemente en zonas áridas. También se observaron algunos puntos en común entre las dos especies asociadas comúnmente a ambientes acuáticos (Lontra provocax y el introducido Neovison vison). Ambas se encontraron en zonas bajas y medias en cuanto a altitud; y de temperaturas templadas a cálidas, aunque el segundo también se encontró en zonas frías. Asimismo, ambas especies se encontraron en zonas áridas y lluviosas (Estepa 
Patagónica y Bosques Valdivianos), aunque los registros del huillín en las primeras parecieran casos aislados, mientras que el visón es un habitante "común” de los ríos de la Estepa patagónica, tal y como se observa a lo largo de las cuencas de los ríos Chubut y Senguer (Pagnoni et al., 1986). De las especies estudiadas, el zorrino común estuvo presente en todos los tipos de ambientes, desde zonas bajas a altas, zonas frías a cálidas y áridas a húmedas.

Considerando el esquema biogeográfico de Olson et al. (2001), las dos principales ecorregiones patagónicas (Bosques Valdivianos y Estepa Patagónica) contienen a las cinco especies estudiadas. Sin embargo, según se observó en la Figura 33, el área en el cual todas son simpátricas se ubicó en el noroeste de Patagonia, particularmente situada en el límite entre las mencionadas ecorregiones, donde existe un amplio ecotono entre los dos ambientes (Schlichter y Laclau, 1998). Este ecotono reúne representantes vegetales de ambas ecorregiones, entre las que se encuentran especies arbóreas como el ciprés de la cordillera (Austrocedrus chilensis), el ñire (Nothofagus antarctica) y el maitén (Maytenus boaria), con pastizales de coirón (Stipa spp.) y neneo (Mulinum spinosum); mientras que las características climáticas incluyen una marcada estacionalidad en las precipitaciones y una temperatura que ronda $\operatorname{los} 10^{\circ} \mathrm{C}$ anuales. Esta zona presenta además, un marcado gradiente de precipitaciones de oeste a este, que va desde más de 3000 mm a menos de 300 mm en apenas 50 Km (Veblen y Lorenz, 1988; Paruelo et al., 1998; Schlichter y Laclau, 1998). Es interesante notar que en la misma área se encontró la mayor diversidad de marsupiales sudamericanos (véase Martin, 2008), por lo que representaría un sitio prioritario para la conservación de mamíferos patagónicos. 


\subsubsection{Galictis cuja}

Aunque los registros de G. cuja se extienden a lo largo de casi $6000 \mathrm{Km}$ en sentido noreste-sudoeste en el continente sudamericano, el modelo de distribución potencial con todas las localidades indicó seis núcleos con altas probabilidades de presencia, dos en Brasil (este y noreste), y otros cuatro compartidos entre Argentina, Brasil, Chile y Uruguay. Con excepción de las Yungas Andinas y los de la Mata Atlántica sensu lato (Bosques Atlánticos del Alto Paraná, Bosques de Bahía, Bosques de Sierra del Mar sensu Olson et al., 2001), tanto Caatinga como las Pampas Húmedas, Sabana Uruguaya, Estepa Patagónica y el Matorral Chileno se componen de vegetación baja arbustiva o herbácea, con pequeños parches boscosos, pero presentan condiciones climáticas de temperatura y precipitaciones muy variadas (Dinerstein et al., 1995; Burkart et al., 1999). Esto hace suponer que el hurón menor es una especie generalista en cuanto a sus requerimientos de hábitat, de amplia distribución en el continente sudamericano. Un estudio reciente de su distribución en Patagonia central (Carrera et al., 2012), propone la expansión de G. cuja vinculado a pulsos climáticos y a su relación con estepas arbustivas de la Provincia Fitogeográfica del Monte (sensu León et al., 1998). Sin embargo en el presente estudio, el Monte Bajo (sensu Olson et al., 2001) presentó valores medios a bajos de predicción y de hecho pareciera actuar como una barrera (separando) entre los núcleos de alta predicción (Patagonia-Yungas, y Patagonia-Pampas). Asimismo, las localidades de registro en esta ecoregión, fueron muy escasas.

Si bien la distribución de G. cuja fue evaluada recientemente (pero con posterioridad al inicio de esta tesis), dicho análisis pareciera estar centrado en determinar las áreas de posible simpatría con Galictis vittata (Bornholdt et al., 2013), al 
punto tal que no se relacionan particularmente las localidades de registro con las áreas geográficas.

Los resultados obtenidos a escala continental fueron similares a los encontrados por Yensen y Tarifa (2003a) y Bornholdt et al. (2013), confirmando que la distribución de G. cuja se extiende desde el noreste de Brasil hasta el sur de Argentina y Chile. Sin embargo, el número de localidades en el presente estudio es mayor que en los mencionados anteriormente. Asimismo, en la presente contribución se incluyeron las variables más importantes para explicar la distribución del hurón menor, entre las que se encuentran principalmente la estacionalidad de la temperatura, las temperaturas de los meses más fríos y la altitud. Resulta interesante notar que la única de las ecorregiones con altos valores de predicción que presenta una alta estacionalidad e isotermalidad de la temperatura (i.e., característico de zonas áridas) es la Estepa Patagónica, mientras que las restantes podrían considerarse zonas templadas o subtropicales. Algunos trabajos previos resaltaron la importancia de las temperaturas mínimas como determinantes de la riqueza específica y su importancia en determinar los patrones de distribución de marsupiales (Birney y Monjeau, 2003) y carnívoros sudamericanos (Monjeau et al., 2009), relacionado principalmente a la disponibilidad de energía. El hurón menor es un carnívoro de cuerpo alargado y tubular, particularmente adaptado para entrar en madrigueras subterráneas de sus presas (i.e., roedores; Yensen y Tarifa, 2003a). Los animales de esta morfología presentarían una pobre eficiencia energética, debido a su gran superficie en relación a su área, y quizás a la incapacidad de adquirir una postura de descanso esférica (Brown y Lasiewski, 1972). Quizás se deba a estas razones la importancia de las variables de temperaturas mínimas en explicar sus patrones de distribución, aunque no puede dejar de notarse el gran rango de temperatura $\left(\approx 20^{\circ} \mathrm{C}\right)$ observado entre las localidades de registro más cálidas y más frías, lo que pareciera 
definir al hurón menor como un carnívoro euritérmico. Su presencia en zonas frías podría explicarse por un balance entre su eficiencia energética potencialmente pobre (debido al patrón corporal antes descripto) y por la posibilidad de adquirir un número suficiente de presas para mantener el costo metabólico (Brown y Lasiewski, 1972); de la misma manera que ha sido propuesto para el mustélido de menor tamaño (i.e., Mustela nivalis, véase Sheffield y King, 1994). Otras posibilidades para lidiar con las temperaturas extremas serían la existencia de torpor y/o el almacenaje de grasa, como se ha indicado para Taxidea taxus en Norteamérica (Harlow, 1981); pero no se conocen estudios al respecto sobre las especies aquí analizadas.

Debe destacarse también, que las áreas con altos valores de predicción en el modelo Actual, se corresponden con las cuatro subespecies de G. cuja comúnmente reconocidas (véase Yensen y Tarifa, 2003a). Así, el núcleo con altos valores en el centro de Chile correspondería a $G$. c. cuja; el de valores medios a altos de la región pampeana de Buenos Aires con G. c. huronax; el del este de Brasil con G. $c$. furax; y el del sur de Bolivia con G. c. luteola. Esto resulta interesante dado que los modelos de distribución potencial permitirían así concentrar esfuerzos de muestreo en determinadas zonas geográficas, para profundizar luego el desarrollo de estudios taxonómicos de base (véase Raxworthy et al., 2007; Särkinen et al., 2013).

Por último, se observó una marcada reducción en el área potencialmente habitable desde el modelo Actual al modelo 1950. Esto puede deberse a un sesgo en el número de localidades registradas posteriormente al año 1950, o quizás a la modificación del hábitat debido a la expansión de la frontera agropecuaria, ya que varias de las localidades anteriores al año 1950 se encuentran en áreas con una predominancia actual a los monocultivos (e.g., soja Glycine max), y por ende sujetas a una fuerte reducción en la biodiversidad (Aizen et al., 2009). 


\subsubsection{Lyncodon patagonicus}

La presencia del huroncito patagónico en el este de Buenos Aires durante el Pleistoceno, más allá del rango histórico de distribución de la especie, fue asociada con la existencia de climas más fríos y secos, en base a evidencia revelada por otros mamíferos y sus indicadores bióticos (Prevosti y Pardiñas, 2001; Prevosti et al., 2009). Los registros fósiles con buena información estratigráfica de L. patagonicus son de edad Lujanense (125-4,5ka, sensu Cione y Tonni, 1995), con uno de ellos muy cercano al UMG (Camet Norte), mientras que un espécimen de Luján (provincia de Buenos Aires) fue colectado en el "Pampeano Lacustre" de Ameghino (1889), y su edad podría ser asignada a un amplio período entre 73 y 12 ka (Prevosti y Pardiñas, 2001; Toledo, 2011). Lo mismo podría ser dicho para los registros del Holoceno del noreste y sur de la provincia de Buenos Aires, que también fue relacionada a una fauna asociada a climas más secos (Prevosti y Pardiñas, 2001; Quattrocchio et al., 2008). Así, la evidencia fósil indica que la presencia de L. patagonicus durante el Pleistoceno-Holoceno del este de Buenos Aires, donde se encuentra ausente desde tiempos históricos, se relaciona con la presencia de climas más áridos, en concordancia con los modelos de distribución presentados.

Los cuatro modelos generados representan el primer intento de analizar la distribución potencial de un pequeño carnívoro raro, endémico del cono sur sudamericano, y así mismo es el primero en utilizar fósiles. Aunque la distribución potencial en los modelos "Pleistoceno-Holoceno" y "Holoceno" podría tener cierto sesgo debido a las diferencias de edades entre los registros y la base de datos temporal (i.e., UMG), son una representación razonable de la distribución de L. patagonicus. En este sentido, se demostró que las mismas variables utilizadas en los modelos son las que afectan su distribución a escala continental (Figura 5A y 5B). Un patrón general puede 
observarse desde un punto de vista histórico, desde el UMG hasta 1950: un cambio de una distribución continua en el este (Figura 25A) hacia una distribución discontinua (o en parches) hacia el oeste (Figura 26B). Este patrón podría indicar una retracción en la distribución de L. patagonicus desde el UMG (i.e., vicarianza), acentuándose en el último siglo.

Aunque los modelos de distribución potencial "Pleistoceno-Holoceno" y "Holoceno" parecen estar sobreestimando algunas áreas (especialmente para valores altos de predicción), varios patrones pueden explicarse por las condiciones climáticas de ese tiempo. El cambio desde el oeste hacia el este, alejándose de los Andes, podría explicarse por las grandes extensiones glaciales que cubrían dichas áreas, y por la presencia de condiciones climáticas extremas, típicas de ambientes periglaciales (Rabassa et al., 2011). Asimismo, un descenso de unos 100-140 m del nivel del mar durante las glaciaciones, expuso gran parte de la plataforma continental, sumando una superficie importante que pudo ser ocupada por la biota, incluyendo a L. patagonicus (Rabassa et al., 2005). Aún más importante, durante las glaciaciones pudo haberse producido un desplazamiento en los anticiclones pacíficos (Rabassa et al., 2005). De este modo, el anticiclón del Pacífico se habría desplazado hacia el norte, y las (actuales) provincias de La Pampa y Buenos Aires se verían afectadas por la influencia de los westerlies (vientos secos y fríos del oeste, Rabassa et al., 2005). En otras palabras, las condiciones climáticas típicas de la Patagonia (vientos fríos y secos, temperatura moderada) se habrían extendido hacia el noreste, cubriendo parte de la región Pampeana (Iriondo y García, 1993). Debido al descenso del nivel del mar, la misma región Pampeana experimentaría un clima con condiciones más extremas o continental (i.e., alta amplitud térmica), alejándose de la influencia oceánica del clima actual. En el 
contexto de la distribución de L. patagonicus, esto se corrobora por la presencia de fósiles en esta área (véase localidades en Figura 25).

Los modelos con datos actuales mostraron un gran área de alta predicción en el centro y oeste de Patagonia sensu lato, otra área con altos valores dispersa en el oeste de Argentina, y otra pequeña en Chile, que pareciera expandirse desde el modelo Actual al de 1950, lo que resulta consistente con proyecciones de cambio climático para el centro de Chile, que conllevan un incremento en la aridez (Watson et al., 1998).

Ambos modelos actuales mostraron las mismas áreas geográficas con alta probabilidad de ocurrencia, aunque el modelo Actual pareciera sobreestimar algunas áreas, debido a la inclusión de localidades "históricas", tales como aquellas de las provincias de Buenos Aires y La Pampa. Así, se observa el área con altos valores de predicción en el sur de Buenos Aires, pese a que la intensa ocupación humana y a las modificaciones en las precipitaciones ocurridas en los últimos 100 años hacen que la presencia de L. patagonicus en esa área sea improbable (véase Prevosti y Pardiñas, 2001).

Varios puntos en común se observaron en las variables más importantes para explicar su distribución, en coincidencia con el hurón menor G. cuja, ya que se observó una gran importancia de la estacionalidad de la temperatura, de las temperaturas mínimas y de la altitud, aunque en este caso también jugaron un papel importante las precipitaciones, particularmente las de primavera. De esta manera, las áreas frías con marcada estacionalidad de la temperatura, precipitaciones en primavera y altitudes menores a 2000 m.s.n.m parecieran indicadas como hábitat para L. patagonicus.

Las localidades actuales no se distribuyen uniformemente entre las ecorregiones, con la mayoría provenientes de la Estepa Patagónica, seguida por el Monte Alto y el Chaco Seco (sensu Olson et al., 2001). Estas tres ecorregiones reciben menos de 700 
mm de precipitación anual y están compuestas estructuralmente por estepas arbustivas o bosques secos (Burkart et al., 1999). Ambas áreas de altos valores de predicción en los modelos Actual y 1950 coinciden en parte con la extensión de dos ecorregiones: la primera en el norte de Argentina con el Monte Alto, y con menos valores de predicción, con la parte oeste del Chaco Seco; mientras que la segunda área se corresponde con la Estepa Patagónica, la cual es fuertemente afectada por los vientos secos del anticiclón del Pacífico y bajas temperaturas anuales de $5-10^{\circ} \mathrm{C}$ (Mancini et al., 2008). Es importante destacar que en el sur de Argentina, las áreas de alta predicción se restringen a la Estepa Patagónica, evitando la ecorregión de Monte Bajo, lo que podría deberse a la ausencia en este ecosistema de estepas arbustivas y a la predominancia de la "jarilla", Larrea spp. (Roig-Juñent et al., 2001).

Al igual que para G. cuja, las áreas con altos valores de predicción para $L$. patagonicus en los modelos actuales se corresponden con las supuestas distribuciones de las dos subespecies comúnmente reconocidas: L. p. thomasi Cabrera, 1929 y L. p. patagonicus (de Blainville, 1842) para el noroeste y el sur de Argentina, respectivamente.

\subsubsection{Lontra provocax}

Según lo observado en ambos modelos de distribución potencial y los porcentajes de localidades según ecorregiones, L. provocax parece un habitante típico de los Bosques Valdivianos y de manera secundaria, de Bosques Magallánicos. Asimismo, los datos climáticos de localidades mostraron preferencia por hábitats con altitudes menores a 1000 m.s.n.m, temperaturas que rondan $\operatorname{los} 9^{\circ} \mathrm{C}$ y precipitaciones superiores a los $1000 \mathrm{~mm}$. Los Bosques patagónicos presentan paisajes montañosos, con valles glaciarios y numerosos lagos y cursos de agua de vertiente atlántica o pacífica. En 
cuanto a vegetación, presentan típicamente un bosque húmedo con representantes del género Nothofagus y Austrocedrus chilensis, aunque la composición de especies varía mucho según la altitud, exposición y la latitud (Burkart et al., 1999), de acuerdo a lo cual se pueden identificar varios tipos de formaciones vegetales leñosas, boscosas y matorrales (Rusch et al., 2008). Varios autores han expuesto la necesidad de cobertura vegetal cercana a cursos de agua como un requerimiento básico para la presencia de $L$. provocax (Sielfeld y Castilla, 1999; Vianna et al., 2011), lo cual sumado a las diferencias de precipitaciones explicaría su presencia en zonas de bosques, y su virtual ausencia de áreas más abiertas como los ríos de la Estepa Patagónica (véase Chehébar et al., 1986), que presentan un clima árido y frío, con una vegetación arbustiva-herbácea (Vallarades, 2004a).

Existen varios registros "visuales" sin material voucher conocido para algunas provincias argentinas, lo que dificulta el estudio de su distribución actual (véase Chebez, 2008). Sólo unas pocas localidades de L. provocax se ubicaron en la ecorregión Estepa Patagónica, tratándose de los especímenes MACN 4.402, colectado por F. Ameghino en "Río Senguer, Santa Cruz"; del espécimen SNMNH 171959 de "cerca de la boca del Río Negro", colectado en 1910 por A. Hrdlicka (y actualmente extraviado); y otros dos catalogados como "Lago Buenos Aires" en Santa Cruz y "Esquel” en Chubut (Cabrera y Yepes, 1940), el cual probablemente se refiera a un avistamiento en el P.N. Los Alerces (véase Chébez, 2008). El río Senguer es un cauce que nace en los lagos La Plata y Fontana al oeste de la provincia del Chubut (i.e., Bosques Valdivianos), y se dirige aguas abajo hacia la Estepa Patagónica, ingresando solamente unos pocos kilómetros en la provincia de Santa Cruz (Vallarades, 2004b). El Río Negro nace de una confluencia del río Limay (donde se conocen poblaciones de huillín) con el Río Neuquén. De esta manera, podría tratarse de individuos migrantes o transeúntes (véase 
Chehébar y Benoit, 1988), colectados unos 100 años atrás, de modo que su presencia hoy día en la Estepa Patagónica sería poco probable, ya que el resto de las localidades de colecta del huillín se concentran en los Bosques Valdivianos. Asimismo, esta retracción observada en las localidades y en el área de distribución potencial observada desde el modelo Actual hacia el de 1950, podría deberse en parte a la presión de cacería impuesta sobre la especie por el valor monetario de sus pieles, lo que derivó en un problema de conservación, ya que se trata de una de las nutrias más amenazadas de la Argentina, catalogada como "amenazada" por la IUCN (Sepúlveda et al., 2008), como “insuficientemente conocida" y "amenazada” en Chile (República de Chile, 2007), y “amenazada" en Argentina (Valenzuela et al., 2012a). En este contexto, la distribución actual del huillín se vería restringida en su extensión hacia el este por varios cientos de kilómetros, ya que si bien la localidad más oriental (acorde a las localidades de 1950) sería "Isla de los Estados", se trata de una localidad muy austral correspondiente a los Bosques Valdivianos. El resto de las localidades para Argentina parecieran escasas si se comparan con las localidades de Chile. Aún más, la mayoría de los registros provienen de relevamientos centrados en el P.N. Nahuel Huapi (Chehébar, 1983; Porro y Chehébar, 1995). En los modelos generados se observaron valores medios de predicción en el oeste de Chubut, como en las cuencas de los lagos del P.N. Los Alerces. Sin embargo, su presencia en esas cuencas en general se descartaría por la falta de los ítems alimenticios más consumidos por el huillín, como los crustáceos Aegla spp., Sammastacus spinifrons o moluscos del género Diplodon (Chehébar, 1983; Aued et al., 2003; Fasola et al., 2006; Chebez, 2008). 


\subsubsection{Neovison vison}

Las primeras introducciones del visón en el sur de Sudamérica se corresponden a los años 1930-1940 en Argentina y Chile, donde se habrían importado desde EUA varios grupos de individuos con fines peleteros (Jaksic et al., 2002). En Chubut, los visones se habrían dispersado desde dos puntos básicos: uno situado al noroeste de la provincia, desde el cual habrían migrado hacia el este siguiendo la cuenca del Río Chubut; y otro desde el centro-sur de la provincia, desde donde habrían migrado hacia el lago Colhué Huapi y luego hacia el oeste siguiendo la cuenca del río Senguer hacia los lagos La Plata y Fontana (Pagnoni et al., 1986).

El modelo de distribución potencial indicó altos valores de predicción en el noroeste y centro-este de Patagonia, correspondiéndose con ecorregiones de Bosques Valdivianos y de Estepa Patagónica, así como del ecotono situado entre ellas. Los datos climáticos indican que el visón introducido es una especie extremadamente generalista, habitando cuencas de vertiente atlántica o pacífica, con condiciones de vegetación y clima muy diversas. Asimismo, resulta interesante tener en cuenta que algunos especímenes se han colectado inclusive a unos $500 \mathrm{~m}$ (estimados) de distancia respecto de ríos y/o arroyos (individuos LIEB-M-885 y LIEB-M-886), lo que es importante debido al consumo de micromamíferos durante diversas épocas del año (véase Ibarra et al., 2009). Esto indicaría que si bien el visón es un habitante típico de ambientes acuáticos, también se lo podría encontrar ocasionalmente en ambientes terrestres. Se han reportado composiciones dietarias muy diversas para esta especie, desde predominancia de crustáceos en el P.N. Nahuel Huapi (Previtali et al., 1998), hasta predominancia de micromamíferos y peces en Isla Navarino (Chile, Ibarra et al., 2009), y en Tierra del Fuego (Valenzuela et al., 2013). Esta alta plasticidad ecológica se corresponde con los resultados obtenidos en cuanto a los tipos de hábitat utilizados por 
el visón en Patagonia, demostrando una variación en el uso de hábitat de acuerdo con la disponibilidad de presas (Eagle y Whitman, 1987).

Existen pocos antecedentes referidos a la distribución del visón en Argentina y/o Chile, dado que el trabajo de Pagnoni et al. (1986) se restringe a la provincia del Chubut; y los trabajos de Fasola et al. (2009) y Valenzuela et al. (2012b) se enfocan en las interacción con el huillín y en su ecología trófica, en el área en que estas especies habitan en simpatría. Un estudio en el sur de Chile presenta varias localidades nuevas (Medina, 1997), mientras que otro estudio en Patagonia identificó una gran variedad de condiciones (muy variables) de hábitat utilizadas por visones, desde interferencias humanas (e.g., visitantes, animales domésticos, asentamientos) a coberturas vegetales de las riberas (Previtali et al., 1998). Algunos estudios se han realizado en Europa (donde también ha sido introducido), identificando la situación general en cada país y algunos cambios en su abundancia (Bonesi y Palazón, 2007), o estudiando patrones de uso de hábitat a pequeña escala (Zabala et al., 2007; Melero et al., 2008). Sin embargo, este es el primer intento de modelar la distribución de este carnívoro introducido a escala regional para América, donde en un período aproximado de 70 años la especie ha invadido una gran superficie de Patagonia, avanzando alrededor de 7,7 Km/año en ambientes esteparios y 5,3 Km/año en ambientes boscosos (Pagnoni et al., 1986). Esto podría deberse a la falta de predadores o competidores, lo que es característico en los procesos de invasión (Vitousek et al., 1997). Asimismo, los altos valores de predicción observados en el modelo en diversas cuencas, caracterizan a esta especie como "invasiva" (sensu Kolar y Lodge, 2001), dado el gran movimiento desde los centros originales de dispersión (Cholila y Lago Futalaufquen, y Sarmiento ubicados en el noroeste y sur del Chubut, respectivamente; Pagnoni et al., 1986). 


\subsubsection{Conepatus chinga}

A partir de la sinonimización de las dos especies de zorrinos comúnmente reconocidas para el sur de Sudamérica, los límites de su distribución conocida deberían reevaluarse. De esta manera, $C$. chinga se distribuye por gran parte del continente sudamericano desde Perú y sur de Brasil hasta el sur de Argentina y Chile. Ambos modelos de distribución potencial presentaron patrones similares, con altos valores de predicción en las mismas áreas, pero reducidas en el modelo 1950. El área con altos valores de predicción que se extiende desde el sur del Perú hasta la provincia argentina de San Luis, comprende en realidad a ecorregiones con condiciones climáticas y de vegetación muy variables (e.g., Puna Central, Yungas Andinas, y oeste del Chaco Seco). La Puna Central se compone típicamente de pastizales de altura (o de montaña), con condiciones climáticas extremas como una gran amplitud térmica y escasas precipitaciones (100-200mm; Villagrán et al., 1981; Dinerstein et al., 1995; Burkart et al., 1999). Las Yungas Andinas se conocen típicamente como bosques de montaña o de ladera, tratándose de uno de los ecosistemas de montaña más ricos del mundo (Dinerstein et al., 1995), con formaciones boscosas muy variables en función de la altitud, pero presentando típicamente un clima cálido, con precipitaciones que oscilan alrededor de los $1000 \mathrm{~mm}$ (Burkart et al., 1999). El Chaco Seco presenta una vasta planicie compuesta principalmente por bosque xerófilo, con zonas de sabanas o pastizales, temperatura que ronda $20^{\circ} \mathrm{C}$ anuales y precipitaciones entre $500-700 \mathrm{~mm}$ (Burkart et al., 1999). Separado de esta área por valores medios y bajos de predicción, se observaron otras dos áreas con altos valores de predicción, una en la región pampeana y otra en Patagonia sensu lato. La primera se compone típicamente de una llanura con clima templado-húmedo y precipitaciones distribuidas uniformemente durante el año, presentando una vegetación de pastizal (Burkart et al., 1999); mientras 
que las ecorregiones patagónicas ya se han descripto previamente. De esta manera, se puede caracterizar al zorrino común como la especie más generalista de las aquí estudiadas, habitando tanto zonas frías como cálidas, secas como lluviosas y con las más variadas composiciones vegetales. Este patrón de distribución tan general, puede explicarse por varias motivos, como el uso de madrigueras subterráneas, y una morfología dentaria que le permite alimentarse de ítems muy variados. Varios trabajos han reportado el uso de madrigueras subterráneas como "sitios de descanso" (Donadio et al., 2001; Castillo et al., 2011; Kasper et al., 2012a) en C. chinga, lo que le conferiría tres ventajas básicas: escape de posibles depredadores, fuente de alimento, y beneficios en cuanto a termorregulación, ya que le permitiría evitar temperaturas extremas (Endres y Smith, 1993), como las de la Puna Central o la Estepa Patagónica. A su vez, la presencia del P4, M1 y m1 con grandes cuencas debido a las expansiones del protocono, hipocono, entocónido e hipocónido respectivamente, permiten la presencia de grandes superficies de trituración, lo que le confiere a los zorrinos la capacidad de alimentarse de ítems muy variados. Si bien la dieta de estos carnívoros en general se compone principalmente de insectos (particularmente coléopteros), también se ha comprobado el consumo de otros ítems que incluyen material vegetales y vertebrados, eso último debido posiblemente al consumo de carroña (véase Travaini et al., 1998; Medina et al., 2009; Peters et al., 2011).

Se observaron los menores valores de predicción a lo largo de la Diagonal Árida, principalmente en Monte Alto y Monte Bajo, y bordeando la región pampeana de Buenos Aires, a lo largo del Espinal. Esto resulta llamativo, dado que esta última ecorregión presenta típicamente un bosque abierto, con uno o dos estratos arbóreos, uno arbustivo y otro herbáceo (Secretaría de Ambiente y Desarrollo Sustentable, 2003), y no pareciera haber razón en particular para no presentar áreas con altos valores de 
predicción; sumado a la existencia de varias localidades de registro en esa ecorregión, particularmente en el sur de Buenos Aires y este de La Pampa (Figura 32), aunque podría deberse a falta de muestreos. El Monte sensu lato sin embargo, es típicamente un desierto templado-cálido, y constituye el área más árida de Argentina (Fernández y Busso, 1997; Abraham et al., 2009).

Una aclaración es importante respecto de estas áreas con bajos valores de predicción, pero con localidades de registro presentes, válida tanto para el zorrino común como para las especies antes mencionadas. Debe tenerse en cuenta la relación directa entre la distribución de las especies y su abundancia variable en esas zonas geográficas. Una especie generalista (e.g., en este estudio el zorrino común o el hurón menor) se denomina así por su capacidad de tolerar diversas condiciones climáticas, la presencia de predadores, o utilizar un amplio rango de recursos; mientras que una especialista (e.g., huroncito patagónico) posee características contrarias (Brown, 2003). Los atributos de las especies generalistas, que Darwin (1859) llamó “dominantes” no sólo le permitirían existir en áreas geográficas extensas, sino también presentar altas densidades poblacionales en esas zonas; mientras que las especialistas, no sólo presentarían distribuciones acotadas espacialmente, sino que los mismos requerimientos restringidos que condicionan su extensión geográfica, causarían que presente bajas densidades poblacionales incluso en las áreas más susceptibles de ser habitadas (Brown, 2003).

En el marco de los modelos de distribución potencial para pequeños carnívoros, resulta particularmente difícil asociar los modelos con las densidades poblacionales (i.e., a menudo poco abundantes, de hábitos nocturnos, elusivos; Sargeant et al., 1998; Tobler et al., 2008). Si consideramos que los modelos de distribución potencial modelan el nicho fundamental de una especie (fundamental niche, definido como la respuesta de 
una especie a su ambiente en ausencia de interacciones bióticas), en oposición a su nicho real (realized niche, definido como el nicho ecológico, que incluye las dimensiones ambientales en las cuales la especies puede vivir y desarrollarse, incluyendo las interacciones bióticas; véase Franklin, 2009), podría entenderse que las áreas con altos valores de predicción en los modelos se corresponden en realidad con las áreas que presentan las condiciones ambientales óptimas, y presenten posiblemente a su vez, las mayores densidades poblaciones de las especies en estudio. Asimismo, las áreas con bajos valores de predicción que cuentan con diversas localidades de registro, podrían representar zonas que presentan solamente algunas condiciones favorables, y por ende la densidad poblacional sería más baja. El desarrollo de estudios de ecología acerca de la estructura poblacional de las especies estudiadas, podría poner a prueba las hipótesis precedentes.

\subsection{Segregación trófica}

Los carnívoros son considerados "piezas claves" en el control top-down de los ecosistemas (Palomares y Caro, 1999). Cuando se encuentran especies muy similares en simpatría, se espera un cambio en el tamaño y/o en algunos caracteres morfológicos (Jones, 1997) para minimizar la competencia, lo que ha sido denominado desplazamiento de caracteres y ha sido objeto de numerosas contribuciones (Jones, 1997; Dayan y Simberloff, 1998; Dayan et al., 1998; Palomares y Caro, 1999; Dayan y Simberloff, 2005). Lontra provocax se separa de las otras especies en estudio (con la excepción de Neovison vison) por estar presente en hábitats semi-acuáticos. Estudiando los procesos competitivos entre L. provocax y N. vison en Patagonia, Fasola et al. (2009) no encontraron divergencia dietaria entre estas dos especies simpátricas, aunque L. provocax presentó una dieta más especializada hacia el consumo de crustáceos y 
algunas diferencias en cuanto al uso de hábitat (e.g., grado de interferencia humana y abundancia de crustáceos). Más recientemente, Valenzuela et al. (2012b) identificaron a la segregación trófica como el proceso principal que permite la coexistencia de las especies en Tierra del Fuego, Argentina, con el huillín consumiendo más cantidad de presas acuáticas y el visón modificando la composición de su dieta consumiendo menos peces y más mamíferos terrestres en presencia de huillines. Los resultados presentados en este estudio parecieran estar en concordancia con esto último. Basado en la posición relativa de cada especie en el morfoespacio generado por los ACP y CVA, se observó que existen considerables diferencias morfológicas entre estas dos especies (incluso las distancias de Procrustes fueron las mayores entre las especies estudiadas, véase Tabla 19), presentando L. provocax grandes superficies de trituración en sus carniceros y molares post-carniceros, que son típicos de especies "hipocarnívoras”, especializadas en romper alimento duro, tales como crustáceos y valvas de moluscos. Por otro lado, $N$. vison se encontró más cerca de las especies “hipercarnívoras” del gremio, con pequeños talónidos en el m1 y bordes cortantes bien desarrollados en sus carniceros, que son típicos de especies que se alimentan de carne de vertebrados (Van Valkenburgh, 2007). Si se asume que la morfología refleja las adaptaciones ecológicas (Wainright, 1991), la existencia de un proceso de explotación competitiva entre L. provocax y $N$. vison parece poco probable. Diversos estudios han señalado la preferencia dietaria de L. provocax por consumir crustáceos y peces menores a 100 mm de largo (Chehébar et al., 1986; Medina, 1998; Sielfeld y Castilla, 1999; Fasola et al., 2009); mientras que el visón tiende a alimentarse de mamíferos, aves, peces y crustáceos de acuerdo a su disponibilidad (Porro y Chehébar, 1995; Fasola et al., 2009; Ibarra et al., 2009; Valenzuela et al., 2013). Aún más, los resultados indicaron diferencias significativas en tamaño de cráneo entre estas dos especies, con la media del cráneo del huillín siendo 
casi dos veces la media del visón. Sin embargo, dado que el visón es una especie introducida en el sur de Sudamérica (Pagnoni et al., 1986), debe tenerse en cuenta que las consecuencias de las introducciones van más allá de los procesos competitivos, incluyendo alteración de los ciclos de productividad y descomposición, dispersión de patógenos y enfermedades, predación, y transformación de hábitat entre otras (Vitousek et al., 1997; Mack et al., 2000; Olden et al., 2004; Novillo y Ojeda, 2008).

El visón mostró un grado variable de superposición con otras dos especies nativas en los ACP (i.e., Lyncodon patagonicus y Galictis cuja), aunque este solapamiento no se observó en los CVA. Estos resultados serían esperables, dado que este último método maximiza las diferencias de forma entre los grupos estudiados, y se observaron también diferencias significativas en las distancias de Procrustes entre ellas. El visón a menudo es descripto como un carnívoro generalista semi-acuático, capaz de alimentarse de presas acuáticas, así como de aves y mamíferos (véase Valenzuela et al., 2013). Por lo tanto, se esperarían diferencias en distribución a nivel de hábitat a priori con L. patagonicus que pareciera habitar regiones frías y áridas, mientras que aunque $G$. cuja puede habitar un gran rango de hábitats, cierta controversia existe respecto de su capacidad para nadar, ya que si bien se ha propuesto que sus extremidades estarían adaptadas para correr y trepar en lugar de cavar o nadar (Yensen y Tarifa, 2003a), un estudio reciente encontró algunos rasgos en la miología de las patas traseras que son comunes a los Lutrinae, y que posiblemente le permitirían nadar (Ercoli et al., 2012). Las tres especies presentan una morfología corporal similar, con cuerpos largos y tubulares (Larivière, 1999b; Yensen y Tarifa, 2003a; Prevosti et al., 2009), que les permitirían ingresar en madrigueras subterráneas ocupadas por diferentes presas. Aunque N. vison se considera a menudo como un depredador de presas acuáticas (i.e., 
peces y crustáceos), su dieta pareciera reflejar la disponibilidad actual de ítems alimenticios y también incluye presas terrestres.

Los dos hurones, L. patagonicus y G. cuja, son las especies estudiadas más cercanas filogenéticamente (Sato et al., 2012). Ambas se incluyeron en un morfotipo "hipercarnívoro", con fuertes arcos cigomáticos, largos trigónidos y dentición postcarnicera reducida, lo que representa una especialización hacia el consumo de carne de vertebrados. Estas dos especies son simpátricas y sintópicas (sensu Rivas, 1964) en algunas localidades (e.g., noroeste de Patagonia). La dieta de G. cuja se compone principalmente de pequeños mamíferos, particularmente roedores y lagomorfos (Delibes et al., 2003; Zapata et al., 2005). Un estudio realizado en Uruguay, identificó al hurón menor como el responsable de la extinción local de una población de Cavia magna (Rodentia: Caviidae; Kraus y Rödel, 2004). La información sobre la dieta del huroncito patagónico es escasa y resulta anecdótica, pero se supone que se alimenta principalmente de roedores fosoriales, como Ctenomys (tuco-tucos, Rodentia: Ctenomyidae) y Microcavia (cuises, Rodentia: Caviidae; Prevosti et al., 2009 y referencias allí citadas). Aún más, algunos ectoparásitos típicos de Ctenomys se encontraron en pieles de L. patagonicus (Castro y Cicchino, 1986). En el presente estudio se encontraron diferencias significativas en el tamaño entre estas especies, siendo G. cuja notoriamente más grande. Las diferencias en tamaño pueden reducir la competencia por recursos limitados (Dayan y Simberloff, 1998), ya que los depredadores de mayor tamaño se alimentan de un rango mayor de presas (Schoener, 1969). Por estos motivos, puede haber una segregación trófica en cuanto al tamaño, alimentándose G. cuja de una variedad de roedores y lagomorfos introducidos (i.e., liebre europea Lepus europaeus) mientras que L. patagonicus estaría especializado en depredar sobre roedores fosoriales, como los previamente mencionados. Claramente, 
son necesarias futuras investigaciones ecológicas y dietarias sobre el enigmático huroncito patagónico para probar estas hipótesis.

Tanto los ACP como los CVA mostraron que C. chinga presenta un morfotipo que no se solapa o superpone con ninguna de las otras especies del gremio. El zorrino común presentó una gran variabilidad intraespecífica, tanto en tamaño como en algunos caracteres mofológicos (e.g., arcos cigomáticos rectos o redondeados, cráneos robustos o delgados, largo mandibular variable). Un estudio previo encontró cierto grado de solapamiento entre $C$. chinga y Lycalopex griseus (zorro gris), debido principalmente a la presencia de áreas de trituración similar en sus carniceros, indicando que cierto solapamiento trófico (i.e., consumo de invertebrados) podría existir (Zapata et al., 2008). Futuros estudios deberían tener en cuenta las posibles relaciones con otros pequeños mamíferos presentes en el cono sur, como el xenartro Zaedyus pichiy (piche). La dieta de este pequeño mamífero $(\approx 1 \mathrm{~kg})$ fue estudiada en la provincia de Mendoza (Argentina), encontrándose que se alimenta principalmente de escarabajos (Coleoptera), hormigas (Formicidae), y material vegetal (Superina et al., 2009). Llamativamente, estos son los mismos ítems alimenticios consumidos por $C$. chinga (véase Travaini et al., 1998; Donadio et al., 2001; Medina et al., 2009), lo que podría implicar cierto solapamiento trófico.

Combinando los análisis de forma y tamaño y utilizando el índice de ClarkEvans, resulta claro que existe una buena separación entre las especies estudiadas, lo que podría reflejar una reducida competencia y solapamiento ecológico (Dayan et al., 1990). Los resultados también indicaron que podría existir cierta competencia entre $G$. cuja, L. patagonicus y $N$. vison, pero que sería reducida; al igual que con $C$. chinga y $L$. provocax. Además, existe una separación en cuanto al uso de hábitat entre L. provocax y el resto de las especies, a excepción de $N$. vison. Los CPO mostraron que una gran 
proporción de la variación morfológica se correlaciona con eventos cladogenéticos, particularmente con el nodo 2 (Figura 8), que separa a los mustélidos de $C$. chinga. Este evento en particular ocurrió hace $\approx 30$ Mya (millones de años) y es responsable de cerca del 60\% de la variación morfológica observada. Las dos especies más similares (G. cuja y L. patagonicus) pertenecen a la misma subfamilia (Ictonychinae), y la diversificación basal pareciera haber ocurrido hace sólo $\approx 2,9$ Mya, luego del establecimiento del Istmo de Panamá (Sato et al., 2012). Estos análisis indican que las diferencias morfológicas y dietarias entre estos taxones se relacionan de manera directa con factores históricos (i.e., procesos relacionados a la cladogénesis). Sin embargo los procesos ecológicos podrían ayudar a estructurar el gremio minimizando el solapamiento ecológico. En este sentido, los factores históricos también parecieran responsables de un cierto grado de diferencias de tamaño, particularmente entre los dos hurones, lo que indicaría que sólo una pequeña porción de las diferencias en tamaño sería resultado de procesos ecológicos. Además, sólo una pequeña proporción (10\%), aunque significativa, fue explicada por patrones geográficos. Esta discordancia entre: 1) la ausencia de solapamiento ecológico entre $L$. provocax y $N$. vison, que era esperable debido a la morfología cráneo/mandibular y al tamaño y 2) el solapamiento trófico observado en algunas localidades (Fasola et al., 2009), también podría ser explicada por factores históricos, ya que N. vison parece retener un morfotipo "hipercarnívoro" heredado de sus ancestros (quizás debido a una restricción evolutiva; Losos, 2011), en contraposición a su dieta más generalizada.

\subsection{Variaciones geográficas}

No se encontró una asociación significativa entre el tamaño del cráneo y las mandíbulas de C. chinga y G. cuja con la latitud, o del tamaño con la temperatura, lo que contradice la regla de Bergmann. En contraste, se encontró que el tamaño de estas 
dos especies ampliamente distribuidas por el continente sudamericano se relaciona fundamentalmente con la productividad, sugiriendo que las clinas responden a variaciones en la disponibilidad de recursos a lo largo de América del Sur, que presenta un amplio rango de ambientes, con productividad, precipitaciones y altitudes muy variables (Morello, 1985; Naumann y Madariaga, 2003). Aunque algunos autores han utilizado la temperatura en vez de la latitud para probar la regla de Bergmann (véase Ashton et al., 2002; Ochocinska y Taylor, 2003), los resultados aquí presentados tampoco mostraron una asociación significativa del tamaño con la temperatura. Aunque en este estudio se analizó la regla de Bergmann desde un punto de vista intraespecífico, es probable que el patrón tampoco se observe a nivel interespecífico. La especies hermanas de C. chinga y G. cuja en Sudamérica son Conepatus semistriatus y Galictis vittata respectivamente (véase Sato et al., 2012; Schiaffini et al., 2013b), que habitan el norte del continente y son notoriamente más grandes (M. Schiaffini, obs. pers.; véase además Yensen y Tarifa, 2003b). En este estudio, se encontró que la evidencia pareciera apoyar la hipótesis de McNab (2010) acerca de la disponibilidad de recursos. De hecho, ni C. chinga ni G. cuja presentaron el patrón latitudinal de aumento de tamaño esperable según la regla de Bergmann. Esto sugiere que los individuos pequeños de ambas especies se encontrarían en hábitats de baja productividad, y los individuos más grandes en hábitats más productivos (e.g., Pampas Húmedas y/o la Sabana Uruguaya). La estacionalidad en áreas áridas (e.g., la Diagonal Árida), probablemente influencie la germinación de semillas, la supervivencia de insectos y la disponibilidad de frutas (Johnson, 2006), que constituyen por un lado la base dietaria de los zorrinos (véase Travaini et al., 1998; Zapata et al., 2001, Medina et al., 2009); y por otro la base dietaria de las presas (i.e., roedores) del hurón menor. Una de las ecorregiones con individuos de menor tamaño de ambas especies fue el Monte Bajo (sensu Olson et al., 2001), que 
como se dijo previamente es un desierto cálido (Roig-Juñent et al., 2001; Abraham et al., 2009) y constituye el área más árida de Argentina (Fernández y Busso, 1997). Su vegetación es bastante uniforme, y se compone principalmente de arbustos de Larrea spp. y algunos árboles de Prosopis spp. (Abraham et al., 2009). Tal y como fue caracterizado por Noy-Meir (1974), las áreas áridas poseen tres atributos principales relacionados a las precipitaciones: 1) escasas (y por ende, factor limitante); 2) altamente variables (estacional y anualmente); y 3) muy impredecibles (véase también Reynolds et al., 2004). De esta manera, los pulsos de precipitaciones tienen un efecto directo sobre el crecimiento de las plantas y sobre las reservas de carbón y energía (Reynolds et al., 2004).

Las ecorregiones con una alta Producción Primaria Neta, tal y como la Sabana Uruguaya y las Pampas Húmedas (6,00E+11 y 5,36E+11 g carbón, Olson et al., 2001) albergaron la mayoría de los especímenes de mayor tamaño para ambas especies. Una excepción fueron los zorrinos de gran tamaño colectados en la ecorregión de Puna Central, a pesar de ser un área fría, árida y con una altitud típicamente mayor a los 3000 m.s.n.m. (Burkart et al., 1999). Aunque la productividad en la Puna Central es mayor que en el Monte Bajo y en la Estepa Patagónica (1,46E+11 vs. 8,07E+10 y 7,27E+10 g carbón respectivamente, Olson et al., 2001), no pareciera explicar por sí sola el inusual tamaño de los zorrinos de esa región, dado que su Producción Primaria Neta es asimismo menor que otras ecorregiones que contenían individuos de mayor tamaño (e.g., Espinal). Aunque al momento no se cuenta con una explicación precisa para este patrón, los resultados también indicaron (al igual que para G. cuja) que la altitud también posee un rol importante para explicar los cambios de tamaño, quizás debido a la influencia de las temperaturas bajas y altamente variables. Un mayor tamaño podría ser beneficioso en desiertos fríos, debido a que un incremento en el tamaño corporal 
permite un incremento en la cobertura de pelo (véase Lindstedt y Boyce, 1985), y provee por tanto una mejor conservación del calor. Es interesante notar que al menos los zorrinos del noroeste de Argentina, parecieran tener pelos largos y blancos en su dorso, o al menos más largos que especímenes de otras localidades (M. Schiaffini, obs. pers.). Otra posible explicación podría encontrarse en la relación entre el calor producido por el metabolismo corporal y su pérdida por la superficie del cuerpo (i.e., relación volumen/superficie corporal), que indicaría que los animales de mayor tamaño presentan una mejor retención del calor (Bergmann, 1847). Sin embargo, esta explicación ha sido explícitamente criticada, argumentando que los animales de mayor tamaño pierden más calor (en términos absolutos) que los pequeños: “... an animal does not live on a per-gram basis..." (McNab, 1971; véase también McNab, 2002). Además, se esperaría entonces encontrar a los zorrinos y hurones de mayor tamaño a mayores latitudes, lo que no se sustenta con los resultados aquí presentados.

Aunque una proporción importante de la variación en tamaño fue explicada de manera independiente por la precipitación del mes más seco, precipitación del trimestre más seco y precipitación del trimestre más frío, debe tenerse en cuenta que son variables altamente colineares $(r>0.7)$, que se relacionan principalmente con la estacionalidad de las precipitaciones y por ende, podrían relacionarse a la Producción Primaria Neta.

La asociación entre variables ambientales y cambio morfológico no ha sido tan extensamente estudiada como la asociación con la variación en tamaño. Esto dificulta en gran medida la comparación de los datos obtenidos en el presente estudio. Aunque se observó cierto grado de variación morfológica en los zorrinos (no así en hurones) relacionada principalmente a la productividad en los análisis de regresión multivariada, los RDA indicaron que sólo un pequeño porcentaje de la variación morfológica se relacionó con las ecorregiones. Un resultado similar se encontró para un ensamble de 
félidos Neotropicales (Morales y Giannini, 2010). Los cambios morfológicos más notorios se relacionaron con el tamaño relativo de la dentición postcanina, tanto de las hileras dentarias superiores e inferiores; y la forma y tamaño de los premolares y molares ha sido correlacionada extensamente con los tipos de dieta y la disponibilidad de presa (Van Valkenburgh, 1989, 2007). Es interesante notar que aunque pequeña, una porción significativa de la variación morfológica fue explicada por ecorregiones con NPP muy diferente. Así, al igual que para el tamaño, la variación morfológica pareciera relacionarse con ecorregiones áridas (e.g., mayores P4 y M1, cavidad glenoidea más amplia, mandíbulas robustas) o húmedas (e.g., menores P4 y M1, menor cavidad glenoidea, mandíbulas delgadas). 


\section{Conclusiones}

Este trabajo constituye una revisión general sobre los ensambles de pequeños carnívoros patagónicos, extendido a escala regional. Las especies estudiadas se analizaron desde ópticas muy diversas, incluyendo análisis morfométricos con técnicas de morfometría geométrica y tradicional, análisis biogeográficos y distribución potencial, análisis de superposición de nicho en función de la morfología craneodentaria y su relación con variables climáticas/geográficas, y de variaciones geográficas intraespecíficas con la utilización de diversos SIG. De esta manera, se obtuvo un conocimiento general sobre las especies de pequeños carnívoros patagónicos, su composición taxonómica, su relación con los ambientes que habitan y sobre la posibilidad de interacciones interespecíficas entre las especies que componen los ensambles. Al momento del inicio de la presente contribución existía un gran desbalance en el conocimiento de estas especies, habiéndose registrado diversos estudios dietarios y de uso de hábitat sobre los zorrinos, algunos análisis sobre la distribución del huroncito patagónico y sobre interacciones ecológicas entre el huillín y el visón. Estos trabajos mostraban la falta de conocimiento en lo que respecta a cuestiones básicas, como estado taxonómico y distribución a escala regional.

Entre las principales contribuciones de esta Tesis deben destacarse los análisis taxonómicos de las especies de zorrinos, que desde el estudio de diversas vistas cráneo/mandibulares expresaron superposición en el morfoespacio, incluyendo el análisis de holotipos. Si a esto se le suma lo variable de los caracteres utilizados en sus descripciones originales y un estudio incluyendo técnicas moleculares (Schiaffini et al., 2013b), debería aceptarse la propuesta de sinonimia entre Conepatus chinga y C. humboldtii, que pasarían a representar una única especie de zorrino presente en la mitad sur de Sudamérica, bajo el nombre de $C$. chinga (Molina, 1782). Asimismo, esta especie 
se encontraría ampliamente distribuida, desde el sur de Brasil y Perú hasta el sur de Argentina y Chile, incluyendo Bolivia, Paraguay y Uruguay. Esto caracteriza al zorrino común como una especie muy generalista en cuanto a su uso de hábitat, encontrándose en ambientes con condiciones climáticas y de vegetación muy diversas y diferentes. Sin embargo, pese a ser una especie ampliamente distribuida regionalmente, los modelos de distribución potencial indicaron ciertas áreas como las de mayores valores de predicción, tal y como la Sabana Uruguaya, las Pampas Húmedas, la Estepa Patagónica y las Yungas Andinas. Los análisis de variaciones geográficas de tamaño y forma indicaron una marcada relación con ambientes más productivos, relacionándose estos últimos con los zorrinos de mayor tamaño, mientras que aquellos menos productivos contenían a los de menor tamaño. Así, los zorrinos de mayor tamaño se encontraron en Sabana Uruguaya y Pampas Húmedas (Uruguay y provincias argentinas de Entre Ríos y Corrientes) y en zonas de la Puna Central (provincias argentinas de Salta y Jujuy), mientras que los más pequeños se observaron a lo largo de la Diagonal Árida, particularmente en provincia de Mendoza. Este patrón de variación en tamaño no se corresponde con un incremento hacia latitudes mayores, según fue descripto por Bergmann (Bergmann, 1847). El zorrino común en el presente estudio fue definido como un "hipocarnívoro" debido a sus caracteres dentarios y craneales, mostrando una alimentación en donde predomina la trituración de alimentos duros, aunque también pareciera poder alimentarse de ítems muy variados. Una gran parte de las diferencias morfológicas y de tamaño entre esta especie y el resto (y aún entre las otras especies), se debió a procesos cladogenéticos sucedidos hace $\approx 30$ Mya, indicando que los factores históricos determinan en gran medida la estructura del gremio estudiado, con los procesos ecológicos ayudando a minimizar el solapamiento ecológico, pero explicando una porción menor de los patrones observados. 
Otra de las especies presentes en Patagonia pero distribuida de manera regional por buena parte del continente Sudamericano fue el hurón menor (Galictis cuja). Se encontró que esta especie también puede ser considerada como generalista en cuanto a sus preferencias de hábitat, aunque pareciera preferir hábitats con vegetación baja o arbustiva. Sus caracteres dentarios lo caracterizaron como un predador especializado en vertebrados, observando cierta superposición en el morfoespacio con el huroncito patagónico y con el visón. Sin embargo, se observaron notorias diferencias de tamaño con el primero, mientras que existiría una separación a nivel de hábitat con el segundo, que estaría más asociado a ambientes cercanos al agua.

En la presente contribución se realizó el primer análisis de distribución potencial utilizando fósiles y bases de datos climáticas correspondientes para un carnívoro sudamericano (i.e., Lyncodon patagonicus). De esta manera se observó que las mismas variables influenciaron su distribución a lo largo de diferentes épocas, mostrando la especie grandes cambios en su patrón de distribución, asociados a fluctuaciones en estas principales variables ambientales. La misma pareciera ampliarse durante periodos glaciares por la extensión de los límites climáticos de Patagonia, observándose condiciones más frías y áridas en la región pampeana, y retraerse en tiempos actuales por el incremento en las precipitaciones observadas. Sus patrones morfológicos cráneodentarios lo caracterizan como una especie "hipercarnívora", posiblemente la más especializada de las estudiadas, dada la desaparición de los molares post-carniceros. Los análisis de tamaño indicaron una separación con el hurón menor debido a su pequeño tamaño, siendo que esta especie se alimentaría principalmente de roedores fosoriales, mientras que G. cuja presentaría un rango de presas mucho mayor.

Los modelos de distribución potencial de la especie introducida parecieran acordes a lo sugerido por Pagnoni et al. (1986) en cuanto a la posible dispersión de los 
visones en Chubut. El cauce del río Chubut sería utilizado como vía de dispersión hacia el este, mientras que desde el centro sur de la provincia se habrían dispersado hacia el oeste, hacia los lagos La Plata y Fontana. Asimismo, se observaron algunas diferencias con los modelos del huillín, siendo que el visón sería más generalista en cuanto al uso de hábitat y estaría posiblemente vinculado a las variaciones en su dieta en relación a la disponibilidad. Los patrones morfológicos indicaron marcadas diferencias con el huillín, con una dentición más cercana a las especies "hipercarnívoras” del gremio; mientras que L. provocax presentó una morfología "hipocarnívora” y mostró un tamaño mucho mayor.

Por último, el huillín se caracterizó como un habitante típico de los bosques patagónicos, probablemente debido a la cobertura vegetal que le brinda distintos refugios. Las localidades de la Estepa Patagónica datan de cerca de 100 años atrás, y los modelos de distribución no parecieran sustentar su presencia en esas zonas.

A partir del presente estudio se logró un conocimiento mucho más preciso sobre las mencionadas especies, integrando información taxonómica, morfológica y biogeográfica. Existen diversas preguntas relacionadas fundamentalmente a lo enigmático y poco abundante de algunos de estos carnívoros que permitirían poner a prueba varias de las hipótesis aquí planteadas, pero requieren de un enfoque distinto al aquí utilizado, y se refieren fundamentalmente a trabajos ecológicos (i.e., dietarios, de uso de hábitat a micro-escala). En este sentido, los modelos de distribución potencial permitieron identificar las áreas más probables de presencia para algunas especies muy poco conocidas, lo que constituye una herramienta esencial al momento de plantear trabajos futuros. Otra línea de investigación abierta a partir del presente estudio se refiere al análisis de taxones fósiles emparentados, a la luz de los estudios de variaciones intraespecíficas y geográficas aquí desarrollados. Este análisis permitiría a 
su vez, una mejor comprensión de los patrones de distribución a escala continental, incluyendo la migración y/o especiación a través del Neógeno-Cuaternario de estos y otros carnívoros. 


\section{Referencias bibliográficas}

Abraham E, HF del Valle, F Roig, L Torres, JO Ares, F Coronato, R Godagnone. 2009. Overview of the geography of the Monte Desert biome (Argentina). Journal of Arid Environments, 73: 144-153.

Abramov AV. 2000. A taxonomic review of the genus Mustela (Mammalia, Carnivora). Zoosystematica Rossica 8(2): 357-364.

Acosta JC, F Murúa. 1999. Lista preliminar y estado de conservación de la mastofauna del Parque Natural Ischigualasto, San Juan- Argentina. Multequina, 8: 121-129.

Aizen MA, LA Garibaldi, M Dondo. 2009. Expansión de la soja y diversidad de la agricultura argentina. Ecología Autral, 19: 45-54.

Akaike H. 1973. Information theory as an extension of the Maximum Likehood Principle. In: Petrov BN. and F Csaki (eds). Second International Symposium on Information Theory. Akademiai Kiado. Budapest. Pp. 267-281.

Allen JA. 1905. The Mammalia of southern Patagonia. Reports of the Princeton University Expedition to Patagonia 1896-1899, vol 3, Zoology: 1-210.

Ameghino F. 1888. Rápidas diagnosis de algunos mamíferos fósiles nuevos de la República Argentina. P.E. Coni, Buenos Aires, Argentina.

Ameghino F. 1889. Contribución al conocimiento de los mamíferos fósiles de la República Argentina. Actas de la Academia Nacional de Ciencias en Córdoba 6: $1-1027$.

Andrade A, L Carignano, C Panti, P Teta. 2005. Bioestratigrafia del sitio arqueológico Cueva y Paredón Loncomán, área Pilcaniyeu, SO. Río Negro. Actas del XII Congreso Nacional de Arqueología, 4: 303-308.

Ashton FG. 2002. Do amphibians follow Bergmann's rule? Canadian Journal of Zoology, 80(4): 708-716. 
Aued MB, C Chehébar, G Porro, DW Macdonald, MH Cassini. 2003. Environmental correlates of the distribution of southern river otters Lontra provocax at different ecological scales. Oryx, 37(4): 413-421.

Auffray JC, P Alibert, C Latieule. 1996. Relative warp analysis of skull shape across the hybrid zone of the house mouse (Mus musculus) in Denmark. Journal of Zoology (London), 240: 441-455.

Barros DM, ML Lorini, VG Persson. 1990. Dioctophymosis in the Little Grison (Galictis cuja). Journal of Wildlife Deseases, 26(4): 538-539.

Baryshnikov GF, AV Abramov. 1997. Structure of baculum (os penis) in Mustelidae (Mammalia, Carnivora), Communication 1. Zoologichesky Zhurnal, 76: 13991410.

Bergmann C. 1847. Ueber die Verhältnisse der Wärmeökonomie der Thiere zu ihrer Grösse. Gottinger Studien, 3: 595-708.

Bernal V, SI Pérez, PN González, JAF Diniz-Filho. 2009. Ecological and evolutionary factors in dental morphological diversification among modern human populations from southern South America. Proceedings of the Royal Society, 277: 1107-1112. Bilenca DN, MP Balla, EM Alvarez, GA Zuleta. 1999. Evaluación de dos técnicas para detectar la actividad y abundancia de mamíferos en el bosque chaqueño, Argentina. Revista de Ecología Latinoamericana, 6(1): 13-18.

Bininda-Emonds ORP, J Gittleman, A Purvis. 1999. Building large trees by combining phylogenetic information: a complete phylogeny of the extant Carnivora (Mammalia). Biological Reviews, 74(2): 143-175.

Birney EC, JA Monjeau. 2003. Latitudinal patterns in South American Marsupial Biology. En: Jones M, C Dickmann, Archer M (eds.). Carnivorous with pouches: 
biology of carnivorous marsupials. 293-313. SCIRO Publishing, Melbourne, Australia.

Blackburn TM., KJ Gaston, N. Loder. 1999. Geographic gradients in body size: a clarification of Bergmann's rule. Diversity and Distributions, 5:165-174.

Blackburn TM, BA Hawkins. 2004. Bergmann's rule and the mammal fauna of northern North America. Ecography, 27:715-724.

Bo MS, JP Isacch, AI Malizia, MM Martínez. 2002. Lista comentada de los mamíferos de la Reserva de Biósfera Mar Chiquita, provincia de Buenos Aires, Argentina. Mastozoología Neotropical, 9(1): 5-11.

Bonesi L, S Palazón. 2007. The American mink in Europe: status, impacts, and control. Biological Conservation, 134: 470-483.

Bookstein FL. 1989. Principal warps: Thin-plate splines and the decomposition of deformations. IEEE. Transactions on Pattern Analysis and Machine Intelligence, $\mathrm{V}: 565-585$.

Bookstein FL. 1991. Morphometric tools for landmark data: geometry and biology. Cambridge University Press. 435 pp.

Bornholdt R, K Helgen, KP Koepfli, L Oliveira, M Lucherini, E Eizirik. 2013. Taxonomic revision of the genus Galictis (Carnivora: Mustelidae): species delimitation, morphological diagnosis, and refined mapping of geographical distribution. Zoological Journal of the Linnean Society, 167: 449-472.

Brown JH. 2003. Macroecología. Sección de Obras de Ciencia y Tecnología. Fondo de Cultura Económica. México, pp 397.

Brown JH, RC Lasiewski. 1972. Metabolism of weasels: the cost of being long and thin. Ecology, 53(5): 939-943. 
Bruniard ED. 1982. La diagonal árida argentina: un límite climático real. Revista Geográfica, 95: 5-20.

Burkart R, NO Bárbaro, RO Sánchez, DA Gómez. 1999. Eco-Regiones de la Argentina. Presidencia de la Nación, Secretaría de Recursos Naturales y Desarrollo Sustentable. Programa Desarrollo Institucional Ambiental. Componente Política Ambiental. 43pp.

Burmeister CV. 1888. Últimas exploraciones en Patagonia. J. A. Alsina, Buenos Aires, Argentina.

Burmeister G. 1879. Description physique de la Rèpublique Argentine d'aprés des observations personelles et étrangères. 3 (Animaux vertébrés, 1: mammifères vivants et éteints). P.E. Coni, Buenos Aires, Argentina.

Burnham KP, DR Anderson. 2002 Model selection and multimodel inference: a practical information- theoretical approach. Springer'-Verlag. $2^{\circ}$ ed. New York.

Cabrera AL. 1929. Sobre Lyncodon patagonicus con descripción de una nueva subespecie. Revista Chilena de Historia Natural 32: 259-263.

Cabrera AL. 1958. Catálogo de los Mamíferos de América del Sur. Revista del Museo Argentino de Ciencias Naturales "Bernardino Rivadavia”. Instituto Nacional de Investigación de las Ciencias Naturales, 307 pp.

Cabrera AL, J Yepes. 1940. Historia Natural Ediar: Mamíferos Sud-Americanos: vida, costumbres y descripción. Buenos Aires, 371 pp.

Canevari M, O Vaccaro. 2007. Guía de Mamíferos del sur de América del Sur. L.O.L.A., Buenos Aires. 414 pp.

Cánovas MG, HJ Villavicencio. 2002. Confirmación de la presencia de Galictis cuja (Carnivora, Mustelidae) en la provincia de San Juan, Argentina. Nótulas Faunísticas, 10: 1-2. 
Carrera M, MJ Nabte, DE Udrizar-Sauthier. 2012. Distribución geográfica, historia natural y conservación del hurón menor Galictis cuja (Carnivora: Mustelidae) en la Patagonia central, Argentina. Revista Mexicana de Biodiversidad, 83: 12521257.

Castillo DF, M Lucherini, EB Casanave. 2011. Denning ecology of Molina's hog-nosed skunk in a farmland area in the Pampas grassland of Argentina. Ecological Research, 26: 845-850.

Castro D, AC Cicchino. 1986. Colonización de Lyncodon patagonicus (Mammalia, Carnivora, Mustelidae) por Phtheiropoios forticulatus (Neumann)(Insecta, Phthiraptera, Gyropidae) en proximidades de Uspallata, provincia de Mendoza, Argentina. II Jornadas Argentinas de Mastozoología, Buenos Aires, Resúmenes 1: 397.

Chatterjee S, AS Hadi. 2006. Analysis of collinear data. Regression Analysis by Example. Fourth Edition, 221-258.

Chebez JC. 2008. Los que se van. Fauna Argentina Amenazada. Albatros. Buenos Aires. 336 pp.

Chehébar C. 1983. Relevamiento del huillín, Lutra provocax Th., en el Parque Nacional Nahuel Huapi, Argentina. Ministerio de Economía. Secretaría de Agricultura y Ganadería. Administriación de Parques Nacionales. 28 pp.

Chehébar C. 1986. The hullin in Argentina. International Union for the Conservation of Nature, Otter Specialist Group Bulletin, 1: 17-18.

Chehébar C, I Benoit. 1988. Transferencia de conocimientos para la identificación de signos de actividad y hábitats del huillín o nutria de río Lutra provocax. Oficina Regional de la FAO para América Latina y el Caribe. Santiago, 30 pp. 
Chehébar C, A Gallur, G Giannico, MD Gottelli, P Yorio. 1986. A Survey of the southern river otter Lutra provocax in Lanin, Puelo and Los Alerces National Parks, Argentina, and evaluation of its conservation status. Biological conservations, 38: 293-304.

Cherem JJ, M Kammers, IR Ghizoni-Jr, A Martins. 2007. Mamíferos de médio e grande porte atropelados em rodovias do Estado de Santa Catarina, sul do Brasil. Biotemas, 20(3): 81-96.

Christiansen P. 2008. Evolution of skull and mandible shape in cats (Carnivora: Felidae). PlosOne, 3(7): e2807.

Cione AL, EP Tonni. 1995. Chronostratigraphy and "Land-Mammal Ages" in the Cenozoic of Southern South America: Principles, Practices, and the "Uquian" Problem. Journal of Paleontology, 69(1): 135-159.

Clark PJ, FC Evans. 1954. Distance to nearest neighbor as a measure of spatial relationship in populations. Ecology, 35:445-453.

Collins WD, CM Bitz, ML Blackmon, GB Bonan, CS Bretherton, JA Carton, P Chang, SC Doney, JJ Hack, TB Henderson, JT Kiehl, WG Large, DS McKenna, BD Santer, RD Smith. 2004. The Community Climate System Model Version 3 (CCSM3). Journal of Climate, 19(11): 2122-2143.

D’Orbigny A, P Gervais. 1847. Voyage dans l'Amerique Méridionale (le Brésil, la République orientale de l’Uruguay, la République Argentina, la Patagonie, la République du Chili, la République de Bolivia, la République du Perou) exécuté pendant les années 1826, 1827, 1828, 1829, 1830, 1831, 1832 et 1833, par Alcides D’Orbigny.Vol. 4. Paris.

Davies TJ, S Meiri, TG Barraclough, JL Gitleman. 2007. Species co-existence and character divergence among carnivores. Ecologial Letters, 10:146-152. 
Davis JC. 1986. Statistics and data analysis in geology, $2^{\circ}$ ed. New York: John Wiley and Sons.

Darwin C. 1859. On the origin of species by means of natural selection. John Murray. Londres.

Dayan T, D Simberloff. 1994. Character displacement, sexual dimorphism, and morphological variation among British and Irish mustelids. Ecology, 75:10631073.

Dayan T, D Simberloff. 1998. Size patterns among competitors: ecological character displacement and character release in mammals, with special reference to island populations. Mammal Review, 28:99-124.

Dayan T, D Simberloff. 2005. Ecological and community-wide character displacement: the next generation. Ecology Letters, 8: 875-894.

Dayan T, D Simberloff, E Tchernov, Y Yom-Tov. 1989. Inter- and intraspecific character displacement in mustelids. Ecology 70:1526-1539.

De Blainville HMD. 1842. Ostéographie ou description iconographique compare du squelette et tu système dentaire des mammifères récents et fossils des cinq classes d'animaux vertebras récents et fossils pour server de base à la zoologie et à la géologie. A. Bertrand, 2(10):1. París.

Delibes M, A Travaini, SC Zapata, F Palomares. 2003. Alien mammals and the trophic position of the lesser grison (Galictis cuja) in Argentinean Patagonia. Canadian Journal of Zoology, 81: 157-162.

Deustúa Aris I, MW León de Castro, P Vásquez Ruesta. 2008. Relaciones entre los pobladores rurales y los carnívoros altoandinos del distrito de Anco, centro-sur de Perú. Ecología Aplicada, 7(1,2): 43.48. 
Díaz MM, M Lucherini. 2006. Mephitidae, Mustelidae, Procyonidae. En: Bárquez, RM, MM Díaz y RA Ojeda (Eds.). 2006. Mamíferos de Argentina, Sistemática y Distribución. Sociedad Argentina para el Estudio de los Mamíferos. 359 pp.

Díaz Isenrath G, G Aprile, L Soler. 2012. Lyncodon patagonicus (de Blainville). En: Ojeda RA, Chillo V, Díaz Isenrath GB (Eds.). Libro rojo, mamíferos amenazados de la Argentina. Sociedad Argentina para el Estudio de los Mamíferos. 107-108. Dinerstein E, DM Olson, DJ Graham, AL Webster, SA Primm, MP Bookbinder, G Ledec. 1995. Una evaluación del estado de conservación de las ecoregiones terrestres de América Latina y el Caribe. Banco Mundial/ World Wildlife Fund, Washington.

Diniz-Filho JAF, LM. Bini. 2005. Modelling geographic patterns in species richness using eigenvetor-based spatial filters. Global Ecology and Biogeography, 14:177185.

Diniz-Filho JAF, TFLVB Rangel, LM Bini. 2008. Model selection and information theory in geographical ecology. Global Ecology and Biogeography, 17: 479- 488. Diniz-Filho JAF, LM Bini, MA Rofríguez, TFLVB Rangel, BA Hawkins. 2007. Seeing the forest for the trees: partitioning ecological and phylogenetic components of Bergmann's rule in European Carnivora. Ecography, 30: 598-608.

Diniz-Filho JAF, JC Nabout, MP de Campos Telles, TN Soares, TFLVB Rangel. 2009. A review of techniques for spatial modeling in geographical, conservation and landscape genetics. Genetics and Molecular Biology, 32(2): 203-211.

Di Rienzo JA, F Casanoves, MG Balzarini, L Gonzalez, M Tablada, CW Robledo. InfoStat versión 2010. Grupo InfoStat, FCA, Universidad Nacional de Córdoba, Argentina. 
Doering, A.O. 1881. Enumeración sistemática de las especies observadas durante la expedición. Vertebrados. Informe Oficial de la Comisión Científica Agregada a la Expedición al Río Negro de 1879. Entrega 1, Zoología. Buenos Aires, Argentina.

Donadio E, S Di Martino, M Aubone, AJ Novaro. 2001. Activity patterns, home range, and habitat selection of the common hog-nosed skunk, Conepatus chinga (Mammalia, Mustelidae), in northwestern Patagonia. Mammalia, 65(1): 49-54.

Donadio E, S Di Martino, M Aubone, AJ Novaro. 2004. Feeding ecology of the Andean hog-nosed skunk (Conepatus chinga) in areas under different land use in northwestern Patagonia. Journal of Arid Environment, 56:709-718.

Dormann CF, J Elith, S Bacher, C Buchmann, G Carl, G Carré, JR García Marquéz, B Gruber, B Lafourcade, PJ Leitão, T Münkemüller, C McClean, PE Osborne, B Reineking, B Schröder, AK Skidmore, D Zurell, S Lautenbach. 2013.

Collinearity: a review of methods to deal with it and a simulation study evaluating their performance. Ecography, 36: 27-46.

dos Santos MFM, M Pellanda, AC Tomazzoni, H Hasenack, SM Hartz. 2004.

Mamíferos carnívoros e sua relação com a diversidade de hábitats no Parque Nacional dos Aparados da Serra, sul do Brasil. Iheringia, 94(3): 235-245.

Dragoo JW, RL Honeycutt. 1997. Systematics of mustelid-like carnivores. Journal of Mammalogy 78(2): 426-443.

Dragoo JW, SR Sheffield. 2009. Conepatus leuconotus. Mammalian Species 827: 1-8. Dragoo JW, RL Honeycutt, DJ Schmidly. 2003. Taxonomic status of white-backed hognosed skunks, genus Conepatus (Carnivora: Mephitidae). Journal of Mammalogy 84(1): 159-176. 
Eagle T, JS Whitman. 1987. Mink. En: Novak M, JA Baker, ME Obbard, B Malloch (eds.). Wild furbearer management and conservation in North America. Ministry of Natural Resources, Ontario, Canadá. 615-624 pp.

Eizirik E, WJ Murphy, KP Koepfli, WE Johnson, JW Dragoo, RK Wayne, SJ O’Brien. 2010. Pattern and timing of diversification of the mammalian order Carnivora inferred from multiple nuclear gene sequences. Molecular Phylogenetics and Evolution, 56: 49-63.

Elith J, CH Graham, RP Anderson, M Dudík, S Ferrier, A Guisan, RJ Hijmans, F Huettmann, JR Leathwick, A Lehmann, J Li, LG Lohmann, BA Loiselle, G Manion, C Moritz, M Nakamura, Y Nakazawa, JM Overton, A Townsend Peterson, SJ Phillips, K Richardson, R Scachetti-Pereira, RE Schapire, J Soberón, S Williams, MS Wisz, NE Zimmermann. 2006. Novel methods improve prediction of species' distributions from occurrence data. Ecography, 29:129-151.

Emmons L, K Helgen. 2008. Conepatus chinga. En: IUCN 2011. IUCN Red List of Threatened Species. Version 2011.1. <www.iucnredlist.org>.

Endres KM, WP Smith. 1993. Influence of age, sex, season and availability on den selection by raccoons within the central basin of Tennessee. American Midland Naturalist, 129: 116-131.

Ercoli MD, S Echarri, F Busker, A Álvarez, MM Morales, GF Turazzini. 2012. The functional and phylogenetic implications of the mycology of the lumbar region, tail, and hind limbs of the lesser grison (Galictis cuja). Journal of Mammalian Evolution, 19(4): 1-28.

ESRI. 2002. Arcview. Version 3.3. Environmental System Research Institute, Redland, California. 
Eva HD, AS Belward, EE de Miranda, CM di Bella, V Gonds, O Huber, S Jones, M Sgrenzaroli, S Fritz. 2004. A land cover map of South America. Global Change Biology, 10: 731-744.

Ewer RF. 1973. The Carnivores. Cornell University Press, Ithaca.

Fasola L, C Chehébar, DW Macdonald, G Porro, MH Cassini. 2009. Do alien North American mink compete for resources with native South American river otter in Argentinean Patagonia? Journal of Zoology, 277: 187-195.

Fernández OA, CA Busso. 1997. Arid and semi-arid rangelands: two thirds of Argentina. RALA report 200. 41-60 pp.

Flynn JJ, GD Wesley-Hunt. 2005. Capítulo 12. Carnivora. En: Rose KD, y JD Archibald (Eds.). 2005. The Rise of Placental Mammals. John Hopkins University Press. 259 pp.

Flynn JJ, JA Finarelli, S Zehr, J Hsu, MA Nedbal. 2005. Molecular phylogeny of the Carnivora (Mammalia): Assessing the impact of increased sampling on resolving enigmatic relationships. Systematic Biology, 54(2): 317-337.

Foley JA, C Prentice, N Ramankutty, S Levis, D Pollard, S Sitch, A Haxeltine, 1996. An integrated biosphere model of land surface processes, terrestrial carbon balance, and vegetation dynamics. Global Biogeochemical Cycles, 10(4): 603628.

Forasiepi AM. 2003. Nuevo registro de Conepatus primaveus (Mammalia, Carnivora, Mustelidae) del Pleistoceno de la Provincia de Buenos Aires, Argentina. Revista del Museo Argentino de Ciencias Naturales, 5(1): 21-29.

Franklin J. 2009. Mapping species distributions. Spatial inference and prediction. Cambridge University Press, New York, EUA. 320 pp. 
Fuller TK, WE Johnson, WL Franklin, KA Johnson. 1987. Notes on the Patagonian hog-nosed skunk (Conepatus humboldtii) in southern Chile. Journal of Mammalogy, 68(4): 864-867.

Galliari CA, Pardiñas UFJ, Goin FJ. 1996. Lista comentada de los mamíferos argentinos. Mastozoología Neotropical, 3(1): 39-62.

Garreaud RD, M Vuille, R Compagnucci, J Marengo. 2009. Present-day South American climate. Palaeogeography, Palaeoclimatology, Palaeoecology, 281(3): 180-195.

Geist V. 1987. Bergmann's rule is invalid. Canadian Journal of Zoology, 65: 10351038.

Giannini NP. 2003. Canonical Phylogenetic Ordination. Systematic Biology, 52:684695.

Gómez-Puerta LA, DS Ticona, MT López-Urbina, AE González. 2009. The Andean hog-nosed skunk Conepatus chinga Molina 1782 as a new definite host for Spirometra erinacei, Faust, Campbell \& Kellog, 1929. Veterinary Parasitology 160(3): 334-336.

Goodall C. 1991. Procrustes methods in the statistical analysis of shape. Journal of the Royal Statistical Society, 52(2): 285-339.

Goswami A. 2006. Morphlogical integration in the carnivorans skull. Evolution, 60(1): 169-183.

Goswami A. 2010. Introduction to Carnivora. Chapter 1.1-24 pp. En: Goswami A y A Friscia (Eds.). Carnivoran Evolution. New views on phylogeny, form and function. Cambridge University Press. 492 pp.

Graham M. 2003. Confronting multicollinearity in ecological multiple regression. Ecology, 84(11): 2809-2815. 
Gray JE. 1837. Conepatus humboldtii. In: Charlesworth E. 1837. The Magazine of Natural History, and Journal of Zoology, Botany, Mineralogy, Geology and Meteorology. Volumen I. London.

Gunz P, P Miteroecker. 2013. Semilandmarks: a method for quantifying curves and surfaces. Hystrix, 24(1): 103-109.

Harlow H. 1981. Torpor and other physiological adaptations of the badger (TaxideaTaxus) to cold environments. Physiological Zoology, 54(3): 267-275.

Harris G. 2008. Guía de aves y mamíferos de la costa patagónica. Editorial El Ateneo, Buenos Aires. 352 pp.

Hawkins BA. 2008. Eight (and a half) deadly sins of spatial analysis. Journal of Biogeography, 39(1): 1-9.

Hernández PA, CH Graham, LL Master, DL Albert. 2006. The effect of sample size and species characteristics on performance on different species distribution modeling methods. Ecography, 29: 773-785.

Hijmans RJ, SE Cameron, JL Parra, PG Jones, A Jarvis. 2005b. Very high resolution interpolated climate surfaces for global land areas. International Journal of Climatology, 25: 1965-1978.

Hijmans RJ, L Guarino, P Mathur, A Jarvis, E Rojas, M Cruz, I Barrantes. 2005a. DIVA-GIS, version 5.2.

Honacki JH, KE Kinman, JW Koeppl. 1982. Mammal species of the world. Lawrence, Kansas: Allen Press and Associates. 694 pp.

Ibarra JT, L Fasola, DW MacDonald, R Rozzi, C Bonacic. 2009. Invasive American mink Mustela vison in wetlands of the Cape Horn Biosphere Reserve, southern Chile: what are they eating? Oryx, 43:87-90. 
Iriondo MH, NO García. 1993. Climatic variations in the Argentine plains during the last 18000 years. Palaeogeography, Palaeoclimatology, Palaeoecology, 01: 209_ 220.

Jaksic FM, JA Iriarte, JE Jiménez, DR Martínez. 2002. Invaders without frontiers: cross-border invasions of exotic mammals. Biological Invasions, 4: 157-173.

Johnson A. 2006. Biogeographical paralles between plants and ants in North American deserts (Hymenoptera: Formicidae; Spermatophyta). Myrmecol. Nachrichten, 8, 209-218.

Johnson JB, KS Omland. 2004. Model selection in ecology and evolution. Trends in Ecology and Evolution, 19(2): 101-108.

Jones M. 1997. Character displacement in Australian dasyurid carnivores: size relationships and prey patterns. Ecology, 78: 2569-2587.

Kasper CB, JBG Soares, TRO Freitas. 2012a. Differential patterns of home range, net displacement and resting sites use of Conepatus chinga in southern Brazil. Mammalian Biology, 77: 358-362.

Kasper CB, ML Fontoura-Rodrigues, GN Cavalcanti, TRO Freitas, FHG Rodrigues, TG de Oliveira, E Eizirik. 2012b. Recent advances in the knowledge of Molina's hognosed skunk Conepatus chinga, and striped hog-nosed skunk $C$. semistriatus in South America. Small Carnivore Conservation, 41: 25-28.

Kipp VH. 1965. Beitrag zur Kenntnis der Gattung Conepatus Molina, 1782. Zeitschr fur Saugetierk, 30 (4): 193-232.

Kissling WD, G Carl. 2007. Spatial autocorrelation and the selection of simultaneous autoregressive models. Global Ecology and Biogeography, 17: 59- 71.

Klingenberg CP. 2011. MorphoJ: An integrated software package for geometric morphometrics. Molecular Ecology Resources, 11: 353-357. 
Koepfli KP, KA Deere, GJ Slater, C Begg, K Begg, L Grassman, M Lucherini, G Veron, RK Wayne. 2008. Multigene phylogeny of the Mustelidae: resolving relationships, tempo and biogeographic history of a mammalian adaptative radiation. BMC Biology, 6(1): 10.

Kolar CS, DM Lodge. 2001. Progress in invasion biology: predicting invaders. Trends in Ecology and Evolution, 16(4): 199-204.

Koslowsky J. 1904. Dos mamíferos de Patagonia cazados en el valle del lago Blanco (Territorio del Chubut). Revista del Museo de La Plata 11(13):129-132.

Kovarovic K, LC Aiello, A Cardini, CA Lockwood. 2011. Discriminant function analyses in archaeology: are classification rates too good to be true? Journal of Archaeological Science, 38: 3006-3018.

Kraglievich L, C Rusconi. 1931. Restos de vertebrados vivientes y extinguidos hallados por los señores E.R. Wagner y hermano en túmulos precolombianos de Santiago del Estero. Physis, 10: 229-241.

Kraus C, HG Rödel. 2004. Where have all the cavies gone? Causes and consequences of predation by the minor grisson on a wild cavy population. Oikos, 105: 489-500.

Kucharik CJ, JA Foley, C Delire, VA Fisher, MT Coe, JD Lenters, C Young-Molling, N Ramankutty. 2000. Testing the performance of a Dynamic Global Ecosystem Model: Water balance, carbon balance, and vegetation structure. Global Biogeochemical Cycles, 14(3): 795-825.

Kühn I, CF Dormann. 2013. Less than eight (and a half) misconceptions of spatial analysis. Journal of Biogeography 39(5): 995-998.

Kufner M, D Tamburini, L Giraudo, V Briguera. 2005. Conservación de mastofauna en fragmentos de bosque chaqueño en la región de Mar Chiquita (Córdoba, Argentina). Ecología Aplicada, 4(1,2): 53-58. 
Kullback S, RA Leibler. 1951. On information and suffiency. Annals of Mathematical Statistics 22: 79.86 .

Kurtén B. 1973. Geographic variation in size in the Puma (Felis concolor).

Commentationes Biologicae, 63: 1-8.

Larivière S. 1999a. Lontra provocax. Mammalian Species, 610: 1-4.

Larivière S. 1999b. Mustela vison. Mammalian Species, 608: 1 -9.

Latorre C. 1998. Paleontología de mamíferos del Alero Tres Arroyos I, Tierra del Fuego, XII Región, Chile. Anales Instituto Patagonia, Serie Ciencias Naturales (Chile), 26:77-90.

Legendre P. 1993. Spatial autocorrelation: Trouble or new paradigm? Ecology, 74(6):1659-1673.

Legendre P, L Legendre. 1998. Numerical ecology, $2^{\circ}$ English ed. Amsterdam: Elsevier. León RJC, D Bran, M Collantes, JM Paruelo, A Soriano. 1998. Grandes unidades de vegetación de la Patagonia extra andina. Ecología Austral, 8(2): 125-144.

Lindstedt SL, MS Boyce. 1985. Seasonality, fasting endurance, and body size in mammals. The American Naturalist, 125(6): 873-878.

Losos JB. 2011. Convergence, adaptation and constraint. Evolution, 65: 1827-1840.

Lucherini M, C Manfredi, E Luengos, F Dias Mazim, L Soler, E Casanave. 2006. Body mass variation in the Geoffroy's cat (Oncifelis geoffroyi). Revista Chilena de Historia Natural, 79: 169-174.

Mack RN, D Simberloff, WM Lonsdale, H Evans, M Clout. 2000. Biotic invasions: causes, epidemiology, global consequences and control. Issues in Ecology, 5: 125. 
Mancini MV, MM Paez, AR Prieto, S Stutz, M Tonello, I Vilanova. 2005. Mid-

Holocene climatic variability reconstruction from pollen records $\left(32-52^{\circ} \mathrm{S}\right.$, Argentina). Quaternary International, 132: 47-59.

Mancini MV, AR Prieto, MM Paez, F Schäbitz. 2008. Late Quaternary vegetation and climate of Patagonia. En: Rabassa J (ed.). Late Cenozoic of Patagonia and Tierra del Fuego, developments in Quaternary sciences. Elsevier, Amsterdam, the Netherlands. 351-367 pp.

Marcus LF, E Hingst-Zaher, H Zaher. 2000. Application of landmark morphometrics to skulls representing the orders of living mammals. Hystrix, 11(1):27-47.

Mares MA, RA Ojeda, RM Bárquez. 1989. Guide to the mammals of Salta Province, Argentina. University of Oklahoma Press, Norman. 303 pp.

Martin GM. 2008. Sistemática, distribución y adaptaciones de los marsupiales patagónicos. Tesis Doctoral. Facultad de Ciencias Naturales y Museo, Universidad Nacional de La Plata.

Martin GM. 2010a. Geographical distribution and historical occurrence of Dromiciops gliroides Thomas (Metatheria: Microbiotheria). Journal of Mammalogy, 91(4): $1025-1035$.

Martin GM. 2010b. Patrones de riqueza en la distribución de marsupiales sudamericanos. XXIII Jornadas Argentinas de Mastozoología. Bahía Blanca. Martin GM. 2011. Geographic distribution of Rhyncholestes raphanurus Osgood, 1924 (Paucituberculata: Caenolestidae), an endemic marsupial of the Valdivian Temperate Rainforest. Australian Journal of Zoology, 59: 118-126.

Martínez O, ME Pérez, E Taucer, J Rechberger. 2009. Fauna vertebrada de San Cristóbal en el altiplano sur de Bolivia. Kempffiana, 5(1): 28-55. 
Martínez PA, DA Marti, WF Molina, CJ Bidau. 2013. Bergmann's rule across the equator: a case study in Cerdocyon thous (Canidae). Journal of Animal Ecology, 82(5): 997-1008.

Massoia E. 1992. Zooarqueología, I. Mammalia. En: Fernández J. (ed). La cueva de Haichol. Arqueología de los pinares cordilleranos del Neuquén. Anales de Arqueología y Etnología 1: 43-45.

Massoia E, JA Latorraca. 1992. Contribución al conocimiento de la Mastofauna reciente de la provincia de Santiago del Estero-1. Boletín Científico Asociación para la Protección de la Naturaleza 23: 49-57.

McDonald RA. 2002. Resource partitioning among British and Irish mustelids. Journal of Animal Ecology, 75:185-200.

McNab BK. 1971. On the ecological significance of Bergmann's rule. Ecology, $52(5): 845-854$

McNab BK. 2002. The physiological ecology of vertebrates. A view from energetic. Cornell University Press. 576 pp.

McNab BK. 2010. Geographic and temporal correlations of mammalian size reconsidered: a resource rule. Oecología 164: 13-23.

Medina G. 1997. A comparison of the diet and distribution of southern river otter (Lutra provocax) and mink (Mustela vison) in southern Chile. Journal of Zoology of London, 242: 291-297.

Medina G. 1998. Seasonal variations and changes in the diet of the southern river otter in different freshwater habitats in Chile. Acta Theriologica, 43: 285-292.

Medina CE, CV Díaz, FA Delgado, GA Ynga, HF Zela. 2009. Dieta de Conepatus chinga (Carnivora: Mephitidae) en un bosque de Polylepis del departamento de Arequipa, Perú. Revista Peruana de Biología, 16:183-186. 
Medina-Vogel G, VS Kaufman, R Monsalve, V Gomez. 2003. The influence of riparian vegetation, woody debris, stream morphology and human activity on the use of rivers by southern river otter in Lontra provocax in Chile. Oryx, 37(4): 422-430.

Meiri S, T Dayan. 2003. On the validity of Bergmann's rule. Journal of Biogeography, 30: $331-351$.

Meiri S, T Dayan, D Simberloff. 2004. Carnivores, biases and Bergmann's rule. Biological Journal of the Linnean Society, 81: 579-588.

Meiri S, Y Yom-Tov, E Geffen. 2007. What determines conformity to Bergman0s rule? Global Ecology and Biogeography, 16: 788-794.

Melero Y, S Palazón, E Revilla, J Martelo, J Gosálbez. 2008. Space use and habitat preferences of the invasive American mink (Mustela vison) in a Mediterranean area. European Journal of Wildlife Research, 54: 609-617.

Merow C, MJ Smith, JA Silander Jr. 2013. A practical guide to MaxEnt for modeling species' distribution: what it does, and why inputs and setting matter. Ecography, 36: $1058-1069$.

Milne-Edwards A, L Vaillant, P Gervais. 1891. Mission scientifique du Cap Horn. 1882-1883. Tome VI. Zoologie. Première partie. Gauthier-Villars et. Fils. Imprimeurs- Libraires De L'Ecole Polytechnique, Du Bureau Des Longitudes. Molina GI. 1782. Saggio sulla storia naturale del Chili. Stamperia di Sto. Tomasso d' Aquino. Bologna, Italia.

Monjeau JA, JA Tort, J Márquez, P Jayat, BN Palmer Fry, SD Nazar Anchorena, A Di Vicenzo, F Polop. 2009. Latitudinal patterns of species richness distribution in South American carnivores. Mastozoología Neotropical, 16(1): 95-108. 
Montalvo CI, ME Pessino, FC Bagatto. 2008. Taphonomy of the bones of rodents consumed by Andean hog-nosed skunk (Conepatus chinga) in central Argentina. Journal of Archaeological Science. 35(6): 1481-1488.

Morales MM, NP Giannini. 2010. Morphofunctional patterns in Neotropical felids: species co-existence and historical assembly. Biological Journal of the Linnean Society, 100:711-724.

Moratelli R, CS de Andreazzi, JA de Oliveira, JLP Cordeiro. 2011. Current and potential distribution of Myotis simus (Chiroptera, Vespertilionidae). Mammalia, 75: 227-234.

Morello JA. 1985. Grandes ecosistemas de Sudamérica. Textos para Discusión. Fundación Bariloche/3. Bariloche.

Morrone JJ. 2001. Biogeografía de América Latina y El Caribe. Manuales y Tesis SEA 3. Zaragoza, España. 148 pp.

Morrone JJ. 2006. Biogeographic areas and transition zones of Latin America and the Caribbean Islands based on panbiogeographic and cladistic analyses of the entomofauna. Annual Review of Entomology, 51: 467-494.

Muzzachiodi N, RA Sabattini. 2002. Las mastofauna como indicador de conservación del bosque nativo en un área protegida de Entre Ríos. Revista Científica Agropecuaria, 6: 5-15.

Naumann M, M Madariaga. 2003. Atlas Argentino/Argentinienatlas. Programa de Acción Nacional de Lucha contra la Desertificación, Secretaría de Ambiente y Desarrollo Sustentable, Instituto Nacional de Tecnología Agropecuaria, Deutsche Gesekkschaft für Technische Zusammenarbeit, Buenos Aires.

Novillo A, RA Ojeda. 2008. The exotic mammals of Argentina. Biological Invasions, 10: 1333-1344 
Nowak RM. 1991. Walker's Mammals of the World. John Hopkins University Press. $818 \mathrm{pp}$.

Noy-Meir I. 1974. Desert ecosystems: higher trophic levels. Annual Review in Ecology and Systematics, 5: 195-214.

Nyakatura K , ORP Bininda-Emonds. 2012. Updating the evolutionary history of Carnivora (Mammalia): a new species-level supertree complete with divergece time estimates. BMC Biology, 10:12.

Ochocinska D, JRE Taylor. 2003. Bergmann's rule in shrews: geographical variation of body size in Paleartic Sorex species. Biological Journal of the Linnean Society, $78: 365-381$

Olalla-Tárraga MA, MA Rodríguez, BA Hawkins. 2006. Broad-scale patterns of body size in squamate reptiles of Europe and North America. Journal of Biogeography, 33:781-793.

Olden JD, N Leroy Poff, MR Douglas, ME Douglas, KD Fausch. 2004.Ecological and evolutionary consequences of biotic homogenization. Trends in Ecology and Evolution, 19: 18-24.

Olrog CC. 1958. Notas mastozoológicas sobre la colección del Instituto Miguel Lillo (Tucumán). Acta Zoológica Lilloana, 16: 91-95.

Olrog CC. 1976. Sobre mamíferos del noroeste argentino. Acta Zoológica Lilloana 32(1): 5-14.

Olson DM, E Dinerstein, ED Wikramanayake, ND Burgess, GVN Powell, EC Underwood, JA D’Amico, I Itoua, HE Strand, JC Morrison, CJ Loucks, TF Allnutt, TH Ricketts, Y Kura, JF Lamoreux, WW Wettengel, P Hedao, KR Kassem. 2001. Terrestrial ecoregions of the world: a new map of life on earth. Bioscience, 51(11): 933-938. 
Osgood WH. 1943. The mammals of Chile. Zoological Series, Field Museum of Natural History, volume 30. Chicago. 268 pp.

Pagnoni GO, JL Garrido, MR Marín. 1986. Impacto económico y ambiental del visón, Mustela vison (Schreber, 1877) en el norte de la Patagonia. CENPAT-CONICET, Dirección de Fauna Silvestre, Provincia del Chubut, Argentina. 20 pp.

Palomares E, TM Caro. 1999. Interspecific killing among mammalian carnivores. The American Naturalist, 153: 492-508.

Pardiñas UJF, P Teta, G D’Elía, S Cirignoli, PE Ortiz. 2007. Resolución de algunos problemas relativos a localidades típicas de roedores sigmodontinos (Cricetidae, Sigmodontinae). En: Kelt DA, EP Lessa, J Salazar-Bravo, JL Patton (eds.). The Quintessential Naturalist. Honoring the life and legacy of Oliver P. Pearson. University of California Publications, Zoology 134, pp 391-416.

Parera A. 2002. Los mamíferos de Argentina y de la región austral de Sudamérica. Ateneo. Buenos Aires. 454 pp.

Paruelo JM, A Beltrán, E Jobbágy, OE Sala, RA Golluscio. 1998. The climate of Patagonia: general patterns and control on biotic processes. Ecología Austral, 8: 85-101.

Peña L. 1966. Dos especies raras de mamíferos. Noticiario Mensual, Museo Nacional de Historia Natural 11(123): 7-8.

Pérez SI, V Lema, JAF Diniz-Filho, V Bernal, PN González, D Gobbo, HM Pucciarelli. 2011. The role of diet and temperature in shaping cranial diversification of South American human populations: an approach based on spatial regression and divergence rate tests. Journal of Biogeography, 38: 148-163. 
Peters FB, de Oliveira Roth PR, AU Christoff. 2011. Feeding habits of Molina's hognosed skunk, Conepatus chinga (Carnivora: Mephitidae) in the extreme south of Brazil. Zoologia, 28(2): 193-198.

Phillips SJ. 2005. A brief tutorial on Maxent. AT\&T Research.

Phillips SJ, M Dudík, RE Schapire. 2004. A maximum entropy approach to species distribution modeling. Proceedings of the 21st International Conference on Machine Learning, Banff, Canada.

Phillips SJ, RP Anderson, RE Schapire. 2006. Maximum entropy modeling of species geographic distributions. Ecological Modelling, 190:231-259.

Pietrokovsky SM, NJ Schweigmann, A Riarte, A Alberti, O Conti, S Montoya, C Wisnevsky-Colli. 1991. The skunk Conepatus chinga as new host of Trypanozoma cruzi in Argentina. The Journal of Parasitogy, 77(4): 643-645.

Pine R, PH Angle, D Bridge. 1978. Mammals from the sea, mainland and island at the southern tip of South America. Mammalia, 42(1): 105-114.

Pocock RI. 1926. The external characters of the Patagonian Weasel (Lyncodon patagonicus). Proceedings of the Zoological Society of London, 1926:1085-1094.

Politis GG, EP Tonni, F Fidalgo. 1983. Cambios corológicos de algunos mamíferos en el Área Interserrana de la provincia de Buenos Aires durante el Holoceno. Ameghiniana, 20(1-2): 72-80.

Popowics TE. 2003. Postcanine dental form in the Mustelidae and Viverridae (Carnivora: Mammalia). Journal of Morphology, 256: 322-341.

Porro G, C Chehébar. 1995. Monitoreo de la distribución del huillín (Lutra provocax) en el Parque Nacional Nahuel Huapi, Argentina. Delegación Técnica Regional Patagonia, Administración de Parques Nacionales, San Carlos de Bariloche, Argentina. 19 pp. 
Previtali A, MH Cassini, DW MacDonald. 1998. Habitat use and diet of the American mink (Mustela vison) in argentinian Patagonia. Journal of Zoology of London, 246: $482-486$.

Prevosti FJ, UFJ Pardiñas. 2001. Variaciones corológicas de Lyncodon patagonicus (Carnivora, Mustelidae) durante el Cuaternario. Mastozoología Neotropical, 8(1): 21-39.

Prevosti FJ, A Travaini. 2005. New records of Galictis cuja (Molina, 1782) (Carnivora, Mustelidae) in southern Patagonia. Mammalian Biology, 70: 317-320.

Prevosti FJ, P Teta, UFJ Pardiñas. 2009. Distribution, natural history, and conservation of the Patagonian weasel Lyncodon patagonicus. Small Carnivore Consservation, 41:29-34.

Prevosti FJ, GF Turazzini, MD Ercoli, E Hingst-Zaher. 2012. Mandible shape in marsupial and placental carnivorous mammals: a morphological comparative study using geometric morphometrics. Zoological Journal of the Linnean Society, 164: 836-855.

Quattrocchio ME, AM Borromei, CM Deschamps, SC Grill, CA Zavala. 2008. Landscape evolution and climate changes in the Late Pleistocene-Holocene, southern Pampa (Argentina): evidence from palynology, mammals and sedimentology. Quaternary International, 181: 123-138.

R Development Core Team. 2013. R: A Language and environment for statistical computing. Vienna, Austria: R Foundation for Statistical Computing.

Rabassa J, AM Coronato, O Martínez. 2011. Late Cenozoic glaciations in Patagonia and Tierra del Fuego: an updated review. Biological Journal of the Linnean Society, 103: $316-335$. 
Rabassa J, AM Coronato, M Salemme. 2005. Chronology of the Late Cenozoic Patagonian glaciations and their correlation with biostratigraphic units of the Pampean region (Argentina). Journal of South American Earth Sciences, 20: 81103.

Radosavljevic A, RP Anderson. 2014. Making better MAXENT models of species distributions: complexity, overfitting and evaluation. Journal of Biogeography, 41: 629-643.

Rangel TF, JAF Diniz-Filho, LM Bini.2010. SAM: a comprehensive application for spatial analysis in macroecology. Ecography, 33: 1-5.

Raxworthy CJ, CM Ingram, N Rabibisoa, RG Pearson. 2007. Applications of ecological niche modeling for species delimitation: a review and empirical evaluation using day geckos (Phelsuma) from Madagascar. Systematic Biology, 56(6): 907-923.

Redford KH, JF Eisenberg. 1992. Mammals of the Neotropics. The Southern Cone., volume 2, Chile, Argentina, Uruguay, Paraguay. The University of Chicago Press. Chicago. 435 pp.

República de Chile. 2007. Clasificación de especies según conservación. Decreto Supremo 151/06. Ministerio Secretaría General de la Presidencia, Santiago, Chile. Reynolds JF, PR Kemp, K Ogle, RJ Fernández. 2004. Modifying the "pulse-reserve" paradigm for deserts of North America: precipitation pulses, soil water, and plant responses. Oecologia, 141(2): 194-210.

Rivas LR. 1964. A reinterpretations of the concepts "sympatric" and "allopatric" with proposal of the additional terms "syntopic" and "allotropic". Systematic Zoology, 13: 42-43.

Rodríguez MA, IL López-Sañudo, BA Hawkins. 2006. The geographic distribution of mammal body size in Europe. Global Ecology and Biogeography, 15: 173-181. 
Rohlf FJ. 1999. Shape statistics: Procrustes superimpositions and tangent spaces. Journal of Classification, 16: 197-223.

Rohlf JF. 2003. TPSRelw, version 1.35. Ecology and Evolution, SUNY at Stony Brook. Rohlf JF. 2008a. TPSUtil, version 1.40. Ecology and Evolution, SUNY at Stony Brook. Rohlf JF. 2008b. TPSDig2, version 2.12. Ecology and Evolution, SUNY at Stony Brook.

Roig V. 1965. Elenco sistemático de los mamíferos y aves de la provincia de Mendoza y notas sobre su distribución geográfica. Boletín de Estudios Geográficos 12(49): $175-222$.

Roig-Juñent S, G Flores, S Claver, G Debandi, A Marvaldi. 2001. Monte Desert (Argentina): insect biodiversity and natural areas. Journal of Arid Environments, 47: 77-94.

Root RB. 1967. The niche exploitation pattern of the blue-gray gnatcatcher. Ecological Monographs, 37:317-350.

Rozzi R, M Sherriffs. 2003. El vison (Mustela vison Schreber, Carnivora: Mustelidae), un nuevo mamífero exótico para la isla Navarino. Anales Instituto Patagonia (Chile), 31: 97-104.

Ruggiero A, T Kitzberger. 2004. Environmental correlates of mammal species richness in South America: effects of spatial structure, taxonomy and geographic range. Ecography 27: 401-416.

Rusch V, A Vila, B Marqués. 2008. Conservación de la biodiversidad en sistemas productivos. Forestaciones del noroeste de la Patagonia. Instituto Nacional de Tecnología Agropecuaria. INTA EEA Bariloche, pp 89. 
Sanabria EA, LB Quiroga. 2003. Lyncodon patagonicus Blainville, 1842

(Mustelionidae: Carnivora). Primer registro para la provincia de San Juan, Argentina. Nótulas Faunísticas 13: 1-2.

Sargeant GA, DH Johnson, WE Berg. 1998. Interpretating carnivore scent-station surveys. Journal of Wildlife Management, 62(4): 1235-1245.

Sárkinen T, P Gonzáles, S Knapp. 2013. Distribution models and species discovery: the story of a new Solanum species from the Peruvian Andes. PhytoKeys, 31: 1-20.

Sato JJ, M Wolsan, FJ Prevosti, G D’Elia, C Begg, K Begg T Hosoda, KL Campbell, H Suzuki. 2012. Evolutionary and biogeographic history of weasel-like carnivorans (Musteloidea). Molecular Phylogenetics and Evolution, 63(3): 745-757.

Schreber JCD. 1777. Die Säugthiere in Abbildungen nach der Natur mit Beschreibungen 1776-1778. Wolfgang Walther, Erlangen, 3: 377-440.

Schiaffini MI, GM Martin, AL Giménez, FJ Prevosti. 2013a. Distribution of Lyncodon patagonicus (Carnivora: Mustelidae): changes from the Last Glacial Maximum to the present. Journal of Mammalogy, 94(2): 339-350.

Schiaffini MI, M Gabrielli, FJ Prevosti, YP Cardoso, D Castillo, R Bo, E Casanave, M Lizarralde. 2013b. Taxonomic status of southern South American Conepatus (Carnivora: Mephitidae). Zoological Journal of the Linnean Society, 167: 327344.

Schlichter T, P Laclau. 1998. Ecotono estepa-bosque y plantaciones forestales en la patagonia norte. Ecología Austral, 8: 285-296.

Schoener TW. 1969. Models of optimal size for solitary predators. The American Naturalist, 103: 277-313. 
Secretaría de Ambiente y Desarrollo Sustentable. 2003. Atlas de los Bosques Nativos Argentinos. Dirección de Bosques, Secretaría de Ambiente y Desarrollo Sustentable, Buenos Aires.

Segura V, FJ Prevosti, G Cassini. 2013. Cranial ontogeny in the Puma lineage, Puma concolor, Herpailurus yagouaroundi, and Acinonyx jubatus (Carnivora: Felidae): a three-dimensional geometric morphometric approach. Zoological Journal of the Linnean Society, 169: 235-250.

Sepúlveda M, M Franco, G Medina, L Fasola, R Álvarez. 2008. Lontra provocax. En: IUCN, 2014. IUCN Red List of Threatened Species. www.iucnredlist.org. Servat GP, W Mendoza, JA Ochoa. 2002. Flora y fauna de cuatro bosques de Polylepis (Rosacea) en la cordillera del Vilcanota (Cusco, Perú). Ecología Aplicada, 1(1): 25-35.

Sheets HD. 2002. IMP-Integrated Morphometrics Package. Buffalo, NY: Department of Physics, Canisius College.

Sheffield SR, CM King. 1994. Mustela nivalis. Mammalian Species, 454: 1-10.

Sielfeld W, JC Castilla. 1999. Estado de conservación y conocimiento de las nutrias en Chile. Estudios Oceanológicos, 18: 69-79.

Sokal RR, NL Oden. 1978. Spatial autocorrelation in biology. 1. Methodology. Biological Journal of the Linnean Society, 10: 199-228.

Superina M, F Fernández Campón, EL Stevani, R Carrara. 2009. Summer diet of the pichi Zaedyus pichiy (Xenarthra: Dasypodidae) in Mendoza province, Argentina. Journal of Arid Environments, 73: 683-686.

Szuma E. 2004. Evolutionary implications of morphological variation in the lower carnassial of red fox Vulpes vulpes. Acta Theriologica, 49(4): 433-447. 
ter Braak CJ, P Šmilauer. 2002. Canoco 4.5: reference manual and Canodraw for Windows. User's guide: software from Canonical Community Ordination (version 4.5). Microcomputer Power.

Teta P, FJ Prevosti, A Trejo. 2008. Raptor predation and new locality records for the poorly known Patagonian Weasel (Lyncodon patagonicus) (Carnivora: Mustelidae). Mammalian Biology, 73:238-240.

Thomas O. 1898. On some new mammals from the neighborhood of Mount Sahama, Bolivia. Annals and Magazine of Natural History Series 1, vol. 4.

Thomas O. 1900a. On a new skunk from Perú. Annals and Magazine of Natural History, Series 7, vol. 5.

Thomas O. 1900b. New Peruvian species of Conepatus, Phyllotis and Akodon. Annals and Magazine of Natural History, Series 7, vol. 6.

Thomas O. 1902a. On mammals from Cochabamba, Bolivia, and the region north of that place. Annals and Magazine of Natural History, Series 7, vol. 9.

Thomas O. 1902b. On mammals collected at Cruz del Eje, Central Cordova, by Mr. PO Simons. Annals and Magazine of Natural History, Series 9, vol. 52.

Thomas O. 1903. Notes on South American Monkeys, Bats, Carnivores, and Rodents, with descriptions of new species. Annals and Magazine of Natural History, Series 7, vol. 12.

Thomas O. 1907. On Neotropical mammals of the genera Calycebus, Reithrodontomys, Ctenomys, Dasypus, and Marmosa. Annals and Magazine of Natural History, Series 7, vol. 20.

Thomas O. 1910. A collection of mammals from eastern Buenos Ayres, with descriptions of related new mammals from other localities. Annals and Magazine of Natural History, Series 8, vol. 5. 
Thomas O. 1912. Small mammals form South America. Annals and Magazine of Natural History, Series 8, vol. 10.

Thomas O. 1913. On small mammals collected in Jujuy by Señor E. Budin. Annals and Magazine of Natural History, Series 8, vol. 11.

Thomas O. 1919. On small mammals from “Otro Cerro”, north-eastern Rioja, collected by Sr. L. Budin. Annals and Magazine of Natural History, Series 9, vol. 3.

Thomas O. 1920. Report on the Mammalia collected by Mr. Edmund Heller during the Peruvian expedition of 1915 under the auspices of Yale University and the National Geographic Society. Proceedings of the United States National Museum, 58: $217-249$.

Thomas O. 1921. The "huron" of Argentine. Annals and Magazine of Natural History, Series 9, vol. 8 .

Thomas O. 1924. New Callicebus, Conepatus and Cecomys from Perú. Annals and Magazine of Natural History, Series 9, vol. 14.

Thomas O. 1926. Two new mammals from north Argentina. Annals and Magazine of Natural History, Series 9, vol. 17.

Thomas O. 1927. On further Patagonian mammals from Neuquén and the Rio Colorado collected by Señor E. Budin. Annals and Magazine of Natural History, Series 9, vol. 20 .

Tobler MW, SE Carrilo-Percastegui, R Leite Pitman, R Mares, G Powell. 2008. An evaluation of camera traps for inventorying large- and médium-sized terrestrial rainforest mammals. Animal Conservation, 11(3): 169-178.

Toledo MJ. 2011. El legado Lujaniense de Ameghino: revisión estratigráfica de los depósitos pleistocenos-holocenos del valle del río Luján en su sección tipo. 
Registro paleoclimático en la pampa en los estadios OIS 4 al OIS 1. Revista de la Asociación Geológica Argentina, 68: 121-167.

Torres R, JP Jayat. 2010. Modelos predictivos de distribución para cuatro especies de mamíferos (Cingulata, Artiodactyla y Rodentia) típicas del Chaco en Argentina. Mastozoología Neotropical, 17: 335-352.

Townsend Peterson A, M Papes, M Eaton. 2007. Transferability and model evaluation in ecological niche modeling: a comparison of GARP and Maxent. Ecography, $30: 550-560$.

Trajano E. 1991. Notas biológicas sobre cavernas argentinas (resultados de la primera expedición espeleológica argentino-brasileña, Neuquén-Mendoza). Spelaion 2(2): 3-8.

Travaini A, M Delibes, O Ceballos. 1998. Summer foods of the Andean hog-nosed skunk (Conepatus chinga) in Patagonia. Journal of Zoology of London, 246: 457460.

Valenzuela AEJ, A Gallo, C Pozzi, L Fasola, C Chehébar C. 2012a. Lontra provocax (Thomas). En: Ojeda RA, Chillo V, Díaz Isenrath GB (Eds.). Libro rojo, mamíferos amenazados de la Argentina. Sociedad Argentina para el Estudio de los Mamíferos.105-107 pp.

Valenzuela AEJ, A Raya Rey, L Fasola, A Schiavini. 2012b. Understanding the interspecific dynamics of two co-existing predators in the Tierra del Fuego Archipielago: the native southern river otter and the exotic American mink. Biological Invasions, 15:645-656.

Valenzuela AEJ, A Raya Rey, L Fasola, RA Saénz Samaniego, A Schiavini. 2013. Trophic ecology of a top predator colonizing the southern extreme of South 
America: feeding habits of invasive American mink (Neovison vison) in Tierra del Fuego. Mammalian Biology, 78:104-110.

Vallarades A. 2004a. Cuenca del río Chubut. Cuenca Nº 65. Subsecretaría de Recursos Hídricos. Argentina, 6 pp.

Vallarades A. 2004b. Cuenca de los ríos Senguerr y Chico. Cuenca Nº6. Subsecretaría de Recursos Hídricos. Argentina, 6 pp.

Van Gelder RG. 1968. The genus Conepatus (Mammalia, Mustelidae): variation within a population. American Museum Novitates, 2322: 1-37.

Van Valkenburgh B. 1989. Carnivore dental adaptations and diet: a study of trophic diversity within guilds. En: Gittelman JD. Carnivore Behavior, ecology, and evolution. Springer, EUA. 410-435 pp.

Van Valkenburgh B. 1995. Tracking ecology over geological time: evolution within guilds of vertebrates. Trends in Ecology and Evolution, 10:71-76.

Van Valkenburgh B. 2007. Déjà vu: the evolution of feeding morphologies in the Carnivora. Integrative and Comparative Biology, 47(1): 147-163.

Van Zyll de Jong CG. 1972. A systematic review of the Neartic and Neotropical river otters (Genus Lutra, Mustelidae, Carnivora). Life Sciences Contributions of the Royal Ontario Museum, 80: 1-104.

Vaughan T, J Ryan, N Czaplewski. 2011. Mammalogy. Jones \& Bartlett Learning. 750 pp.

Venzal JM, O Castro, C de Souza, O Correa. 2006. Nuevos registros de piojos Trichodectidae (Phthriraptera: Ischnocera) para Uruguay. Veterinaria, 41(163,164): 31-34. 
Veblen TT, DC Lorenz. 1988. Recent vegetation changes along the forest/steppe ecotono of northern Patagonia. Annals of the Association of American Geographers, 78(1): 93-111.

Vianna JA, Ayerdi P, Medina-Vogel G, Mangel JC, Ceballos H, Apaza M, Faugeron S. 2010. Phylogeography of the Marine Otter (Lontra felina): historical and contemporary factors determining its distribution. Journal of Heredity, 101: 676689.

Vianna JA, G Medina-Vogel, C Chehébar, W Sielfeld, C Olavarría, S Faugerón. 2011. Phylogeography of the Patagonian otter Lontra provocax: adaptative divergence to marine habitat or signature of southern glacial refugia? BMC Evolutionary Biology, 11:53.

Villagrán C, JJ Armesto, MT Kalin Arroyo.1981. Vegetation in an Andean transect betweeen Turi and Cerro León in northern Chile. Vegetation, 48(1): 3-16.

Vitousek PM, CM D’Antonio, LL Loope, M Rejmánek, R Westbrooks. 1997. Introduced species: a significant component of human-caused global change. New Zealand Journal of Ecology, 2: 1-16.

Wainright PC. 1991. Ecomorphology: experimental functional anatomy of ecological problems. American Zoologist, 31: 680-693.

Wang X, O Carranza-Castañeda. 2008. Earliest hog-nosed skunk, Conepatus (Mephitidae, Carnivora), from the early Pliocene of Guajanato, Mexico and origin of South American skunks. Zoological Journal of the Linnean Society, 154: 386407.

Watson RT, MC Zinyowera, RH Moss. 1998. The regional impacts of climate change: an assessment of vulnerability. A Special Report of IPCC Working Group II. Cambridge University Press, Cambridge, United Kingdom. 
Willmott CJ, K Matsuura. 2001. Terrestrial water budget data archive: monthly time series (1959-1999). Center for Climate Reseach, University of Delaware, DE.

Wilson DE, RA Mittermeir. 2009. Handbook of the mammals of the world. 1.

Carnivores. Lynx Editions in association with Conservation International and IUC. 727 pp.

Wolffsohn JA. 1923. Medidas máximas y mínimas de algunos mamíferos chilenos colectados entre los años 1896 y 1917. Revista Chilena de Historia Natural, 27: 59-165.

Wozencraft WC. 2005. Order Carnivora. In: Wilson DE, Reeder DM (eds) Mammal Species of the World. A Taxonomic and Geographic Reference, Volume 1. Third Edition. The John Hopkins University Press, Baltimore, pp 601-624.

Yensen E, T Tarifa. 2003a. Galictis cuja. Mammalian Species, 728: 1-8.

Yensen E, T Tarifa. 2003b. Galictis vittata. Mammalian Species, 727: 1-8.

Yepes J. 1935. Los mamíferos de Mendoza y sus relaciones con las faunas limítrofes. Novena Reunión de la Sociedad de Patología Regional 1: 689-725.

Yepes J. 1936. Mamíferos coleccionados en la parte central y occidental de la provincia de La Rioja. Physis, 12:31-42.

Yom-Tov Y, E. Geffen. 2006. Geographic variation in body size: the effect of ambient temperature and precipitation. Oecologia, 148: 213-218.

Yu L, Q Li, OA Ryder, Y Zang. 2004. Phylogenetic relationships within mammalian order Carnivora indicated by sequences of two nuclear DNA genes. Molecular Phylogenetics and Evolution, 33: 694-705.

Zabala J, I Zuberogoitia, JA Martínez-Climent. 2007. Winter habitat preferences of feral American mink Mustela vison in Biscay, northern Iberian Peninsula. Acta Theriologica, 52(1): 27-36. 
Zapata SC, A Travaini, R Martínez-Peck. 2001. Seasonal feeding hábitats of the Patagonian hog-nosed skunk Conepatus humboldtii in southern Patagonia. Acta Theriologica, 46(1): 97-102.

Zapata SC, A Travaini, M Delibes, R Martínez-Peck. 2005. Annual food habits of the lesser grison (Galictis cuja) at the southern limit of its range. Mammalia, 69:8588.

Zapata SC, A Travaini, M Delibes, R Martínez-Peck. 2008. Identificación de morfogremios como aproximación al estudio de reparto de recursos en ensambles de carnívoros terrestres. Mastozoología Neotropical, 15:85-101.

Zelditch ML, DL Swiderski, HD Sheets and WL Fink. 2004. Geometric morphometrics for biologist. A primer. Elsevier Academic Press, San Diego. 436 pp. 
Figuras 
Figura 1. Ecorregiones del sur de América del Sur, sensu Olson et al. (2001). Escala= $1000 \mathrm{Km}$.

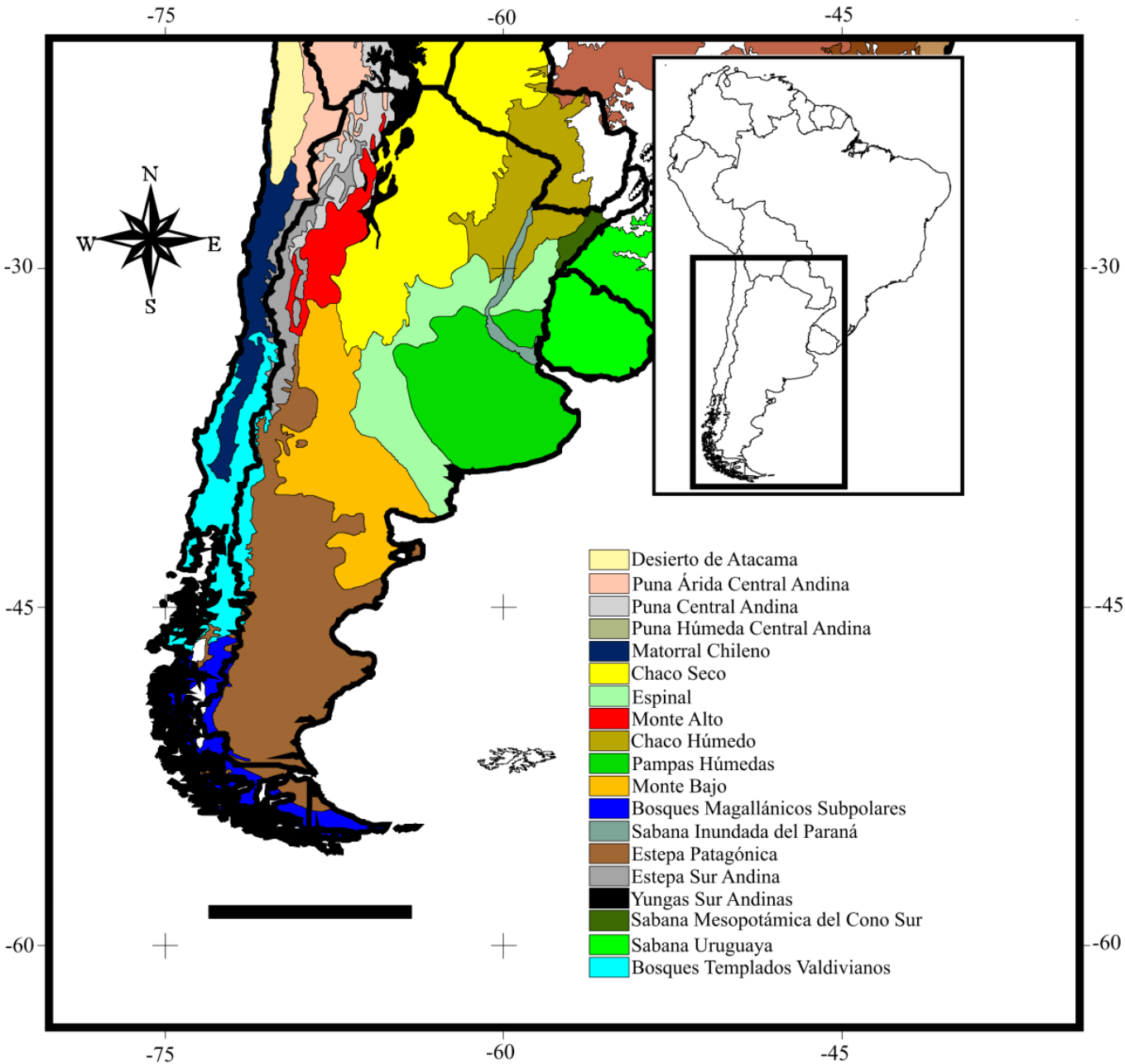


Figura 2. Medidas craneodentarias y mandibulares tomadas con calibre digital (véase sección 3.3.2). Se utilizaron los especímenes LIEB-M-799 y LIEB-M-810 para graficarlas (Conepatus chinga).

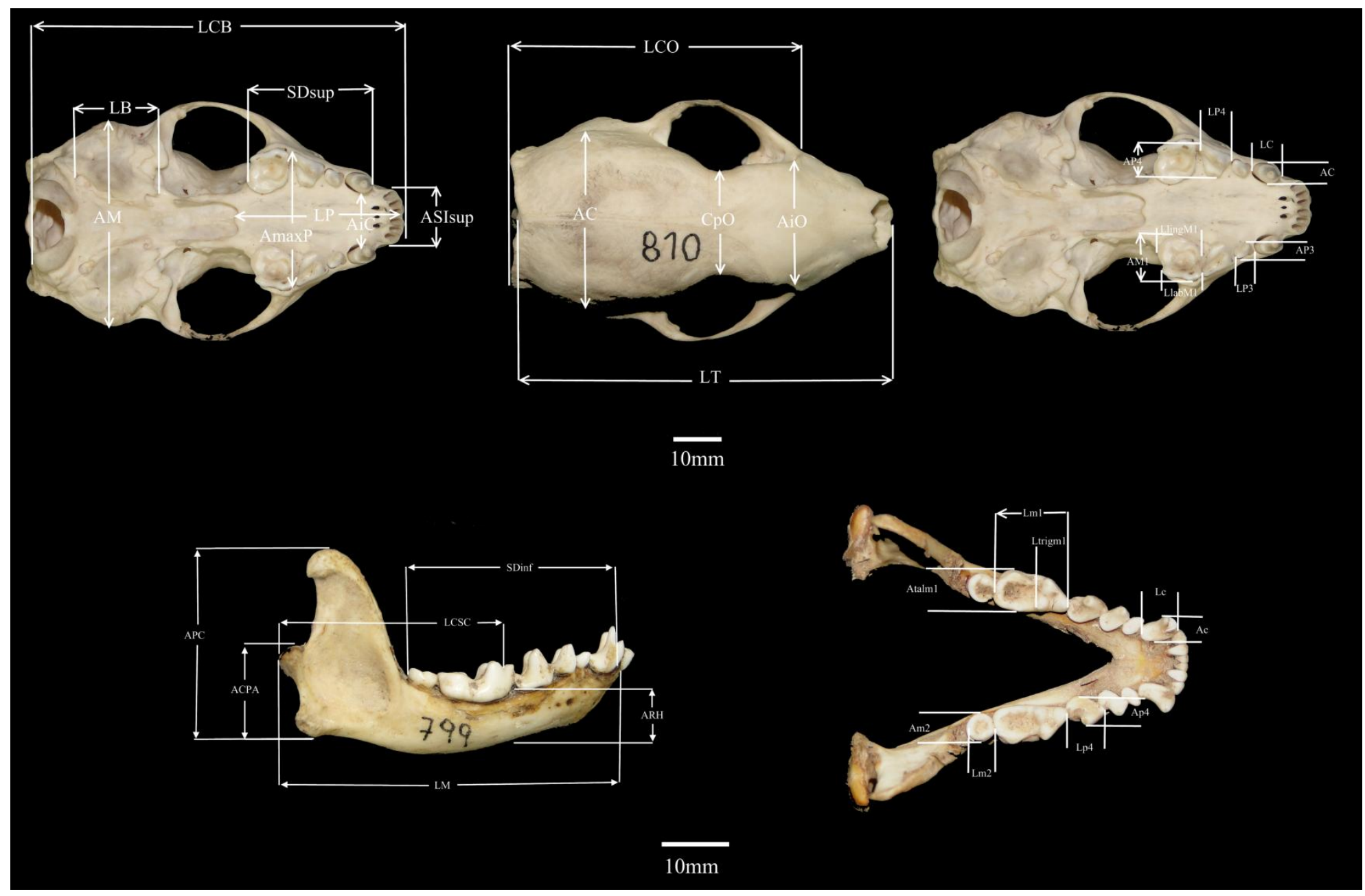


Figura 3. Landmarks (círculos blancos) y semilandmarks (cuadrados blancos) utilizados en análisis de morfometría geométrica, en el estudio taxonómico de las especies de Conepatus (véase sección 3.4 y Tabla 1). Se utilizaron los especímenes LIEB-M-799 y LIEB-M-810 para graficarlos (Conepatus chinga).

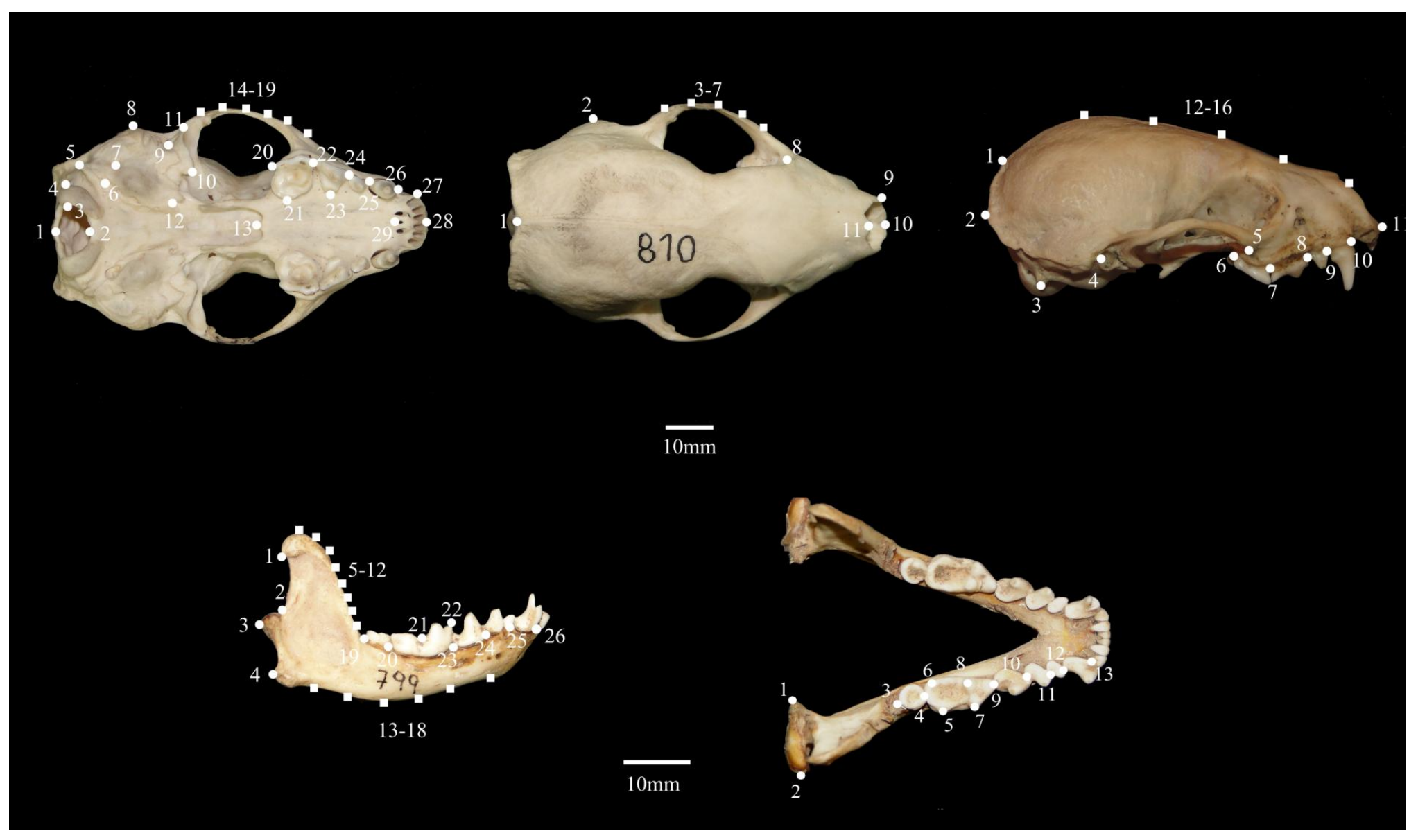


Figura 4. Distribuciones geográficas de Conepatus chinga (área punteada) y C. humboldtii (rayas diagonales) según los esquemas taxonómicos de Redford y Eisenberg (1992; A) y de Kipp (1965; B). Escala (barra negra)= $1000 \mathrm{Km}$.

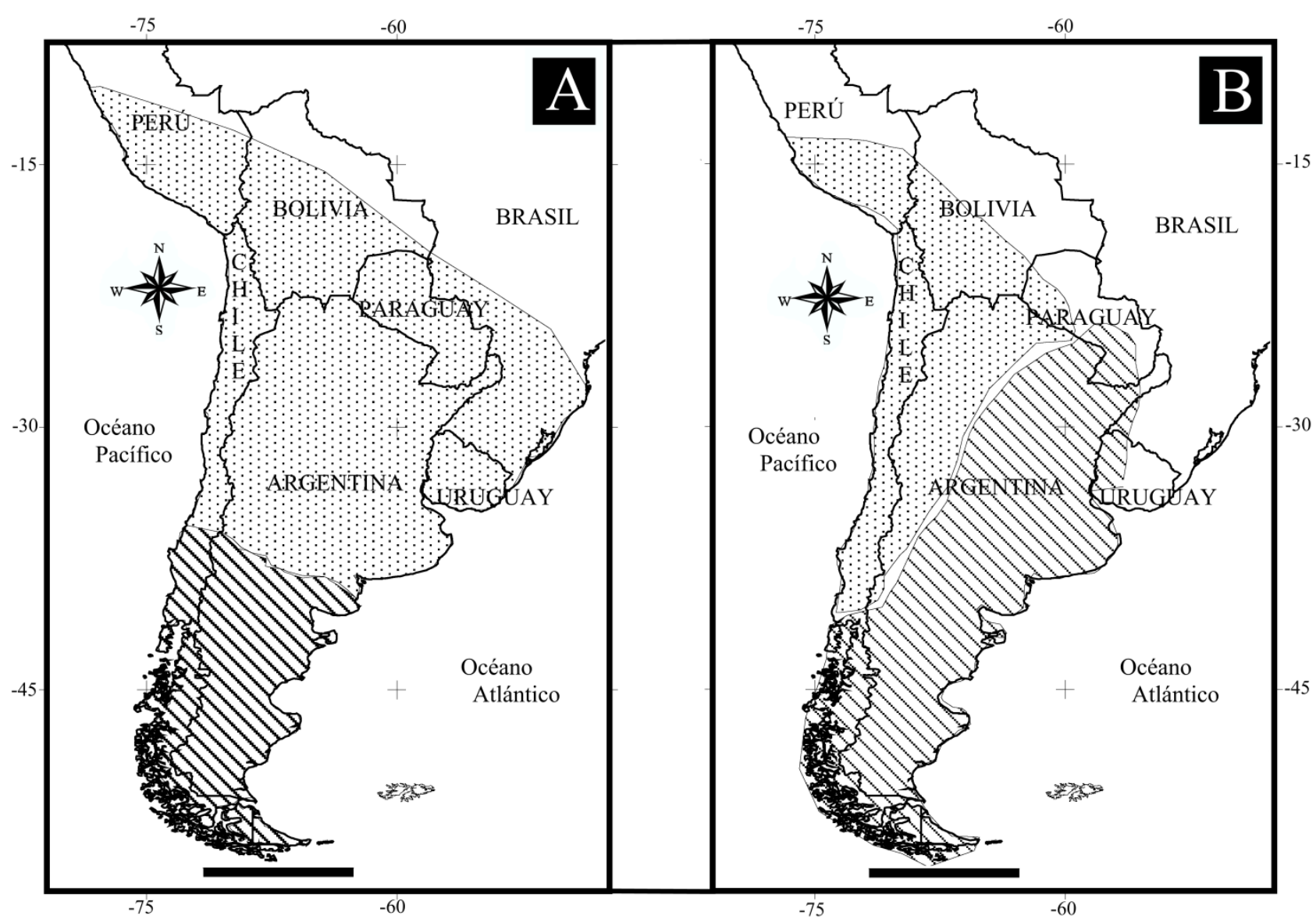


Figura 5. Valores medios de las variables bioclimáticas de temperatura (A) y precipitaciones (B) en los modelos Actual y Pleistoceno-Holoceno para Lyncodon patagonicus. Para una adecuada representación de la escala, BIO4 fue eliminada. Véase sección 3.5.1.a.

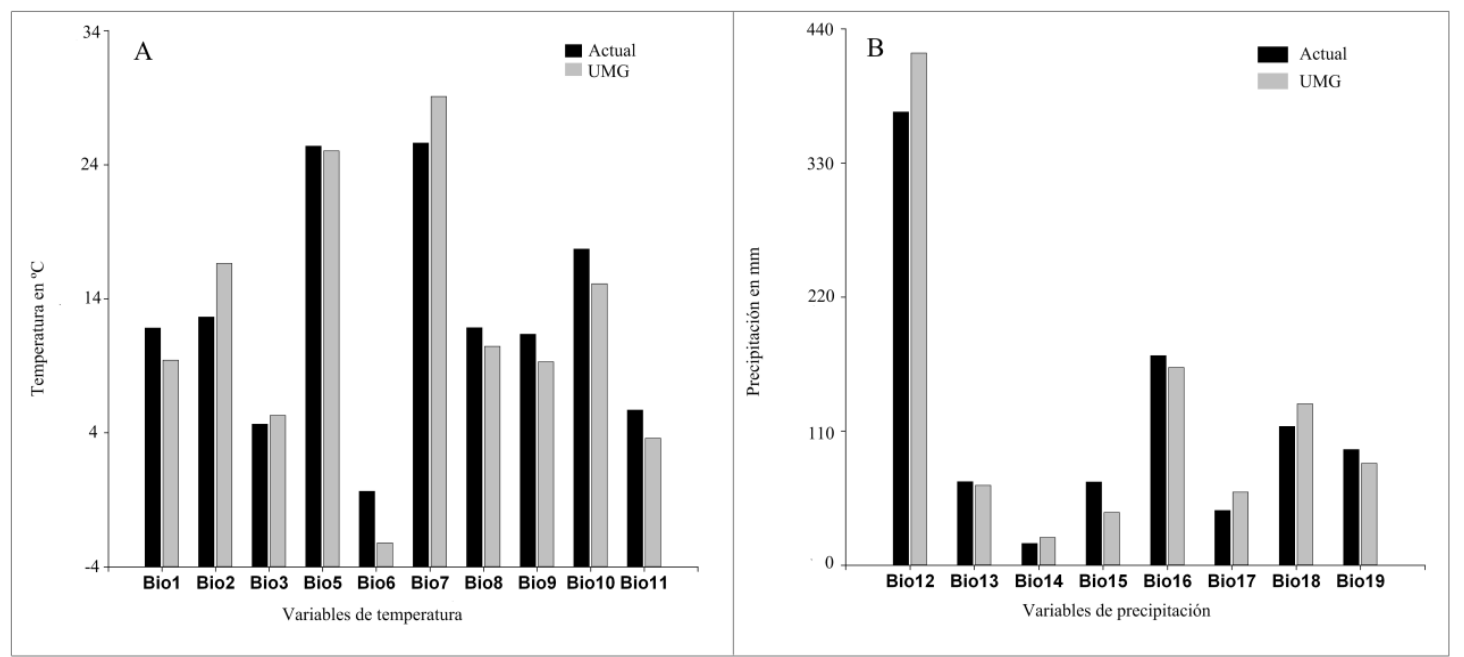


Figura 6. Localidades de registro para las especies estudiadas en los análisis de segregación trófica. Cuadrados negros= Conepatus chinga ; círculos azules= Galictis cuja ; cruces negras=Lontra provocax , triángulos verdes= Lyncodon patagonicus; asteriscos rojos $=$ Neovison vison . Escala (barra negra) $=1000 \mathrm{Km}$. Véase sección 3.6.

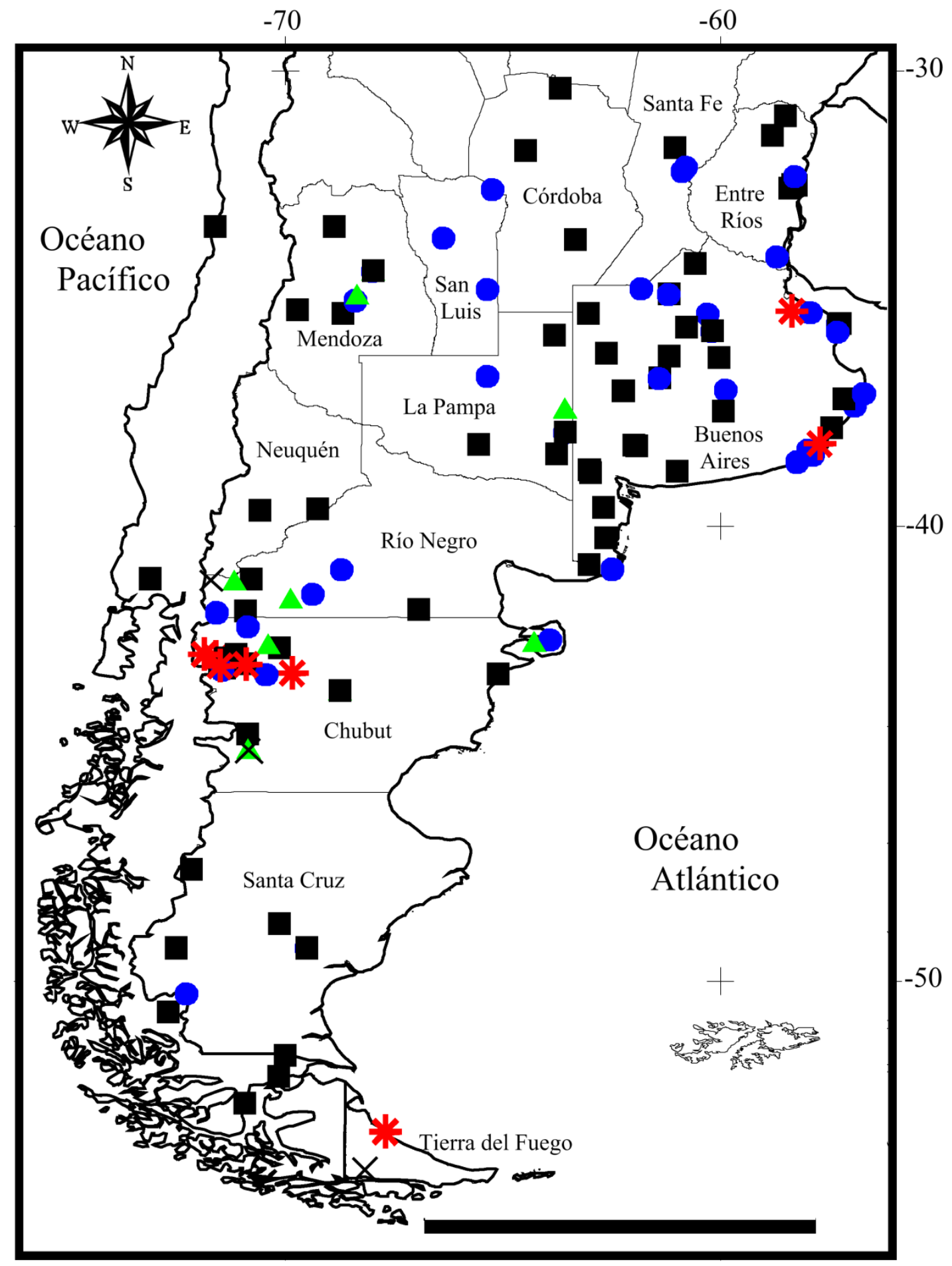


Figura 7. Landmarks (círculos blancos) y semilandmarks (cuadrados blancos) utilizados en análisis de morfometría geométrica para el estudio de segregación trófica. Véase sección 3.6. Se utilizó el especímen LIEB-M-799 para graficarlos (Conepatus chinga).

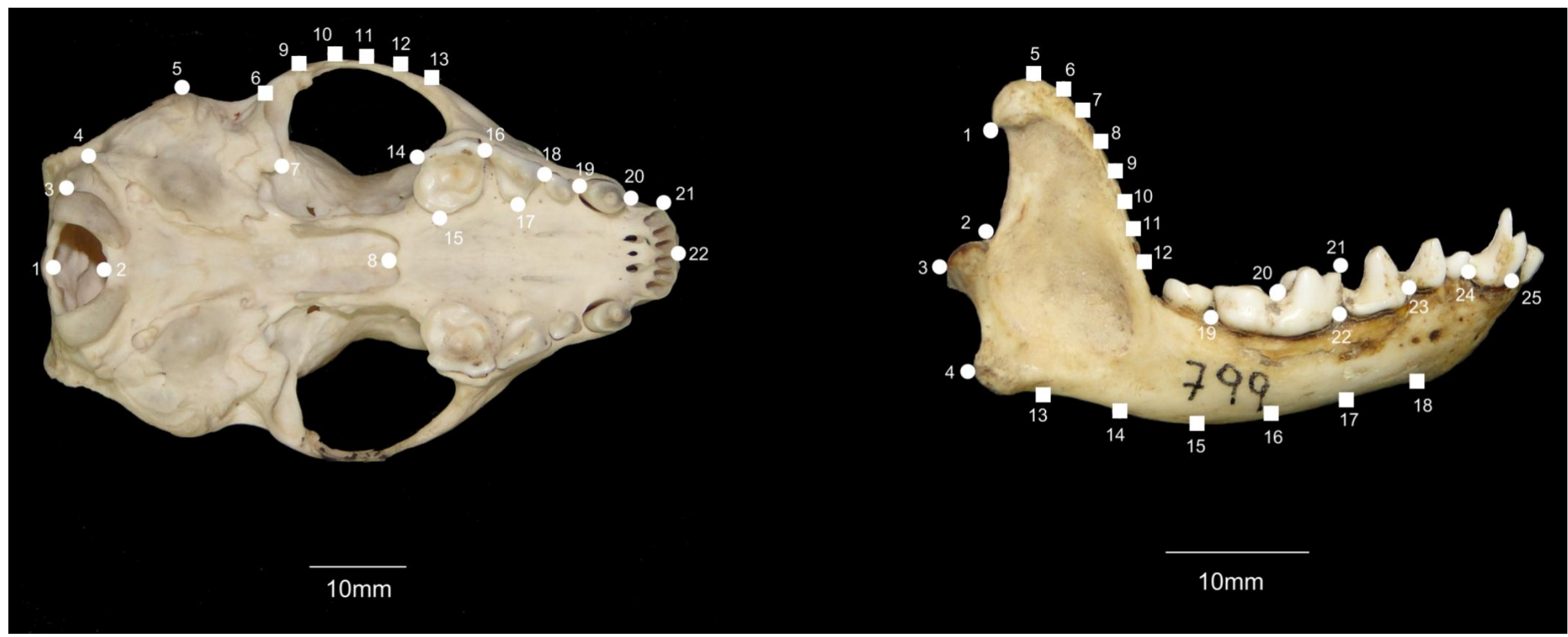


Figura 8. Árbol filogenético recortado, derivado de Sato et al. (2012), con los números asignados a cada nodo en función de la codificación binaria. Véase sección 3.6.2.

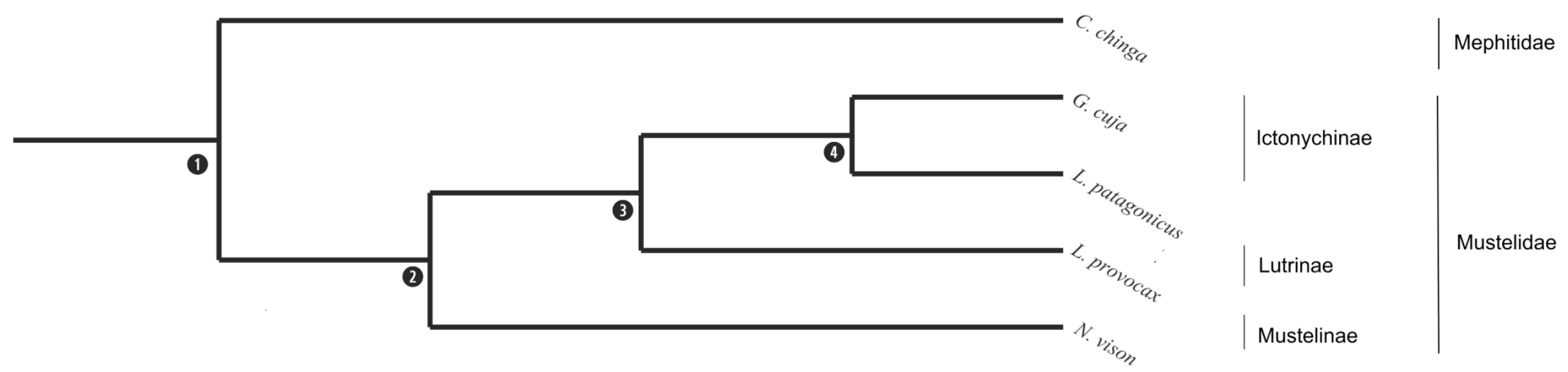


Figura 9. Esquema explicativo de la sección 3.7.2. Se observa el procedimiento realizado para evitar la multicolinearidad entre los filtros espaciales y las variables predictoras.

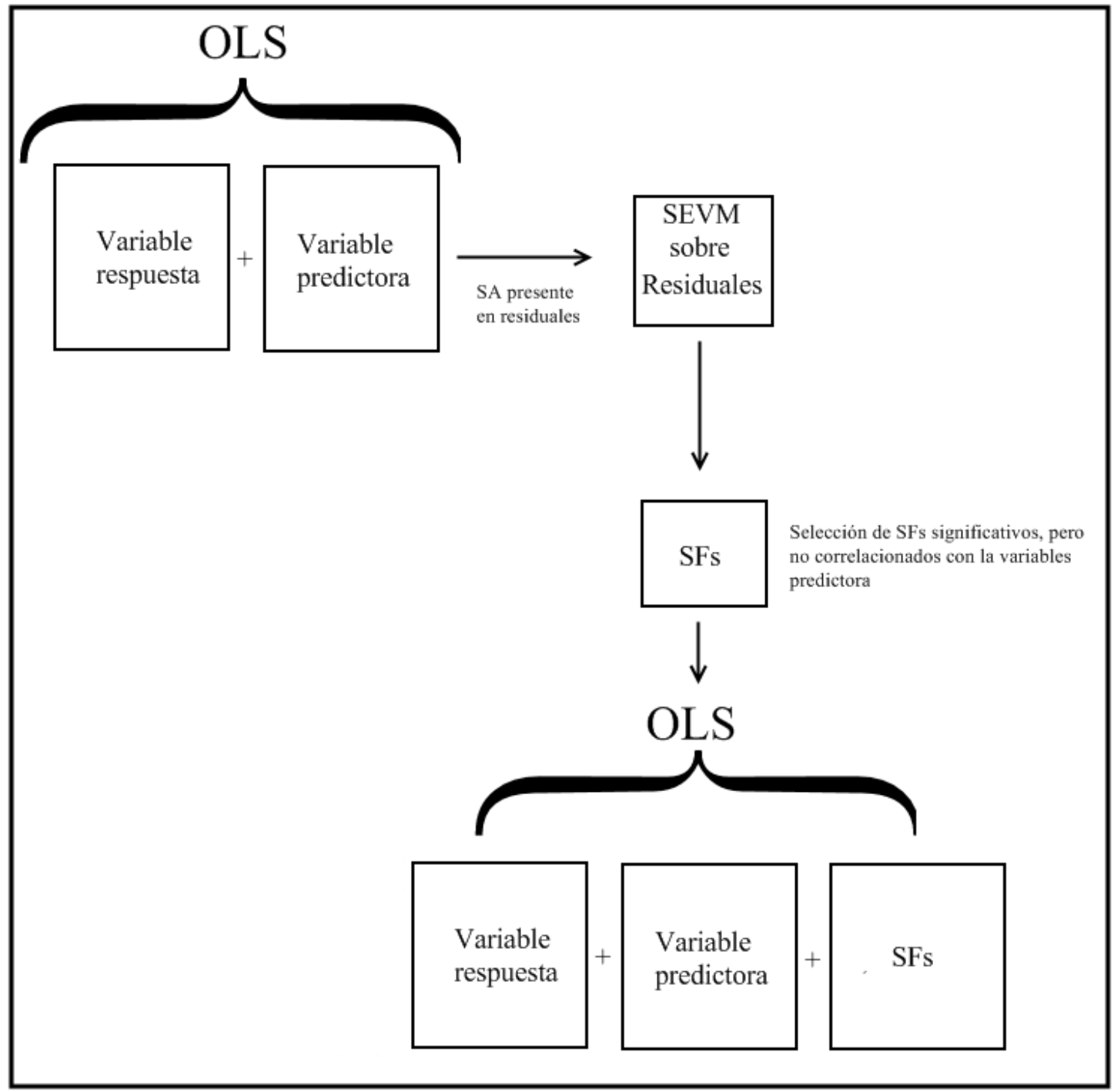


Figura 10. Diagramas de dispersión y grillas de deformación de los CP1 y CP2 siguiendo el esquema de clasificación de Redford y Eisenberg (1992), a partir del ACP de cráneo en vista ventral. Círculos negros $=C$. chinga , círculos grises $=C$. humboldtii, cruces $=$ Holotipos de los sinónimos junior.

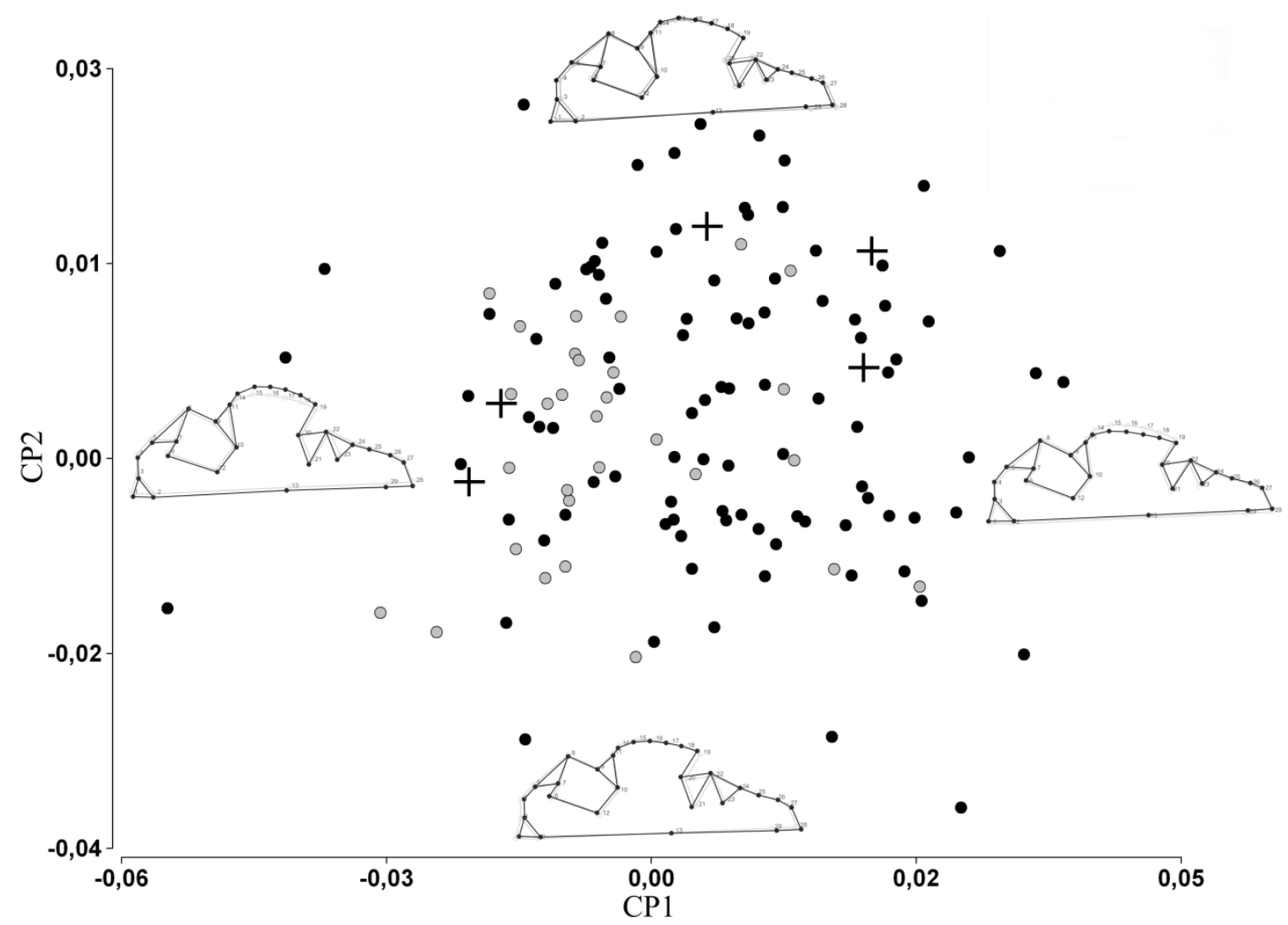


Figura 11. Diagramas de dispersión y grillas de deformación de los PC3 y PC4, a partir del ACP de cráneo en vista ventral. Las grillas de deformación se exageraron dos veces para facilitar la visualización de los cambios morfológicos. Círculos negros $=C$. chinga, círculos grises $=C$. humboldtii, cruces $=$ Holotipos de los sinónimos junior.

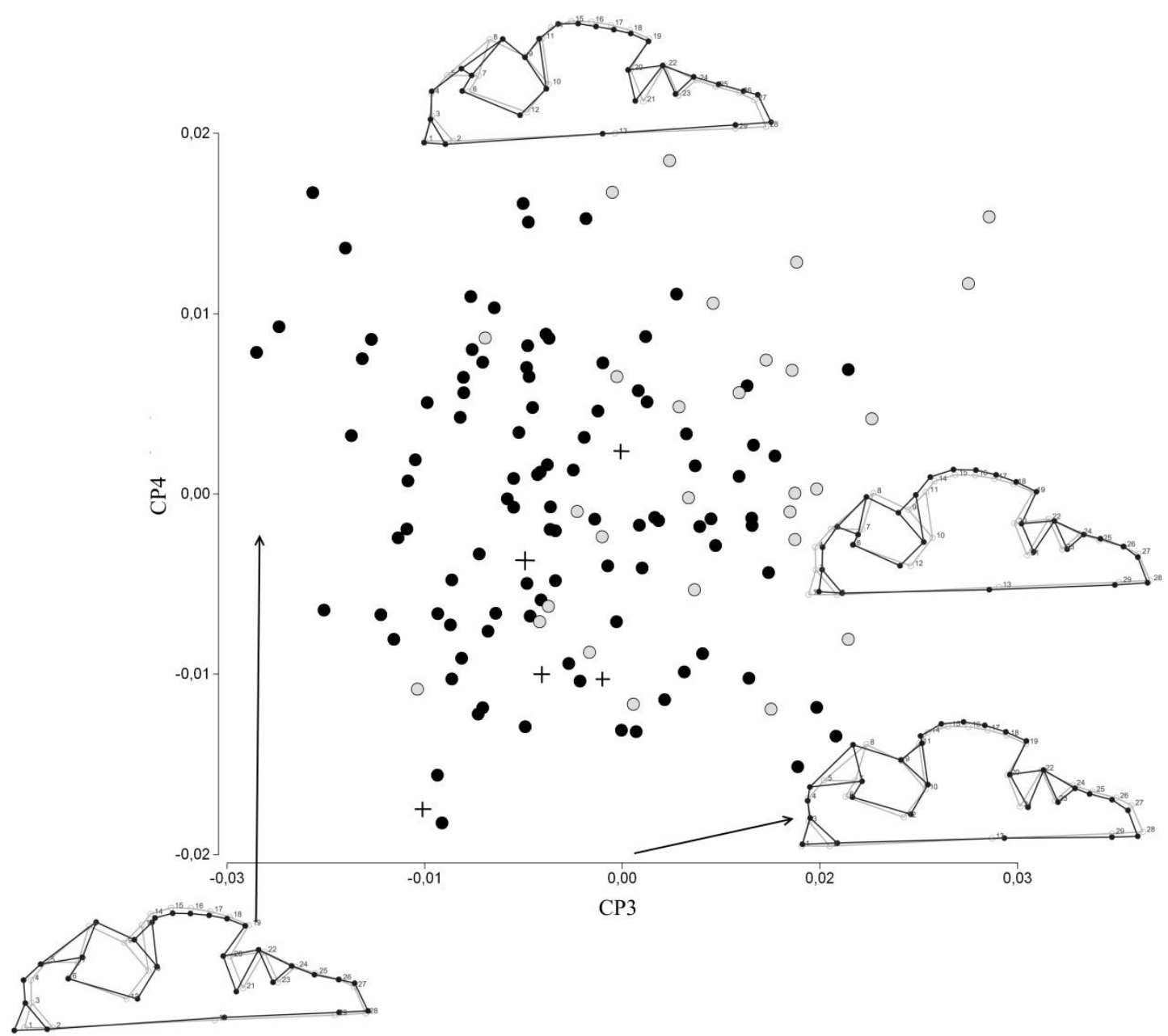


Figura 12. Diagramas de dispersión y grillas de deformación de los CP1 y CP2 siguiendo el esquema de clasificación de Kipp (1965), a partir del ACP de cráneo en vista ventral. Círculos negros $=C$. ching , círculos grises $=C$. humboldtii .

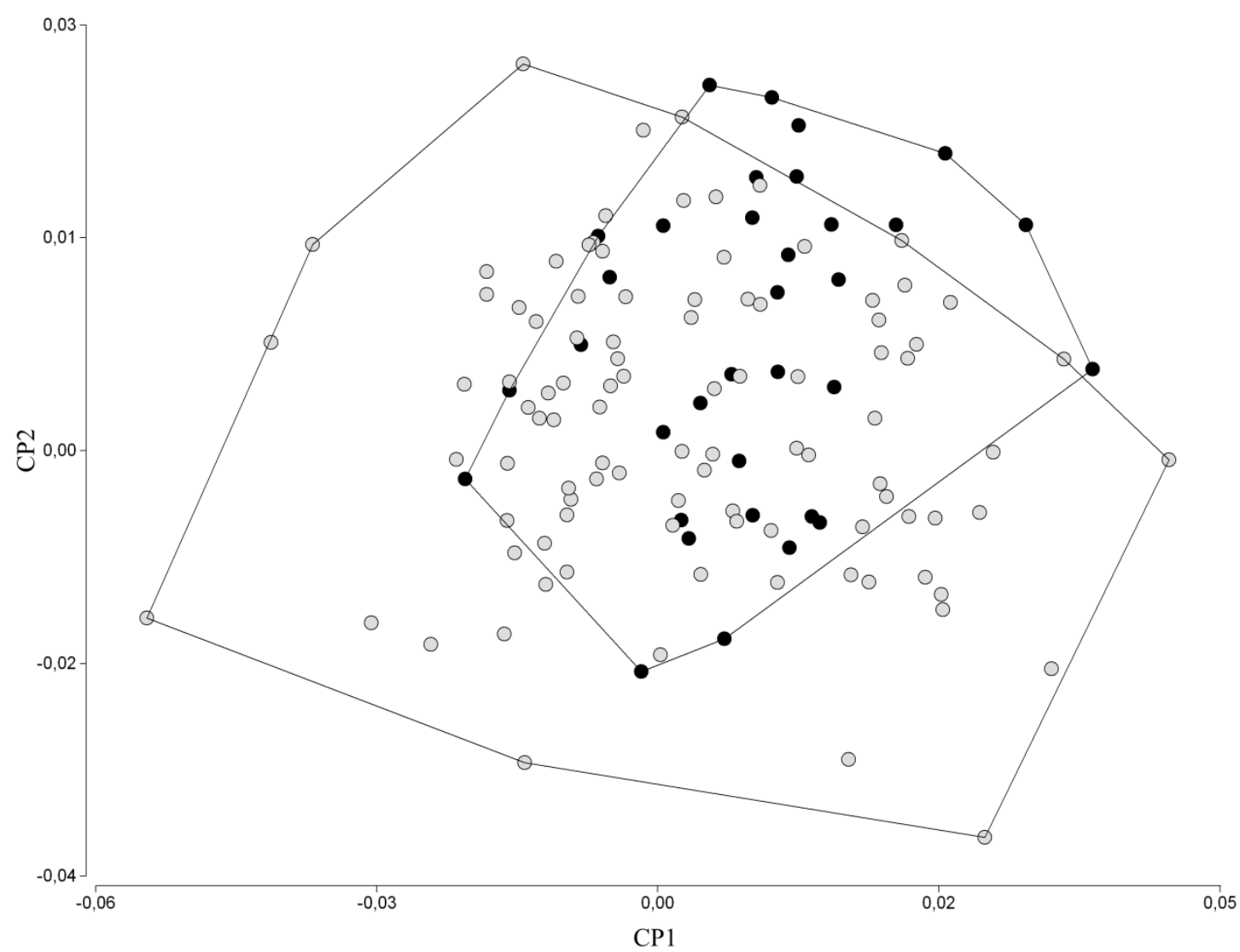


Figura 13. Diagrama de dispersión del CP1 y CP2, a partir del ACP de cráneo en vista ventral con un dataset complementario, incluyendo el holotipo de C. castaneus (asterisco negro). Círculos negros $=C$. ching $a$, círculos grises $=C$. humboldtii, cruces $=$ Holotipos de los sinónimos junior.

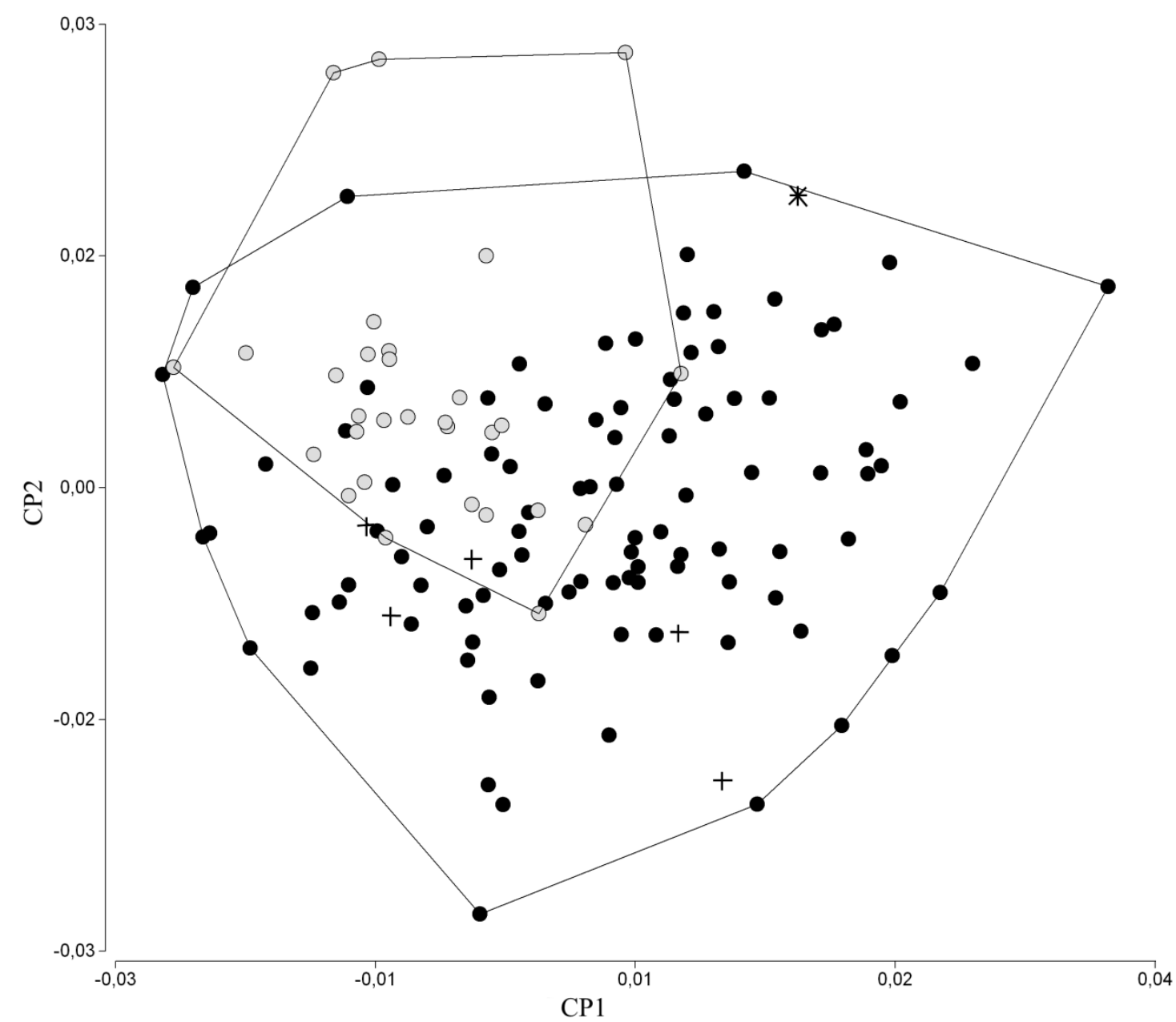


Figura 14. Diagrama de dispersión del CP1 y CP2, a partir del ACP de cráneo en vista ventral con un dataset complementario, incluyendo el holotipo de $C$. humboldtii (cuadrado gris). Círculos negros $=C$. chinga , círculos grises $=C$. humboldtii, cruces $=$ Holotipos de los sinónimos junior.

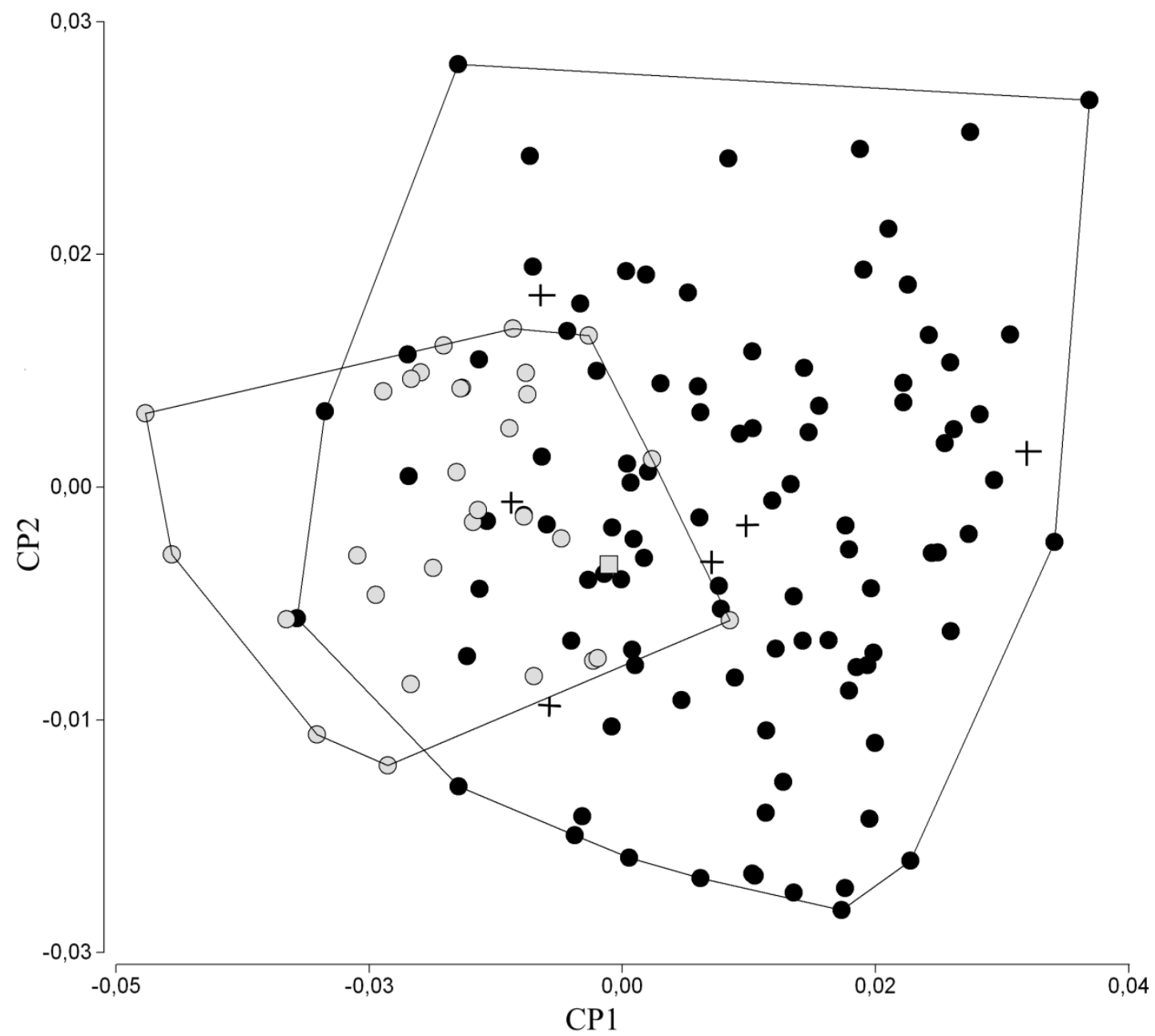


Figura 15. Diagrama de dispersión y grillas de deformación de los CP1 y CP2 a partir del ACP de cráneo en vista lateral. Círculos negros $=C$. ching $a$, círculos grises $=C$. humboldtii. Las grillas de deformación se exageraron dos veces para facilitar la visualización de los cambios de forma.

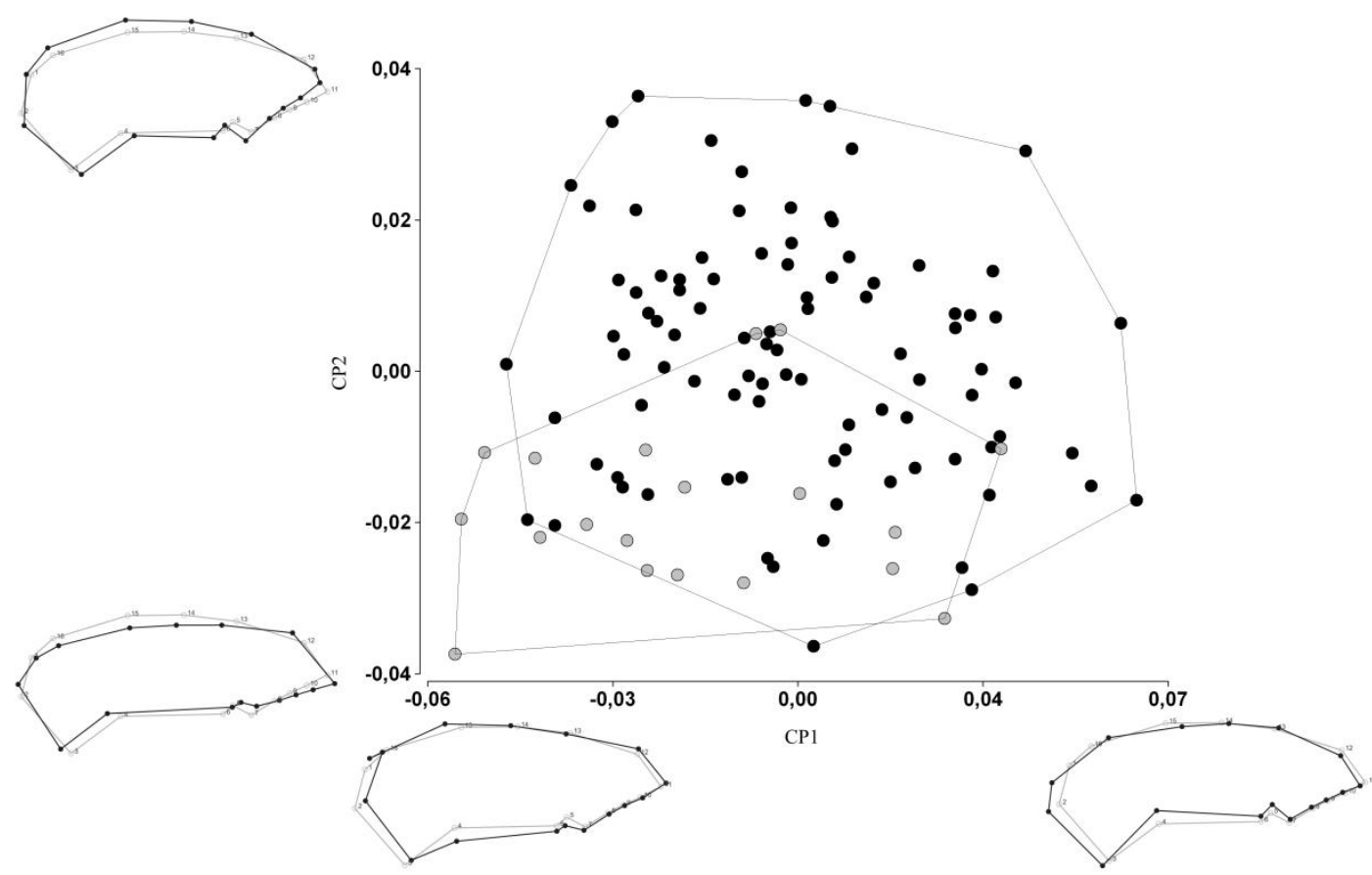


Figura 16. Diagrama de dispersión y grillas de deformación de los CP1 y CP2 a partir del ACP de cráneo en vista dorsal. Las grillas de deformación se exageraron dos veces para facilitar la visualización de los cambios de forma. Círculos negros $=C$. chinga, círculos grises $=C$. humboldtii .

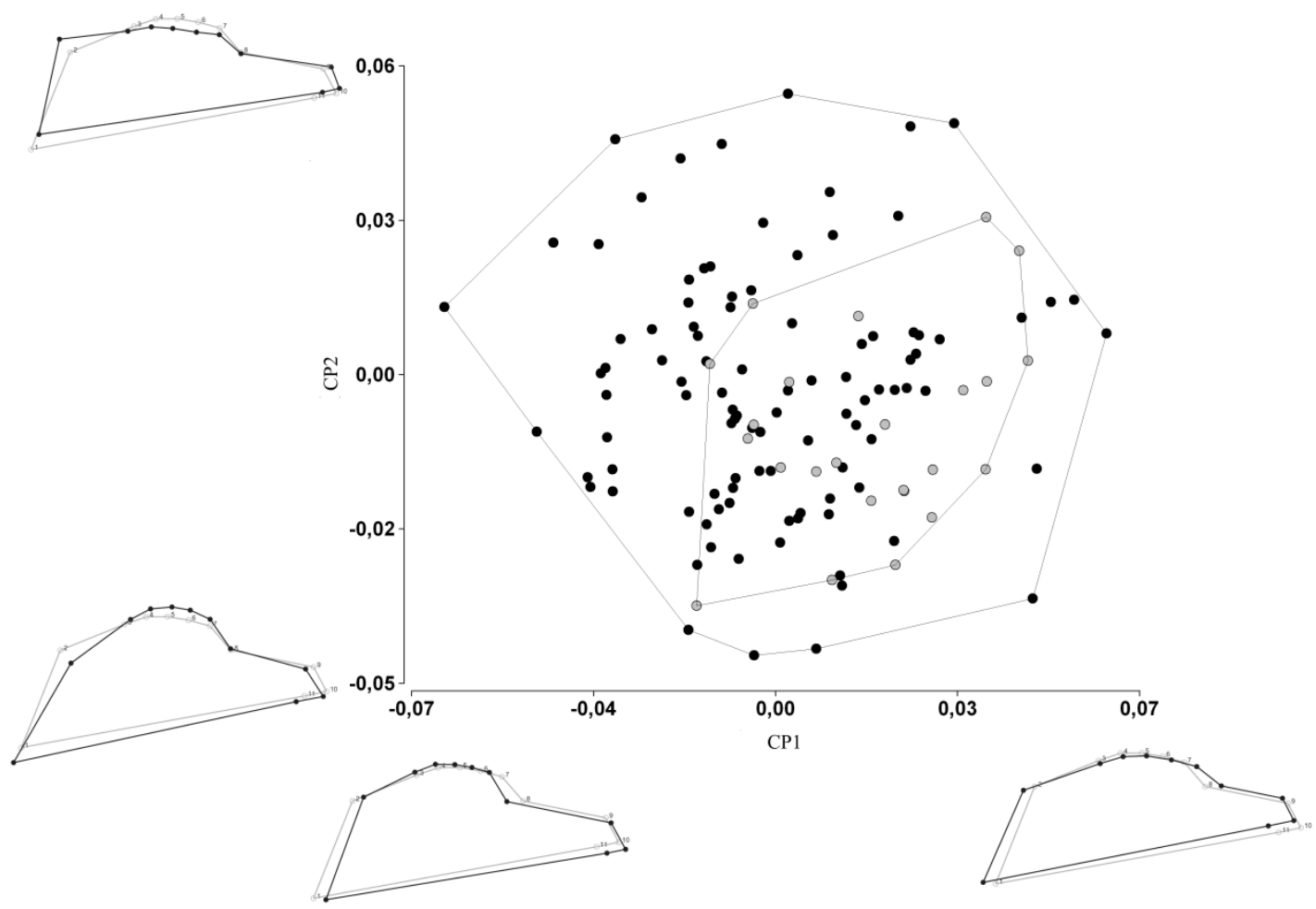


Figura 17. Diagramas de dispersión y grillas de deformación de los CP1 y CP2, a partir del ACP de mandíbula en vista lateral. Círculos negros $=C$. chinga, Círculos grises $=C$. humboldtii.

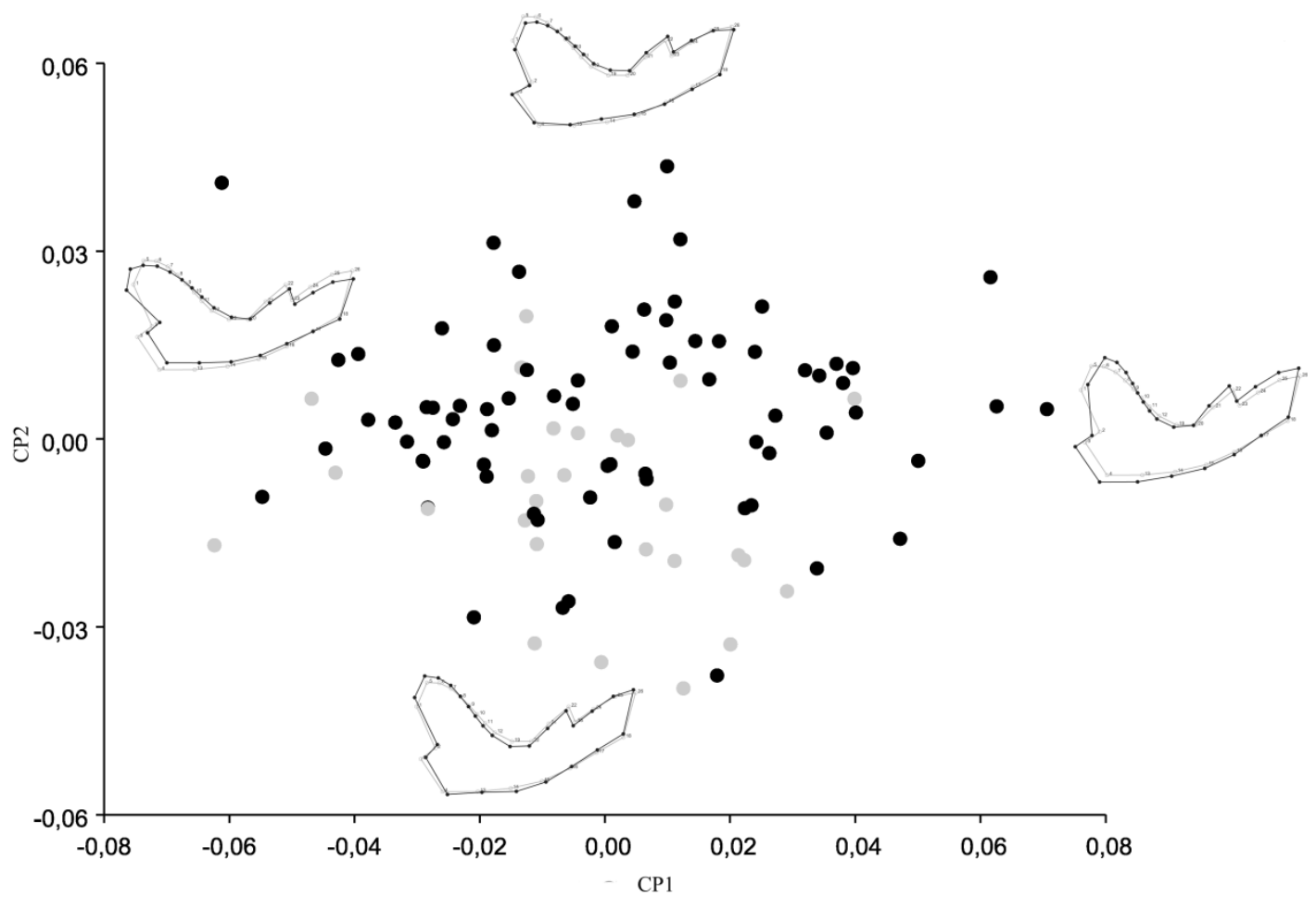


Figura 18. Diagramas de dispersión y grillas de deformación de los CP3 y CP4, a partir del ACP de mandíbula en vista lateral. Las grillas de deformación se exageraron dos veces para facilitar la visualización de los cambios morfológicos. Círculos negros $=C$. chinga, círculos grises $=C$. humboldtii .

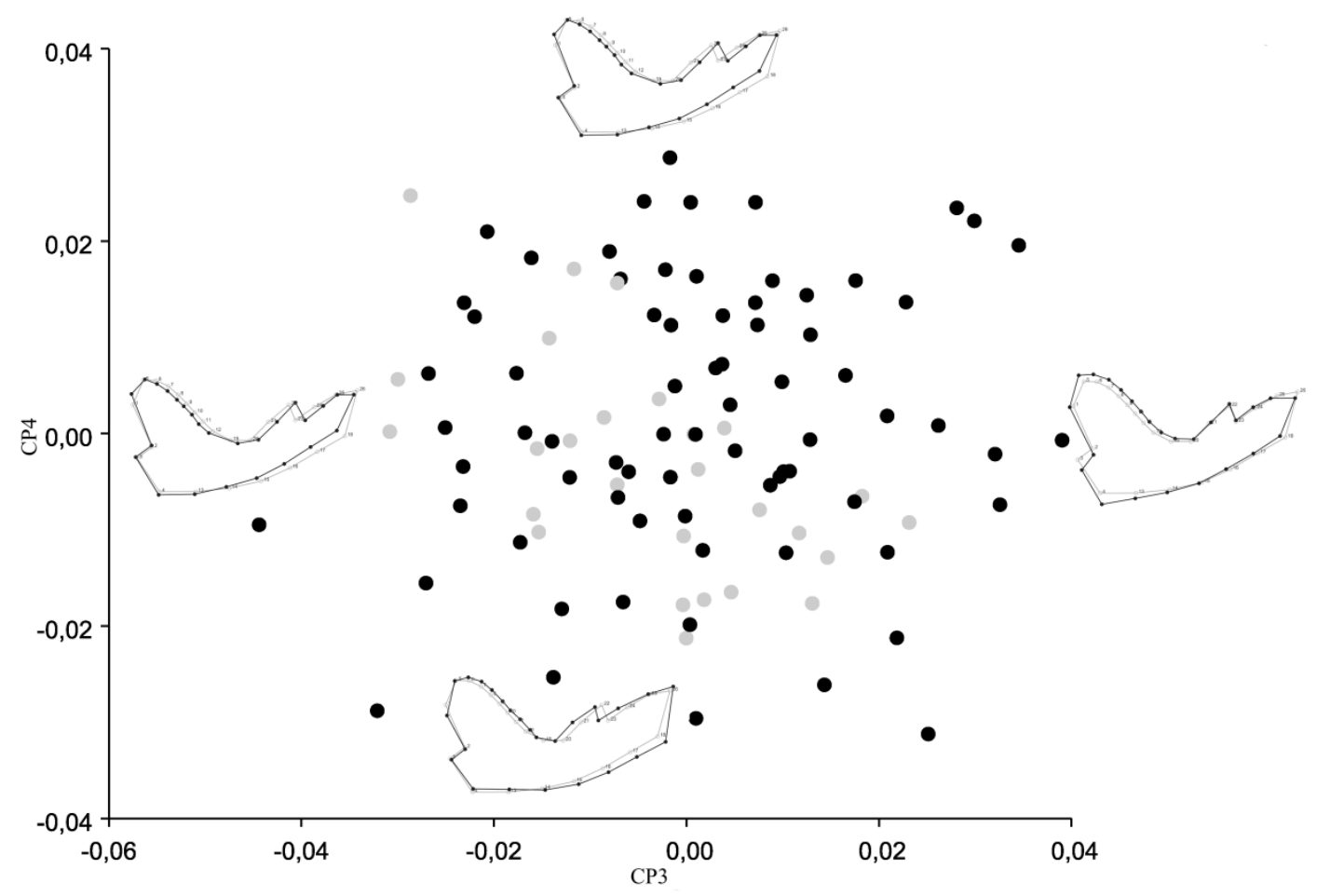


Figura 19. Diagramas de dispersión y grillas de deformación de los CP1 y CP2, a partir del ACP de mandíbula en vista superior. Las grillas de deformación se exageraron dos veces para facilitar la visualización de los cambios morfológicos. Círculos negros $=C$. chinga, círculos grises $=C$. humboldtii .

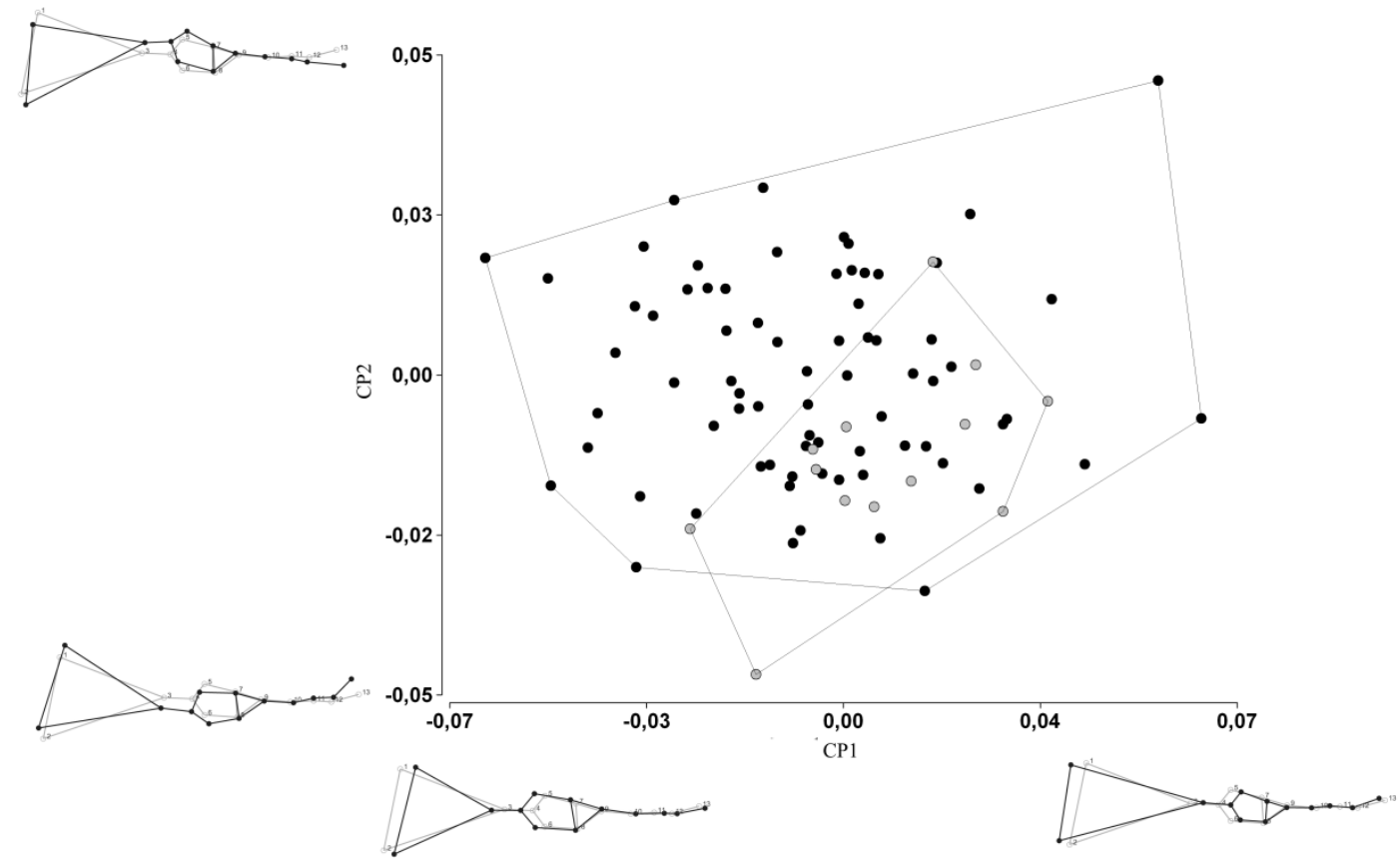


Figura 20. Diagrama de dispersión de los puntajes de regresión entre forma y tamaño de cráneo en vista ventral para $C$. chinga (círculos negros) y $C$. humboldtii (círculos grises), y grillas de deformación.
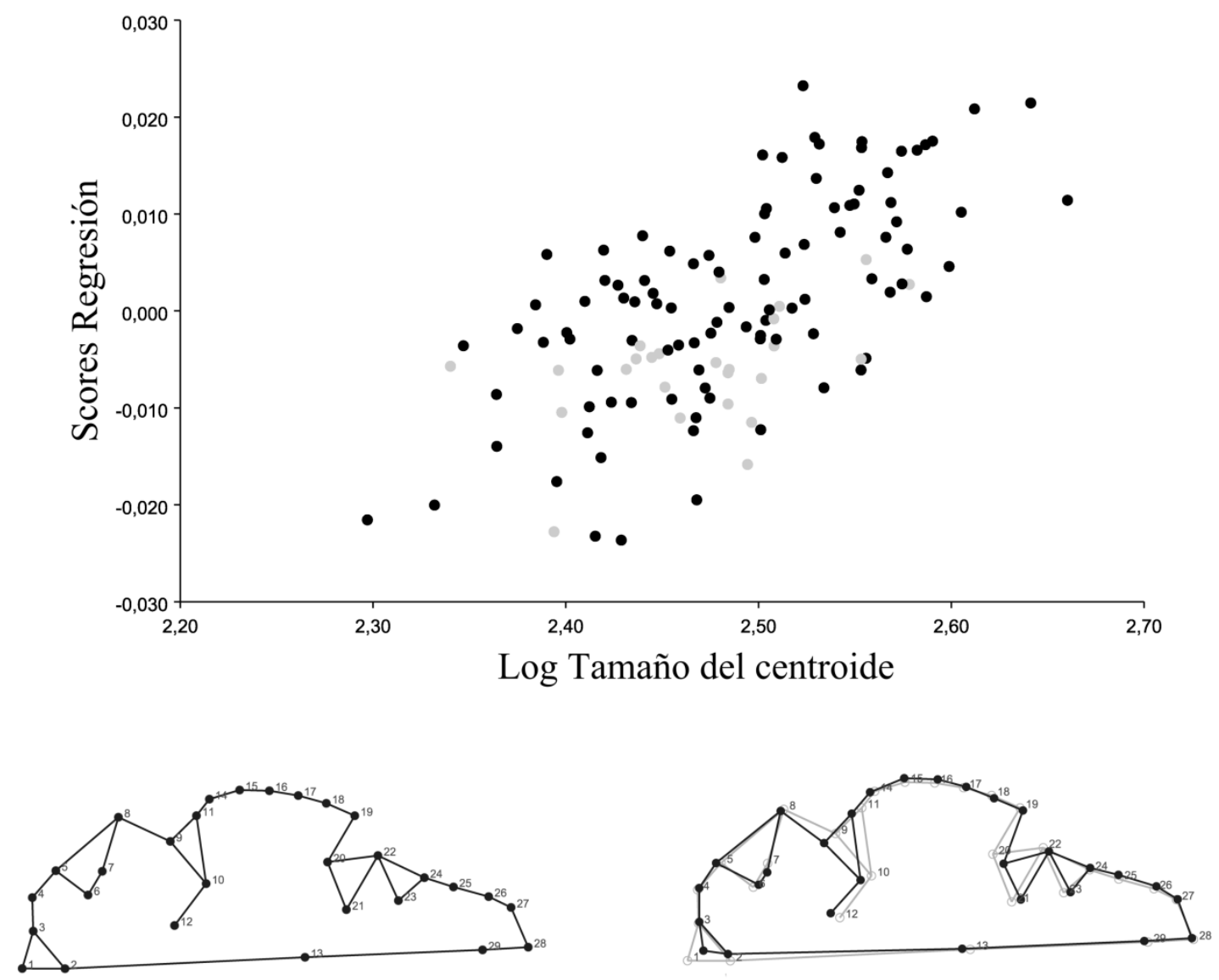

Tamaño del centroide 
Figura 21. Diagrama de dispersión de los puntajes de regresión entre forma y tamaño de mandíbula en vista lateral para $C$. chinga (círculos negros) y $C$. humboldtii (círculos grises), y grillas de deformación.
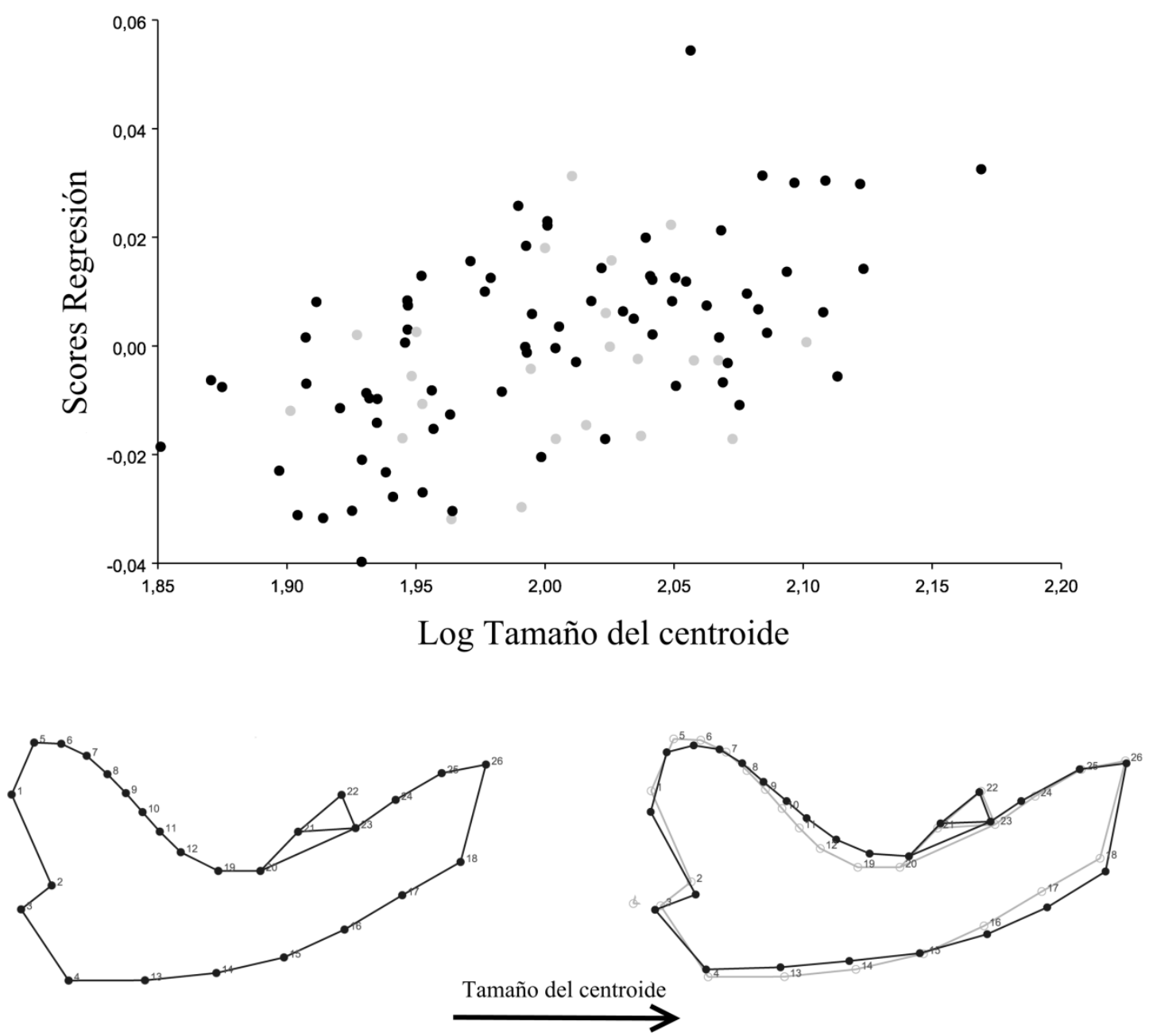
Figura 22. Diagramas representando las localidades de muestreo/captura de Galictis cuja y su relación con la altitud (A), temperatura media anual (B) y precipitación anual (C).
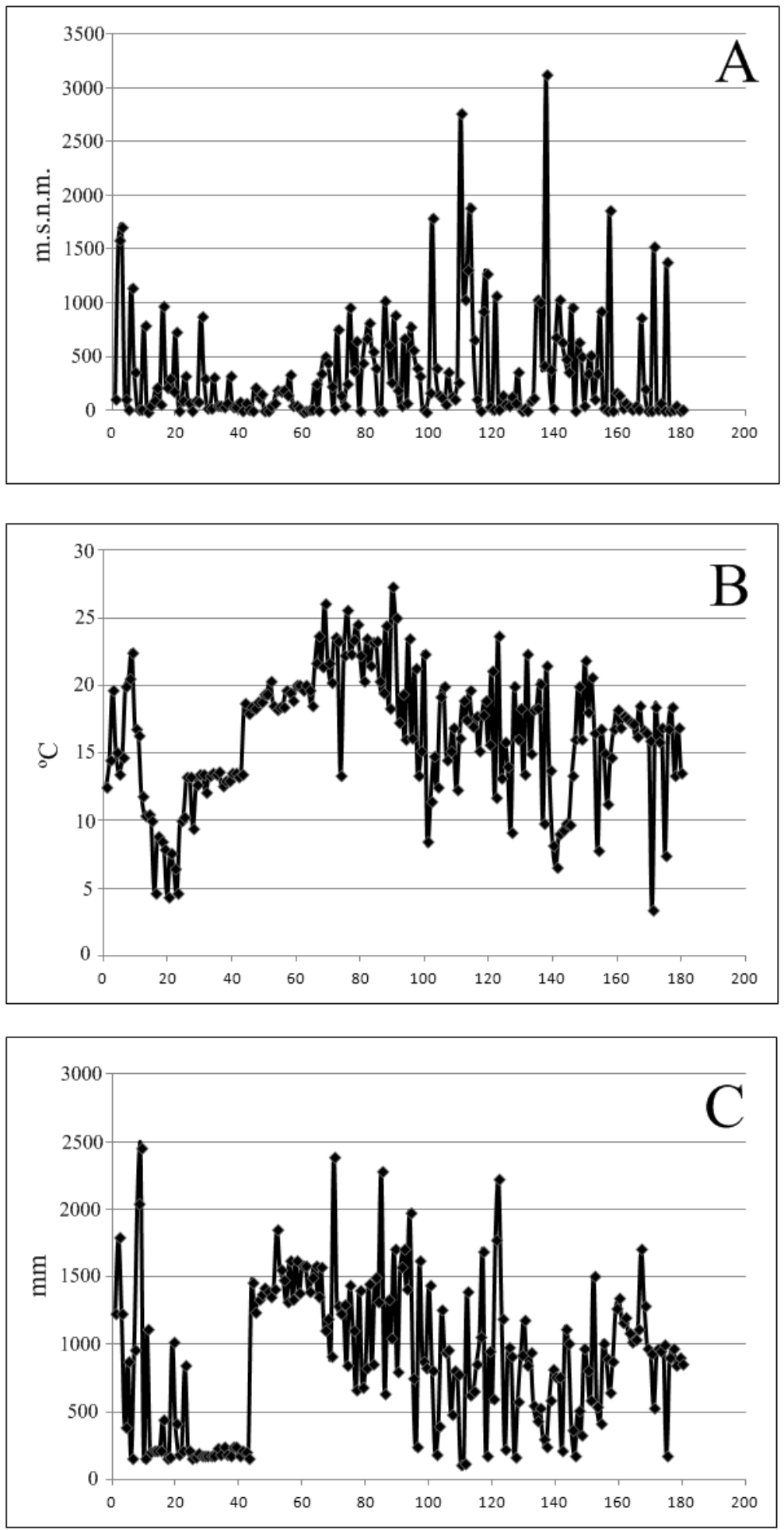
Figura 23. Modelos de distribución potencial para Galictis cuja, utilizando localidades (círculos blancos) actuales (A) y posteriores (cuadrados blancos) a 1950 (B). Valores de probabilidad representados por los siguientes colores: 100-51 (rojo), 50-26 (naranja), 25-11 (amarillo), 10-2 (verde) y 1-0 (blanco). Escala (barra negra) $=2000 \mathrm{Km}$. Véase sección 3.5.1.

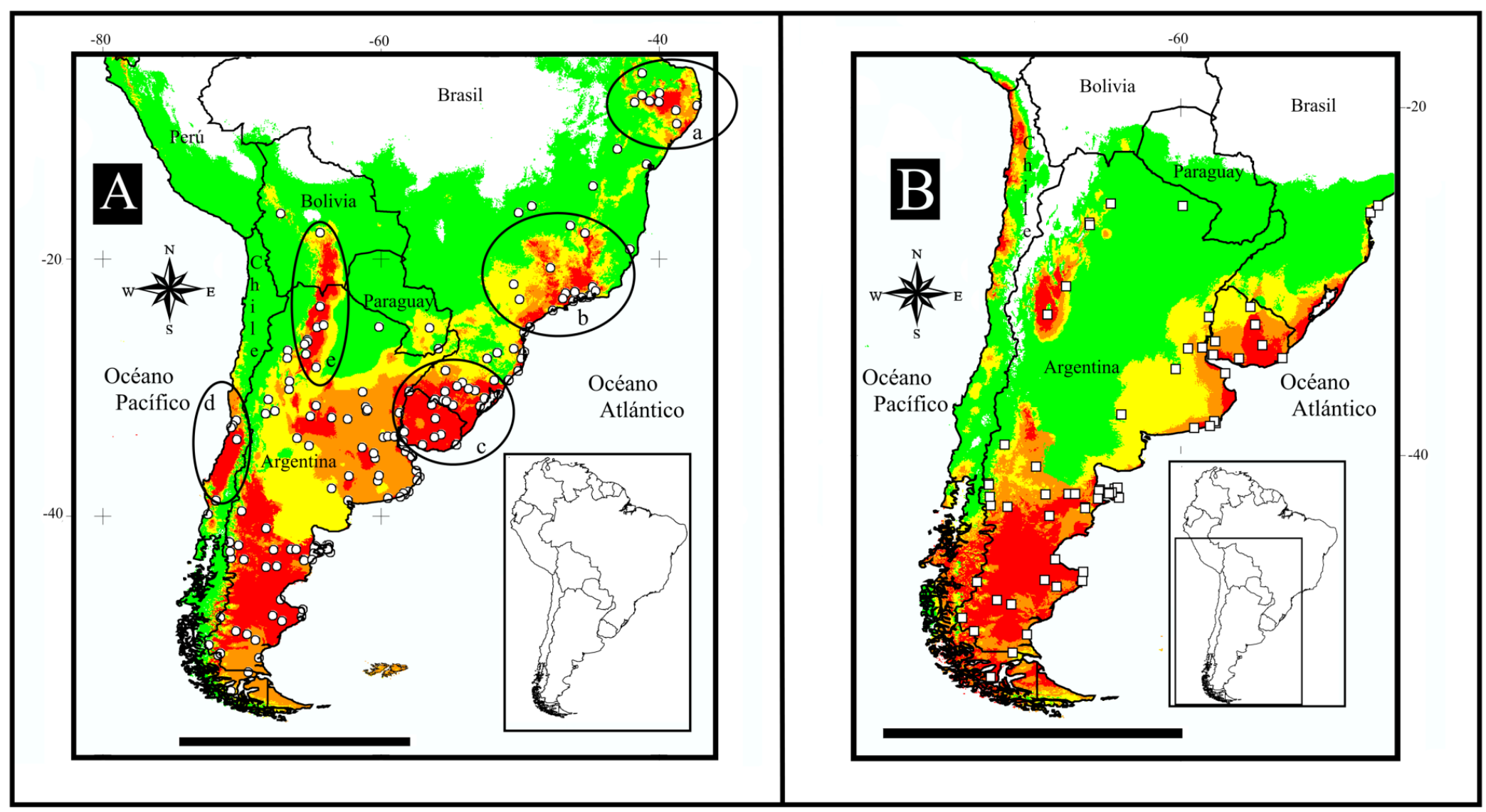


Figura 24. Diagramas representando las localidades de muestreo/captura de Lyncodon patagonicus y su relación con la altitud (A), temperatura media anual (B) y precipitación anual (C).
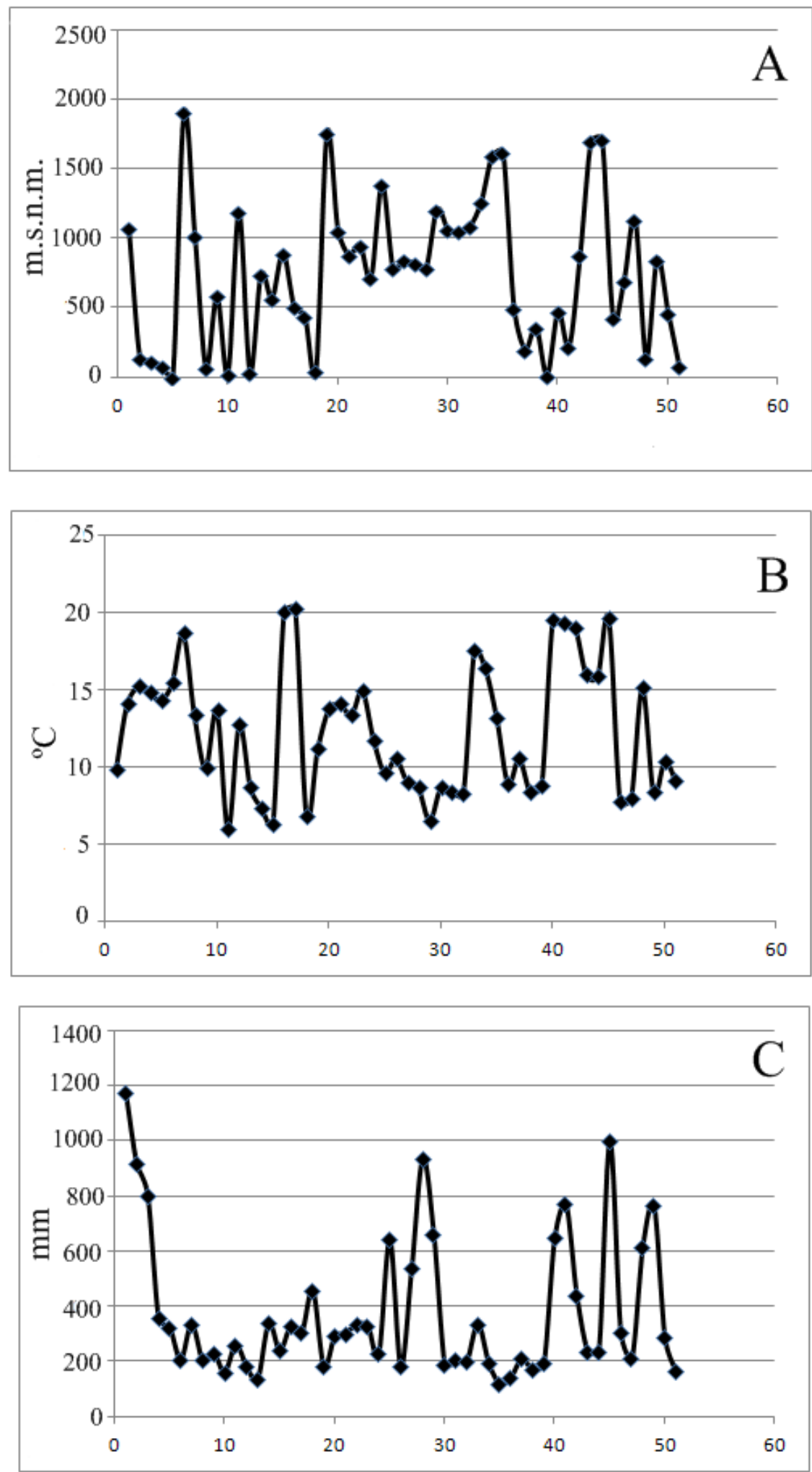
Figura 25. Modelos de distribución potencial para Lyncodon patagonicus, utilizando localidades del Pleistoceno-Holoceno (A, triángulos blancos), y del Holoceno (B, cuadrados blancos). Valores de probabilidad representados por los siguientes colores: 100-51 (rojo), 50-26 (naranja), 25-11 (amarillo), 10-2 (verde) y 1-0 (blanco) Escala (barra negra)=2000 Km. Véase sección 3.5.1.a.

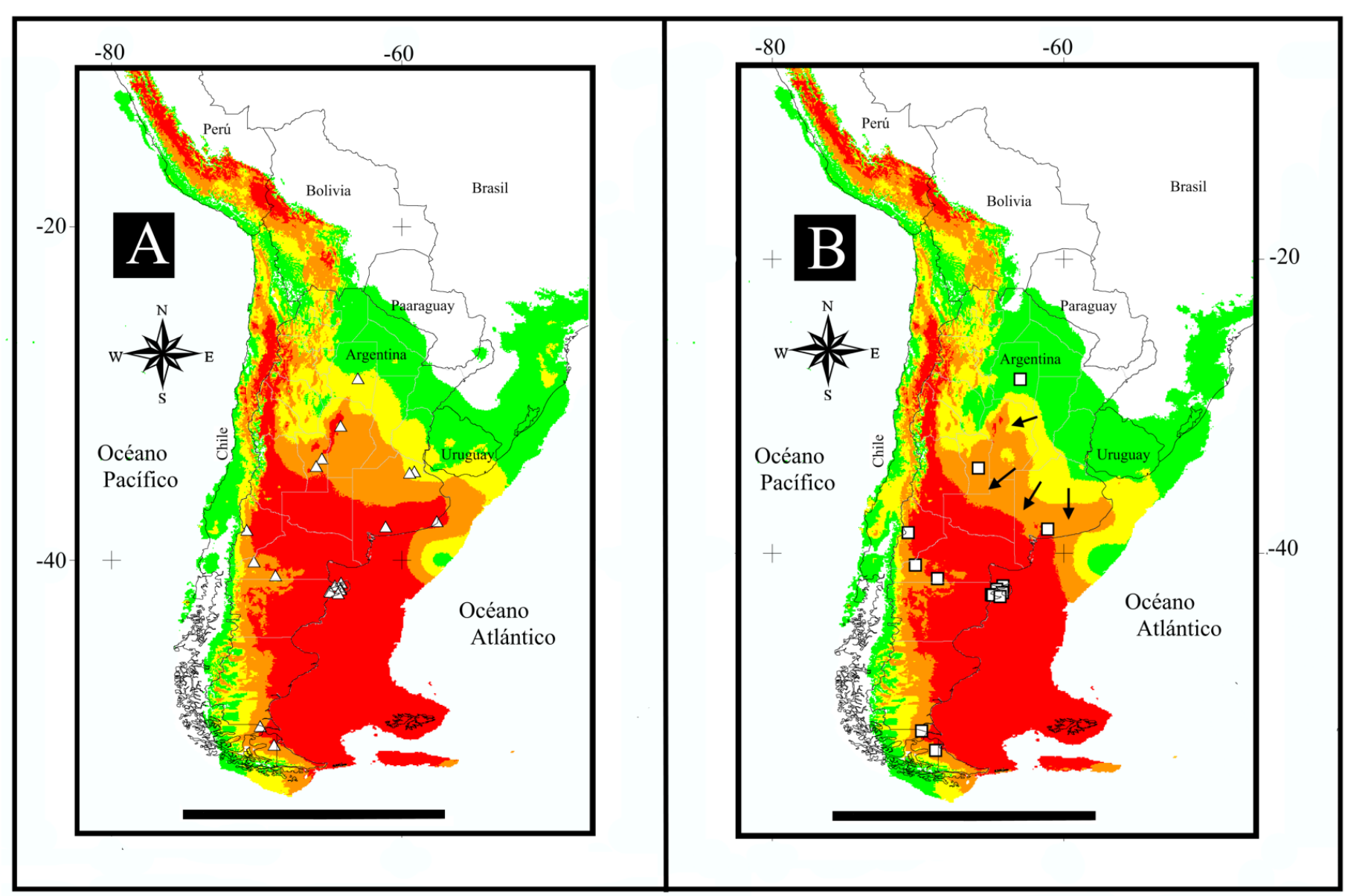


Figura 26. Modelos de distribución potencial para Lyncodon patagonicus, utilizando localidades actuales (A, círculos blancos) y posteriores a 1950 (B, cuadrados blancos). Valores de probabilidad representados por los siguientes colores: 100-51 (rojo), 50-26 (naranja), 25-11 (amarillo), 10-2 (verde) y 1-0 (blanco) Escala (barra negra)= 2000 Km. Véase sección 3.5.1.a.

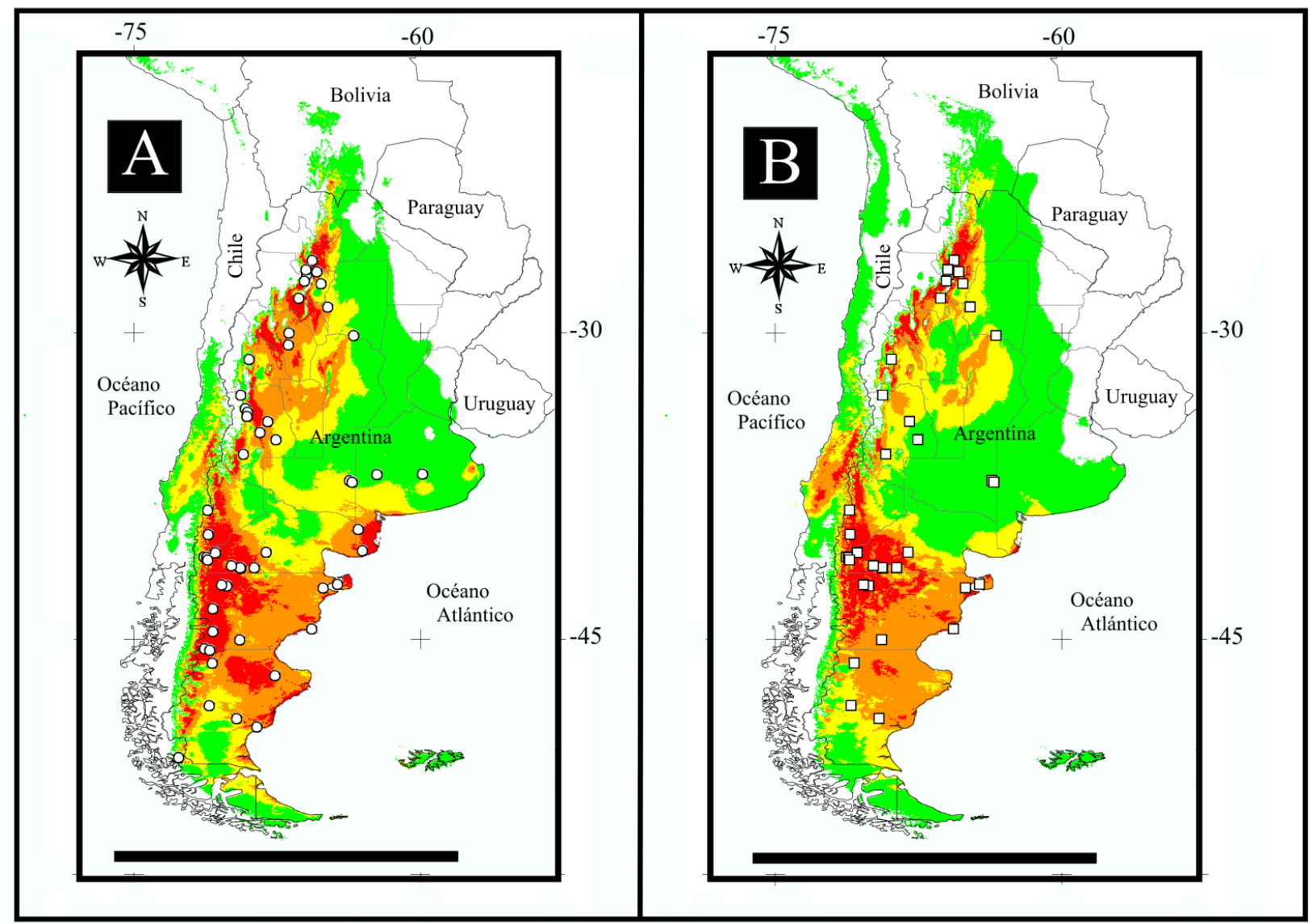


Figura 27. Diagramas representando las localidades de muestreo/captura de Lontra provocax y su relación con la altitud (A), temperatura media anual (B) y precipitación anual $(\mathrm{C})$.
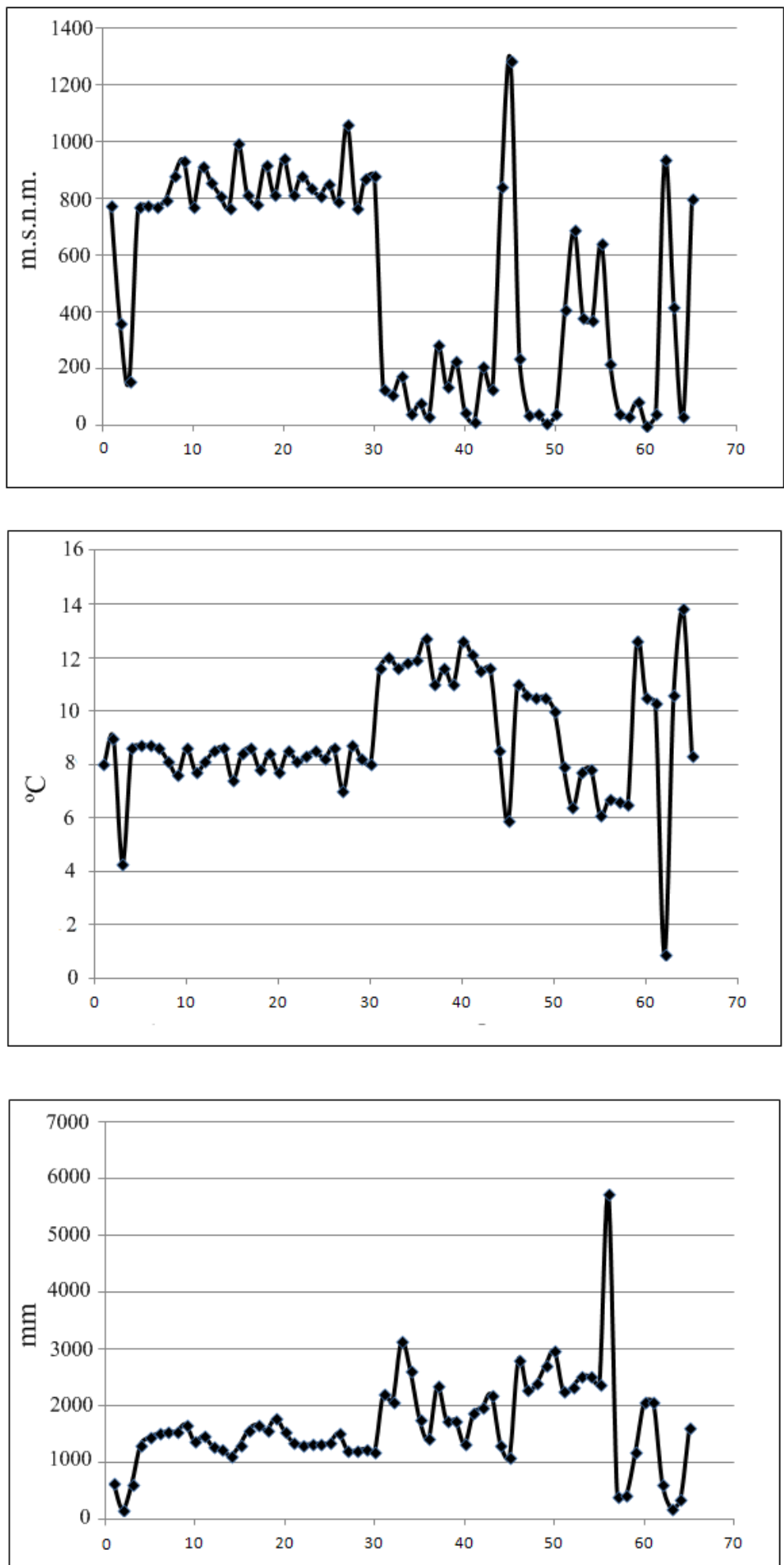
Figura 28. Modelos de distribución potencial para Lontra provocax, utilizando localidades actuales (A, círculos blancos) y posteriores a 1950 (B, cuadrados blancos). Valores de probabilidad representados por los siguientes colores: 100-51 (rojo), 50-26 (naranja), 25-11 (amarillo), 10-2 (verde) y 1-0 (blanco). Escala (barra negra)= $500 \mathrm{Km}$. Véase sección 3.5.1.

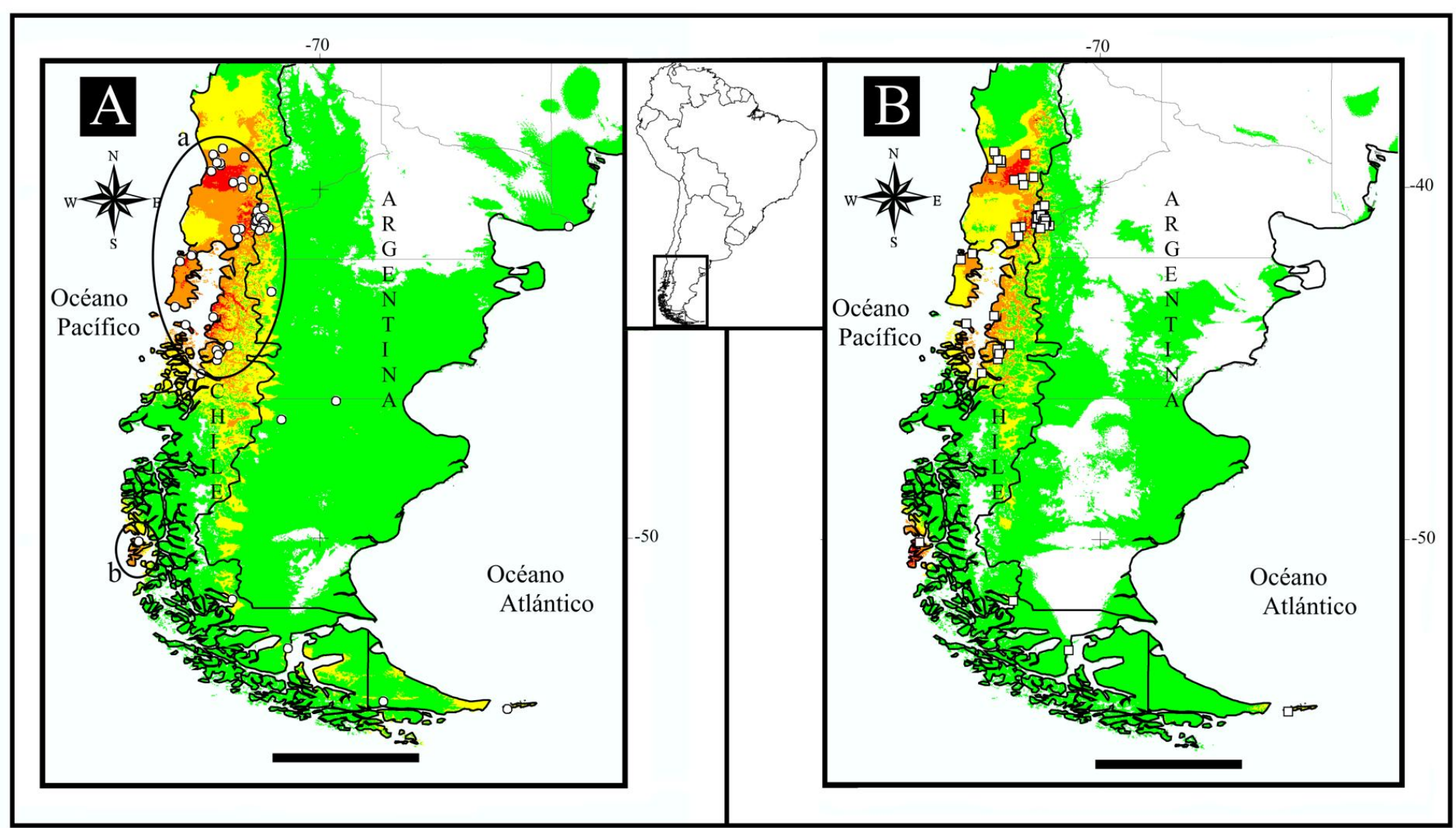


Figura 29. Diagramas representando las localidades de muestreo/captura de Neovison vison y su relación con la altitud (A), temperatura media anual (B) y precipitación anual (C).
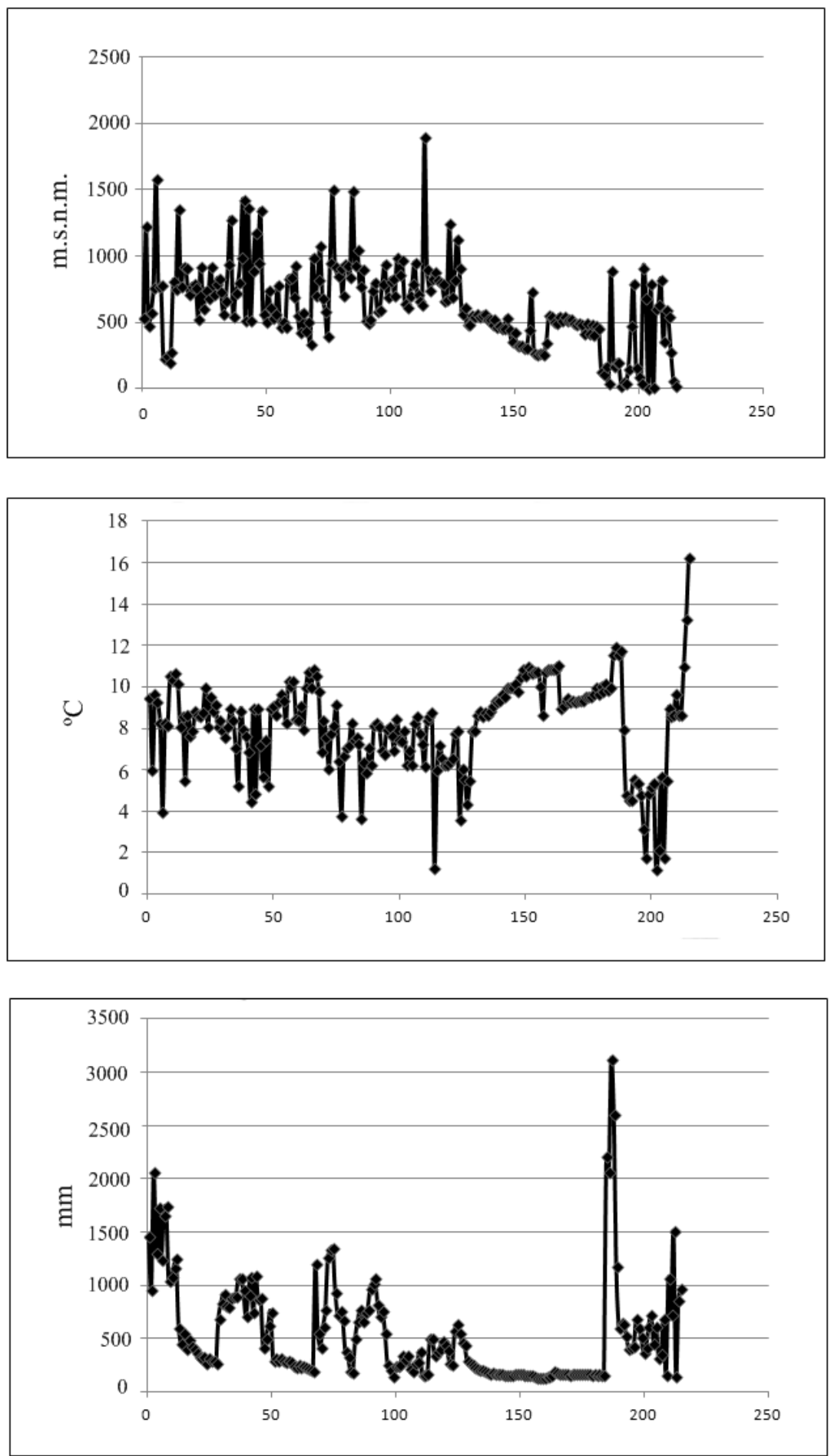
Figura 30. Modelo de distribución potencial para Neovison vison, utilizando localidades actuales (círculos blancos). Valores de probabilidad representados por los siguientes colores: 100-51 (rojo), 50-26 (naranja), 25-11 (amarillo), 10-2 (verde) y 1-0 (blanco). Escala $($ barra negra $)=500 \mathrm{Km}$. Véase sección 3.5.1.

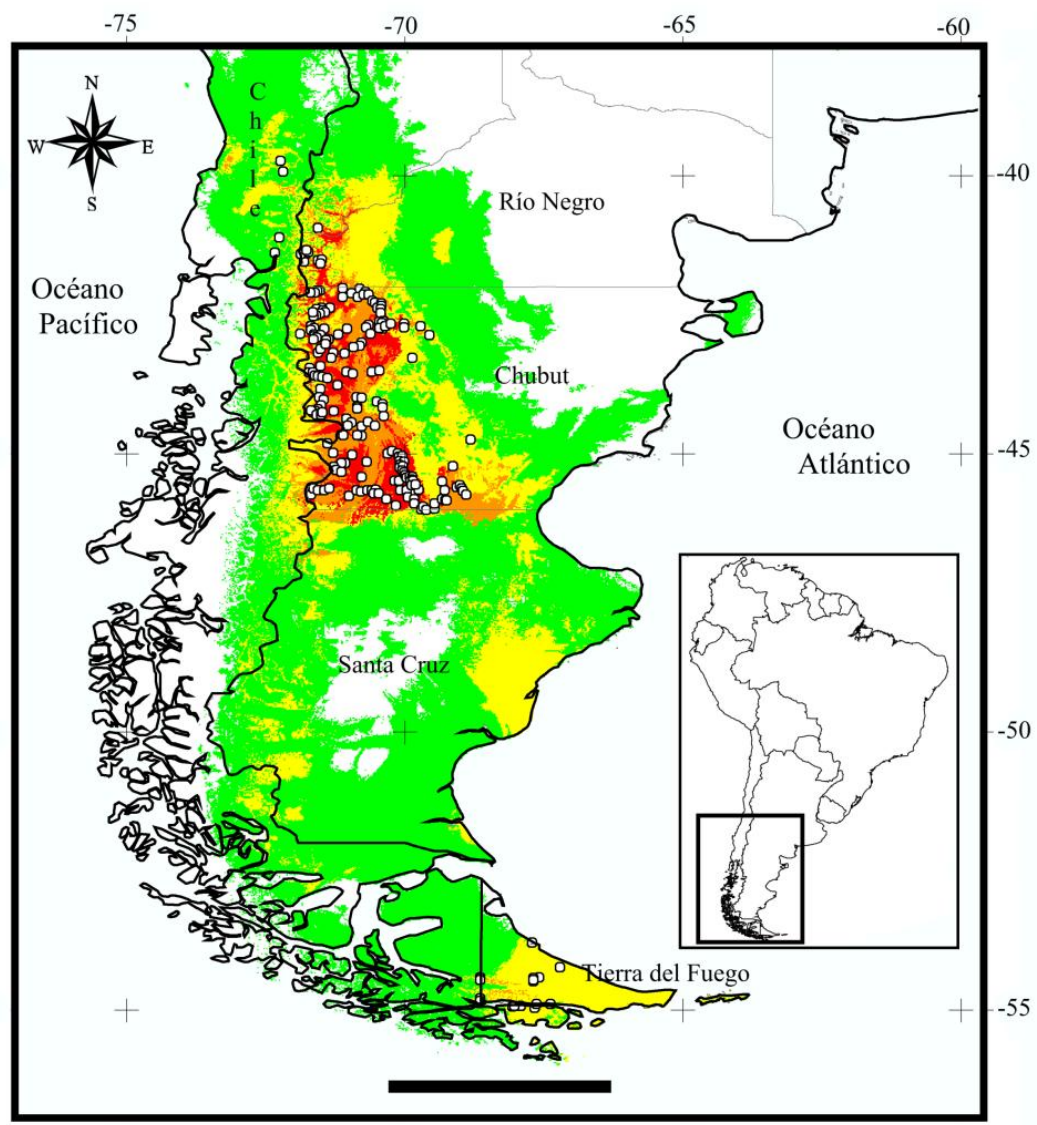


Figura 31. Diagramas representando las localidades de muestreo/captura de Conepatus chinga y su relación con la altitud (A), temperatura media anual (B) y precipitación anual (C).
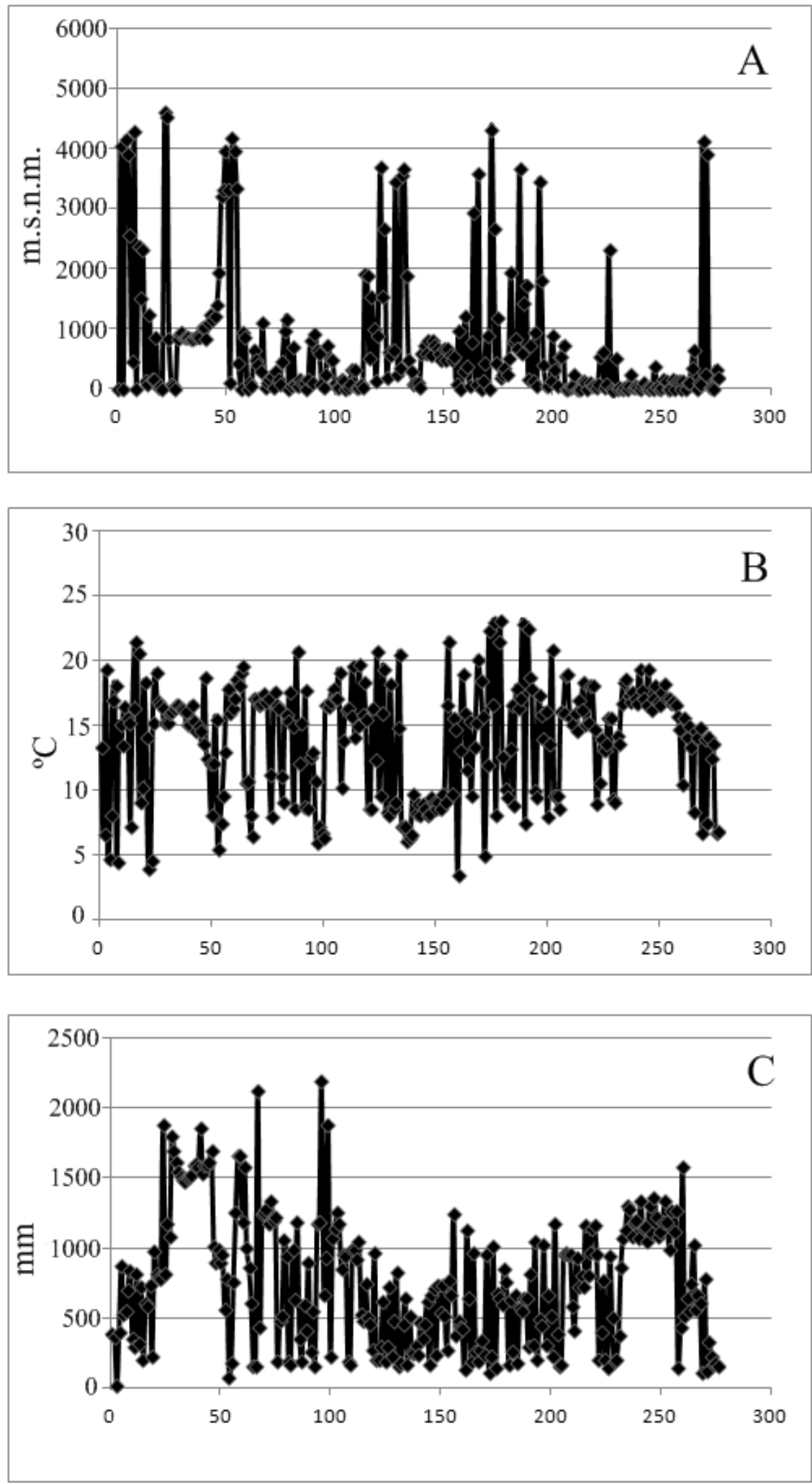
Figura 32. Modelos de distribución potencial para Conepatus chinga, utilizando localidades actuales (A, círculos blancos) y posteriores a 1950 (B, cuadrados blancos). Valores de probabilidad representados por los siguientes colores: 100-51 (rojo), 50-26 (naranja), 25-11 (amarillo), 10-2 (verde) y 1-0 (blanco). Escala (barra negra)=2000 Km. Véase sección 3.5.1.

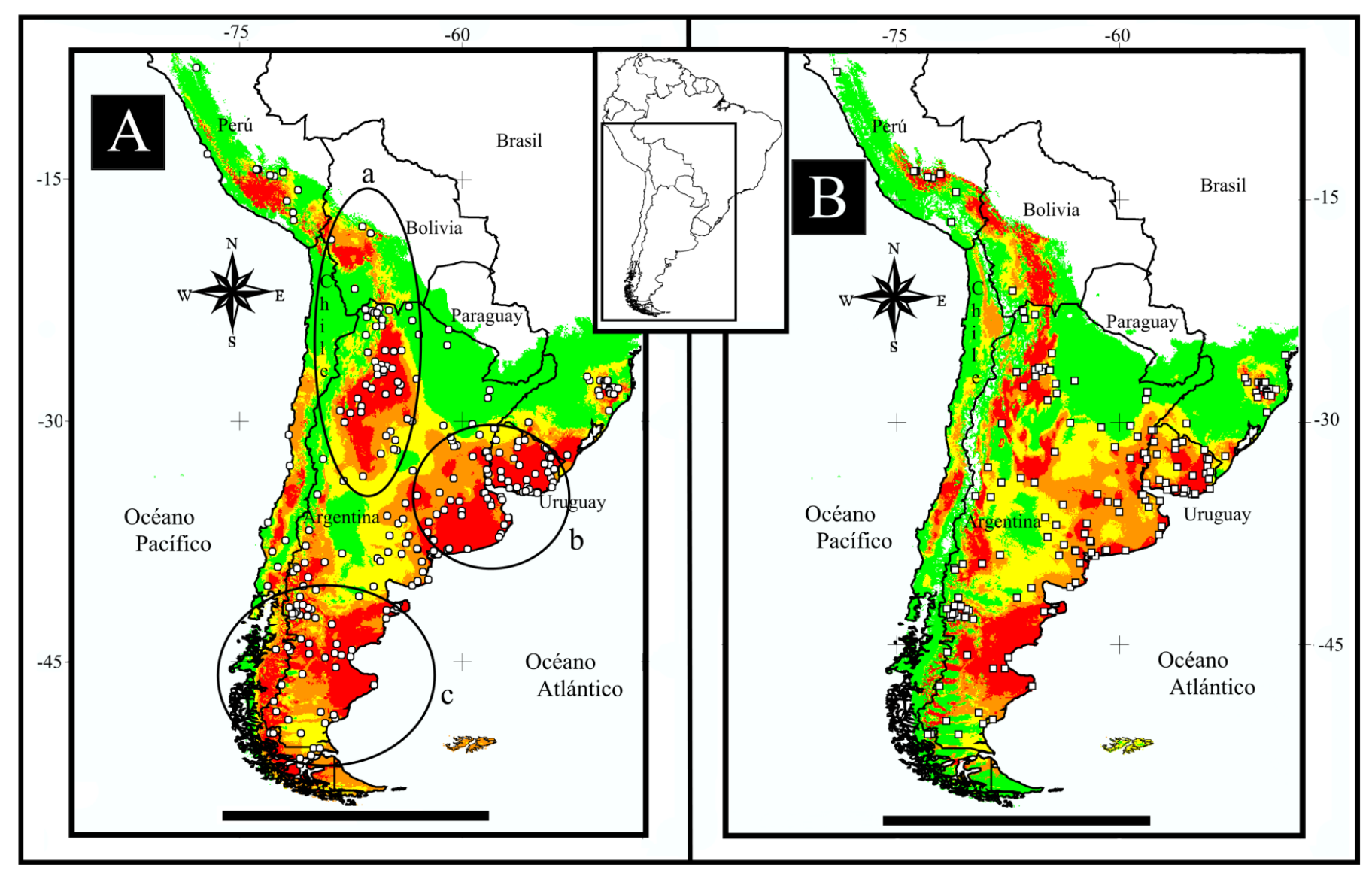


Figura 33. Mapa de riqueza específica de las especies estudiadas en el sur de América del Sur. La elipse "a" marca la zona de mayor riqueza. Cantidad de especies presentes: 5 especies (rojo), 4 especies (naranja), 3 especies (amarillo), 2 especies (verde oscuro), 1 especie (verde claro) y ausencia (blanco). Escala (barra negra) $=2000 \mathrm{Km}$.

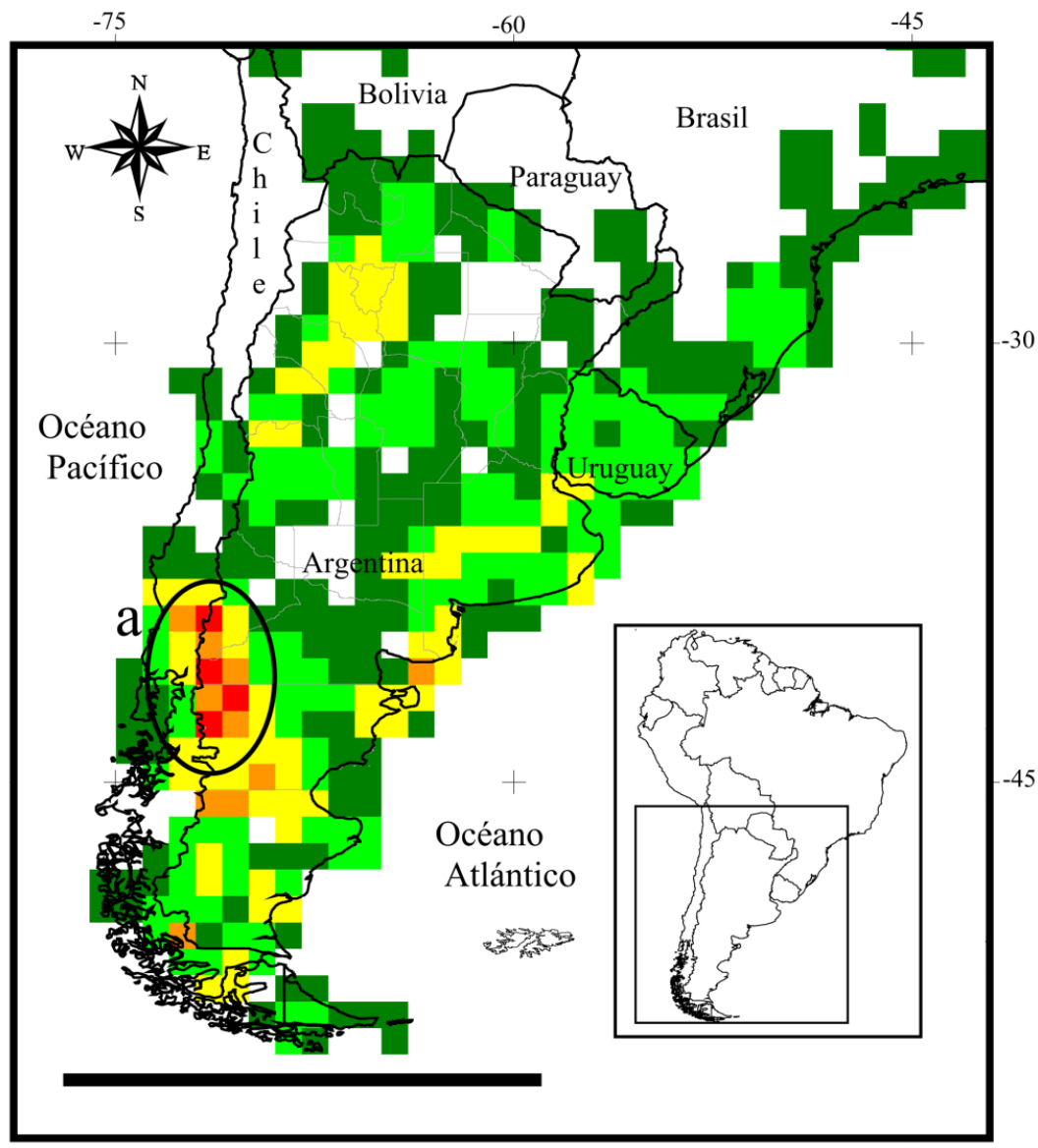


Figura 34. Diagrama de dispersión y grillas de deformación del CP1 y CP2, a partir del ACP de cráneo en vista ventral, para análisis de segregación trófica. Los símbolos se corresponden con los de la Figura 6: Cuadrados negros= Conepatus chinga; círculos azules $=$ Galictis cuja ; cruces negras $=$ Lontra provocax , triángulos verdes $=$ Lyncodon patagonicus; asteriscos rojos $=$ Neovison vison.

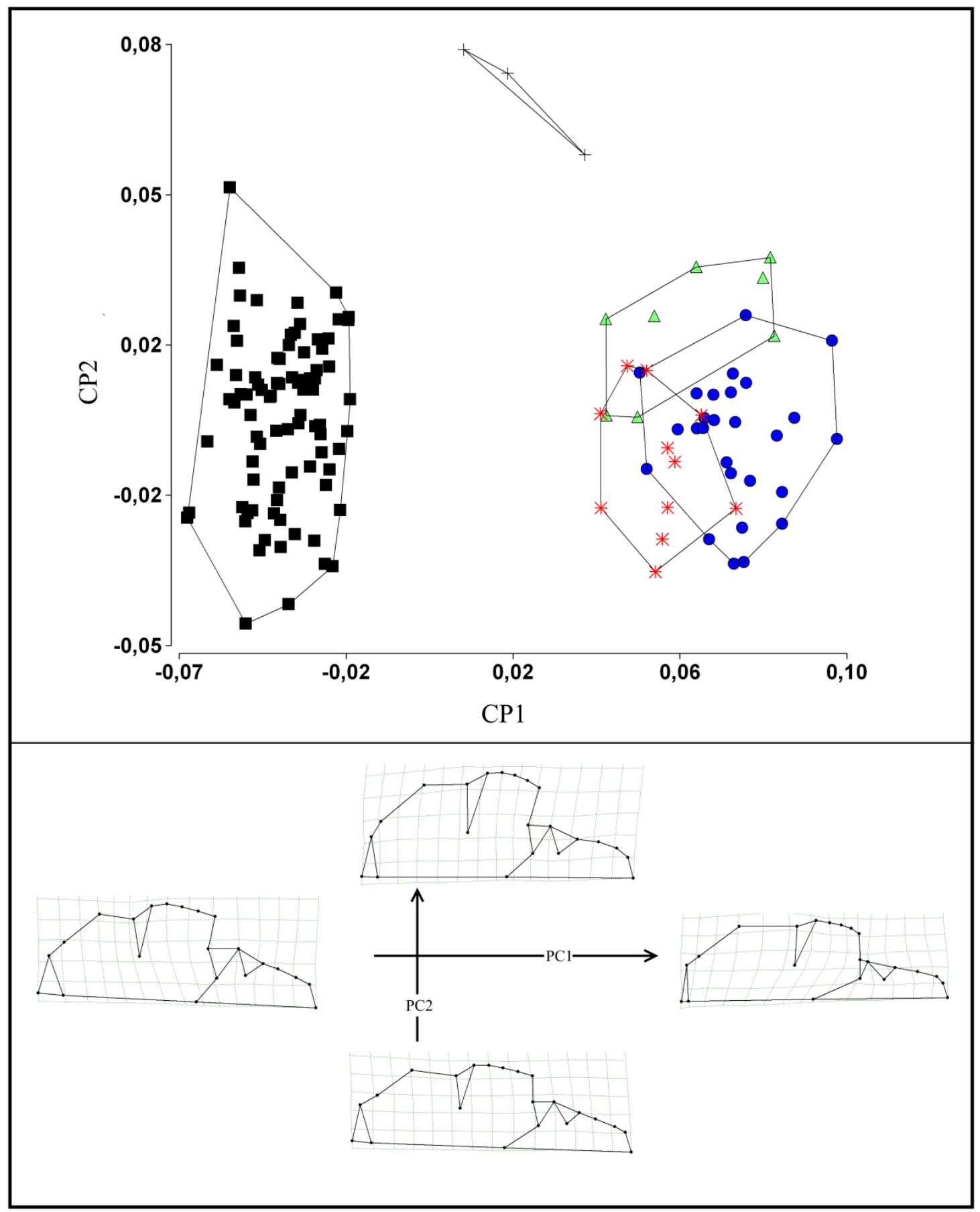


Figura 35. Diagrama de dispersión y grillas de deformación del CP1 y CP2, a partir del ACP de mandíbula en vista lateral, para análisis de segregación trófica. Los símbolos se corresponden con los de las Figuras 6 y 34: Cuadrados negros= Conepatus chinga; círculos azules = Galictis cuja ; cruces negras= Lontra provocax; triángulos verdes= Lyncodon patagonicus; asteriscos rojos $=$ Neovison vison.

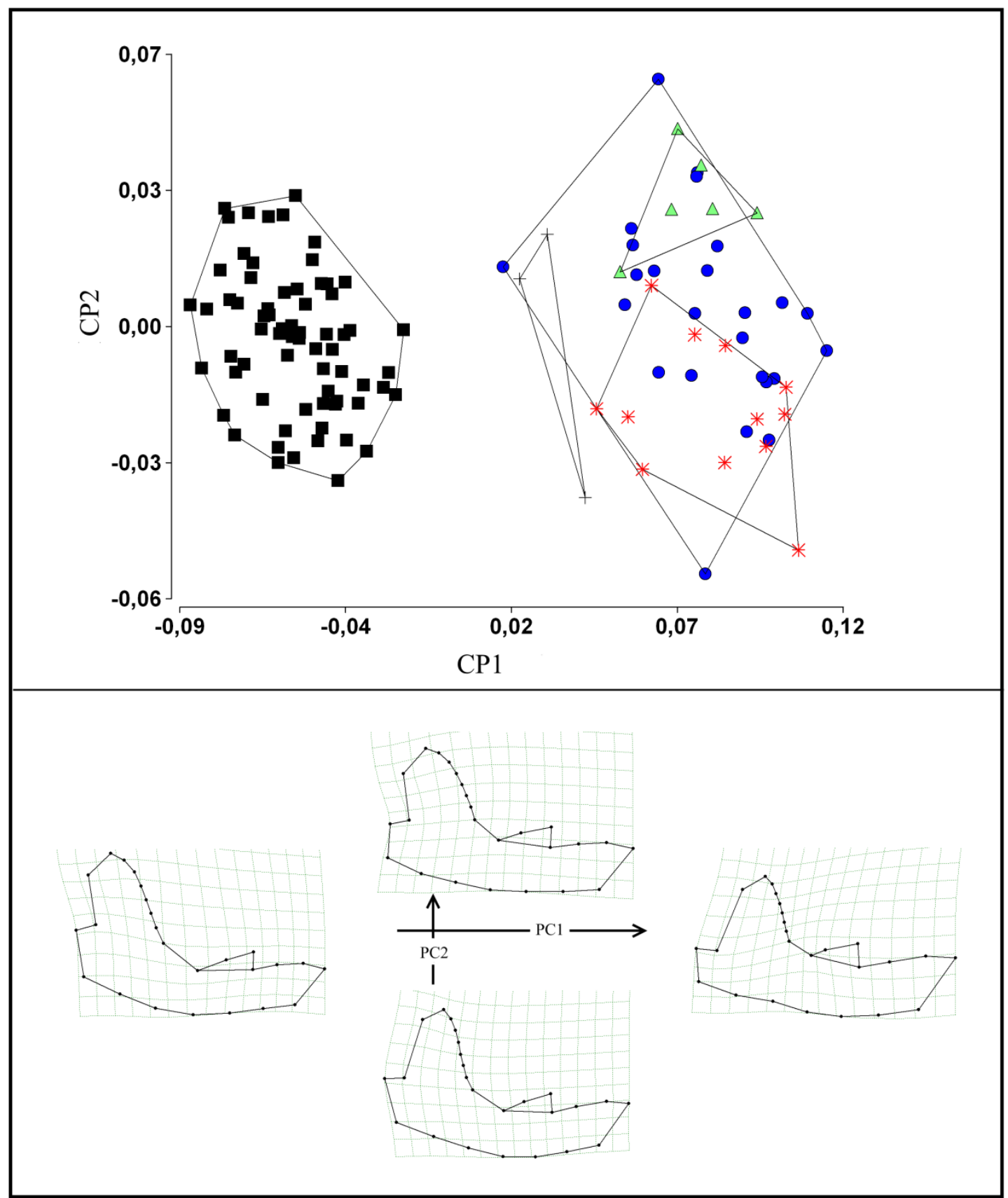


Figura 36. Diagrama de dispersión del CVA de cráneo y grillas de deformación.

Círculos negros $=C$. chinga , círculos azules $=G$. cuja , círculos verdes $=L$. patagonicus, círculos grises $=L$. provocax , círculos rojos $=N$. vison . Las elipses representan probabilidad de 0.9 de pertenencia a un grupo.

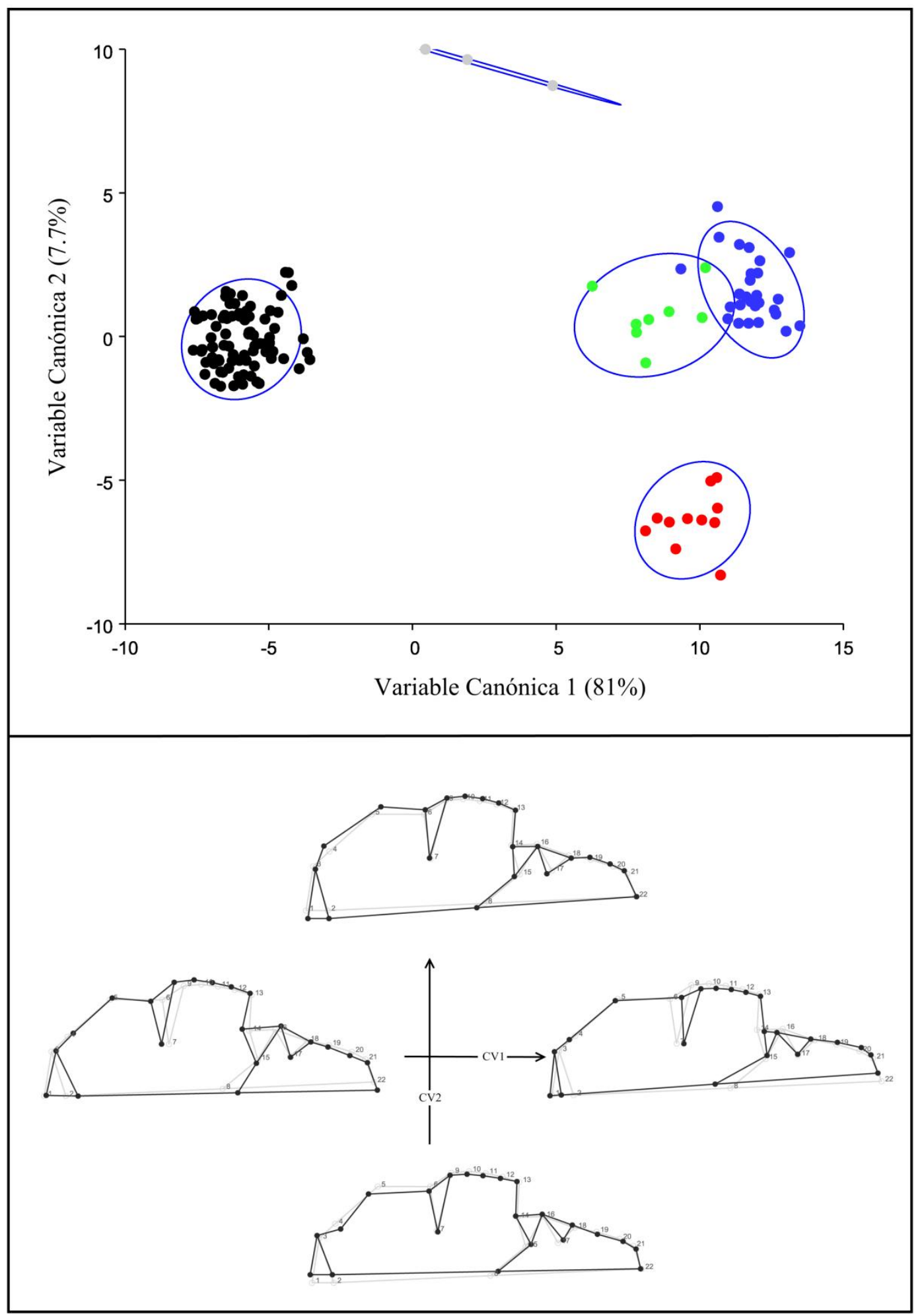


Figura 37. Diagrama de dispersión del CVA de mandíbula y grillas de deformación.

Círculos negros $=C$. chinga , círculos azules $=G$. cuja , círculos verdes $=L$. patagonicus, círculos grises $=L$. provocax , círculos rojos $=N$. vison . Las elipses representan probabilidad de 0.9 de pertenencia a un grupo.

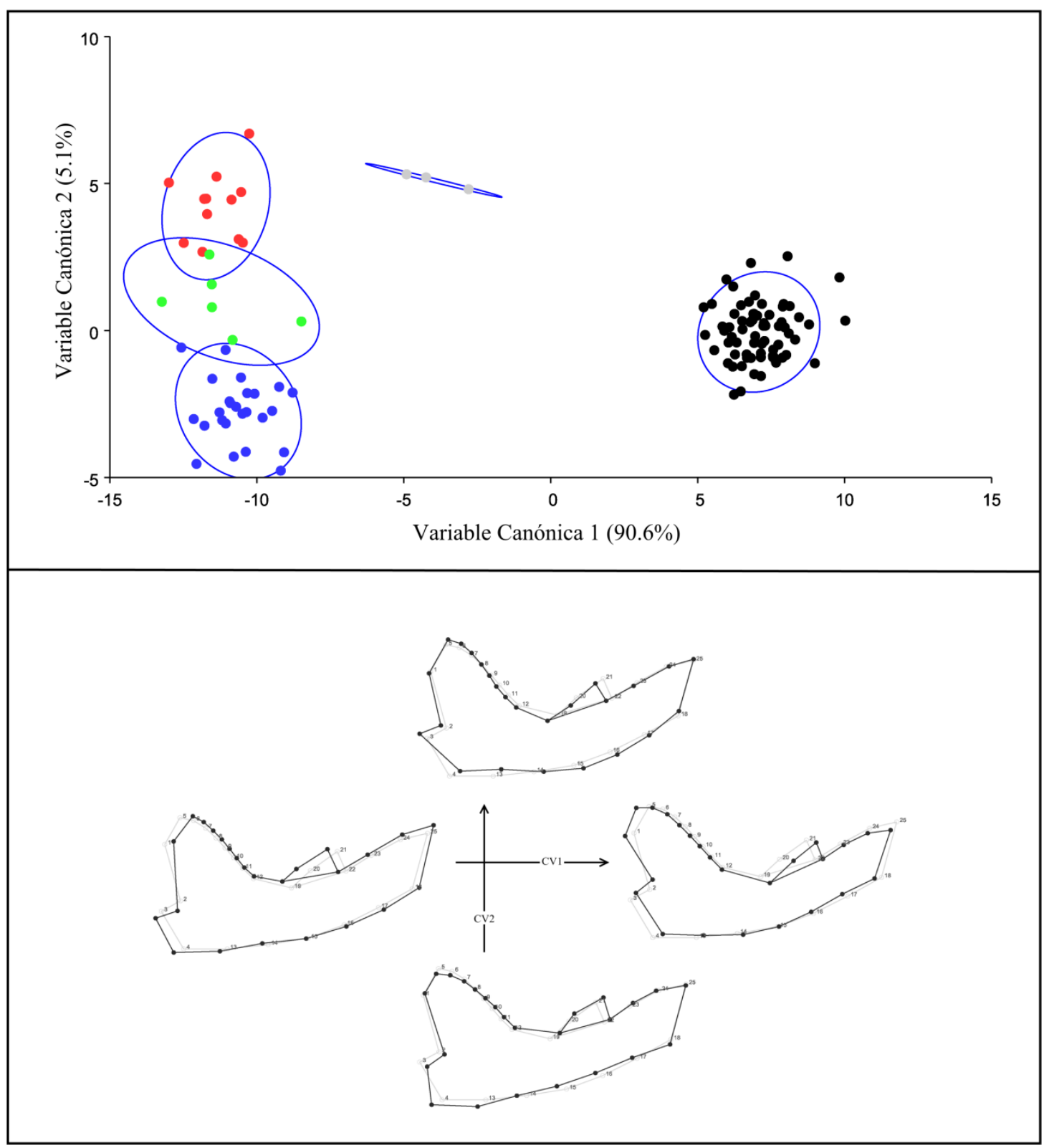


Figura 38. Diagrama de cajas de tamaño de centroide de todas las especies. El cuadrado negro dentro de cada caja representa la media y la línea horizontal la mediana. Se presentan además los cuartiles de 0,$05 ; 0 ; 25 ; 0,75$ y 0,95 .

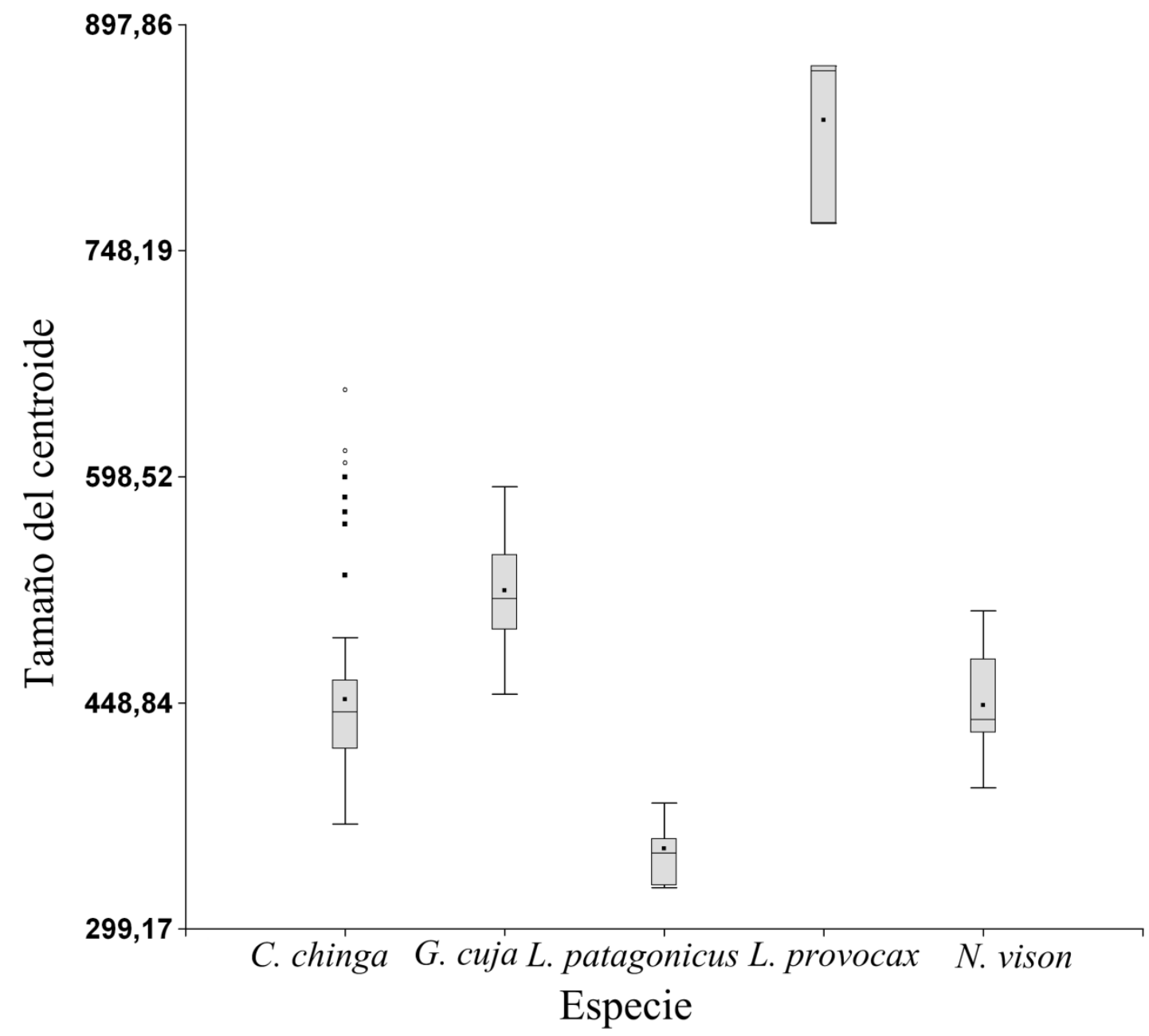


Figura 39. Diagrama de dispersión de CP1 y CP2 a partir del ACP con morfometría tradicional, para análisis de segregación trófica. Los símbolos se corresponden con los de las Figuras 6 y 34: Cuadrados negros= Conepatus chinga ; círculos azules $=$ Galictis cuja $;$ cruces negras $=$ Lontra provocax $;$ triángulos verdes= Lyncodon patagonicus; asteriscos rojos $=$ Neovison vison . Las líneas unen individuos conespecíficos.

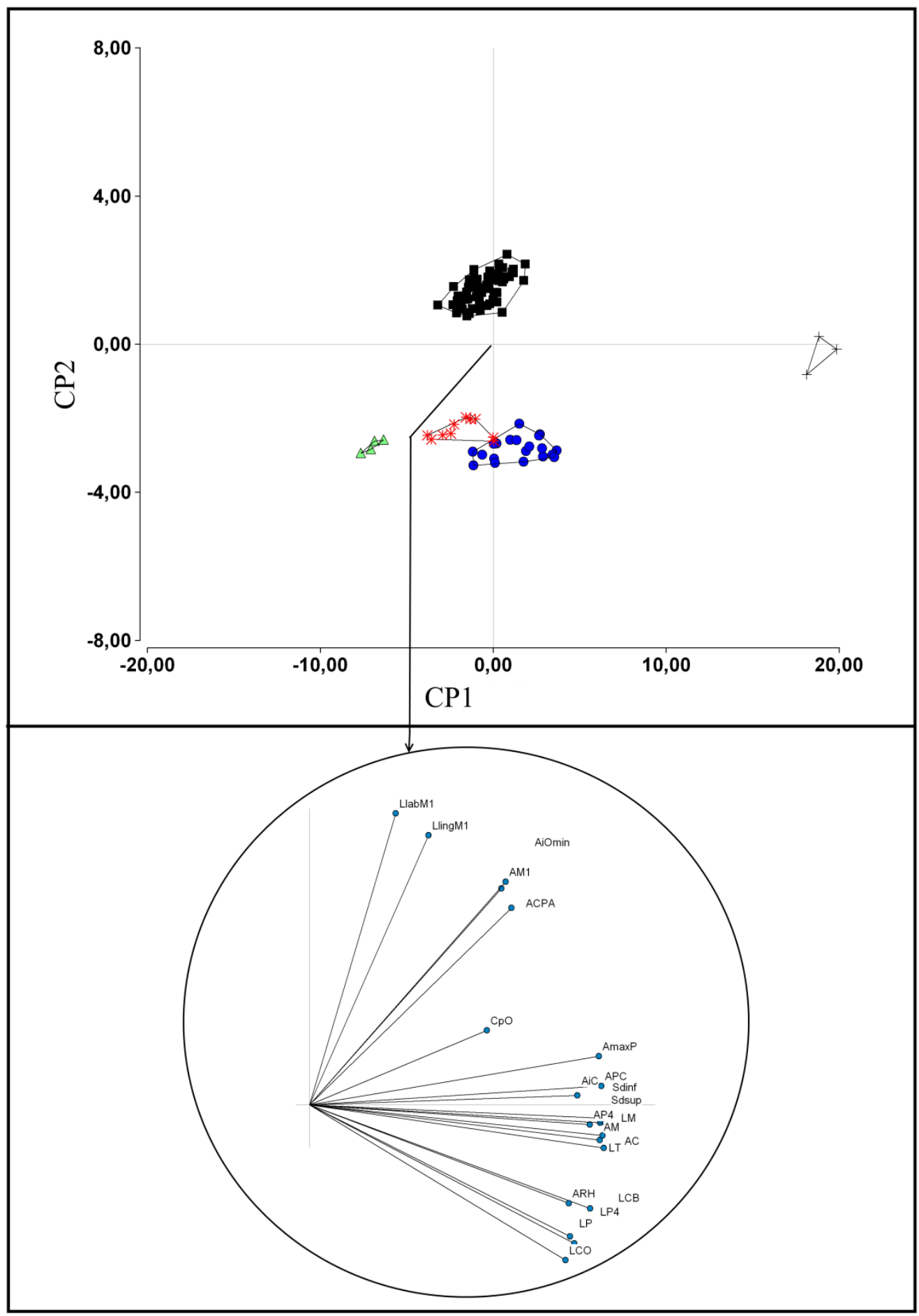


Figura 40. Diagrama de dispersión de CP1 y CP3 a partir del ACP con morfometría tradicional, para análisis de segregación trófica. Cuadrados negros= Conepatus chinga; círculos azules $=$ Galictis cuja $;$ cruces negras $=$ Lontra provocax , triángulos verdes $=$ Lyncodon patagonicus; asteriscos rojos= Neovison vison . Las líneas unen individuos conespecíficos.

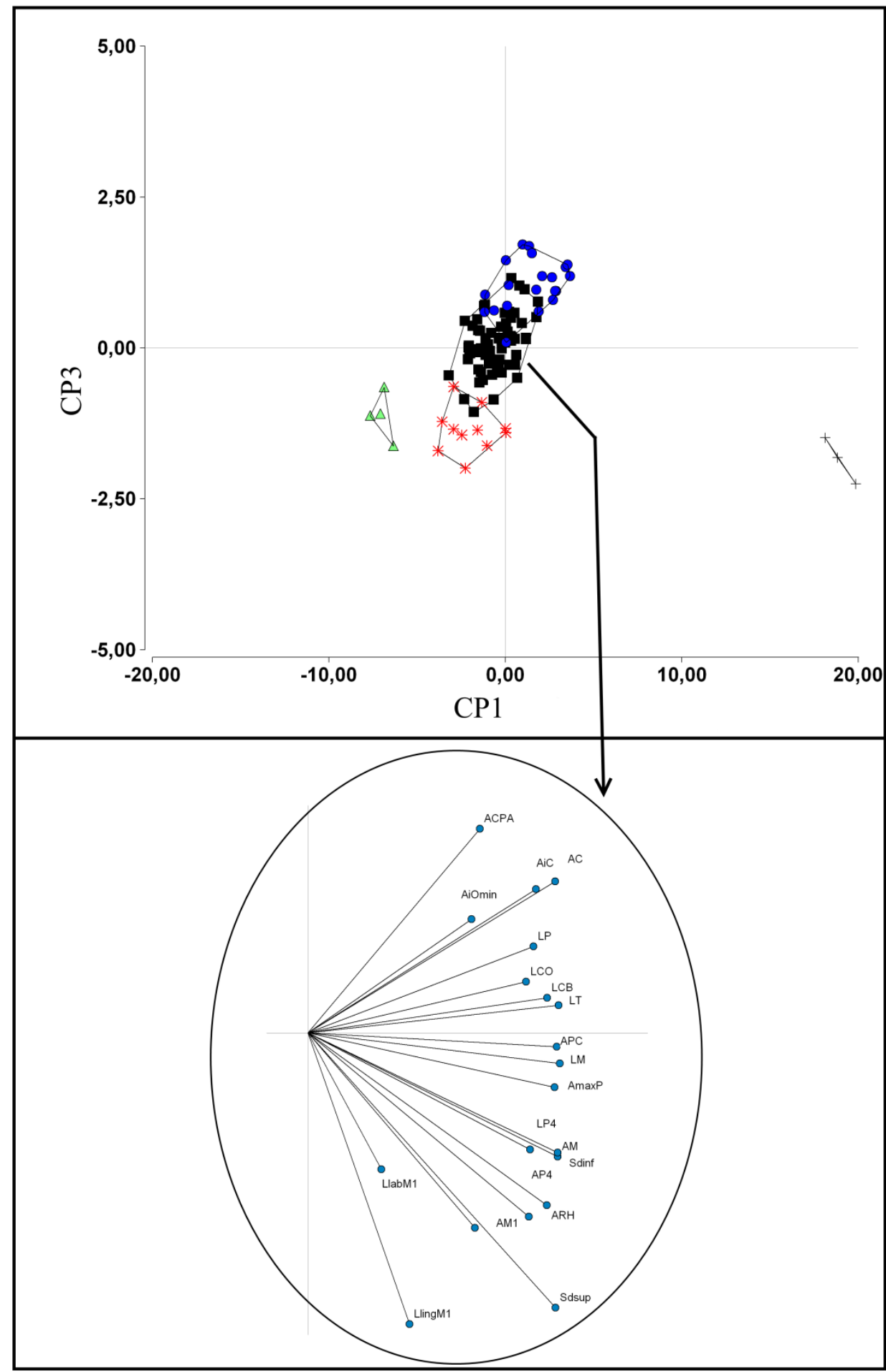


Figura 41. Diagrama de dispersión de CP2 y CP3 a partir de ACP con morfometría tradicional, para análisis de segregación trófica. Cuadrados negros= Conepatus chinga; círculos azules $=$ Galictis cuja $;$ cruces negras $=$ Lontra provocax , triángulos verdes $=$ Lyncodon patagonicus; asteriscos rojos= Neovison vison. Las líneas unen individuos conespecíficos.

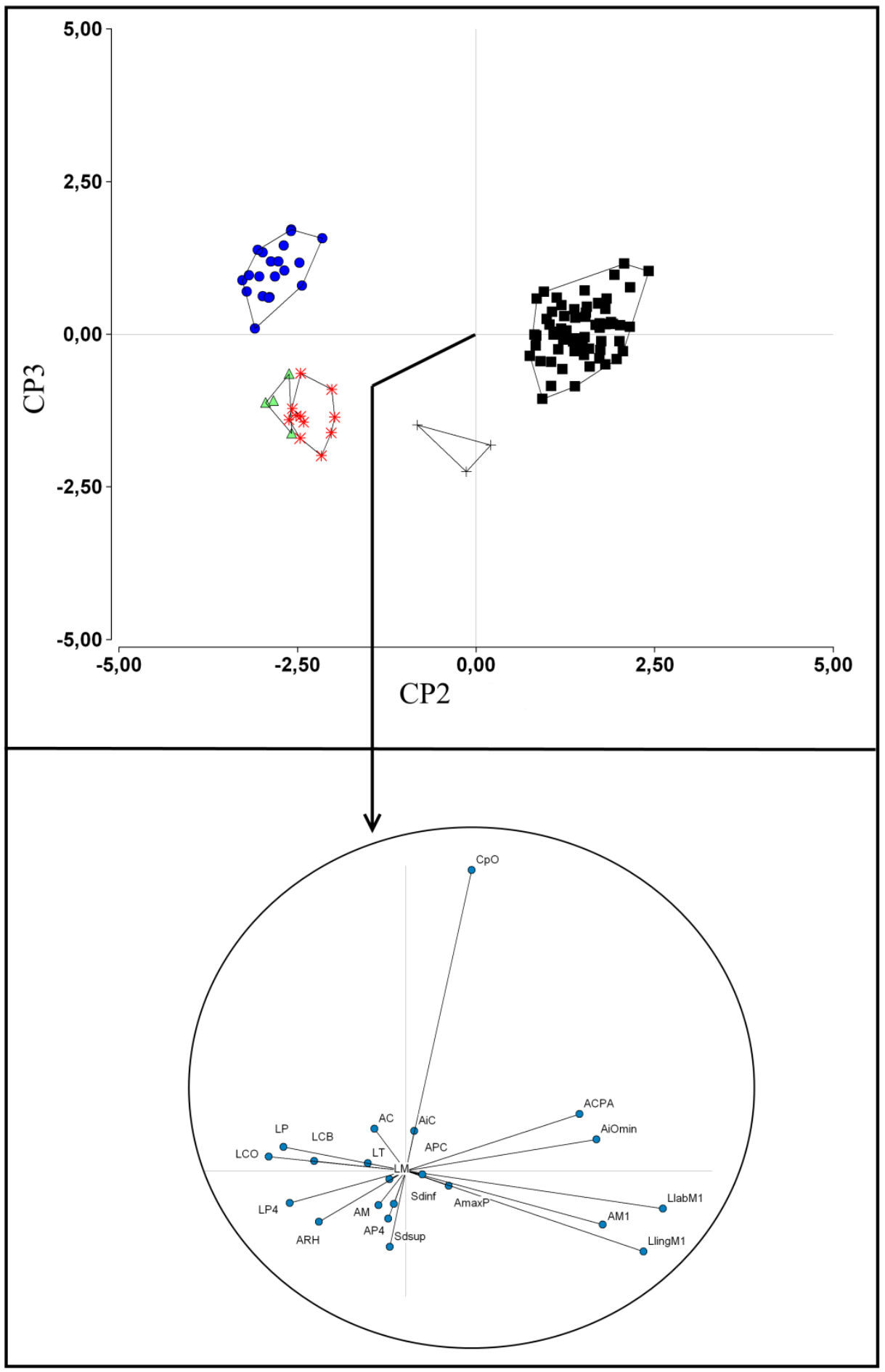


Figura 42. Diagrama de dispersión del CCA1 y CCA2 del CCA de cráneo ventral.

Cuadrados negros $=$ Conepatus chinga $;$ círculos azules $=$ Galictis cuja $;$ cruces negras $=$ Lontra provocax ; triángulos verdes $=$ Lyncodon patagonicus $;$ asteriscos rojos $=$ Neovison vison.

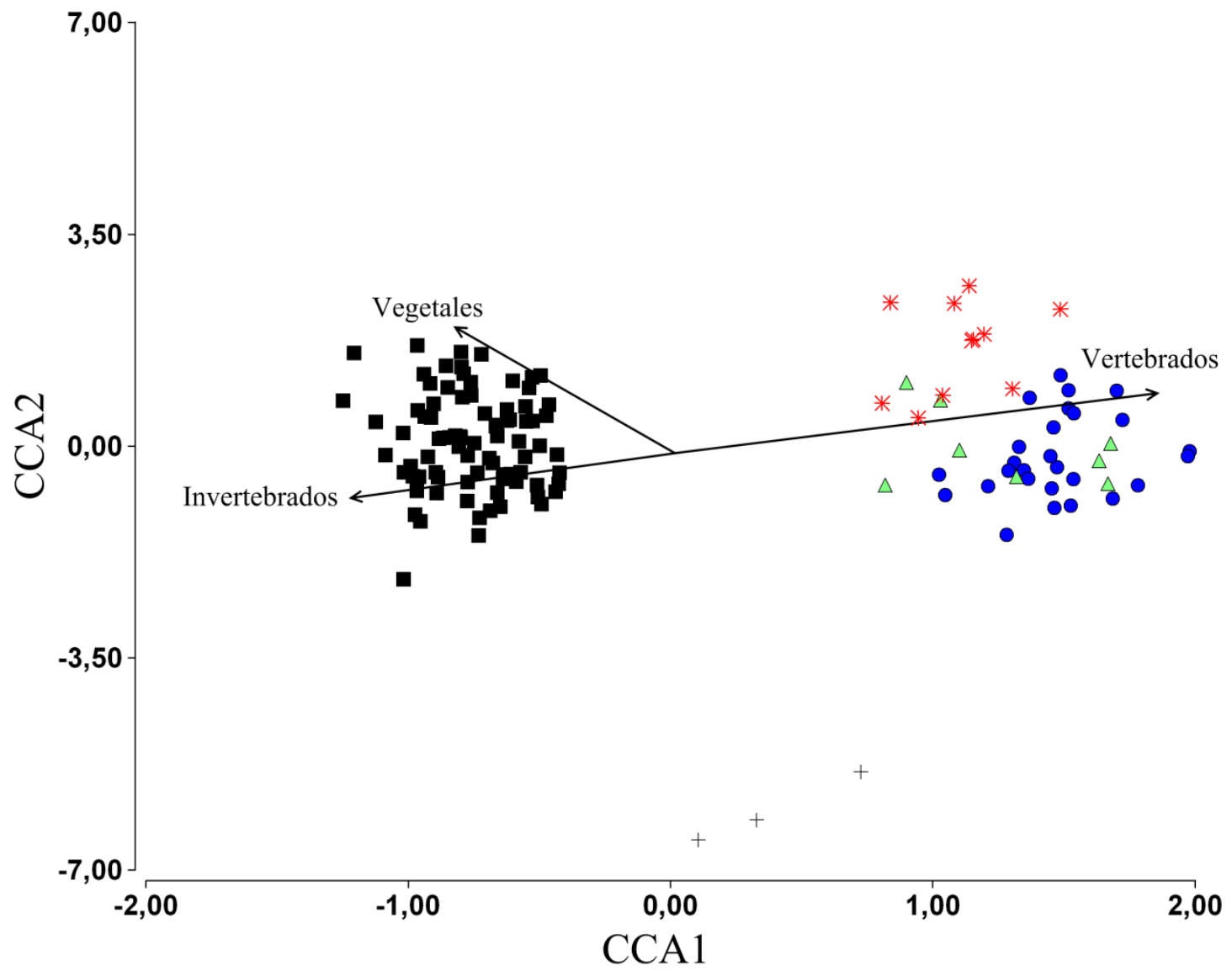


Figura 43. Diagrama de dispersión del CCA1 y CCA2 del CCA de mandíbula lateral. Cuadrados negros $=$ Conepatus chinga ;írculos azules $=$ Galictis cuja $;$ cruces negras $=$ Lontra provocax; triángulos verdes $=$ Lyncodon patagonicus; asteriscos rojos $=$ Neovison vison.

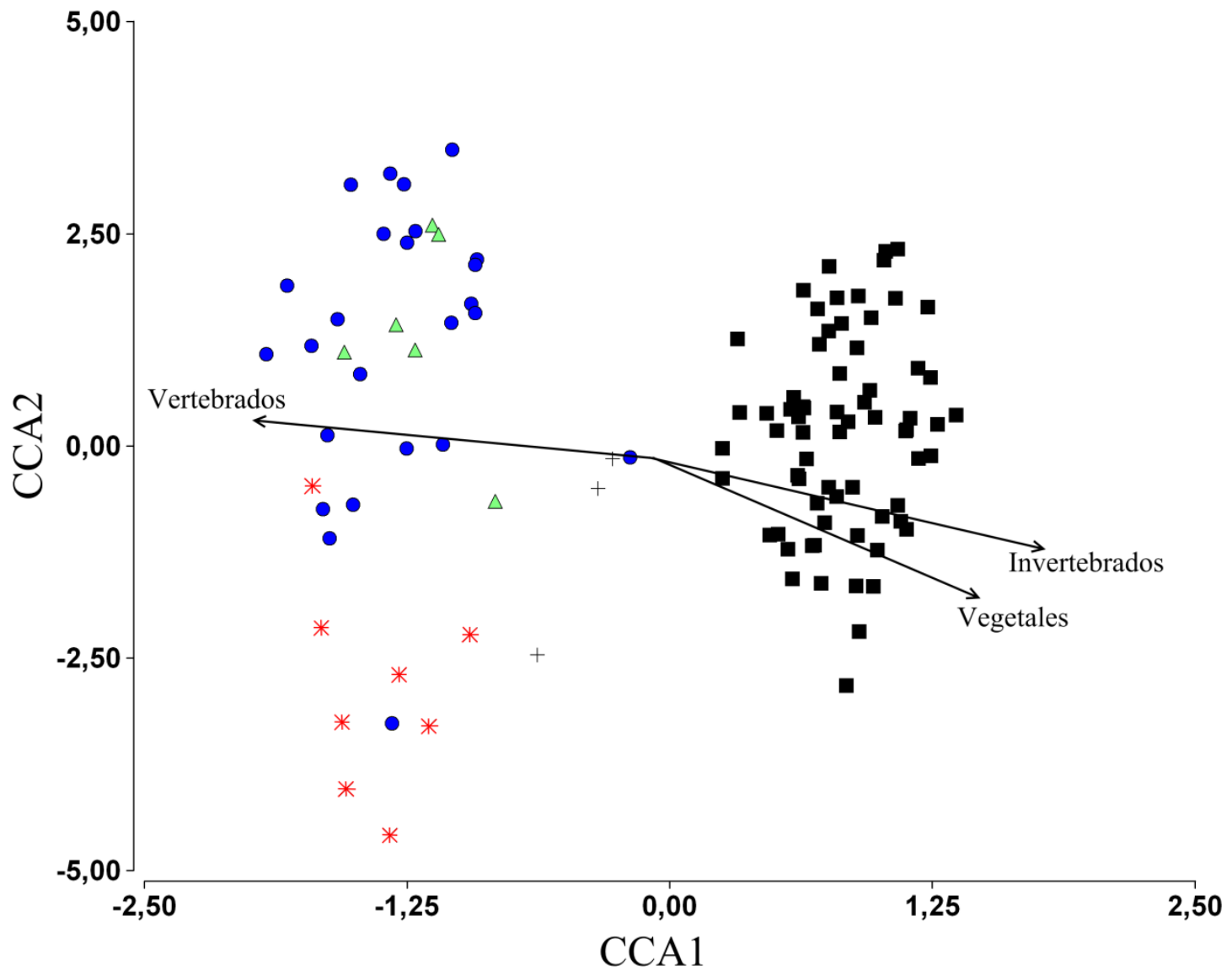


Figura 44. Diagrama de cajas del tamaño de centroide de G. cuja, clasificado según ecorregiones de Olson et al. (2001): Esp= Espinal, $\mathrm{ChS}=$ Chaco Seco, PH= Pampas Húmedas, $\mathrm{ChH}=$ Chaco Húmedo, EP= Estepa Patagónica, $\mathrm{MB}=$ Monte Bajo, $\mathrm{YA}=$ Yungas Andinas, $\mathrm{BV}=$ Bosques Valdivianos, PFS= Sabana Inundada del Paraná, US= Sabana Uruguaya.

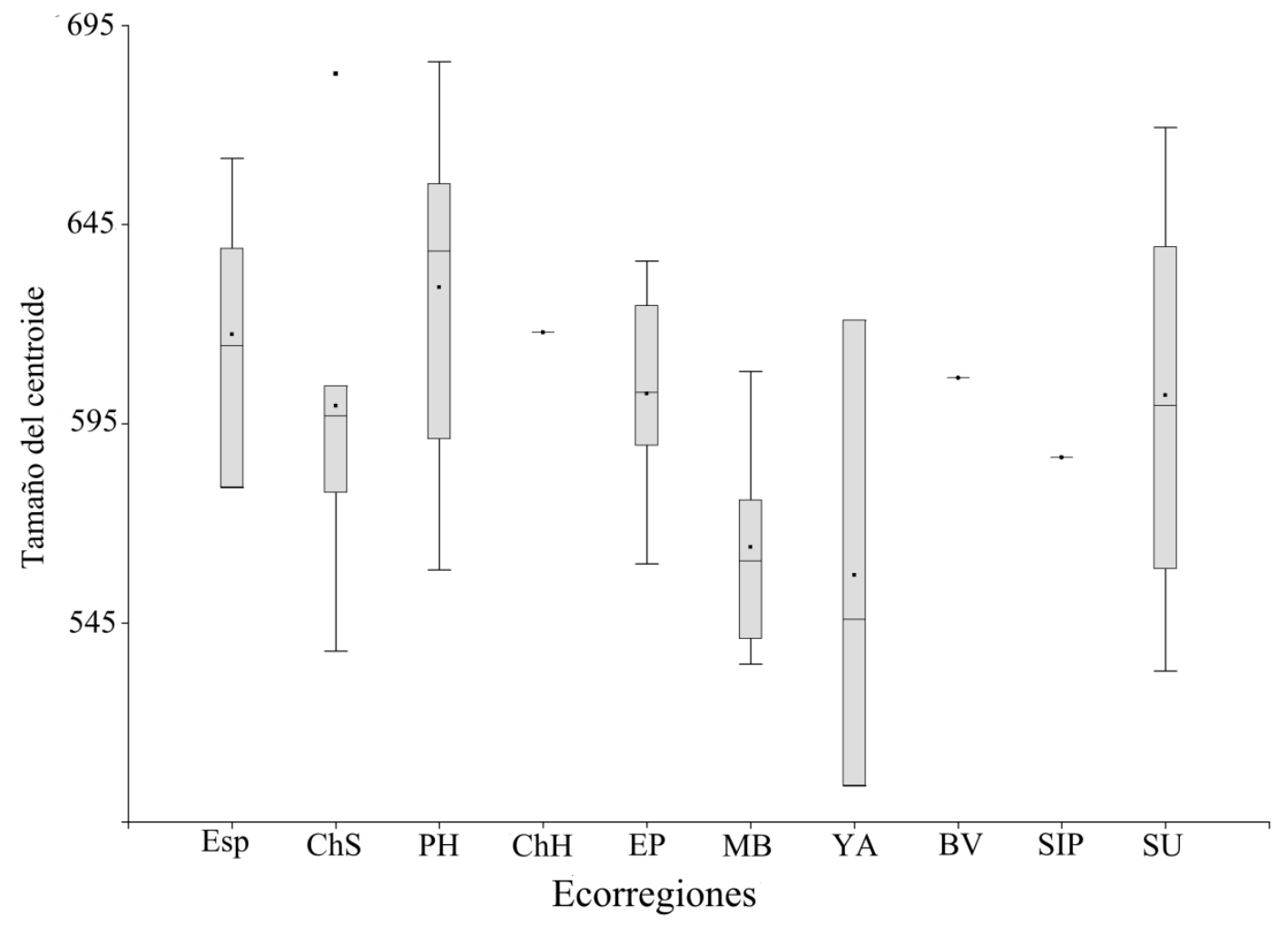


Figura 45. Diagrama de dispersión de los puntajes de regresión entre forma y tamaño de cráneo ventral para G. cuja, y grillas de deformación.
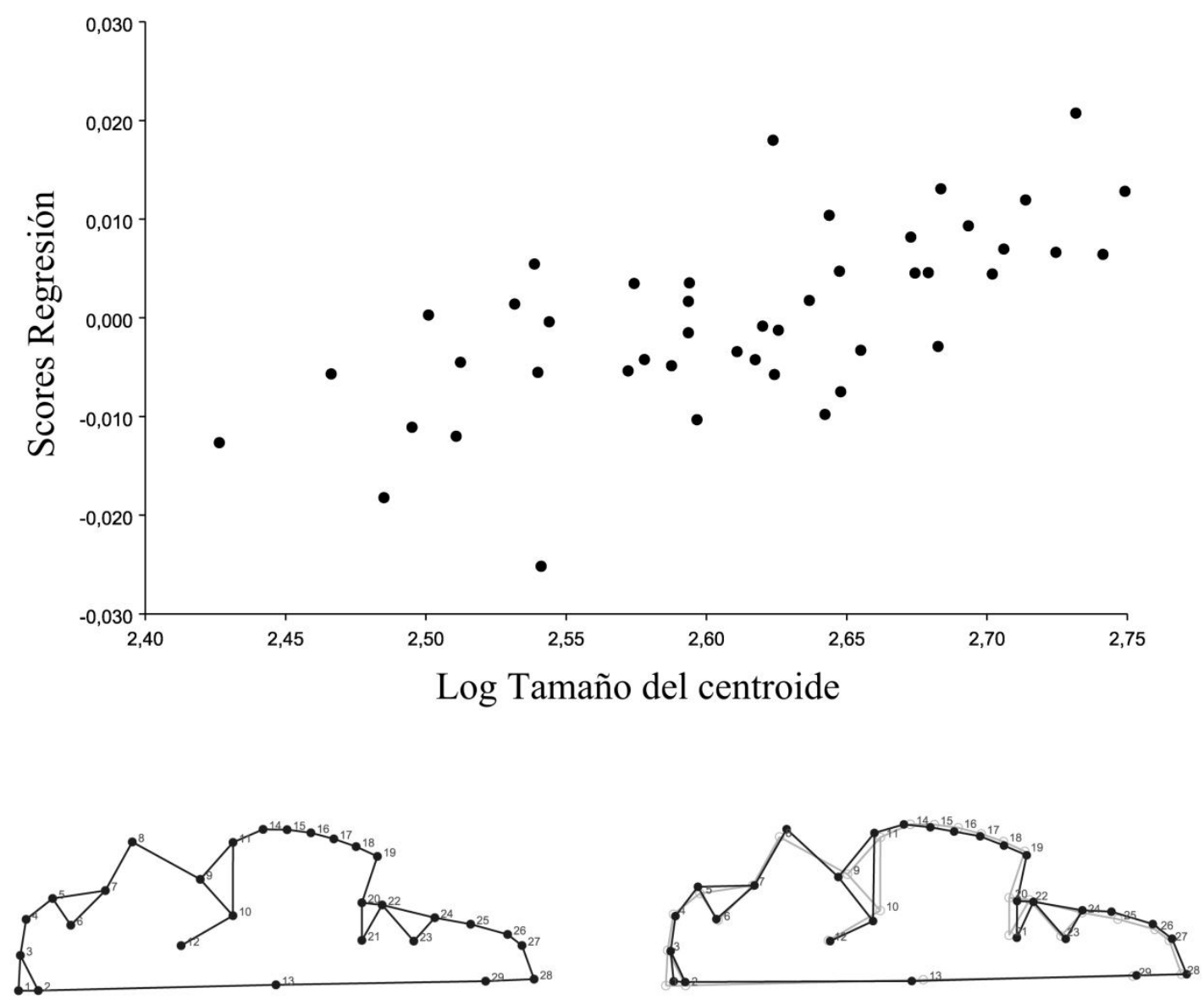

Tamaño del centroide 
Figura 46. Diagrama de dispersión de los puntajes de regresión entre forma y tamaño de mandíbula lateral para G. cuja, y grillas de deformación.
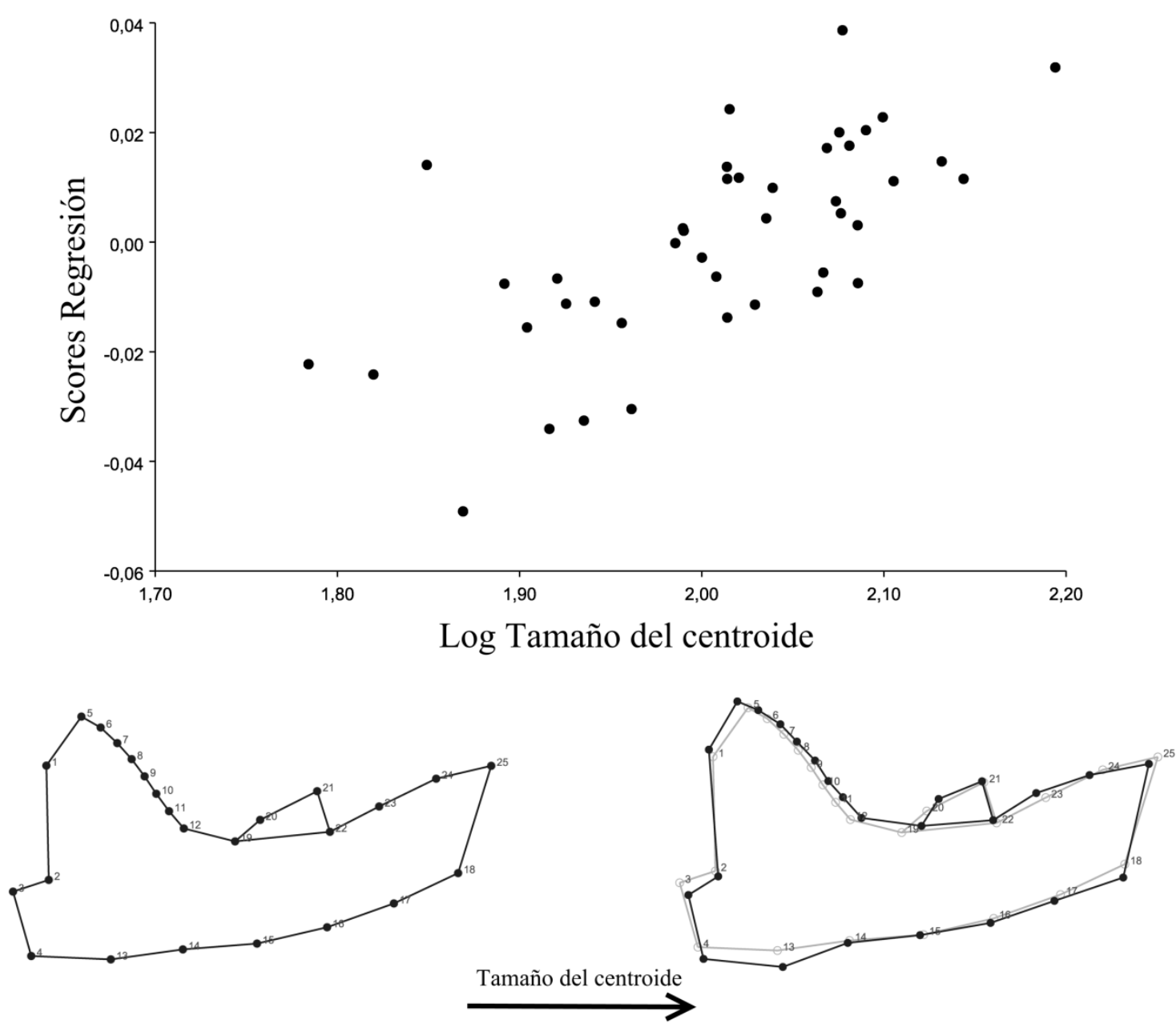
Figura 47. Diagrama de cajas del tamaño de centroide de $C$. chinga, clasificado según ecorregiones de Olson et al. (2001): $\mathrm{PC}=$ Puna Central, $\mathrm{ChS}=$ Chaco Seco, Esp= Espinal, MA= Monte Alto, $\mathrm{ChH}=$ Chaco Húmedo, $\mathrm{PH}=$ Pampas Húmedas, $\mathrm{MB}=$ Monte Bajo, EP= Estepa Patagónica, EA= Estepa Andina, $\mathrm{YA}=$ Yungas Andinas, $\mathrm{SU}=$ Sabana Uruguaya.

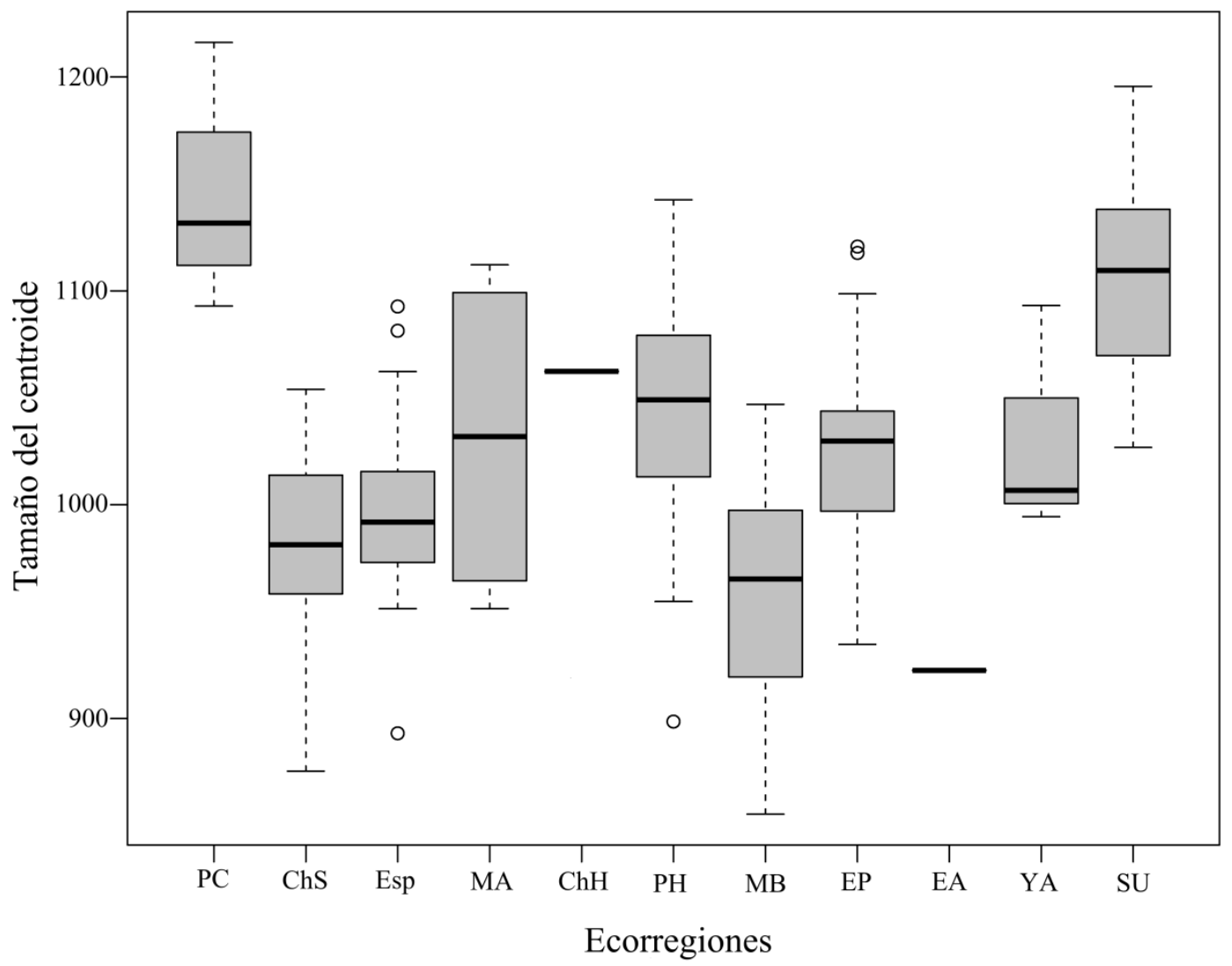


Figura 48. Correlograma de regresión múltiple de cráneo ventral de $C$. chinga y variables ambientales seleccionadas. En gris oscuro los valores de Cs, y en gris claro los residuales del modelo.

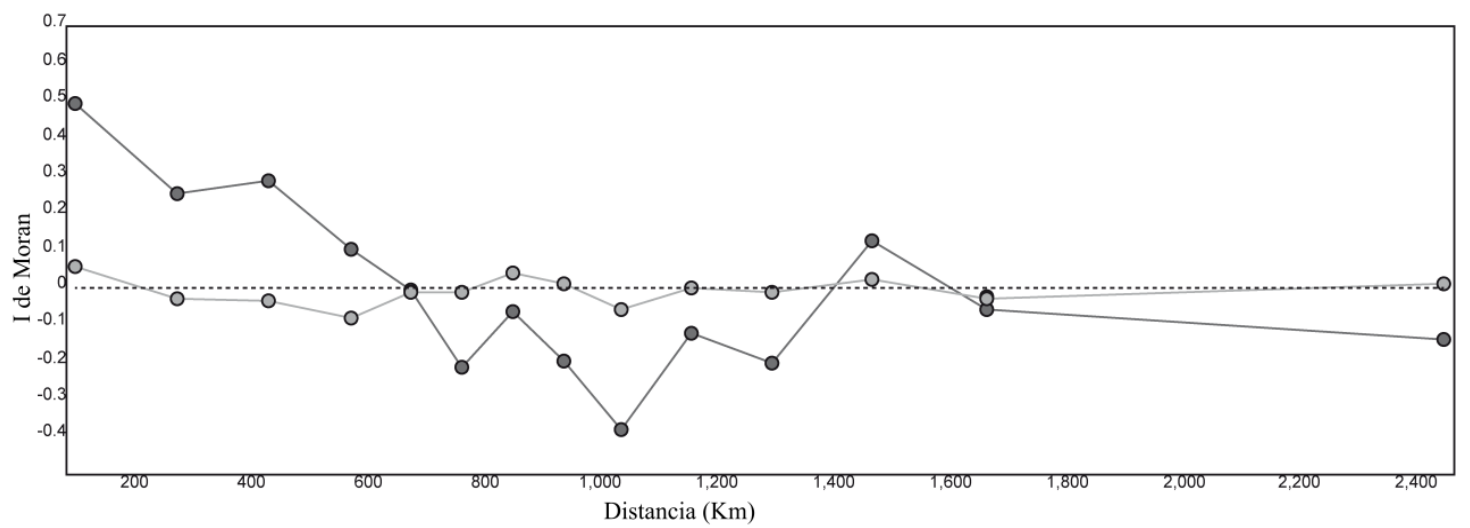


Figura 49. Valores estimados de tamaño (tamaño del centroide) para cráneos (A) y mandíbulas (B) de C. chinga a partir del análisis de regresión múltiple. Se presenta un incremento en tamaño desde los círculos pequeños y blancos, hacia los grises, y luego hacia los negros y más grandes. Escala (barra negra) $=2000 \mathrm{Km}$.

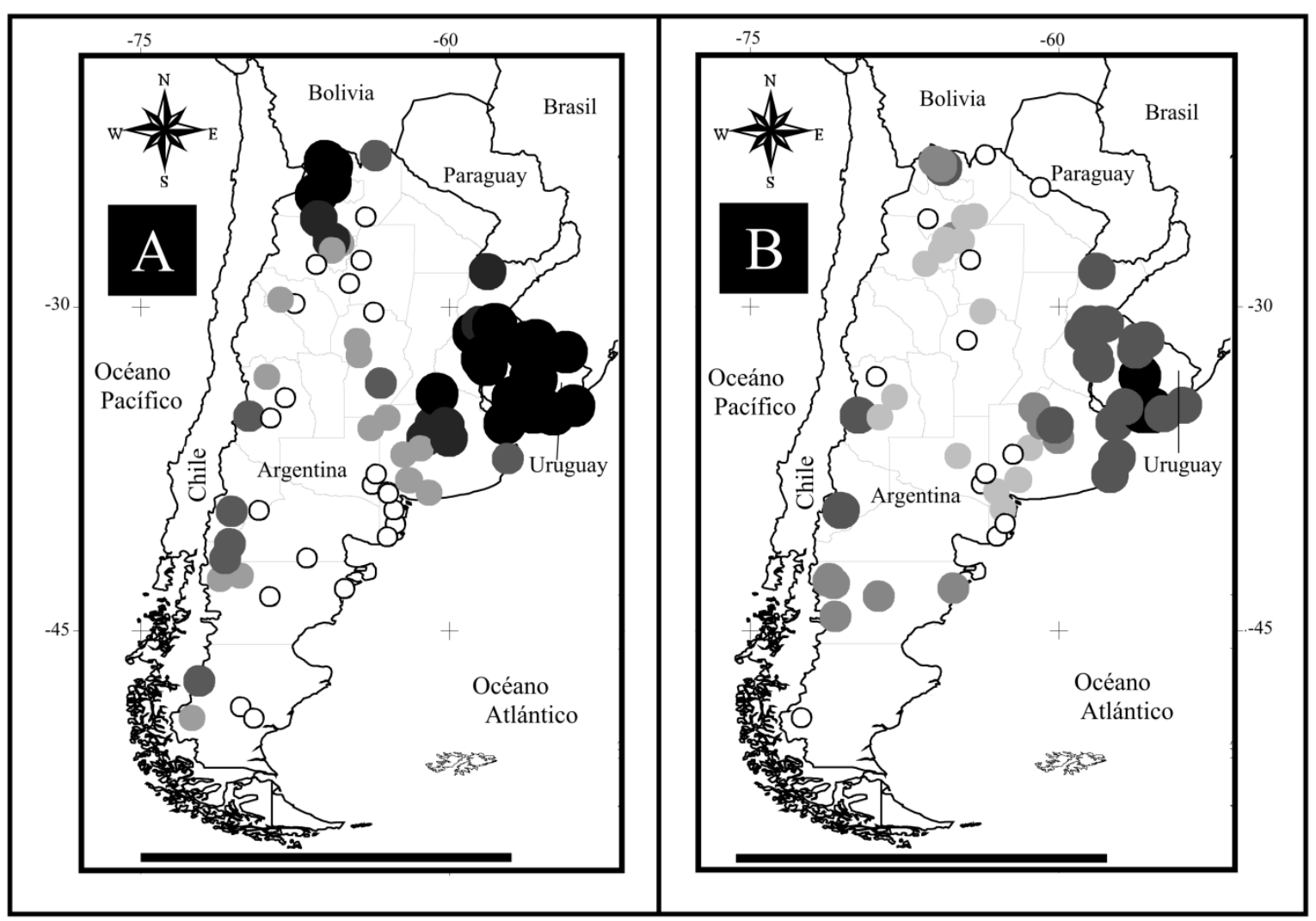


Figura 50. Regresión multivariada entre forma de cráneo y variables predictoras seleccionadas para $C$. chinga. Se presentan además, las grillas de deformación para NPP y PET (véase sección 4.4.2.2.a)
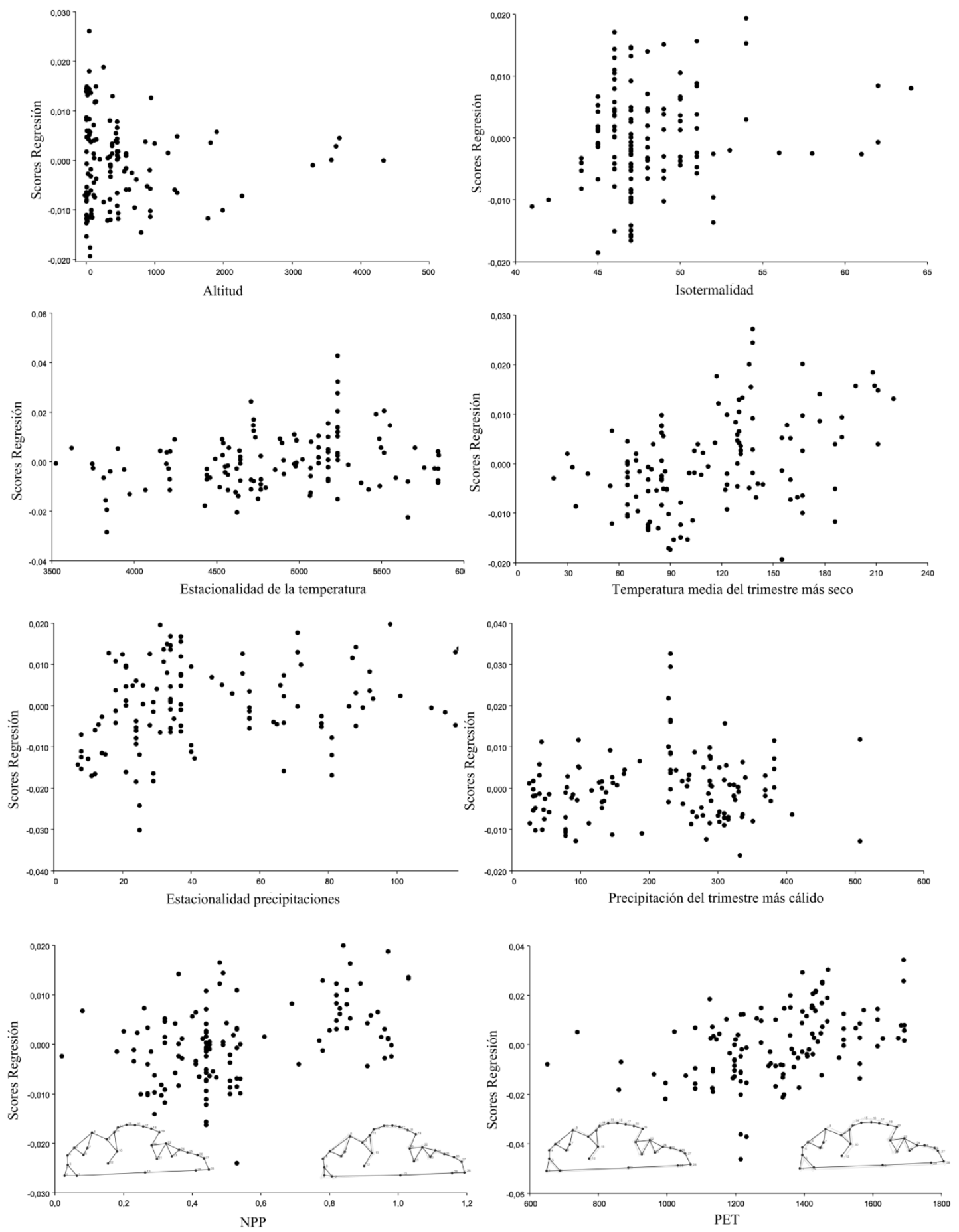
Figura 51. Regresión multivariada entre forma de mandíbulas y variables predictoras seleccionadas para $C$. chinga. Se presentan además, las grillas de deformación para NPP y PET (véase sección 4.4.2.2.a)
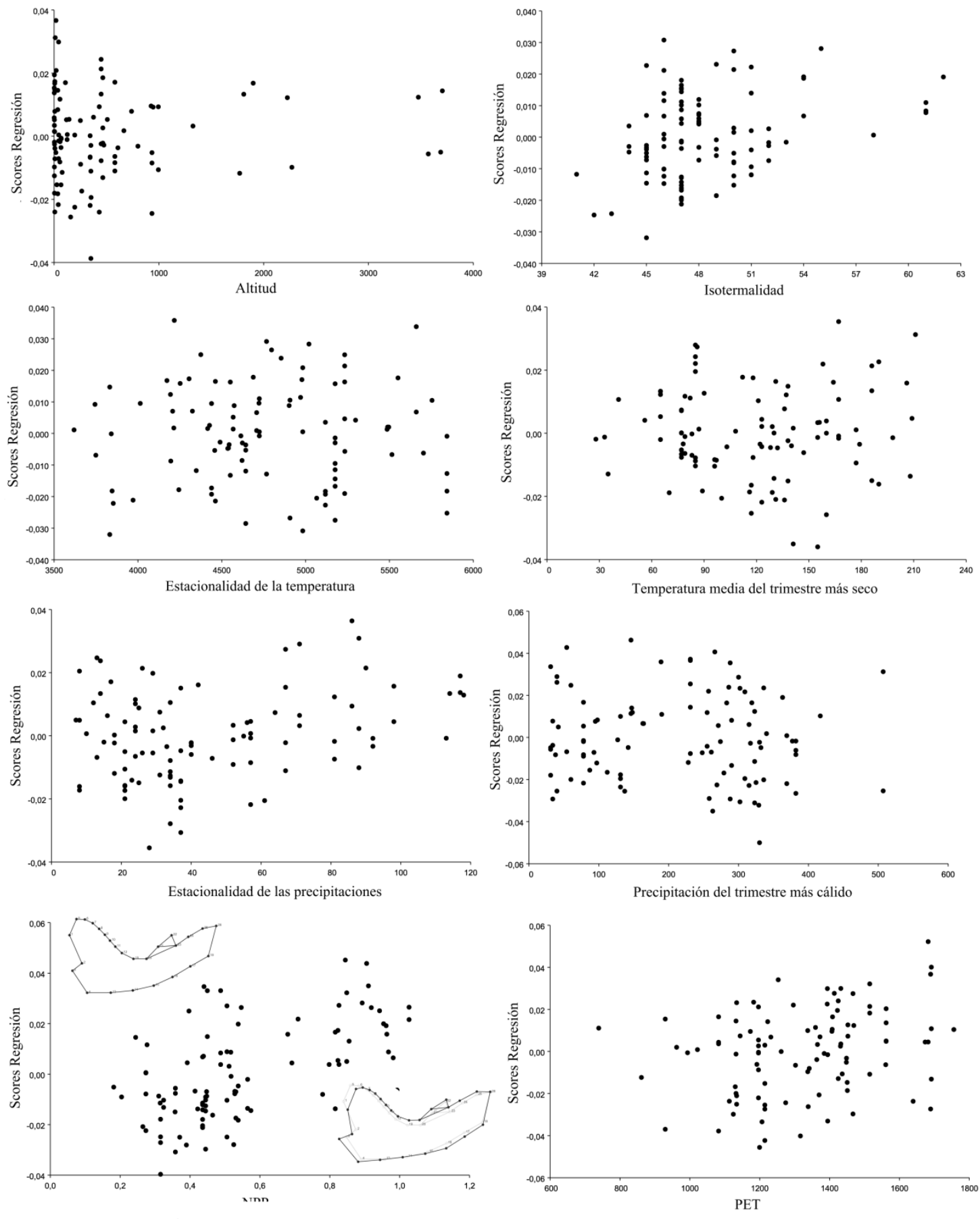
Figura 52. Diagrama de cajas de longitud cóndilobasal de L. patagonicus, clasificado según ecorregiones de Olson et al. (2001): EP= Estepa Patagónica, Esp: Espinal, YA= Yungas Andinas, $\mathrm{ChS}=$ Chaco Seco, $\mathrm{MB}=$ Monte Bajo.

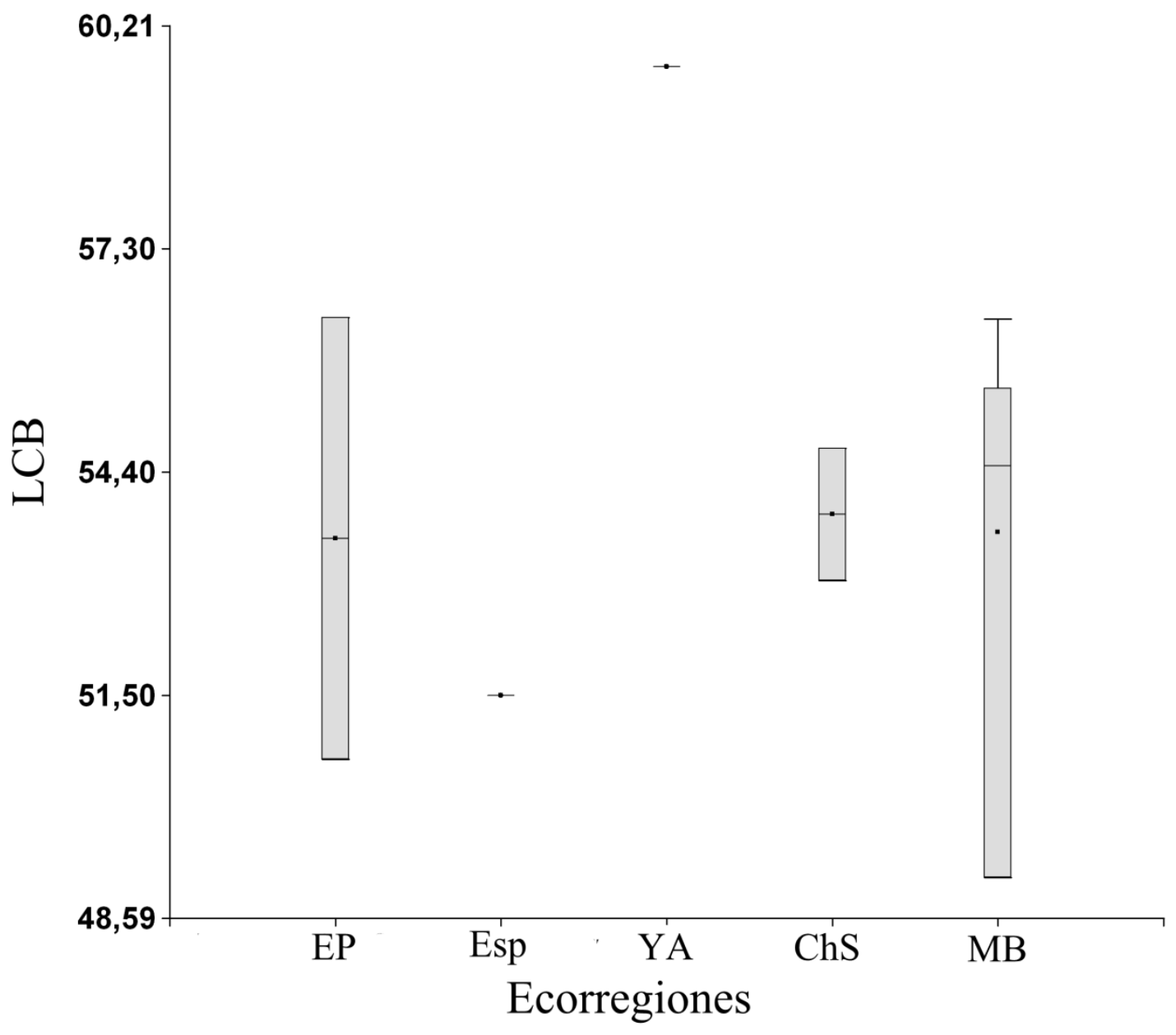


Tablas 
Tabla 1. Landmarks y semilandmarks utilizados en análisis de morfometría geométrica

para estudiar la taxonomía de las especies de Conepatus. Véase sección 3.4.

Cráneo vista ventral

\begin{tabular}{|c|c|}
\hline 1 & Borde posterior del foramen magnum \\
\hline 2 & Borde anterior del foramen magnum \\
\hline 3 & Borde interno del cóndilo occipital \\
\hline 4 & Borde externo del cóndilo occipital \\
\hline 5 & Proceso paracondilar \\
\hline 6 & Foramen lacerado posterior \\
\hline 7 & Foramen yugular \\
\hline 8 & Punto más externo del proceso mastoideo \\
\hline 9 & Abertura del meato auditivo externo \\
\hline 10 & Punto más interno de la fosa glenoidea \\
\hline 11 & Punto más externo de la fosa glenoidea \\
\hline 12 & Foramen lacerado medio \\
\hline 13 & Torus palatino \\
\hline $14-19$ & Semilandmarks sobre el arco cigomático \\
\hline 20 & Punto más posterior del M1 \\
\hline 21 & Punto más lingual del M1 \\
\hline 22 & Punto más anterior del M1 \\
\hline 23 & Punto más lingual del Pm4 \\
\hline 24 & Punto más anterior del Pm4 \\
\hline 25 & Punto más posterior del $\mathrm{C}$ \\
\hline 26 & Punto más anterior del C \\
\hline 27 & Punto más externo de la serie incisiva \\
\hline 28 & Punto medio de la serie incisiva \\
\hline 29 & Foramen palatino medio anterior \\
\hline \multicolumn{2}{|r|}{ Cráneo vista dorsal } \\
\hline 1 & Inion \\
\hline 2 & Punto más externo del proceso mastoide \\
\hline $3-7$ & Semilandmarks del arco cigomático \\
\hline 8 & Punto más anterior del borde órbito-facial \\
\hline 9 & Punto más anterior y externo del premaxilar \\
\hline 10 & Punto más anterior de la unión de los premaxilares \\
\hline 11 & Punto terminal de la sutura entre los nasales \\
\hline
\end{tabular}

\begin{tabular}{ll}
\hline & \multicolumn{1}{c}{ Cráneo vista lateral } \\
\hline 1 & Inion \\
2 & Borde más posterior de la cresta lamboidea \\
3 & Proceso paracondilar \\
4 & Meato auditivo externo \\
5 & Punto más anterior del yugal, en contacto con premaxilar \\
6 & Punto más posterior del M1
\end{tabular}




\section{Continuación Tabla 1}

7

8

9

10

11

$12-16$
Punto más anterior del M1

Punto más anterior del Pm4

Punto más anterior del Pm3

Punto más anterior del C

Punto más posterior del $\mathrm{C}$

Semilandmarks de la bóveda craneana
1

2

3

4

5-12

$13-18$

19

20

21

22

23

24

25

26

\begin{tabular}{|c|c|}
\hline & Mandíbula vista superior \\
\hline 1 & Punto más interno del cóndilo mandibular \\
\hline 2 & Punto más externo del cóndilo mandibular \\
\hline 3 & Punto más posterior del m2 \\
\hline 4 & Punto más anterior del m2 \\
\hline 5 & Entocónido del m1 \\
\hline 6 & Hipocónido del m1 \\
\hline 7 & Metacónido del m1 \\
\hline 8 & Protocónido del m1 \\
\hline 9 & Paracónido del m1 \\
\hline 10 & Punto más posterior del pm3 \\
\hline 11 & Punto más anterior del pm3 \\
\hline 12 & Punto más anterior del c \\
\hline 13 & Punto más posterior del c \\
\hline
\end{tabular}

Ápice del proceso coronoide

Punto más bajo del arco formado por procesos coronoides y mandibular

Punto más posterior del cóndilo mandibular

Punto más posterior del proceso angular

Semilandmarks sobre la cara anterior del proceso coronoide

Semilandmarks sobre el borde inferior del dentario

Punto más posterior del $\mathrm{m} 2$

Punto más anterior del $\mathrm{m} 2$

Surco entre talónido y trigónido del m1

Punto más anterior del trigónido del m1 (sobre el paracónido)

Punto más posterior del Pm4

Punto más anterior del Pm4

Punto más posterior del c

Punto más anterior del c

\section{Mandíbula vista superior}

Mandíbula vista lateral 
Tabla 2. Localidades de registro de Galictis cuja, utilizadas en los análisis de distribución, sin duplicados. Las localidades correspondientes al trabajo de Bornholdt et al. (2013) poseen coordenadas geográficas, pero no presentan nombres de cada localidad ni fecha de colecta. En negrita se presentan las localidades de registro más extremas en su distribución. Ht=Holotipo. Ver acrónimos en Material y Métodos. Ecorregiones sensu Olson et al. (2001): $\mathrm{MCh}=$ Matorral Chileno; $\mathrm{BCSM}=$ Bosques Costeros Sierra del Mar; YB= Yungas Bolivianas; $\mathrm{PH}=\mathrm{Pampas}$ Húmedas; $\mathrm{MA}=\mathrm{Monte}$ Alto; $\mathrm{ChS}=\mathrm{Chaco}$ Seco; MB= Monte Bajo; SU= Sabana Uruguaya; EP= Estepa Patagónica; RCA= Restingas de las Costas Atlánticas; BAAP= Bosques Atlánticos del Alto Paraná; Ce= Cerrado; $\mathrm{Ca}=$ Caatinga; $\mathrm{BHA}=$ Bosques Húmedos de Araucaria; $\mathrm{BIB}=$ Bosques Interiores de Bahía; $\mathrm{BAM}=$ Bosques Atlánticos de Manglares; $\mathrm{BCP}=\mathrm{Bosques}$ Costeros de Pernambuco; $\mathrm{SMCP}=$ Sabana Montana de Campos Rupestres; $\mathrm{BMB}=$ Bosques Montanos Bolivianos; $\mathrm{BV}=$ Bosques Valdivianos; $\mathrm{BCB}=\mathrm{Bosques}$ Costeros de Bahía; $\mathrm{ChH=}$ Chaco Húmedo; Esp= Espinal; YA= Yungas Andinas; SIP= Sabana Inundada del Paraná.

\begin{tabular}{|c|c|c|c|c|c|c|c|c|}
\hline $\mathbf{N}^{0}$ Registro & Localidad & $\begin{array}{l}\text { Provincia /Región/ } \\
\text { Departamento }\end{array}$ & País & Ecorregión & Latitud & Longitud & Modelo & Referencia \\
\hline 1 & Temuco & De la Araucanía & Chile & $\mathrm{MCh}$ & $-38,73$ & $-72,60$ & Actual & Molina, 1782 (Ht. Grisonella cuja) \\
\hline 2 & San Francisco dos campos, 1580m.s.n.m & Minas Gerais & Brasil & BCSM & $-22,60$ & $-45,30$ & Actual & Thomas, 1907 (Ht. Grison furax) \\
\hline 3 & Chulumani, 1800m.s.n.m & $\mathrm{LaPaz}$ & Bolivia & YB & $-16,41$ & $-67,53$ & Actual & Thomas, 1907 (Ht. Grison furax luteolus) \\
\hline 4 & Quillota, near Valparaiso, Central Chili & Valparaiso & Chile & $\mathrm{MCh}$ & $-32,88$ & $-71,27$ & Actual & Thomas, 1912 (Ht. Grisonella melina) \\
\hline 5 & Mar del Plata, south- eastern BsAs province & Buenos Aires & Argentina & $\mathrm{PH}$ & $-38,00$ & $-57,55$ & Actual & Thomas, 1921 (Ht. Grisonella huronax) \\
\hline 6 & Pedernal & San Juan & Argentina & MA & $-31,98$ & $-68,73$ & Actual & Thomas, 1921 (Ht. Grisonella ratelina) \\
\hline 7 & Concepción & Tucumán & Argentina & $\mathrm{ChS}$ & $-27,33$ & $-65,58$ & Actual & Thomas, 1926 (Ht. Grisonella shiptoni) \\
\hline 8 & Paranaguá & Paraná & Brasil & BCSM & $-25,65$ & $-48,55$ & Actual-1950 & Barros et al., 1990 \\
\hline 9 & Quatro Barras & Paraná & Brasil & BCSM & $-25,55$ & $-48,08$ & Actual-1950 & Barros et al., 1990 \\
\hline 10 & Departamento Caucete, RN 141 Km 149 & San Juan & Argentina & MB & $-31,75$ & $-68,00$ & Actual-1950 & Cánovas y Villavicencio, 2002 \\
\hline 11 & Refugio de Fauna Laguna de los Castillos & Rocha & Uruguay & SU & $-34,36$ & $-53,86$ & Actual-1950 & Kraus y Rodel, 2004 \\
\hline 12 & Río Deseado & Santa Cruz & Argentina & EP & $-47,78$ & $-65,82$ & Actual-1950 & Zapata et al., 2005 \\
\hline
\end{tabular}


Continuación Tabla 2

Cabo Blanco
10.5 km NW conj. RPNo1 y RPN²2
11 km E Istmo C. Ameghino
14 km E de Gan Gan
19 km E Telsen
2.5 km SW Dolavon
5.5 km S Dolavon
Cañadón Carbón
Ea. El Centro
Ea. La Entrada
Ea. La Ernestina
Ea. La Esperanza
Est. María de Las Nieves
Est. San Félix 1
Est. San Félix 2
Est. San Francisco
Playa Fracasso
Playa Larralde
Playa Paraná
----
----
----
----
----
----
----
----

\begin{tabular}{l} 
Santa Cruz \\
Chubut \\
Chubut \\
Chubut \\
Chubut \\
Chubut \\
Chubut \\
Chubut \\
Chubut \\
Chubut \\
Chubut \\
Chubut \\
Chubut \\
Chubut \\
Chubut \\
Chubut \\
Chubut \\
Chubut \\
Chubut \\
---- \\
---- \\
---- \\
---- \\
---- \\
---- \\
---- \\
--- \\
\hline
\end{tabular}

$\begin{array}{lll}\text { Argentina } & \text { EP } & -47,20 \\ \text { Argentina } & \text { MB } & -42,58 \\ \text { Argentina } & \text { EP } & -42,47 \\ \text { Argentina } & \text { EP } & -42,53 \\ \text { Argentina } & \text { MB } & -42,52 \\ \text { Argentina } & \text { MB } & -43,32 \\ \text { Argentina } & \text { MB } & -43,36 \\ \text { Argentina } & \text { EP } & -43,83 \\ \text { Argentina } & \text { EP } & -42,21 \\ \text { Argentina } & \text { MB } & -42,42 \\ \text { Argentina } & \text { EP } & -42,08 \\ \text { Argentina } & \text { EP } & -42,11 \\ \text { Argentina } & \text { MB } & -42,52 \\ \text { Argentina } & \text { EP } & -42,74 \\ \text { Argentina } & \text { EP } & -42,74 \\ \text { Argentina } & \text { MB } & -42,34 \\ \text { Argentina } & \text { EP } & -42,43 \\ \text { Argentina } & \text { EP } & -42,41 \\ \text { Argentina } & \text { MB } & -42,80 \\ ---- & \text { SU } & -30,45 \\ ---- & \text { SU } & -31,32 \\ ---- & \text { SU } & -30,93 \\ ---- & \text { SU } & -30,88 \\ ---- & \text { RCA } & -29,42 \\ ---- & \text { RCA } & -29,32 \\ ---- & \text { SU } & -30,17 \\ ---- & \text { BAAP } & -30,02 \\ & & \\ \text { Ar } & & \end{array}$

$\begin{array}{lll}-65,75 & \text { Actual-1950 } & \text { Zapata et al., 2005 } \\ -64,93 & \text { Actual-1950 } & \text { Carrera et al., 2012 } \\ -64,37 & \text { Actual-1950 } & \text { Carrera et al., 2012 } \\ -68,11 & \text { Actual-1950 } & \text { Carrera et al., 2012 } \\ -66,74 & \text { Actual-1950 } & \text { Carrera et al., 2012 } \\ -65,73 & \text { Actual-1950 } & \text { Carrera et al., 2012 } \\ -65,72 & \text { Actual-1950 } & \text { Carrera et al., 2012 } \\ -67,87 & \text { Actual-1950 } & \text { Carrera et al., 2012 } \\ -63,94 & \text { Actual-1950 } & \text { Carrera et al., 2012 } \\ -64,71 & \text { Actual-1950 } & \text { Carrera et al., 2012 } \\ -63,76 & \text { Actual-1950 } & \text { Carrera et al., 2012 } \\ -64,82 & \text { Actual-1950 } & \text { Carrera et al., 2012 } \\ -66,32 & \text { Actual-1950 } & \text { Carrera et al., 2012 } \\ -63,68 & \text { Actual-1950 } & \text { Carrera et al., 2012 } \\ -63,68 & \text { Actual-1950 } & \text { Carrera et al., 2012 } \\ -64,91 & \text { Actual-1950 } & \text { Carrera et al., 2012 } \\ -64,13 & \text { Actual-1950 } & \text { Carrera et al., 2012 } \\ -64,31 & \text { Actual-1950 } & \text { Carrera et al., 2012 } \\ -64,94 & \text { Actual-1950 } & \text { Carrera et al., 2012 } \\ -50,52 & \text { Actual } & \text { Bornholdt et al., 2013 } \\ -54,10 & \text { Actual } & \text { Bornholdt et al., 2013 } \\ -54,75 & \text { Actual } & \text { Bornholdt et al., 2013 } \\ -54,85 & \text { Actual } & \text { Bornholdt et al., 2013 } \\ -49,80 & \text { Actual } & \text { Bornholdt et al., 2013 } \\ -49,72 & \text { Actual } & \text { Bornholdt et al., 2013 } \\ -52,37 & \text { Actual } & \text { Bornholdt et al., 2013 } \\ -52,88 & \text { Actual } & \text { Bornholdt et al., 2013 }\end{array}$


Continuación Tabla 2

\begin{tabular}{ll}
40 & ---- \\
41 & ---- \\
42 & ---- \\
43 & --- \\
44 & --- \\
45 & ---- \\
46 & --- \\
47 & --- \\
48 & --- \\
49 & --- \\
50 & ---- \\
51 & ---- \\
52 & --- \\
53 & --- \\
54 & ---- \\
55 & ---- \\
56 & ---- \\
57 & --- \\
58 & ---- \\
59 & ---- \\
60 & ---- \\
61 & ---- \\
62 & ---- \\
63 & ---- \\
64 & ---- \\
65 & ---- \\
66 & ---- \\
\hline 5
\end{tabular}

\begin{tabular}{|c|c|c|c|c|c|}
\hline --- & ---- & SU & $-28,62$ & $-54,67$ & Actual \\
\hline --- & ---- & SU & $-30,22$ & $-54,72$ & Actual \\
\hline ---- & ---- & SU & $-30,87$ & $-55,52$ & Actual \\
\hline ---- & ---- & SU & $-30,98$ & $-54,62$ & Actual \\
\hline --- & ---- & BAAP & $-29,53$ & $-53,38$ & Actual \\
\hline ---- & ---- & SU & $-30,22$ & $-57,53$ & Actual \\
\hline ---- & ---- & SU & $-29,82$ & $-53,78$ & Actual \\
\hline ---- & ---- & SU & $-30,75$ & $-51,63$ & Actual \\
\hline---- & ---- & BCSM & $-27,23$ & $-48,62$ & Actual \\
\hline ---- & ---- & BCSM & $-27,15$ & $-48,53$ & Actual \\
\hline ---- & ---- & BCSM & $-28,65$ & $-49,02$ & Actual \\
\hline ---- & ---- & BHA & $-27,67$ & $-48,77$ & Actual \\
\hline---- & ---- & BCSM & $-26,92$ & $-49,35$ & Actual \\
\hline ---- & ---- & SU & $-31,37$ & $-51,97$ & Actual \\
\hline ---- & ---- & BAAP & $-22,10$ & $-43,20$ & Actual \\
\hline ---- & ---- & $\mathrm{Ce}$ & $-17,35$ & $-44,92$ & Actual \\
\hline ---- & ---- & BAAP & $-21,90$ & $-49,35$ & Actual \\
\hline ---- & ---- & $\mathrm{Ca}$ & $-7,02$ & $-37,97$ & Actual \\
\hline ---- & ---- & BCSM & $-23,93$ & $-46,32$ & Actual \\
\hline ---- & ---- & $\mathrm{Ce}$ & $-23,07$ & $-48,92$ & Actual \\
\hline ---- & ---- & BIB & $-12,58$ & $-38,97$ & Actual \\
\hline ---- & ---- & BCSM & $-22,90$ & $-43,55$ & Actual \\
\hline ---- & ---- & PH & $-37,20$ & $-59,98$ & Actual \\
\hline ---- & ---- & $\mathrm{Ce}$ & $-16,32$ & $-48,97$ & Actual \\
\hline ---- & ---- & $\mathrm{Ca}$ & $-7,20$ & $-39,32$ & Actual \\
\hline ---- & ---- & $\mathrm{Ca}$ & $-8,37$ & $-36,70$ & Actual \\
\hline ---- & ---- & BCSM & $-22,75$ & $-43,43$ & Actual \\
\hline
\end{tabular}

Bornholdt et al., 2013

Bornholdt et al., 2013

Bornholdt et al., 2013

Bornholdt et al., 2013

Bornholdt et al., 2013

Bornholdt et al., 2013

Bornholdt et al., 2013

Bornholdt et al., 2013

Bornholdt et al., 2013

Bornholdt et al., 2013

Bornholdt et al., 2013

Bornholdt et al., 2013

Bornholdt et al., 2013

Bornholdt et al., 2013

Bornholdt et al., 2013

Bornholdt et al., 2013

Bornholdt et al., 2013

Bornholdt et al., 2013

Bornholdt et al., 2013

Bornholdt et al., 2013

Bornholdt et al., 2013

Bornholdt et al., 2013

Bornholdt et al., 2013

Bornholdt et al., 2013

Bornholdt et al., 2013

Bornholdt et al., 2013

Bornholdt et al., 2013 
Continuación Tabla 2

\begin{tabular}{|c|c|}
\hline 67 & ---- \\
\hline 68 & ---- \\
\hline 69 & ---- \\
\hline 70 & ---- \\
\hline 71 & ---- \\
\hline 72 & --- \\
\hline 73 & -- \\
\hline 74 & ---- \\
\hline 75 & --- \\
\hline 76 & ---- \\
\hline 77 & 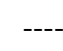 \\
\hline 78 & --- \\
\hline 79 & --- \\
\hline 80 & ---- \\
\hline 81 & --- \\
\hline 82 & 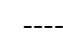 \\
\hline 83 & -- \\
\hline 84 & ---- \\
\hline 85 & ---- \\
\hline 86 & ---- \\
\hline 87 & -- \\
\hline 88 & ---- \\
\hline 89 & - \\
\hline 90 & ---- \\
\hline 91 & ---- \\
\hline 92 & ---- \\
\hline 93 & ---- \\
\hline
\end{tabular}

\begin{tabular}{|c|c|c|c|c|c|}
\hline ---- & ---- & $\mathrm{Ca}$ & $-7,77$ & $-39,92$ & Actual \\
\hline ---- & ---- & $\mathrm{Ca}$ & $-7,72$ & $-38,00$ & Actual \\
\hline ---- & ---- & $\mathrm{Ce}$ & $-20,62$ & $-46,50$ & Actual \\
\hline ---- & ---- & $\mathrm{Ca}$ & $-7,67$ & $-38,75$ & Actual \\
\hline ---- & ---- & BAAP & $-22,50$ & $-44,57$ & Actual \\
\hline ---- & ---- & BCSM & $-22,78$ & $-43,30$ & Actual \\
\hline ---- & ---- & BAM & $-23,22$ & $-44,72$ & Actual \\
\hline ---- & ---- & $\mathrm{Ca}$ & $-11,40$ & $-41,27$ & Actual \\
\hline ---- & ---- & BCSM & $-23,02$ & $-45,53$ & Actual \\
\hline ---- & ---- & $\mathrm{Ca}$ & $-9,42$ & $-36,62$ & Actual \\
\hline ---- & ---- & BCSM & $-22,42$ & $-42,97$ & Actual \\
\hline ---- & ---- & $\mathrm{Ca}$ & $-5,48$ & $-39,32$ & Actual \\
\hline ---- & ---- & $\mathrm{BCP}$ & $-8,00$ & $-35,03$ & Actual \\
\hline ---- & ---- & BHA & $-27,67$ & $-51,42$ & Actual \\
\hline ---- & ---- & BAAP & $-30,02$ & $-52,88$ & Actual \\
\hline ---- & ---- & BHA & $-29,38$ & $-50,88$ & Actual \\
\hline ---- & ---- & $\mathrm{Ca}$ & $-14,27$ & $-43,17$ & Actual \\
\hline ---- & ---- & $\mathrm{MCh}$ & $-32,50$ & $-71,00$ & Actual \\
\hline ---- & ---- & BAAP & $-25,28$ & $-55,93$ & Actual \\
\hline ---- & ---- & PH & $-38,00$ & $-57,53$ & Actual \\
\hline ---- & ---- & $\mathrm{PH}$ & $-36,38$ & $-56,97$ & Actual \\
\hline ---- & ---- & BCSM & $-22,93$ & $-44,02$ & Actual \\
\hline ---- & ---- & $\mathrm{MCh}$ & $-33,97$ & $-70,98$ & Actual \\
\hline ---- & ---- & EP & $-43,88$ & $-68,67$ & Actual \\
\hline ---- & ---- & MCh & $-32,87$ & $-71,27$ & Actual \\
\hline ---- & ---- & $\mathrm{MCh}$ & $-38,72$ & $-72,58$ & Actual \\
\hline ---- & ---- & Esp & $-30,27$ & $-61,13$ & Actual \\
\hline
\end{tabular}

Bornholdt et al., 2013

Bornholdt et al., 2013

Bornholdt et al., 2013

Bornholdt et al., 2013

Bornholdt et al., 2013

Bornholdt et al., 2013

Bornholdt et al., 2013

Bornholdt et al., 2013

Bornholdt et al., 2013

Bornholdt et al., 2013

Bornholdt et al., 2013

Bornholdt et al., 2013

Bornholdt et al., 2013

Bornholdt et al., 2013

Bornholdt et al., 2013

Bornholdt et al., 2013

Bornholdt et al., 2013

Bornholdt et al., 2013

Bornholdt et al., 2013

Bornholdt et al., 2013

Bornholdt et al., 2013

Bornholdt et al., 2013

Bornholdt et al., 2013

Bornholdt et al., 2013

Bornholdt et al., 2013

Bornholdt et al., 2013

Bornholdt et al., 2013 
Continuación Tabla 2

\begin{tabular}{|c|c|}
\hline 94 & --- \\
\hline 95 & ---- \\
\hline 96 & ---- \\
\hline 97 & ---- \\
\hline 98 & ---- \\
\hline 99 & ---- \\
\hline 100 & ---- \\
\hline 101 & ---- \\
\hline 102 & ---- \\
\hline 103 & ---- \\
\hline 104 & ---- \\
\hline 105 & ---- \\
\hline 106 & --- \\
\hline 107 & ---- \\
\hline 108 & ---- \\
\hline 109 & ---- \\
\hline 110 & ---- \\
\hline 111 & ---- \\
\hline 112 & Península de Valdés \\
\hline 113 & 25 de Mayo \\
\hline 114 & Azul \\
\hline 115 & Cañadón Darwin, Corpen Aike \\
\hline 116 & Choya, Villa La Punta \\
\hline 117 & Punta Indio \\
\hline 118 & PN El Palmar, Palmar de Colón \\
\hline 119 & Gral. Alvarado, Arroyo Brusquitas, Miramar \\
\hline 120 & Patiño, Colonia Juanita, Ibarreta \\
\hline
\end{tabular}

\begin{tabular}{|c|c|c|c|c|c|c|}
\hline---- & --- & $\mathrm{ChS}$ & $-27,32$ & $-65,57$ & Actual & Bornholdt et al., 2013 \\
\hline---- & ---- & $\mathrm{MCh}$ & $-33,03$ & $-71,43$ & Actual & Bornholdt et al., 2013 \\
\hline ---- & ---- & $\mathrm{PH}$ & $-36,82$ & $-62,22$ & Actual & Bornholdt et al., 2013 \\
\hline---- & ---- & Esp & $-32,28$ & $-63,57$ & Actual & Bornholdt et al., 2013 \\
\hline ---- & ---- & MA & $-27,07$ & $-66,98$ & Actual & Bornholdt et al., 2013 \\
\hline---- & --- & MA & $-30,87$ & $-68,52$ & Actual & Bornholdt et al., 2013 \\
\hline---- & ---- & SMCP & $-17,92$ & $-43,78$ & Actual & Bornholdt et al., 2013 \\
\hline---- & ---- & $\mathrm{BMB}$ & $-17,88$ & $-64,47$ & Actual & Bornholdt et al., 2013 \\
\hline ---- & ---- & $\mathrm{ChS}$ & $-25,25$ & $-64,70$ & Actual & Bornholdt et al., 2013 \\
\hline---- & ---- & $\mathrm{PH}$ & $-32,37$ & $-62,32$ & Actual & Bornholdt et al., 2013 \\
\hline---- & ---- & SU & $-33,25$ & $-58,02$ & Actual & Bornholdt et al., 2013 \\
\hline---- & --- & BHA & $-27,22$ & $-50,62$ & Actual & Bornholdt et al., 2013 \\
\hline ---- & ---- & MA & $-27,63$ & $-67,02$ & Actual & Bornholdt et al., 2013 \\
\hline---- & --- & Esp & $-31,43$ & $-60,92$ & Actual & Bornholdt et al., 2013 \\
\hline---- & ---- & Esp & $-38,72$ & $-62,27$ & Actual & Bornholdt et al., 2013 \\
\hline ---- & ---- & $\mathrm{Ce}$ & $-15,82$ & $-47,92$ & Actual & Bornholdt et al., 2013 \\
\hline---- & ---- & $\mathrm{BV}$ & $-39,78$ & $-73,22$ & Actual & Bornholdt et al., 2013 \\
\hline ---- & ---- & $\mathrm{BCB}$ & $-19,18$ & $-40,30$ & Actual & Bornholdt et al., 2013 \\
\hline Chubut & Argentina & $\mathrm{EP}$ & $-42,51$ & $-63,88$ & Actual & FHN 5594 \\
\hline Buenos Aires & Argentina & $\mathrm{PH}$ & $-35,43$ & $-60,17$ & Actual & FHN 9751 \\
\hline Buenos Aires & Argentina & $\mathrm{PH}$ & $-36,78$ & $-59,85$ & Actual & FHN 4374 \\
\hline Santa Cruz & Argentina & EP & $-49,58$ & $-69,50$ & Actual & FHN 9369 \\
\hline Santiago del Estero & Argentina & $\mathrm{ChS}$ & $-28,37$ & $-64,78$ & Actual & FHN 11067 \\
\hline Buenos Aires & Argentina & PH & $-35,27$ & $-57,24$ & Actual & FHN 9742 \\
\hline Entre Ríos & Argentina & $\mathrm{PH}$ & $-31,88$ & $-58,27$ & Actual-1950 & FHN 8299 \\
\hline Buenos Aires & Argentina & $\mathrm{PH}$ & $-38,27$ & $-57,85$ & Actual-1950 & FHN 2692 \\
\hline Formosa & Argentina & $\mathrm{ChH}$ & $-25,22$ & $-59,85$ & Actual-1950 & FHN 4601 \\
\hline
\end{tabular}


Continuación Tabla 2

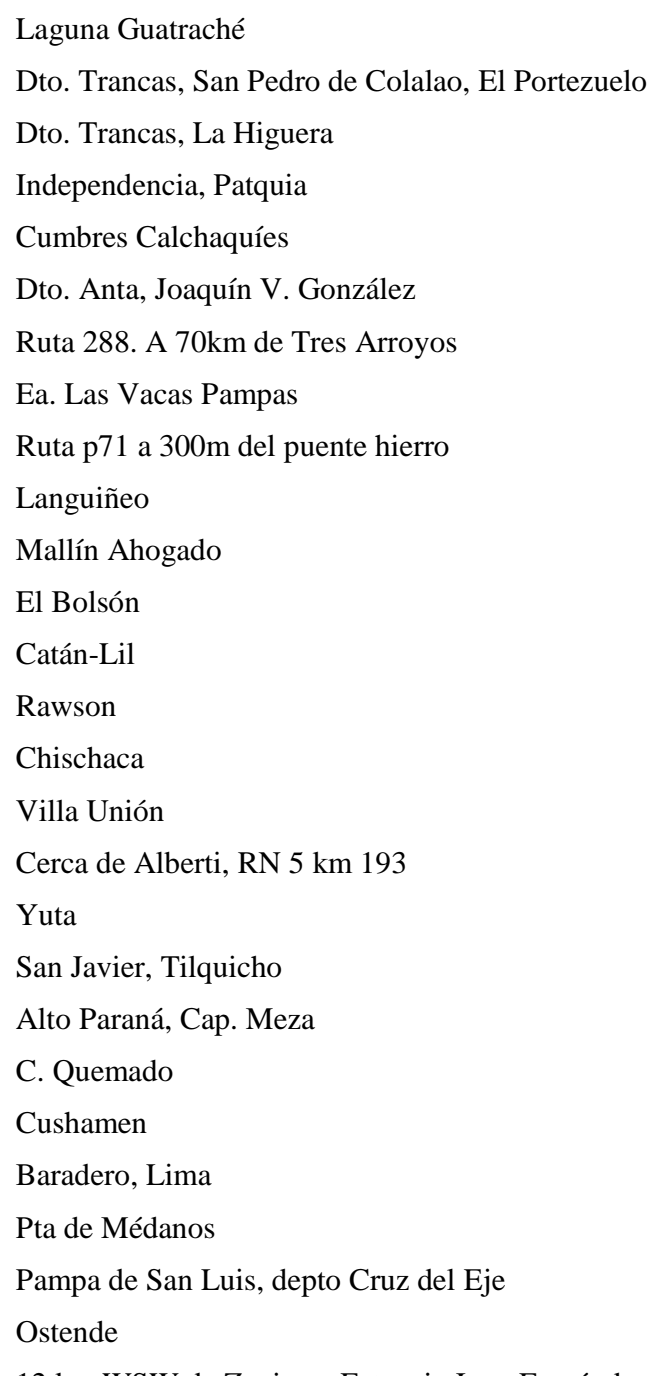

La Pampa
Tucumán
Tucumán
La Rioja
Tucumán
Salta
Buenos Aires
Chubut
Chubut
Chubut
Río Negro
Río Negro
Neuquén
Chubut
San Luis
La Rioja
Buenos Aires
Jujuy
Córdoba
Itapúa
La Pampa
Chubut
Buenos Aires
Buenos Aires
Córdoba
Buenos Aires
Lavalleja

$\begin{array}{llllll}\text { Argentina } & \text { Esp } & -37,76 & -63,55 & \text { Actual-1950 } & \text { FHN 10555 } \\ \text { Argentina } & \text { YA } & -26,23 & -65,48 & \text { Actual-1950 } & \text { IML 1587 } \\ \text { Argentina } & \text { ChS } & -26,38 & -65,43 & \text { Actual-1950 } & \text { IML 1043 } \\ \text { Argentina } & \text { ChS } & -30,05 & -66,88 & \text { Actual-1950 } & \text { IML 3734 } \\ \text { Argentina } & \text { YA } & -26,56 & -65,68 & \text { Actual } & \text { IML 3728 } \\ \text { Argentina } & \text { ChS } & -25,08 & -64,18 & \text { Actual-1950 } & \text { IML 7127 } \\ \text { Argentina } & \text { PH } & -38,54 & -59,16 & \text { Actual-1950 } & \text { LIEB 883 } \\ \text { Argentina } & \text { BV } & -43,20 & -71,42 & \text { Actual-1950 } & \text { LIEB 884 } \\ \text { Argentina } & \text { BV } & -42,69 & -71,48 & \text { Actual-1950 } & \text { LIEB 911 } \\ \text { Argentina } & \text { EP } & -43,30 & -70,42 & \text { Actual-1950 } & \text { MACN 13939 } \\ \text { Argentina } & \text { BV } & -41,88 & -71,55 & \text { Actual-1950 } & \text { MACN 13963 } \\ \text { Argentina } & \text { BV } & -41,97 & -71,52 & \text { Actual-1950 } & \text { MACN 13965 } \\ \text { Argentina } & \text { EP } & -39,55 & -70,58 & \text { Actual-1950 } & \text { MACN 13498 } \\ \text { Argentina } & \text { MB } & -43,30 & -65,10 & \text { Actual } & \text { MACN 28.75 } \\ \text { Argentina } & \text { Esp } & -33,87 & -66,25 & \text { Actual } & \text { MACN 26.80 } \\ \text { Argentina } & \text { ChS } & -29,43 & -66,85 & \text { Actual } & \text { MACN 34.331 } \\ \text { Argentina } & \text { PH } & -35,03 & -60,27 & \text { Actual-1950 } & \text { MACN 23291 } \\ \text { Argentina } & \text { YA } & -23,63 & -64,47 & \text { Actual } & \text { MACN 18201 } \\ \text { Argentina } & \text { ChS } & -32,18 & -65,22 & \text { Actual } & \text { MACN 29.191 } \\ \text { Paraguay } & \text { BAAP } & -26,93 & -55,23 & \text { Actual } & \text { MACN 47.373 } \\ \text { Argentina } & \text { Esp } & -34,47 & -65,33 & \text { Actual } & \text { MACN 15.584 } \\ \text { Argentina } & \text { EP } & -42,20 & -70,83 & \text { Actual } & \text { MACN 16.520 } \\ \text { Argentina } & \text { PH } & -33,80 & -59,52 & \text { Actual-1950 } & \text { MACN 23.659 } \\ \text { Argentina } & \text { PH } & -36,87 & -56,67 & \text { Actual } & \text { MACN 26.166 } \\ \text { Argentina } & \text { ChS } & -31,33 & -64,77 & \text { Actual } & \text { MACN 23.658 } \\ \text { Argentina } & \text { PH } & -37,15 & -56,88 & \text { Actual } & \text { MACN 13.075 } \\ \text { Uruguay } & \text { SU } & -33,60 & -55,04 & \text { Actual-1950 } & \text { MHNM 1236 }\end{array}$


Continuación Tabla 2

\begin{tabular}{|c|c|c|c|c|c|c|c|c|}
\hline 148 & Estancia Los Abuelos FYMNSA & Rivera & Uruguay & SU & $-31,29$ & $-55,76$ & Actual-1950 & MHNM 6433 \\
\hline 149 & Playa Pascual & San José & Uruguay & SU & $-34,38$ & $-56,46$ & Actual-1950 & MHNM 3233 \\
\hline 150 & Río Negro, $7 \mathrm{~km}$ aguas arriba del río Tacuarembó & Tacuarembó & Uruguay & SU & $-32,35$ & $-55,47$ & Actual-1950 & MHNM 1158 \\
\hline 151 & Estancia San Elena, Arroyo Perdido & Soriano & Uruguay & SU & $-33,37$ & $-57,88$ & Actual-1950 & MHNM 295 \\
\hline 152 & Arroyo Limetas, Estancia San Jorge & Colonia & Uruguay & SU & $-34,16$ & $-58,10$ & Actual-1950 & MHNM 2690 \\
\hline 153 & Estancia San Jorge, Conchillas & Colonia & Uruguay & SU & $-34,15$ & $-58,01$ & Actual-1950 & MHNM 1923 \\
\hline 154 & Dunas de Cabo Polonia, Km 264 ruta 10 & Rocha & Uruguay & SU & $-34,39$ & $-53,83$ & Actual & MHNM 6412 \\
\hline 155 & Teresopolis & Río de Janeiro & Brasil & BCSM & $-22,41$ & $-42,97$ & Actual & MHNM 1339 \\
\hline 156 & Cerro Copetón & Florida & Uruguay & SU & $-33,80$ & $-55,53$ & Actual & MHNM 1246 \\
\hline 157 & La Plata, camino a Arana, sobre $\mathrm{A}^{\circ}$ El Pescado & Buenos Aires & Argentina & $\mathrm{PH}$ & $-34,90$ & $-57,78$ & Actual & MLP 25-IV-01-1 \\
\hline 158 & Pdo. Punta Indio Monte Veloz & Buenos Aires & Argentina & $\mathrm{PH}$ & $-35,27$ & $-57,29$ & Actual-1950 & MLP 15-V-97-42 \\
\hline 159 & Depto Lago Argentino, Cerro Verlika, Sierra, Baguales & Santa Cruz & Argentina & $\mathrm{EP}$ & $-50,62$ & $-72,25$ & Actual & MLP 19-XII-02-21 \\
\hline 160 & Sauce Viejo & Santa Fé & Argentina & Esp & $-31,77$ & $-60,85$ & Actual & MLP 674 \\
\hline 161 & Pdo. De Junín, Ea. Agustina & Buenos Aires & Argentina & $\mathrm{PH}$ & $-34,58$ & $-61,17$ & Actual & MLP 8-V-59-6 \\
\hline 162 & Ibicuy & Entre Ríos & Argentina & SIP & $-33,73$ & $-59,17$ & Actual & MLP 1706 \\
\hline 163 & Pdo Patagones, Faro Segunda & Buenos Aires & Argentina & $\mathrm{EP}$ & $-40,89$ & $-68,68$ & Actual-1950 & MLP 3-V-99-4 \\
\hline 164 & Brazo Largo & Buenos Aires & Argentina & SIP & $-33,78$ & $-58,60$ & Actual & MLP 1705 \\
\hline 165 & Santo Tomé & Santa Fé & Argentina & Esp & $-31,67$ & $-60,77$ & Actual & MLP 704 \\
\hline 166 & Ruta 88 a 400m del cruce a Miramar. Partido Alvarado & Buenos Aires & Argentina & PH & $-38,15$ & $-57,96$ & Actual-1950 & MMP 4230 \\
\hline 167 & Paranacito & Entre Ríos & Argentina & SIP & $-33,73$ & $-58,67$ & Actual-1950 & MMP 1368 \\
\hline 168 & Centinela del Mar. Pdo. Necochea & Buenos Aires & Argentina & $\mathrm{PH}$ & $-38,43$ & $-58,22$ & Actual-1950 & MMP 4018 \\
\hline
\end{tabular}


Tabla 3. Localidades de registro actuales de Lyncodon patagonicus, utilizadas en los análisis de distribución. En negritas se observan las localidades de registro más extremas en su distribución. Ver acrónimos en Material y Métodos. Ecorregiones sensu Olson et al. (2001): PH= Pampas

Húmedas; Esp= Espinal; EP= Estepa Patagónica; BMg= Bosques Magallánicos; $\mathrm{ChS}=$ Chaco Seco; MB= Monte Bajo; EA= Estepa Andina; BV= Bosques Valdivianos; MA=

Monte Alto; $\mathrm{YA}=$ Yungas Andinas.

\begin{tabular}{|c|c|c|c|c|c|c|c|c|}
\hline $\begin{array}{l}\mathbf{N}^{\mathbf{o}} \\
\text { Registro }\end{array}$ & Localidad & $\begin{array}{l}\text { Provincia/Región/ } \\
\text { Departamento }\end{array}$ & País & Ecorregión & Latitud & Longitud & Modelo & Referencia \\
\hline 1 & Azul & Buenos Aires & Argentina & $\mathrm{PH}$ & $-36,78$ & $-59,85$ & Actual & Burmeister, 1879 \\
\hline 3 & Carmen de Patagones & Buenos Aires & Argentina & Esp & $-40,8$ & -63 & Actual & Doering, 1881 \\
\hline 4 & $\mathrm{~A}^{\circ}$ Quichaure & Chubut & Argentina & $\mathrm{EP}$ & $-43,83$ & $-70,83$ & Actual & Burmeister, 1888 \\
\hline 5 & Lago Blanco & Chubut & Argentina & $\mathrm{EP}$ & $-45,93$ & $-71,27$ & Actual & Koslowsky, 1904 \\
\hline 6 & Rio Guenguel & Chubut & Argentina & $\mathrm{EP}$ & -46 & -71 & Actual & Koslowsky, 1904 \\
\hline 7 & Cerca Puerto Santa Cruz & Santa Cruz & Argentina & $\mathrm{EP}$ & $-50,02$ & $-68,53$ & Actual & Allen, 1905 \\
\hline 8 & Puerto Prat & Magallanes & Chile & $\mathrm{BMg}$ & $-51,62$ & $-72,63$ & Actual & Wolffsohn, 1923 \\
\hline 9 & Bonifacio & Buenos Aires & Argentina & $\mathrm{PH}$ & $-36,82$ & $-62,25$ & Actual & Pocock, 1926 \\
\hline 10 & La Rioja & La Rioja & Argentina & $\mathrm{ChS}$ & $-29,41$ & $-66,85$ & Actual & Cabrera, 1929 \\
\hline 11 & Aguada Grande & Santa Cruz & Argentina & EP & $-47,33$ & $-67,58$ & Actual & Yepes, 1935 \\
\hline 12 & San Rafael & Mendoza & Argentina & MB & $-34,61$ & $-68,35$ & Actual & Yepes, 1935 \\
\hline 14 & Tupungato & Mendoza & Argentina & EA & $-33,37$ & $-69,13$ & Actual & Roig, 1965 \\
\hline 15 & Tunuyán & Mendoza & Argentina & MB & $-33,57$ & $-69,02$ & Actual & Roig, 1965 \\
\hline 16 & San Carlos & Mendoza & Argentina & MB & $-33,77$ & $-69,03$ & Actual & Roig, 1965 \\
\hline 17 & Marimenuco & Araucanía & Chile & $\mathrm{BV}$ & $-38,7$ & $-71,1$ & Actual-1950 & Peña, 1966 \\
\hline 18 & El Timbó & Tucumán & Argentina & $\mathrm{ChS}$ & $-26,23$ & $-65,38$ & Actual-1950 & Olrog, 1958 \\
\hline 19 & Andalgalá & Catamarca & Argentina & MA & $-27,6$ & $-66,33$ & Actual-1950 & Olrog, 1958 \\
\hline
\end{tabular}


Continuación Tabla 3

Sol de Julio
Colalao del Valle
Amaicha del Valle
Banda del río Salí
Alemania
Cafayate
Santa María
Uspallata
Cueva del Tigre
San Carlos de Bariloche
Guampacha
Ea. Cerro de los Pinos
9 km SE Los Menucos
Puerto Pirámide
Macachín
Salinas Grande
Aeropuerto Bariloche
Río Senguer
2000m al E. de Pto Pirámides, 50msnm
Pampa de Gualilán
Cabo Dos Bahias
Ea. San Pedro
Ea. El Desafío
Puesto Horno, Ea. Maquinchao
Cañadón Angostura de Cides, Ea. Calcatreo
Ea. Calcatreo
Piedra Parada
and

$\begin{array}{lll}\text { Santiago del Estero } & \text { Argentina } & \text { ChS } \\ \text { Tucumán } & \text { Argentina } & \text { MA } \\ \text { Tucumán } & \text { Argentina } & \text { MA } \\ \text { Tucumán } & \text { Argentina } & \text { YA } \\ \text { Salta } & \text { Argentina } & \text { ChS } \\ \text { Salta } & \text { Argentina } & \text { MA } \\ \text { Catamarca } & \text { Argentina } & \text { MA } \\ \text { Mendoza } & \text { Argentina } & \text { MA } \\ \text { Mendoza } & \text { Argentina } & \text { EP } \\ \text { Río Negro } & \text { Argentina } & \text { BV } \\ \text { Santiago del Estero } & \text { Argentina } & \text { ChS } \\ \text { Neuquén } & \text { Argentina } & \text { EP } \\ \text { Río Negro } & \text { Argentina } & \text { EP } \\ \text { Chubut } & \text { Argentina } & \text { EP } \\ \text { La Pampa } & \text { Argentina } & \text { Esp } \\ \text { La Pampa } & \text { Argentina } & \text { Esp } \\ \text { Río Negro } & \text { Argentina } & \text { EP } \\ \text { Chubut } & \text { Argentina } & \text { EP } \\ \text { Chubut } & \text { Argentina } & \text { EP } \\ \text { San Juan } & \text { Argentina } & \text { EA } \\ \text { Chubut } & \text { Argentina } & \text { EP } \\ \text { Río Negro } & \text { Argentina } & \text { EP } \\ \text { Río Negro } & \text { Argentina } & \text { EP } \\ \text { Río Negro } & \text { Argentina } & \text { EP } \\ \text { Río Negro } & \text { Argentina } & \text { EP } \\ \text { Río Negro } & \text { Argentina } & \text { EP } \\ \text { Chubut } & \text { Argentina } & \text { EP }\end{array}$

$-63,45$ Actual-1950 Olrog, 1976

-65,93 Actual-1950 Olrog, 1976

$-65,92$ Actual-1950 Olrog, 1976

$-65,17$ Actual-1950 Olrog, 1976

$-65,62$ Actual-1950 Olrog, 1976

$-65,95$ Actual-1950 Olrog, 1976

$-66,03$ Actual-1950 Olrog, 1976

-69,37 Actual-1950 Castro y Cicchino, 1986

-69,22 Actual-1950 Trajano, 1991

-71,28 Actual-1950 Massoia, 1992

-64,80 Actual-1950 Massoia y Latorraca,1992

-71,08 Actual-1950 Prevosti y Pardiñas, 2001

-68,05 Actual-1950 Prevosti y Pardiñas, 2001

-64,30 Actual-1950 Prevosti y Pardiñas, 2001

-63,67 Actual-1950 Prevosti y Pardiñas, 2001

-63,55 Actual-1950 Prevosti y Pardinas, 2001

-71,16 Actual-1950 Prevosti y Pardiñas, 2001

-70,83 Actual-1950 Prevosti y Pardiñas, 2001

-64,26 --- $\quad$ Prevosti y Pardiñas, 2001

$-68,92$ Actual-1950 Sanabria y Quiroga, 2003

-65,65 Actual-1950 Harris, 2008

$-70,70$ Actual-1950 Teta et al., 2008

$-71,10$ Actual-1950 Teta et al., 2008

$-68,65$ Actual-1950 Teta et al., 2008

$-69,37$ Actual-1950 Teta et al., 2008

-69,40 Actual-1950 Prevosti et al., 2009

-70,10 Actual-1950 Prevosti et al., 2009 
Continuación Tabla 3

\begin{tabular}{lllllllll}
47 & Puerto Madryn & Chubut & Argentina & MB & $-42,75$ & $-65,05$ & Actual-1950 & Prevosti et al., 2009 \\
48 & Puesto El Chango, Ea. Santa María & Chubut & Argentina & EP & $-45,46$ & $-69,43$ & Actual-1950 & Prevosti et al., 2009 \\
49 & 10 km S Perito Moreno, RN 40 & Santa Cruz & Argentina & EP & $-46,68$ & $-70,87$ & Actual-1950 & Prevosti et al., 2009 \\
50 & Extremo NE Lago Cardiel, RN 40 & Santa Cruz & Argentina & EP & $-48,90$ & $-71,02$ & Actual-1950 & Prevosti et al., 2009 \\
51 & Nacuñán & Mendoza & Argentina & MB & $-34,05$ & $-67,97$ & Actual-1950 & CMI-05814 \\
52 & (Río Chalia) RN 288, a 110 Km Piedrabuena & Santa Cruz & Argentina & EP & $-49,58$ & $-69,57$ & Actual-1950 & LIEB 891 \\
53 & Costa del Chubut & Chubut & Argentina & EP & $-42,60$ & $-70,37$ & Actual-1950 & LIEB 889 \\
54 & Ea. Yuquiche & Río Negro & Argentina & EP & $-41,58$ & $-69,86$ & Actual-1950 & MLP 29-XII-00-17 \\
55 & Bowen, Gral Alvear & Mendoza & Argentina & MB & $-35,00$ & $-67,52$ & Actual-1950 & MHNSR 39 \\
\hline
\end{tabular}


Tabla 4. Localidades de registro fósiles para Lyncodon patagonicus, utilizadas en los análisis de distribución.

\begin{tabular}{|c|c|c|c|c|c|c|c|}
\hline $\mathbf{N}^{0}$ Registro & Localidad & $\begin{array}{l}\text { Provincia/Región/ } \\
\text { Departamento }\end{array}$ & País & Latitud & Longitud & Modelo & Referencia \\
\hline 1 & Luján & Buenos Aires & Argentina & $-34,57$ & $-59,1$ & Pleistoceno-Holoceno & Ameghino, 1888 \\
\hline 2 & Córdoba & Córdoba & Argentina & $-31,42$ & $-64,2$ & Pleistoceno-Holoceno & Ameghino, 1889 \\
\hline 3 & Las Represas de las Indias & Santiago del Estero & Argentina & $-28,17$ & -63 & Pleistoceno-Holoceno; Holoceno & Kraglievich y Rusconi, 1931 \\
\hline 4 & Cortaderas & Buenos Aires & Argentina & $-38,35$ & $-61,1$ & Pleistoceno-Holoceno; Holoceno & Politis et al,, 1983 \\
\hline 5 & Chenque Haichol & Neuquén & Argentina & $-38,58$ & $-70,67$ & Pleistoceno-Holoceno; Holoceno & Massoia, 1992 \\
\hline 6 & Tres Arroyos 1 & Magallanes & Chile & $-53,38$ & $-68,78$ & Pleistoceno-Holoceno; Holoceno & Latorre, 1998 \\
\hline 7 & Estación Manuel J, García & Buenos Aires & Argentina & $-34,67$ & $-59,43$ & Pleistoceno-Holoceno & Prevosti y Pardiñas, 2001 \\
\hline 8 & Camet Norte & Buenos Aires & Argentina & -38 & $-57,55$ & Pleistoceno-Holoceno & Prevosti y Pardiñas, 2001 \\
\hline 9 & Las Lagunitas & San Luis & Argentina & $-33,68$ & $-65,47$ & Pleistoceno-Holoceno & Prevosti y Pardiñas, 2001 \\
\hline 10 & Cueva y Paredón Loncomán & Río Negro & Argentina & $-40,78$ & $-70,17$ & Pleistoceno-Holoceno; Holoceno & Andrade et al., 2005 \\
\hline 11 & Alero Santo Rosario & Río Negro & Argentina & $-41,72$ & $-68,67$ & Pleistoceno-Holoceno; Holoceno & Andrade et al., 2005 \\
\hline 12 & Ea, El Centenario & San Luis & Argentina & $-34,21$ & $-65,87$ & Pleistoceno-Holoceno; Holoceno & Prevosti et al., 2009 \\
\hline 13 & Punta Buenos Aires & Chubut & Argentina & $-42,21$ & $-64,17$ & Pleistoceno-Holoceno; Holoceno & Prevosti et al., 2009 \\
\hline 14 & El Riacho & Chubut & Argentina & $-42,43$ & $-64,6$ & Pleistoceno-Holoceno; Holoceno & Prevosti et al., 2009 \\
\hline 15 & Playa Pardelas & Chubut & Argentina & $-42,63$ & $-64,2$ & Pleistoceno-Holoceno; Holoceno & Prevosti et al., 2009 \\
\hline 16 & Establecimiento San Pablo & Chubut & Argentina & $-42,67$ & $-64,22$ & Pleistoceno-Holoceno; Holoceno & Prevosti et al., 2009 \\
\hline 17 & Punta Este & Chubut & Argentina & $-42,81$ & $-64,95$ & Pleistoceno-Holoceno; Holoceno & Prevosti et al., 2009 \\
\hline 18 & Cerro Avanzado & Chubut & Argentina & $-42,85$ & $-64,87$ & Pleistoceno-Holoceno; Holoceno & Prevosti et al., 2009 \\
\hline 19 & El Pedral & Chubut & Argentina & $-42,95$ & $-64,37$ & Pleistoceno-Holoceno; Holoceno & Prevosti et al., 2009 \\
\hline 20 & Cueva de los Chingues, PN Pali-Aike & Magallanes & Chile & $-52,09$ & $-69,74$ & Pleistoceno-Holoceno; Holoceno & Prevosti et al., 2009 \\
\hline
\end{tabular}


Tabla 5. Localidades de registro para Lontra provocax, utilizadas en los análisis de distribución. Las coordenadas de algunas localidades provenientes de Vianna et al. (2011) fueron ligeramente modificadas, dado que no coincidían con la base de datos utilizada. En negrita se presentan las localidades de registro más extremas en su distribución. Ver acrónimos en Materiales y Métodos. Ecorregiones sensu Olson et al. (2001): EP= Estepa Patagónica; $\mathrm{BMg}=$ Bosques Magallánicos; BV= Bosques Valdivianos; MCh= Matorral Chileno; Espinal= Esp.

\begin{tabular}{|c|c|c|c|c|c|c|c|c|}
\hline $\begin{array}{l}\mathbf{N}^{\mathbf{o}} \\
\text { Registro } \\
\end{array}$ & Localidad & $\begin{array}{l}\text { Provincia/Región/ } \\
\text { Departamento }\end{array}$ & País & Ecorregión & Latitud & Longitud & Modelo & Referencia \\
\hline 1 & Esquel & Chubut & Argentina & $\mathrm{EP}$ & $-42,9$ & $-71,36$ & Actual & Cabrera y Yepes, 1940 \\
\hline 2 & Lago Buenos Aires & Chubut & Argentina & $\mathrm{EP}$ & $-46,57$ & $-71,08$ & Actual & Cabrera y Yepes, 1940 \\
\hline 3 & Isla de los Estados & Tierra del Fuego & Argentina & $\mathrm{BMg}$ & $-54,87$ & $-64,62$ & Actual-1950 & Pine et al., 1978 \\
\hline 4 & Lago Nahuel Huapi, Bahía López & Río Negro & Argentina & $\mathrm{BV}$ & $-41,07$ & $-71,56$ & Actual-1950 & Chehébar, 1983 \\
\hline 5 & Lago Nahuel Huapi, adyacente a Villa La Angostura & Neuquén & Argentina & $\mathrm{BV}$ & $-40,78$ & $-71,64$ & Actual-1950 & Chehébar, 1983 \\
\hline 6 & Lago Nahuel Huapi, desembocadura río Correntoso & Neuquén & Argentina & BV & $-40,74$ & $-71,67$ & Actual-1950 & Chehébar, 1983 \\
\hline 7 & Río Ruca-Malén, Hotel Ruca-Malén & Neuquén & Argentina & $\mathrm{BV}$ & $-40,60$ & $-71,71$ & Actual-1950 & Chehébar, 1983 \\
\hline 8 & Laguna Calcú & Neuquén & Argentina & $\mathrm{BV}$ & $-40,60$ & $-71,76$ & Actual-1950 & Chehébar, 1983 \\
\hline 9 & Lago Nahuel Huapi, Bahía Puerto Blest & Río Negro & Argentina & $\mathrm{BV}$ & $-41,02$ & $-71,83$ & Actual-1950 & Chehébar, 1983 \\
\hline 10 & Lago Nahuel Huapi, Brazo de la Tristeza, boca, costa norte & Río Negro & Argentina & $\mathrm{BV}$ & $-41,07$ & $-71,59$ & Actual-1950 & Chehébar, 1983 \\
\hline 11 & Arroyo Anasagasti & Río Negro & Argentina & BV & $-41,14$ & $-71,70$ & Actual-1950 & Chehébar, 1983 \\
\hline 12 & Lago Nahuel Huapi, Brazo de la Tristeza, boca, costa sur & Río Negro & Argentina & $\mathrm{BV}$ & $-41,08$ & $-71,59$ & Actual-1950 & Chehébar, 1983 \\
\hline 13 & Laguna del Pescado, Isla Victoria & Neuquén & Argentina & $\mathrm{BV}$ & $-40,89$ & $-71,55$ & Actual-1950 & Chehébar, 1983 \\
\hline 14 & Lago Nahuel Huapi, Península San Pedro & Río Negro & Argentina & $\mathrm{BV}$ & $-41,07$ & $-71,44$ & Actual-1950 & Chehébar, 1983 \\
\hline 15 & Lago Nahuel Huapi, Brazo Puerto Blest, costa norte & Neuquén & Argentina & $\mathrm{BV}$ & $-41,02$ & $-71,65$ & Actual-1950 & Chehébar, 1983 \\
\hline 16 & Laguna Machete & Neuquén & Argentina & $\mathrm{BV}$ & $-40,78$ & $-71,73$ & Actual-1950 & Chehébar, 1983 \\
\hline 17 & Lago Nahue Huapi, Brazo Machete & Neuquén & Argentina & $\mathrm{BV}$ & $-40,80$ & $-71,75$ & Actual-1950 & Chehébar, 1983 \\
\hline 18 & Lago Gallardo, extremo norte & Neuquén & Argentina & $\mathrm{BV}$ & $-40,83$ & $-71,78$ & Actual-1950 & Chehébar, 1983 \\
\hline 19 & Lago Gallardo, extremo sur & Neuquén & Argentina & $\mathrm{BV}$ & $-40,88$ & $-71,82$ & Actual-1950 & Chehébar, 1983 \\
\hline
\end{tabular}


Continuación Tabla 5

Lago Gallardo, al centro
Lago Nahuel Huapi, Puerto Manzano
Laguna Huahuan
Estancia Quetrihue
Lago Nahuel Huapi, península de Quetrihue, costa oeste
Lago Nahuel Huapi, península de Quetrihue, costa este
Lago Nahuel Huapi, Isla Menéndez
Arroyo Vinagre, tramo final
Lago Nahuel Huapi, Isla Victoria, antepuerto
Lago Nahuel Huapi, Isla Victoria, punta norte
Lago Nahuel Huapi, Isla Victoria, laguna Larga
Lago Panguipulli
Río Enco
Lago Todos los Santos
Río Petrohué
Arroyo Pidenco
Río Quinque
Río Colico
Río Mahuidanche
Río Queule
Río Huilío
Río Lingue
Río Cua cua
Lago Riñihue
Lago Traful
Lago Nahuel Huapi
Río Petrohue
Lat

\begin{tabular}{|c|c|c|c|c|c|c|}
\hline Neuquén & Argentina & $\mathrm{BV}$ & $-40,86$ & $-71,78$ & Actual-1950 & Chehébar, 1983 \\
\hline Neuquén & Argentina & $\mathrm{BV}$ & $-40,80$ & $-71,60$ & Actual-1950 & Chehébar, 1983 \\
\hline Neuquén & Argentina & $\mathrm{BV}$ & $-40,83$ & $-71,62$ & Actual-1950 & Chehébar, 1983 \\
\hline Neuquén & Argentina & $\mathrm{BV}$ & $-40,85$ & $-71,61$ & Actual-1950 & Chehébar, 1983 \\
\hline Neuquén & Argentina & $\mathrm{BV}$ & $-40,84$ & $-71,60$ & Actual-1950 & Chehébar, 1983 \\
\hline Neuquén & Argentina & $\mathrm{BV}$ & $-40,85$ & $-71,63$ & Actual-1950 & Chehébar, 1983 \\
\hline Neuquén & Argentina & $\mathrm{BV}$ & $-40,77$ & $-71,68$ & Actual-1950 & Chehébar, 1983 \\
\hline Neuquén & Argentina & $\mathrm{BV}$ & $-40,94$ & $-71,62$ & Actual-1950 & Chehébar, 1983 \\
\hline Neuquén & Argentina & $\mathrm{BV}$ & $-40,97$ & $-71,53$ & Actual-1950 & Chehébar, 1983 \\
\hline Neuquén & Argentina & $\mathrm{BV}$ & $-40,88$ & $-71,58$ & Actual-1950 & Chehébar, 1983 \\
\hline Neuquén & Argentina & $\mathrm{BV}$ & $-40,94$ & $-71,55$ & Actual-1950 & Chehébar, 1983 \\
\hline Araucania & Chile & $\mathrm{BV}$ & $-39,72$ & $-72,22$ & Actual-1950 & Medina, 1997 \\
\hline Araucania & Chile & $\mathrm{BV}$ & $-39,92$ & $-72,18$ & Actual-1950 & Medina, 1997 \\
\hline Los Lagos & Chile & $\mathrm{BV}$ & $-41,10$ & $-72,25$ & Actual-1950 & Medina, 1997 \\
\hline Los Lagos & Chile & $\mathrm{BV}$ & $-41,37$ & $-72,32$ & Actual-1950 & Medina, 1997 \\
\hline Araucania & Chile & $\mathrm{BV}$ & $-39,28$ & $-72,82$ & Actual-1950 & Medina-Vogel et al., 2003 \\
\hline Araucania & Chile & $\mathrm{BV}$ & $-39,03$ & $-72,98$ & Actual-1950 & Medina-Vogel et al., 2003 \\
\hline Araucania & Chile & $\mathrm{MCh}$ & $-39,05$ & $-72,13$ & Actual-1950 & Medina-Vogel et al., 2003 \\
\hline Araucania & Chile & $\mathrm{BV}$ & $-39,22$ & $-72,83$ & Actual-1950 & Medina-Vogel et al., 2003 \\
\hline Araucania & Chile & $\mathrm{BV}$ & $-39,20$ & $-72,92$ & Actual-1950 & Medina-Vogel et al., 2003 \\
\hline Araucania & Chile & $\mathrm{BV}$ & $-38,97$ & $-73,02$ & Actual-1950 & Medina-Vogel et al., 2003 \\
\hline Los Lagos & Chile & $\mathrm{BV}$ & $-39,45$ & $-73,08$ & Actual-1950 & Vianna et al., 2011 \\
\hline Los Lagos & Chile & $\mathrm{BV}$ & $-39,70$ & $-71,90$ & Actual-1950 & Vianna et al., 2011 \\
\hline Los Lagos & Chie & $\mathrm{BV}$ & $-39,77$ & $-72,45$ & Actual-1950 & Vianna et al., 2011 \\
\hline Neuquén & Argentina & $\mathrm{BV}$ & $-40,50$ & $-71,58$ & Actual-1950 & Vianna et al., 2011 \\
\hline Río Negro & Argentina & $\mathrm{BV}$ & $-41,08$ & $-71,58$ & Actual-1950 & Vianna et al., 2011 \\
\hline Los Lagos & Chile & $\mathrm{BV}$ & $-41,13$ & $-72,40$ & Actual-1950 & Vianna et al., 2011 \\
\hline
\end{tabular}


Continuación Tabla 5

\begin{tabular}{|c|c|c|c|c|c|c|c|c|}
\hline 47 & Darwin, Isla de Chiloé & Los Lagos & Chile & BV & $-41,87$ & $-73,65$ & Actual-1950 & Vianna et al., 2011 \\
\hline 48 & Río Chepu, Isla de Chiloé & Los Lagos & Chile & $\mathrm{BV}$ & $-42,03$ & $-73,97$ & Actual-1950 & Vianna et al., 2011 \\
\hline 49 & Isla Tictoc & Los Lagos & Chile & $\mathrm{BV}$ & $-43,63$ & $-73,02$ & Actual-1950 & Vianna et al., 2011 \\
\hline 50 & Melinka & Aysén & Chile & BV & $-43,85$ & $-73,82$ & Actual-1950 & Modificado de Vianna et al., 2011 \\
\hline 51 & Río Queulat & Magallanes & Chile & $\mathrm{BV}$ & $-44,45$ & $-72,58$ & Actual-1950 & Modificado de Vianna et al., 2011 \\
\hline 52 & Seno Magdalena, Isla Magdalena & Magallanes & Chile & $\mathrm{BV}$ & $-44,58$ & $-72,93$ & Actual-1950 & Vianna et al., 2011 \\
\hline 53 & Valle Marta, Isla Magdalena & Magallanes & Chile & $\mathrm{BV}$ & $-44,87$ & $-72,92$ & Actual-1950 & Vianna et al., 2011 \\
\hline 54 & Canal Puyuhuapi, Isla Magdalena & Magallanes & Chile & $\mathrm{BV}$ & $-44,71$ & $-72,88$ & Actual-1950 & Modificado de Vianna et al., 2011 \\
\hline 55 & Puerto Aguirre & Aysén & Chile & BV & $-45,25$ & $-73,38$ & Actual-1950 & Modificado de Vianna et al., 2011 \\
\hline 56 & Isla Madre de Dios & Magallanes & Chile & $\mathrm{BMg}$ & $-50,06$ & $-75,15$ & Actual-1950 & Modificado de Vianna et al., 2011 \\
\hline 57 & Alrededor de Puerto Natales & Magallanes & Chile & $\mathrm{BMg}$ & $-51,72$ & $-72,48$ & Actual-1950 & Vianna et al., 2011 \\
\hline 58 & Alrededor de Punta Arenas & Magallanes & Chile & $\mathrm{BMg}$ & $-53,13$ & $-70,90$ & Actual-1950 & Vianna et al., 2011 \\
\hline 59 & Temuco, Maquegua & Araucania & Chile & $\mathrm{MCh}$ & $-38,80$ & $-72,75$ & Actual & AMNH 33295 \\
\hline 60 & Río Inio, Isla de Chiloé & Los Lagos & Chile & $\mathrm{BV}$ & $-43,35$ & $-74,12$ & Actual & FMNH 24224 \\
\hline 61 & Boca del río Inio, Isla de Chiloé & Los Lagos & Chile & BV & $-43,33$ & $-74,11$ & Actual & Modificado de FMNH 24222 \\
\hline 62 & PN T. del Fuego, Costa canal Beagle & Tierra del Fuego & Argentina & $\mathrm{BMg}$ & $-54,65$ & $-68,17$ & Actual & MACN 20281 \\
\hline 63 & Río Senguer & Santa Cruz & Argentina & $\mathrm{EP}$ & $-46,04$ & $-69,52$ & Actual & MACN 4.402 \\
\hline 64 & Cerca de la boca del Río Negro, justo al S & Río Negro & Argentina & Esp & $-41,04$ & $-62,87$ & Actual & SNMNH 171959 \\
\hline 65 & Brazo tristeza, Orilla Oeste, Lago Nahuel Huapi & Neuquén & Argentina & $\mathrm{BV}$ & $-41,15$ & $-71,70$ & Actual-1950 & MMP 141 \\
\hline
\end{tabular}


Tabla 6. Localidades de registro para Neovison vison, utilizadas en los análisis de distribución. Las coordenadas de localidades provenientes de Valenzuela et al. (2013) fueron ligeramente modificadas, dado que no coincidían con la base de datos utilizada. Las localidades provenientes de Pagnoni et al. (1986) no poseían coordenadas ni nombres, por lo cual fueron georeferenciadas directamente del mapa presentado en ese estudio.

El registro No 206 proviene de la CEM (Colección Elio Massoia), que se encuentra depositada en FHN. En negrita se presentan las localidades de registro más extremas en su distribución. Ver acrónimos en Materiales y Métodos. Ecorregiones sensu Olson et al. (2001): BV= Bosques Valdivianos; EP=

Estepa Patagónica; $\mathrm{BMg}=$ Bosques Magallánicos; PH= Pampas Húmedas.

\begin{tabular}{|c|c|c|c|c|c|c|c|c|}
\hline \multirow[b]{2}{*}{$\mathbf{N}^{0}$ Registro } & \multirow[b]{2}{*}{ Localidad } & \multicolumn{7}{|c|}{ Provincia/Región/ } \\
\hline & & Departamento & País & Ecorregión & Latitud & Longitud & Modelo & Referencia \\
\hline 1 & Lago Steffen (costa Norte, al Este) & Río Negro & Argentina & $\mathrm{BV}$ & $-41,51$ & $-71,55$ & 1950 & Chehébar, 1983 \\
\hline 2 & Laguna Hualahue & Río Negro & Argentina & $\mathrm{BV}$ & $-41,50$ & $-71,48$ & 1950 & Chehébar, 1983 \\
\hline 3 & Río Manso inferior & Río Negro & Argentina & $\mathrm{BV}$ & $-41,53$ & $-71,80$ & 1950 & Chehébar, 1983 \\
\hline 4 & Río Villegas (confluencia con el río Manso) & Río Negro & Argentina & $\mathrm{BV}$ & $-41,57$ & $-71,51$ & 1950 & Chehébar, 1983 \\
\hline 5 & Lago Roca & Río Negro & Argentina & $\mathrm{BV}$ & $-41,38$ & $-71,75$ & 1950 & Chehébar, 1983 \\
\hline 6 & Lago Felipe & Río Negro & Argentina & $\mathrm{BV}$ & $-41,40$ & $-71,86$ & 1950 & Chehébar, 1983 \\
\hline 7 & Lago Hess & Río Negro & Argentina & $\mathrm{BV}$ & $-41,36$ & $-71,72$ & 1950 & Chehébar, 1983 \\
\hline 8 & Lago Fonck & Río Negro & Argentina & $\mathrm{BV}$ & $-41,33$ & $-71,76$ & 1950 & Chehébar, 1983 \\
\hline 9 & -- & Chubut & Argentina & $\mathrm{BV}$ & $-42,06$ & $-71,52$ & 1950 & Pagnoni et al., 1986 \\
\hline 10 & -- & Chubut & Argentina & $\mathrm{BV}$ & $-42,06$ & $-71,56$ & 1950 & Pagnoni et al., 1986 \\
\hline 11 & -- & Chubut & Argentina & $\mathrm{BV}$ & $-42,09$ & $-71,61$ & 1950 & Pagnoni et al., 1986 \\
\hline 12 & -- & Chubut & Argentina & $\mathrm{BV}$ & $-42,09$ & $-71,69$ & 1950 & Pagnoni et al., 1986 \\
\hline 14 & -- & Chubut & Argentina & EP & $-42,02$ & $-70,80$ & 1950 & Pagnoni et al., 1986 \\
\hline 15 & -- & Chubut & Argentina & $\mathrm{EP}$ & $-42,17$ & $-71,11$ & 1950 & Pagnoni et al., 1986 \\
\hline
\end{tabular}


Continuación Tabla 6

\begin{tabular}{|c|c|c|c|c|c|c|c|c|}
\hline 16 & -- & Chubut & Argentina & $\mathrm{EP}$ & $-42,08$ & $-70,70$ & 1950 & Pagnoni et al., 1986 \\
\hline 17 & -- & Chubut & Argentina & $\mathrm{EP}$ & $-42,10$ & $-70,95$ & 1950 & Pagnoni et al., 1986 \\
\hline 18 & -- & Chubut & Argentina & $\mathrm{EP}$ & $-42,17$ & $-70,83$ & 1950 & Pagnoni et al., 1986 \\
\hline 19 & -- & Chubut & Argentina & $\mathrm{EP}$ & $-42,13$ & $-70,73$ & 1950 & Pagnoni et al., 1986 \\
\hline 20 & -- & Chubut & Argentina & $\mathrm{EP}$ & $-42,13$ & $-70,64$ & 1950 & Pagnoni et al., 1986 \\
\hline 21 & -- & Chubut & Argentina & $\mathrm{EP}$ & $-42,24$ & $-70,57$ & 1950 & Pagnoni et al., 1986 \\
\hline 22 & -- & Chubut & Argentina & $\mathrm{EP}$ & $-42,27$ & $-70,52$ & 1950 & Pagnoni et al., 1986 \\
\hline 23 & -- & Chubut & Argentina & $\mathrm{EP}$ & $-42,36$ & $-70,48$ & 1950 & Pagnoni et al., 1986 \\
\hline 24 & -- & Chubut & Argentina & $\mathrm{EP}$ & $-42,46$ & $-70,42$ & 1950 & Pagnoni et al., 1986 \\
\hline 25 & -- & Chubut & Argentina & $\mathrm{EP}$ & $-42,28$ & $-70,41$ & 1950 & Pagnoni et al., 1986 \\
\hline 26 & -- & Chubut & Argentina & $\mathrm{EP}$ & $-42,33$ & $-70,41$ & 1950 & Pagnoni et al., 1986 \\
\hline 27 & -- & Chubut & Argentina & $\mathrm{EP}$ & $-42,39$ & $-70,42$ & 1950 & Pagnoni et al., 1986 \\
\hline 28 & -- & Chubut & Argentina & $\mathrm{EP}$ & $-42,46$ & $-70,42$ & 1950 & Pagnoni et al., 1986 \\
\hline 29 & -- & Chubut & Argentina & $\mathrm{EP}$ & $-42,37$ & $-71,33$ & 1950 & Pagnoni et al., 1986 \\
\hline 30 & -- & Chubut & Argentina & $\mathrm{BV}$ & $-42,37$ & $-71,48$ & 1950 & Pagnoni et al., 1986 \\
\hline 31 & -- & Chubut & Argentina & $\mathrm{BV}$ & $-42,39$ & $-71,57$ & 1950 & Pagnoni et al., 1986 \\
\hline 32 & -- & Chubut & Argentina & $\mathrm{BV}$ & $-42,41$ & $-71,46$ & 1950 & Pagnoni et al., 1986 \\
\hline 33 & -- & Chubut & Argentina & $\mathrm{BV}$ & $-42,45$ & $-71,43$ & 1950 & Pagnoni et al., 1986 \\
\hline 34 & -- & Chubut & Argentina & $\mathrm{BV}$ & $-42,47$ & $-71,52$ & 1950 & Pagnoni et al., 1986 \\
\hline 35 & -- & Chubut & Argentina & $\mathrm{BV}$ & $-42,50$ & $-71,58$ & 1950 & Pagnoni et al., 1986 \\
\hline 36 & -- & Chubut & Argentina & $\mathrm{BV}$ & $-42,51$ & $-71,63$ & 1950 & Pagnoni et al., 1986 \\
\hline 37 & -- & Chubut & Argentina & $\mathrm{BV}$ & $-42,45$ & $-71,64$ & 1950 & Pagnoni et al., 1986 \\
\hline 38 & -- & Chubut & Argentina & $\mathrm{BV}$ & $-42,70$ & $-71,68$ & 1950 & Pagnoni et al., 1986 \\
\hline 39 & -- & Chubut & Argentina & $\mathrm{BV}$ & $-42,73$ & $-71,62$ & 1950 & Pagnoni et al., 1986 \\
\hline 40 & -- & Chubut & Argentina & $\mathrm{BV}$ & $-42,74$ & $-71,44$ & 1950 & Pagnoni et al., 1986 \\
\hline 41 & -- & Chubut & Argentina & $\mathrm{BV}$ & $-42,76$ & $-71,68$ & 1950 & Pagnoni et al., 1986 \\
\hline 42 & -- & Chubut & Argentina & $\mathrm{BV}$ & $-42,84$ & $-71,62$ & 1950 & Pagnoni et al., 1986 \\
\hline
\end{tabular}


Continuación Tabla 6

\begin{tabular}{|c|c|c|c|c|c|c|c|c|}
\hline 43 & -- & Chubut & Argentina & $\mathrm{BV}$ & $-42,85$ & $-71,51$ & 1950 & Pagnoni et al., 1986 \\
\hline 44 & -- & Chubut & Argentina & $\mathrm{BV}$ & $-42,88$ & $-71,62$ & 1950 & Pagnoni et al., 1986 \\
\hline 45 & -- & Chubut & Argentina & $\mathrm{BV}$ & $-42,90$ & $-71,57$ & 1950 & Pagnoni et al., 1986 \\
\hline 46 & -- & Chubut & Argentina & $\mathrm{BV}$ & $-42,93$ & $-71,63$ & 1950 & Pagnoni et al., 1986 \\
\hline 47 & -- & Chubut & Argentina & EP & $-42,74$ & $-71,03$ & 1950 & Pagnoni et al., 1986 \\
\hline 48 & -- & Chubut & Argentina & EP & $-42,84$ & $-71,19$ & 1950 & Pagnoni et al., 1986 \\
\hline 49 & -- & Chubut & Argentina & $\mathrm{EP}$ & $-42,93$ & $-71,36$ & 1950 & Pagnoni et al., 1986 \\
\hline 50 & -- & Chubut & Argentina & $\mathrm{BV}$ & $-43,00$ & $-71,41$ & 1950 & Pagnoni et al., 1986 \\
\hline 51 & -- & Chubut & Argentina & EP & $-42,67$ & $-70,64$ & 1950 & Pagnoni et al., 1986 \\
\hline 52 & -- & Chubut & Argentina & EP & $-42,72$ & $-70,68$ & 1950 & Pagnoni et al., 1986 \\
\hline 53 & -- & Chubut & Argentina & $\mathrm{EP}$ & $-42,83$ & $-70,60$ & 1950 & Pagnoni et al., 1986 \\
\hline 54 & -- & Chubut & Argentina & EP & $-42,99$ & $-70,77$ & 1950 & Pagnoni et al., 1986 \\
\hline 55 & -- & Chubut & Argentina & EP & $-43,05$ & $-70,80$ & 1950 & Pagnoni et al., 1986 \\
\hline 56 & -- & Chubut & Argentina & EP & $-42,60$ & $-70,38$ & 1950 & Pagnoni et al., 1986 \\
\hline 57 & -- & Chubut & Argentina & $\mathrm{EP}$ & $-42,62$ & $-70,45$ & 1950 & Pagnoni et al., 1986 \\
\hline 58 & -- & Chubut & Argentina & $\mathrm{EP}$ & $-42,64$ & $-70,40$ & 1950 & Pagnoni et al., 1986 \\
\hline 59 & -- & Chubut & Argentina & EP & $-42,73$ & $-70,44$ & 1950 & Pagnoni et al., 1986 \\
\hline 60 & -- & Chubut & Argentina & EP & $-42,74$ & $-70,39$ & 1950 & Pagnoni et al., 1986 \\
\hline 61 & -- & Chubut & Argentina & EP & $-42,73$ & $-70,45$ & 1950 & Pagnoni et al., 1986 \\
\hline 62 & -- & Chubut & Argentina & $\mathrm{EP}$ & $-42,70$ & $-70,34$ & 1950 & Pagnoni et al., 1986 \\
\hline 63 & -- & Chubut & Argentina & EP & $-42,65$ & $-70,24$ & 1950 & Pagnoni et al., 1986 \\
\hline 64 & -- & Chubut & Argentina & EP & $-42,65$ & $-70,00$ & 1950 & Pagnoni et al., 1986 \\
\hline 65 & -- & Chubut & Argentina & $\mathrm{EP}$ & $-42,72$ & $-70,00$ & 1950 & Pagnoni et al., 1986 \\
\hline 66 & -- & Chubut & Argentina & $\mathrm{EP}$ & $-42,70$ & $-69,70$ & 1950 & Pagnoni et al., 1986 \\
\hline 67 & -- & Chubut & Argentina & $\mathrm{EP}$ & $-42,85$ & $-69,55$ & 1950 & Pagnoni et al., 1986 \\
\hline 68 & -- & Chubut & Argentina & $\mathrm{BV}$ & $-43,17$ & $-71,55$ & 1950 & Pagnoni et al., 1986 \\
\hline 69 & -- & Chubut & Argentina & $\mathrm{BV}$ & $-43,17$ & $-71,28$ & 1950 & Pagnoni et al., 1986 \\
\hline
\end{tabular}


Continuación Tabla 6

\begin{tabular}{|c|c|c|c|c|c|c|c|c|}
\hline 70 & -- & Chubut & Argentina & $\mathrm{EP}$ & $-43,18$ & $-71,07$ & 1950 & Pagnoni et al., 1986 \\
\hline 71 & -- & Chubut & Argentina & $\mathrm{BV}$ & $-43,26$ & $-71,31$ & 1950 & Pagnoni et al., 1986 \\
\hline 72 & -- & Chubut & Argentina & $\mathrm{BV}$ & $-43,41$ & $-71,50$ & 1950 & Pagnoni et al., 1986 \\
\hline 73 & -- & Chubut & Argentina & $\mathrm{BV}$ & $-43,45$ & $-71,70$ & 1950 & Pagnoni et al., 1986 \\
\hline 74 & -- & Chubut & Argentina & $\mathrm{BV}$ & $-43,53$ & $-71,71$ & 1950 & Pagnoni et al., 1986 \\
\hline 75 & -- & Chubut & Argentina & $\mathrm{BV}$ & $-43,53$ & $-71,64$ & 1950 & Pagnoni et al., 1986 \\
\hline 76 & -- & Chubut & Argentina & $\mathrm{BV}$ & $-43,58$ & $-71,61$ & 1950 & Pagnoni et al., 1986 \\
\hline 77 & -- & Chubut & Argentina & $\mathrm{BV}$ & $-43,60$ & $-71,55$ & 1950 & Pagnoni et al., 1986 \\
\hline 78 & -- & Chubut & Argentina & $\mathrm{BV}$ & $-43,61$ & $-71,47$ & 1950 & Pagnoni et al., 1986 \\
\hline 79 & -- & Chubut & Argentina & $\mathrm{BV}$ & $-43,63$ & $-71,38$ & 1950 & Pagnoni et al., 1986 \\
\hline 80 & -- & Chubut & Argentina & $\mathrm{EP}$ & $-43,51$ & $-71,04$ & 1950 & Pagnoni et al., 1986 \\
\hline 81 & -- & Chubut & Argentina & $\mathrm{EP}$ & $-43,55$ & $-70,92$ & 1950 & Pagnoni et al., 1986 \\
\hline 82 & -- & Chubut & Argentina & $\mathrm{EP}$ & $-43,52$ & $-70,58$ & 1950 & Pagnoni et al., 1986 \\
\hline 83 & -- & Chubut & Argentina & $\mathrm{EP}$ & $-43,49$ & $-70,44$ & 1950 & Pagnoni et al., 1986 \\
\hline 84 & -- & Chubut & Argentina & $\mathrm{EP}$ & $-43,76$ & $-71,20$ & 1950 & Pagnoni et al., 1986 \\
\hline 85 & -- & Chubut & Argentina & $\mathrm{BV}$ & $-43,82$ & $-71,50$ & 1950 & Pagnoni et al., 1986 \\
\hline 86 & -- & Chubut & Argentina & $\mathrm{BV}$ & $-43,97$ & $-71,53$ & 1950 & Pagnoni et al., 1986 \\
\hline 87 & -- & Chubut & Argentina & $\mathrm{BV}$ & $-44,02$ & $-71,45$ & 1950 & Pagnoni et al., 1986 \\
\hline 88 & -- & Chubut & Argentina & $\mathrm{BV}$ & $-44,12$ & $-71,49$ & 1950 & Pagnoni et al., 1986 \\
\hline 89 & -- & Chubut & Argentina & $\mathrm{BV}$ & $-44,19$ & $-71,55$ & 1950 & Pagnoni et al., 1986 \\
\hline 90 & -- & Chubut & Argentina & $\mathrm{BV}$ & $-44,22$ & $-71,60$ & 1950 & Pagnoni et al., 1986 \\
\hline 91 & -- & Chubut & Argentina & $\mathrm{BV}$ & $-44,25$ & $-71,64$ & 1950 & Pagnoni et al., 1986 \\
\hline 92 & -- & Chubut & Argentina & $\mathrm{BV}$ & $-44,21$ & $-71,67$ & 1950 & Pagnoni et al., 1986 \\
\hline 93 & -- & Chubut & Argentina & $\mathrm{BV}$ & $-44,29$ & $-71,57$ & 1950 & Pagnoni et al., 1986 \\
\hline 94 & -- & Chubut & Argentina & $\mathrm{BV}$ & $-44,29$ & $-71,49$ & 1950 & Pagnoni et al., 1986 \\
\hline 95 & -- & Chubut & Argentina & $\mathrm{BV}$ & $-44,24$ & $-71,47$ & 1950 & Pagnoni et al., 1986 \\
\hline 96 & -- & Chubut & Argentina & $\mathrm{EP}$ & $-44,22$ & $-71,27$ & 1950 & Pagnoni et al., 1986 \\
\hline
\end{tabular}


Continuación Tabla 6

\begin{tabular}{|c|c|c|c|c|c|c|c|c|}
\hline 97 & -- & Chubut & Argentina & EP & $-43,97$ & $-70,86$ & 1950 & Pagnoni et al., 1986 \\
\hline 98 & -- & Chubut & Argentina & $\mathrm{EP}$ & $-43,98$ & $-70,77$ & 1950 & Pagnoni et al., 1986 \\
\hline 99 & -- & Chubut & Argentina & EP & $-44,05$ & $-70,49$ & 1950 & Pagnoni et al., 1986 \\
\hline 100 & -- & Chubut & Argentina & EP & $-44,14$ & $-70,84$ & 1950 & Pagnoni et al., 1986 \\
\hline 101 & -- & Chubut & Argentina & EP & $-44,18$ & $-70,84$ & 1950 & Pagnoni et al., 1986 \\
\hline 102 & -- & Chubut & Argentina & EP & $-44,50$ & $-70,76$ & 1950 & Pagnoni et al., 1986 \\
\hline 103 & -- & Chubut & Argentina & $\mathrm{EP}$ & $-44,36$ & $-71,04$ & 1950 & Pagnoni et al., 1986 \\
\hline 104 & -- & Chubut & Argentina & EP & $-44,43$ & $-70,95$ & 1950 & Pagnoni et al., 1986 \\
\hline 105 & -- & Chubut & Argentina & $\mathrm{EP}$ & $-44,48$ & $-71,02$ & 1950 & Pagnoni et al., 1986 \\
\hline 106 & -- & Chubut & Argentina & EP & $-44,41$ & $-70,65$ & 1950 & Pagnoni et al., 1986 \\
\hline 107 & -- & Chubut & Argentina & EP & $-44,48$ & $-70,52$ & 1950 & Pagnoni et al., 1986 \\
\hline 108 & -- & Chubut & Argentina & EP & $-44,67$ & $-70,76$ & 1950 & Pagnoni et al., 1986 \\
\hline 109 & -- & Chubut & Argentina & EP & $-44,65$ & $-70,84$ & 1950 & Pagnoni et al., 1986 \\
\hline 110 & -- & Chubut & Argentina & BV & $-44,66$ & $-71,09$ & 1950 & Pagnoni et al., 1986 \\
\hline 111 & -- & Chubut & Argentina & $\mathrm{EP}$ & $-44,10$ & $-70,39$ & 1950 & Pagnoni et al., 1986 \\
\hline 112 & -- & Chubut & Argentina & EP & $-44,15$ & $-70,39$ & 1950 & Pagnoni et al., 1986 \\
\hline 113 & -- & Chubut & Argentina & $\mathrm{EP}$ & $-44,31$ & $-70,37$ & 1950 & Pagnoni et al., 1986 \\
\hline 114 & -- & Chubut & Argentina & $\mathrm{BV}$ & $-44,80$ & $-71,38$ & 1950 & Pagnoni et al., 1986 \\
\hline 115 & -- & Chubut & Argentina & EP & $-44,97$ & $-71,28$ & 1950 & Pagnoni et al., 1986 \\
\hline 116 & -- & Chubut & Argentina & $\mathrm{EP}$ & $-45,01$ & $-70,94$ & 1950 & Pagnoni et al., 1986 \\
\hline 117 & -- & Chubut & Argentina & $\mathrm{EP}$ & $-45,15$ & $-71,06$ & 1950 & Pagnoni et al., 1986 \\
\hline 118 & -- & Chubut & Argentina & $\mathrm{EP}$ & $-45,15$ & $-71,13$ & 1950 & Pagnoni et al., 1986 \\
\hline 119 & -- & Chubut & Argentina & EP & $-45,22$ & $-71,27$ & 1950 & Pagnoni et al., 1986 \\
\hline 120 & -- & Chubut & Argentina & $\mathrm{EP}$ & $-45,28$ & $-71,22$ & 1950 & Pagnoni et al., 1986 \\
\hline 121 & -- & Chubut & Argentina & $\mathrm{EP}$ & $-45,32$ & $-71,13$ & 1950 & Pagnoni et al., 1986 \\
\hline 122 & -- & Chubut & Argentina & $\mathrm{EP}$ & $-45,41$ & $-70,76$ & 1950 & Pagnoni et al., 1986 \\
\hline 123 & -- & Chubut & Argentina & $\mathrm{EP}$ & $-45,13$ & $-70,67$ & 1950 & Pagnoni et al., 1986 \\
\hline
\end{tabular}


Continuación Tabla 6

\begin{tabular}{|c|c|c|c|c|c|c|c|c|}
\hline 124 & -- & Chubut & Argentina & BV & $-45,72$ & $-71,68$ & 1950 & Pagnoni et al., 1986 \\
\hline 125 & -- & Chubut & Argentina & BV & $-45,61$ & $-71,63$ & 1950 & Pagnoni et al., 1986 \\
\hline 126 & -- & Chubut & Argentina & BV & $-45,65$ & $-71,55$ & 1950 & Pagnoni et al., 1986 \\
\hline 127 & -- & Chubut & Argentina & EP & $-45,64$ & $-71,44$ & 1950 & Pagnoni et al., 1986 \\
\hline 128 & -- & Chubut & Argentina & EP & $-45,61$ & $-71,35$ & 1950 & Pagnoni et al., 1986 \\
\hline 129 & -- & Chubut & Argentina & EP & $-45,75$ & $-70,99$ & 1950 & Pagnoni et al., 1986 \\
\hline 130 & -- & Chubut & Argentina & $\mathrm{EP}$ & $-45,65$ & $-70,85$ & 1950 & Pagnoni et al., 1986 \\
\hline 131 & -- & Chubut & Argentina & EP & $-45,67$ & $-70,78$ & 1950 & Pagnoni et al., 1986 \\
\hline 132 & -- & Chubut & Argentina & EP & $-45,64$ & $-70,66$ & 1950 & Pagnoni et al., 1986 \\
\hline 133 & -- & Chubut & Argentina & EP & $-45,64$ & $-70,58$ & 1950 & Pagnoni et al., 1986 \\
\hline 134 & -- & Chubut & Argentina & $\mathrm{EP}$ & $-45,63$ & $-70,51$ & 1950 & Pagnoni et al., 1986 \\
\hline 135 & -- & Chubut & Argentina & EP & $-45,70$ & $-70,55$ & 1950 & Pagnoni et al., 1986 \\
\hline 136 & -- & Chubut & Argentina & EP & $-45,70$ & $-70,46$ & 1950 & Pagnoni et al., 1986 \\
\hline 137 & -- & Chubut & Argentina & EP & $-45,81$ & $-70,32$ & 1950 & Pagnoni et al., 1986 \\
\hline 138 & -- & Chubut & Argentina & EP & $-45,92$ & $-70,15$ & 1950 & Pagnoni et al., 1986 \\
\hline 139 & -- & Chubut & Argentina & $\mathrm{EP}$ & $-45,47$ & $-70,17$ & 1950 & Pagnoni et al., 1986 \\
\hline 140 & -- & Chubut & Argentina & EP & $-45,48$ & $-70,09$ & 1950 & Pagnoni et al., 1986 \\
\hline 141 & -- & Chubut & Argentina & EP & $-45,65$ & $-70,07$ & 1950 & Pagnoni et al., 1986 \\
\hline 142 & -- & Chubut & Argentina & EP & $-45,64$ & $-69,96$ & 1950 & Pagnoni et al., 1986 \\
\hline 143 & -- & Chubut & Argentina & $\mathrm{EP}$ & $-45,77$ & $-69,93$ & 1950 & Pagnoni et al., 1986 \\
\hline 144 & -- & Chubut & Argentina & $\mathrm{EP}$ & $-45,69$ & $-69,80$ & 1950 & Pagnoni et al., 1986 \\
\hline 145 & -- & Chubut & Argentina & $\mathrm{EP}$ & $-45,63$ & $-69,74$ & 1950 & Pagnoni et al., 1986 \\
\hline 146 & -- & Chubut & Argentina & $\mathrm{EP}$ & $-45,80$ & $-69,82$ & 1950 & Pagnoni et al., 1986 \\
\hline 147 & -- & Chubut & Argentina & EP & $-45,89$ & $-69,82$ & 1950 & Pagnoni et al., 1986 \\
\hline 148 & -- & Chubut & Argentina & $\mathrm{EP}$ & $-45,99$ & $-69,69$ & 1950 & Pagnoni et al., 1986 \\
\hline 149 & -- & Chubut & Argentina & $\mathrm{EP}$ & $-45,94$ & $-69,66$ & 1950 & Pagnoni et al., 1986 \\
\hline 150 & -- & Chubut & Argentina & $\mathrm{EP}$ & $-46,00$ & $-69,60$ & 1950 & Pagnoni et al., 1986 \\
\hline
\end{tabular}


Continuación Tabla 6

\begin{tabular}{|c|c|c|c|c|c|c|c|c|}
\hline 151 & -- & Chubut & Argentina & $\mathrm{EP}$ & $-45,98$ & $-69,45$ & 1950 & Pagnoni et al., 1986 \\
\hline 152 & -- & Chubut & Argentina & $\mathrm{EP}$ & $-45,89$ & $-69,45$ & 1950 & Pagnoni et al., 1986 \\
\hline 153 & -- & Chubut & Argentina & $\mathrm{EP}$ & $-45,80$ & $-69,32$ & 1950 & Pagnoni et al., 1986 \\
\hline 154 & -- & Chubut & Argentina & $\mathrm{EP}$ & $-45,83$ & $-69,26$ & 1950 & Pagnoni et al., 1986 \\
\hline 155 & -- & Chubut & Argentina & $\mathrm{EP}$ & $-45,83$ & $-69,24$ & 1950 & Pagnoni et al., 1986 \\
\hline 156 & -- & Chubut & Argentina & $\mathrm{EP}$ & $-45,64$ & $-69,27$ & 1950 & Pagnoni et al., 1986 \\
\hline 157 & -- & Chubut & Argentina & $\mathrm{EP}$ & $-45,49$ & $-69,32$ & 1950 & Pagnoni et al., 1986 \\
\hline 158 & -- & Chubut & Argentina & $\mathrm{EP}$ & $-45,59$ & $-69,06$ & 1950 & Pagnoni et al., 1986 \\
\hline 159 & -- & Chubut & Argentina & $\mathrm{EP}$ & $-45,55$ & $-69,00$ & 1950 & Pagnoni et al., 1986 \\
\hline 160 & -- & Chubut & Argentina & $\mathrm{EP}$ & $-45,61$ & $-68,97$ & 1950 & Pagnoni et al., 1986 \\
\hline 161 & -- & Chubut & Argentina & $\mathrm{EP}$ & $-45,66$ & $-68,94$ & 1950 & Pagnoni et al., 1986 \\
\hline 162 & -- & Chubut & Argentina & $\mathrm{EP}$ & $-45,72$ & $-68,89$ & 1950 & Pagnoni et al., 1986 \\
\hline 163 & -- & Chubut & Argentina & $\mathrm{EP}$ & $-44,73$ & $-68,80$ & 1950 & Pagnoni et al., 1986 \\
\hline 164 & -- & Chubut & Argentina & $\mathrm{EP}$ & $-44,98$ & $-70,30$ & 1950 & Pagnoni et al., 1986 \\
\hline 165 & -- & Chubut & Argentina & $\mathrm{EP}$ & $-44,94$ & $-70,22$ & 1950 & Pagnoni et al., 1986 \\
\hline 166 & -- & Chubut & Argentina & $\mathrm{EP}$ & $-44,98$ & $-70,11$ & 1950 & Pagnoni et al., 1986 \\
\hline 167 & -- & Chubut & Argentina & $\mathrm{EP}$ & $-45,04$ & $-70,09$ & 1950 & Pagnoni et al., 1986 \\
\hline 168 & -- & Chubut & Argentina & $\mathrm{EP}$ & $-45,03$ & $-70,03$ & 1950 & Pagnoni et al., 1986 \\
\hline 169 & -- & Chubut & Argentina & $\mathrm{EP}$ & $-45,12$ & $-70,08$ & 1950 & Pagnoni et al., 1986 \\
\hline 170 & -- & Chubut & Argentina & $\mathrm{EP}$ & $-45,13$ & $-70,00$ & 1950 & Pagnoni et al., 1986 \\
\hline 171 & -- & Chubut & Argentina & $\mathrm{EP}$ & $-45,19$ & $-70,08$ & 1950 & Pagnoni et al., 1986 \\
\hline 172 & -- & Chubut & Argentina & $\mathrm{EP}$ & $-45,24$ & $-70,08$ & 1950 & Pagnoni et al., 1986 \\
\hline 173 & -- & Chubut & Argentina & $\mathrm{EP}$ & $-45,21$ & $-70,02$ & 1950 & Pagnoni et al., 1986 \\
\hline 174 & -- & Chubut & Argentina & $\mathrm{EP}$ & $-45,29$ & $-70,04$ & 1950 & Pagnoni et al., 1986 \\
\hline 175 & -- & Chubut & Argentina & EP & $-45,33$ & $-70,00$ & 1950 & Pagnoni et al., 1986 \\
\hline 176 & -- & Chubut & Argentina & $\mathrm{EP}$ & $-45,37$ & $-69,98$ & 1950 & Pagnoni et al., 1986 \\
\hline 177 & -- & Chubut & Argentina & $\mathrm{EP}$ & $-45,42$ & $-69,96$ & 1950 & Pagnoni et al., 1986 \\
\hline
\end{tabular}


Continuación Tabla 6

\begin{tabular}{|c|c|}
\hline 178 & -- \\
\hline 179 & -- \\
\hline 180 & -- \\
\hline 181 & -- \\
\hline 182 & -- \\
\hline 183 & -- \\
\hline 184 & -- \\
\hline 185 & Lago Panguipulli \\
\hline 186 & Río Enco \\
\hline 187 & Lago Todos los Santos \\
\hline 188 & Río Petrohué \\
\hline 189 & $\begin{array}{l}\text { Isla Victoria } \\
\text { Litoral de Guerrico (costa norte de Isla }\end{array}$ \\
\hline 190 & Navarino) \\
\hline 191 & Desembocadura del río Lum \\
\hline 192 & Bahía Mejillones \\
\hline 193 & Parque Etnobotánico Omora \\
\hline 194 & Lago Chepelmut \\
\hline 195 & Lago Yehuin \\
\hline 196 & Lago Yakush \\
\hline 197 & Lago Roca \\
\hline 198 & Hantuk \\
\hline 199 & Río Almanza \\
\hline 200 & Río Ewan \\
\hline 201 & Río Indio \\
\hline 202 & Río Inn \\
\hline 203 & Río Lapataia \\
\hline
\end{tabular}

\begin{tabular}{|c|c|c|c|c|c|c|}
\hline Chubut & Argentina & $\mathrm{EP}$ & $-45,39$ & $-69,90$ & 1950 & Pagnoni et al., 1986 \\
\hline Chubut & Argentina & $\mathrm{EP}$ & $-45,41$ & $-69,85$ & 1950 & Pagnoni et al., 1986 \\
\hline Chubut & Argentina & EP & $-45,45$ & $-69,87$ & 1950 & Pagnoni et al., 1986 \\
\hline Chubut & Argentina & EP & $-45,49$ & $-69,89$ & 1950 & Pagnoni et al., 1986 \\
\hline Chubut & Argentina & $\mathrm{EP}$ & $-45,48$ & $-69,84$ & 1950 & Pagnoni et al., 1986 \\
\hline Chubut & Argentina & $\mathrm{EP}$ & $-45,56$ & $-69,86$ & 1950 & Pagnoni et al., 1986 \\
\hline Chubut & Argentina & $\mathrm{EP}$ & $-45,54$ & $-69,80$ & 1950 & Pagnoni et al., 1986 \\
\hline Araucania & Chile & BV & $-39,72$ & $-72,22$ & 1950 & Medina, 1997 \\
\hline Araucania & Chile & BV & $-39,92$ & $-72,18$ & 1950 & Medina, 1997 \\
\hline de Los Lagos & Chile & BV & $-41,10$ & $-72,25$ & 1950 & Medina, 1997 \\
\hline de Los Lagos & Chile & BV & $-41,37$ & $-72,32$ & 1950 & Medina, 1997 \\
\hline Río Negro & Argentina & $\mathrm{BV}$ & $-40,93$ & $-71,55$ & 1950 & Previtali et al., 1998 \\
\hline Magallanes & Chile & $\mathrm{BMg}$ & $-54,92$ & $-67,90$ & 1950 & Rozzi y Sheffields, 2003 \\
\hline Magallanes & Chile & $\mathrm{BMg}$ & $-54,93$ & $-68,05$ & 1950 & Rozzi y Sheffields, 2003 \\
\hline Magallanes & Chile & $\mathrm{BMg}$ & $-54,92$ & $-68,02$ & 1950 & Rozzi y Sheffields, 2003 \\
\hline Magallanes & Chile & $\mathrm{BMg}$ & $-54,95$ & $-67,65$ & 1950 & Rozzi y Sheffields, 2003 \\
\hline Tierra del Fuego & Argentina & $\mathrm{BMg}$ & $-54,40$ & $-67,58$ & 1950 & Modificados de Valenzuela et al., 2013 \\
\hline Tierra del Fuego & Argentina & $\mathrm{BMg}$ & $-54,42$ & $-67,68$ & 1950 & Modificados de Valenzuela et al., 2013 \\
\hline Tierra del Fuego & Argentina & $\mathrm{BMg}$ & $-54,47$ & $-67,68$ & 1950 & Modificados de Valenzuela et al., 2013 \\
\hline Tierra del Fuego & Argentina & $\mathrm{BMg}$ & $-54,78$ & $-68,63$ & 1950 & Modificados de Valenzuela et al., 2013 \\
\hline Tierra del Fuego & Argentina & $\mathrm{BMg}$ & $-54,40$ & $-68,63$ & 1950 & Modificados de Valenzuela et al., 2013 \\
\hline Tierra del Fuego & Argentina & $\mathrm{BMg}$ & $-54,88$ & $-67,62$ & 1950 & Modificados de Valenzuela et al., 2013 \\
\hline Tierra del Fuego & Argentina & $\mathrm{BMg}$ & $-54,22$ & $-67,20$ & 1950 & Modificados de Valenzuela et al., 2013 \\
\hline Tierra del Fuego & Argentina & $\mathrm{BMg}$ & $-54,45$ & $-67,68$ & 1950 & Modificados de Valenzuela et al., 2013 \\
\hline Tierra del Fuego & Argentina & $\mathrm{BMg}$ & $-54,42$ & $-68,63$ & 1950 & Modificados de Valenzuela et al., 2013 \\
\hline Tierra del Fuego & Argentina & $\mathrm{BMg}$ & $-54,83$ & $-68,63$ & 1950 & Modificados de Valenzuela et al., 2013 \\
\hline
\end{tabular}


Continuación Tabla 6

\begin{tabular}{|c|c|c|c|c|c|c|c|c|}
\hline 204 & Río Lasifashaj & Tierra del Fuego & Argentina & $\mathrm{BMg}$ & $-54,88$ & $-67,37$ & 1950 & Modificados de Valenzuela et al., 2013 \\
\hline 205 & Río Mímica & Tierra del Fuego & Argentina & $\mathrm{BMg}$ & $-54,45$ & $-68,63$ & 1950 & Modificados de Valenzuela et al., 2013 \\
\hline 206 & Criadero Río Grande & Tierra del Fuego & Argentina & EP & $-53,78$ & $-67,70$ & -- & FHN (CEM) 2274, FHN (CEM) 2275 \\
\hline 207 & $\mathrm{~A}^{\mathrm{o} P e s c a d o}$ & Chubut & Argentina & $\mathrm{EP}$ & $-43,07$ & $-70,91$ & 1950 & LIEB 806 \\
\hline 208 & Alrededores Esquel, $\mathrm{A}^{\circ} \mathrm{Seco}$ & Chubut & Argentina & EP & $-42,95$ & $-71,40$ & 1950 & LIEB 805 \\
\hline 209 & Colan Conhue & Chubut & Argentina & EP & $-43,27$ & $-69,85$ & 1950 & LIEB 807 \\
\hline 210 & PN Los Alerces & Chubut & Argentina & BV & $-43,11$ & $-71,50$ & 1950 & LIEB 886 \\
\hline 211 & Ruta 259 a 12 Km Esquel & Chubut & Argentina & $\mathrm{BV}$ & $-43,01$ & $-71,41$ & 1950 & LIEB 885 \\
\hline 212 & Pn Los Alerces, Futalaufquen & Chubut & Argentina & $\mathrm{BV}$ & $-42,83$ & $-71,87$ & 1950 & MACN 16327 \\
\hline 213 & Lago Músters & Chubut & Argentina & $\mathrm{EP}$ & $-45,21$ & $-69,13$ & 1950 & MACN 22228 \\
\hline 214 & Criadero Batán & Buenos Aires & Argentina & PH & $-38,00$ & $-57,72$ & -- & MACN 19185, MACN 19186, MACN 19187, MACN 19188 \\
\hline 215 & San Vicente & Buenos Aires & Argentina & $\mathrm{PH}$ & $-34,96$ & $-58,36$ & -- & MLP 27.X.97.2, MLP 27.X.97.6 \\
\hline
\end{tabular}


Tabla 7. Localidades de registro de Conepatus chinga, utilizadas en los análisis de distribución. Ht= Holotipo. En negrita se presentan las localidades de registro más extremas en su distribución. Ver acrónimos en Materiales y Métodos. Ecorregiones sensu Olson et al. (2001): Esp=

Espinal; PC= Puna Central; DSch= Desierto de Sechura; BM: Bosques Montanos; ChS= Chaco Seco; PH= Pampas Húmedas; MA= Monte Alto; YA= Yungas Andinas; YP=

Yungas Peruanas; $\mathrm{MB}=$ Monte Bajo; $\mathrm{BMg}=$ Bosques Magallánicos; EP= Estepa Patagónica; BHA= Bosques Húmedos de Araucaria, $\mathrm{SU}=$ Sabana Uruguaya; $\mathrm{BV}=$ Bosques

Valdivianos; $\mathrm{MCh}=$ Matorral Chileno; $\mathrm{ChH}=$ Chaco Húmedo; EA= Estepa Andina.

\begin{tabular}{|c|c|c|c|c|c|c|c|c|}
\hline $\begin{array}{l}\mathbf{N}^{\circ} \\
\text { Registro } \\
\end{array}$ & Localidad & $\begin{array}{l}\text { Provincia /Región/ } \\
\text { Departamento }\end{array}$ & País & Ecorregión & Latitud & Longitud & Modelo & Referencia \\
\hline 1 & Bahía San Blas, cerca de la boca del Río Negro & Buenos Aires & Argentina & Esp & $-40,71$ & $-62,26$ & Actual & d'Orbigny y Gervais, 1847 (Ht. C. castaneus) \\
\hline 2 & Esperanza, $45 \mathrm{~km}$ del Monte Sajama & Dto Oruro & Bolivia & PC & $-17,82$ & $-68,78$ & Actual & Thomas, 1898 (Ht. C. rex) \\
\hline 3 & Callao & Lima & Perú & DSch & $-12,03$ & $-77,13$ & Actual & Thomas, 1900a (Ht. C. inca) \\
\hline 4 & Sumbay & Arequipa & Perú & $\mathrm{PC}$ & $-15,98$ & $-71,36$ & Actual & Thomas, 1900b (Ht. C. arequipae) \\
\hline 5 & Choro, on paramo north of Cochabamba & Cochabamba & Bolivia & $\mathrm{BM}$ & $-16,93$ & $-66,70$ & Actual & Thomas, 1902a (Ht. C. chorensis) \\
\hline 6 & Cochabamba & Cochabamba & Bolivia & $\mathrm{BM}$ & $-17,38$ & $-66,15$ & Actual & Thomas, 1902a (Ht. C. porcinus) \\
\hline 7 & Cruz del Eje & Córdoba & Argentina & $\mathrm{ChS}$ & $-30,73$ & $-64,80$ & Actual & Thomas, $1902 \mathrm{~b}$ (Ht. C. proteus) \\
\hline 8 & Caylloma & Arequipa & Perú & $\mathrm{PC}$ & $-15,19$ & $-71,77$ & Actual & Thomas, 1903 (Ht. C. huntii) \\
\hline 9 & Estancia Los Yngleses & Buenos Aires & Argentina & $\mathrm{PH}$ & $-36,52$ & $-56,88$ & Actual & Thomas, 1910 (Ht. C. gibsoni) \\
\hline 10 & Maimará, near Humahuaca & Jujuy & Argentina & MA & $-23,62$ & $-65,40$ & Actual & Thomas, 1913 (Ht. C. ajax) \\
\hline 11 & Otro Cerro. A 4 Km SSE de Cerro Catalán & Catamarca & Argentina & YA & $-28,75$ & $-66,28$ & Actual & Thomas, 1919 (Ht. C. budini) \\
\hline 12 & Chachapoyas & Amazonas & Perú & YP & $-6,23$ & $-77,87$ & Actual & Thomas, 1924 (Ht. C. inca taxinus) \\
\hline 13 & Pichi Mahuida, on Río Colorado & Rïo Negro & Argentina & MB & $-38,83$ & $-64,95$ & Actual & Thomas, 1927 (Ht. C. proteus gaucho) \\
\hline 14 & Torres del Paine & De Magallanes & Chile & $\mathrm{BMg}$ & $-51,05$ & $-72,92$ & Actual-1950 & Fuller et al., 1987 \\
\hline 15 & Parque Natural Ischigualasto & San Juan & Argentina & MA & $-30,08$ & $-67,92$ & Actual-1950 & Acosta y murúa, 1999 \\
\hline 16 & Anamá and Trinidad, deparment of Moreno & Santiago del Estero & Argentina & $\mathrm{ChS}$ & $-27,21$ & $-63,04$ & Actual-1950 & Pietrokovsky et al. 1991 \\
\hline 17 & Estación experimental La María & Santiago del Estero & Argentina & $\mathrm{ChS}$ & $-28,05$ & $-64,25$ & Actual-1950 & Bilenca et al., 1999 \\
\hline
\end{tabular}


Continuación Tabla 7

\section{Collún-Có}

Deseado River

Parque Prov. Enrique Berduc

Reserva de Biósfera Mar Chiquita

Sacsamonte

Yanacocha

Parque Nacional dos Aparados da Serra

Reserva Bañados del Río Dulce y Laguna de Mar Chiquita

Migues

Ruta 39, proximidades de San Carlos

Erval Belho

Curitibanos

Sao Cristobal do Sul

Ponte Alta

Correia Pinto

Correia Pinto

Lages

Bocaina do Sul

Bocaina do Sul

Bocaina do Sul

\section{Bom Retiro}

Sao Cristobal do Sul

Sao Cristobal do Sul

Agua Doce

Painel

Painel

Sao Joaquim
Neuquén

Santa Cruz

Entre Ríos

Buenos Aires

Arequipa

Cajamarca

Rio Grande do Sul

Córdoba

Canelones

Maldonado

Santa Catarina

Santa Catarina

Santa Catarina

Santa Catarina

Santa Catarina

Santa Catarina

Santa Catarina

Santa Catarina

Santa Catarina

Santa Catarina

Santa Catarina

Santa Catarina

Santa Catarina

Santa Catarina

Santa Catarina

Santa Catarina

Santa Catarina
Argentina EP

Argentina EP

Argentina Esp

Argentina $\mathrm{PH}$

Perú

Perú YP

Brasil BHA

Argentina $\mathrm{ChS}$

Uruguay SU

Uruguay SU

Brasil BHA

Brasil BHA

Brasil BHA

Brasil BHA

Brasil BHA

Brasil BHA

Brasil BHA

Brasil BHA

Brasil BHA

Brasil BHA

Brasil BHA

Brasil BHA

Brasil BHA

Brasil BHA

Brasil BHA

Brasil BHA

Brasil
$-39,83$

$-47,78$

$-31,67$

$-37,58$

$-13,22$

$-13,27$

$-29,32$

$-30,03$

$-34,48$

$-34,78$

$-27,30$

$-27,30$

$-27,34$

$-27,49$

$-27,60$

$-27,65$

$-27,74$

$-27,73$

$-27,74$

$-27,74$

$-27,80$

$-27,30$

$-27,29$

$-27,02$

$-27,93$

$-27,99$

$-28,14$
-71,17 Actual-1950 Donadio et al., 2001

-65,91 Actual-1950 Zapata et al. 2001

-60,33 Actual-1950 Muzzachiodi y Sabattini, 2002

$-57,37$ Actual-1950 Bo et al., 2002

$-72,03$ Actual-1950 Servat et al., 2002

$-72,05$ Actual-1950 Servat et al., 2002

$-50,08$ Actual-1950 dos Santos et al. 2004

$-63,33$ Actual-1950 Kufner et al., 2005

-55,62 Actual-1950 Venzal et al. 2006

$-54,90$ Actual-1950 Venzal et al. 2006

$-51,40$ Actual-1950 Cherem et al. 2007

$-50,69$ Actual-1950 Cherem et al. 2007

$-50,43$ Actual-1950 Cherem et al. 2007

$-50,37$ Actual-1950 Cherem et al. 2007

$-50,35$ Actual-1950 Cherem et al. 2007

$-50,34$ Actual-1950 Cherem et al. 2007

-50,04 Actual-1950 Cherem et al. 2007

-49,96 Actual-1950 Cherem et al. 2007

$-49,85$ Actual-1950 Cherem et al. 2007

$-49,81$ Actual-1950 Cherem et al. 2007

-49,48 Actual-1950 Cherem et al. 2007

$-50,30$ Actual-1950 Cherem et al. 2007

-50,19 Actual-1950 Cherem et al. 2007

$-51,56$ Actual-1950 Cherem et al. 2007

$-50,10$ Actual-1950 Cherem et al. 2007

$-50,09$ Actual-1950 Cherem et al. 2007

$-50,03$ Actual-1950 Cherem et al. 2007 
Continuación Tabla 7

Sao Joaquim
Sao Joaquim
Cconoc
Velavelayoc
Chiquintirca
Auquiraccay
Sacharaccay
Parque Luro
Abra la Raya, Melgar, Cusco
San Cristóbal
Distrito Pocsi
Parque prov E. Tornquist
Arroio Grande municipality
Campo Belo do Sul
Bom Jesus
Arroio Grande
Alegrete
Paraná
Tafí Viejo
Lavalle
Escalante, 100Km NW Comodoro Rivadavia
Sarmiento, Lago Colhue Huapi
Malleco, Angol
Punta Arenas
Melo, 6Km SE Melo
Melo, 20Km SE Melo, Río Tacuarí, Sierra de Vaz

\begin{tabular}{|c|c|c|c|c|c|c|}
\hline Santa Catarina & Brasil & BHA & $-28,19$ & $-50,01$ & Actual-1950 & Cherem et al. 2007 \\
\hline Santa Catarina & Brasil & BHA & $-28,21$ & $-49,78$ & Actual-1950 & Cherem et al. 2007 \\
\hline Apurímac & Perú & YP & $-13,54$ & $-72,63$ & Actual-1950 & Pacheco et al. 2007 \\
\hline Apurímac & Perú & YP & $-13,48$ & $-72,93$ & Actual-1950 & Pacheco et al. 2007 \\
\hline Anco & Perú & YP & $-13,06$ & $-73,71$ & Actual-1950 & Deustúa Aris et al. 2008 \\
\hline Anco & Perú & YP & $-13,10$ & $-73,76$ & Actual-1950 & Deustúa Aris et al. 2008 \\
\hline Anco & Perú & YP & $-13,08$ & $-73,85$ & Actual-1950 & Deustúa Aris et al. 2008 \\
\hline La Pampa & Argentina & Esp & $-36,92$ & $-64,27$ & Actual-1950 & Montalvo et al., 2008 \\
\hline Cusco & Perú & $\mathrm{PC}$ & $-14,48$ & $-71,03$ & Actual-1950 & Gómez-Puerta et al. 2009 \\
\hline Potosí & Bolivia & $\mathrm{CP}$ & $-21,12$ & $-67,20$ & Actual-1950 & Martínez et al. 2009 \\
\hline Pocsi & Perú & DSch & $-16,49$ & $-71,33$ & Actual-1950 & Medina et al., 2009 \\
\hline Buenos Aires & Argentina & $\mathrm{PH}$ & $-38,00$ & $-62,00$ & Actual-1950 & Castillo et al., 2011 \\
\hline Rio Grande do Sul & Brasil & SU & $-32,30$ & $-52,90$ & Actual-1950 & Kasper et al., 2012a \\
\hline Rio Grande do Sul & Brasil & BHA & $-27,97$ & $-50,82$ & Actual-1950 & Kasper et al., 2012b \\
\hline Rio Grande do Sul & Brasil & BHA & $-28,32$ & $-50,72$ & Actual-1950 & Kasper et al., 2012b \\
\hline Rio Grande do Sul & Brasil & SU & $-33,32$ & $-53,90$ & Actual-1950 & Kasper et al., 2012b \\
\hline Rio Grande do Sul & Brasil & SU & $-30,08$ & $-55,50$ & Actual-1950 & Kasper et al., 2012b \\
\hline Entre Rios & Argentina & Esp & $-31,73$ & $-60,53$ & Actual & AMNH 36932 \\
\hline Tucumán & Argentina & YA & $-26,73$ & $-65,27$ & Actual & AMNH 41529 \\
\hline Santiago del Estero & Argentina & $\mathrm{ChS}$ & $-28,20$ & $-65,13$ & Actual & AMNH 41530 \\
\hline Chubut & Argentina & $\mathrm{EP}$ & $-45,04$ & $-68,43$ & Actual & AMNH 94317 \\
\hline Chubut & Argentina & $\mathrm{EP}$ & $-45,65$ & $-68,55$ & Actual & AMNH 94318 \\
\hline Araucanía & Chile & $\mathrm{BV}$ & $-38,05$ & $-71,87$ & Actual & AMNH 93324 \\
\hline Magallanes & Chile & $\mathrm{BMg}$ & $-53,15$ & $-70,92$ & Actual & AMNH 130049 \\
\hline Cerro Largo & Uruguay & SU & $-32,41$ & $-54,12$ & Actual-1950 & AMNH 205837 \\
\hline Cerro Largo & Uruguay & SU & $-32,48$ & $-54,00$ & Actual-1950 & AMNH 205840 \\
\hline
\end{tabular}


Continuación Tabla 7

Zapican, 12 Km WSW de Zapican

Lascano, 22KM SE Lascano

Tacuarembo, 40Km NW Tacuarembó

Cardona, $3 \mathrm{Km}$ E Cardona

Vergara, 13Km WSW Vergara

Choya

Pilcaniyeu, Corralito

Canal de Alombres, Dto Trancas

Costa de mar en Canelones

Pergamino

Cerro Corona Chico, Meseta de Somuncurá

Cañadón Darwin, Corpen Aike

25 de Mayo

$10 \mathrm{Km}$ al E de Santa Rosa

Sarandí de los Perros, ruta 100, Km 60

Ea. Sta Elena, Caleu Caleu

Puerto Santa Cruz (Puerto Quilla), Corpen Aike

Colonia Gamara, Clodomira. Banda

Ea. Haichol, Picunches

Henderson, near

Ea. Huanu-luan

Sierras de Córdoba

R. Ecker (=Arroyo Eke)

Temuco, Maquehue

Concepción, Cerro Chipe

Valdivia, Rinihue

\begin{tabular}{|c|c|c|c|c|c|c|}
\hline Lavalleja & Uruguay & SU & $-33,59$ & $-55,06$ & Actual-1950 & AMNH 205843 \\
\hline Rocha & Uruguay & SU & $-33,80$ & $-53,99$ & Actual-1950 & AMNH 205870 \\
\hline Tacuarembó & Uruguay & SU & $-31,42$ & $-56,23$ & Actual-1950 & AMNH 205880 \\
\hline Soriano & Uruguay & SU & $-33,88$ & $-57,34$ & Actual-1950 & AMNH 205889 \\
\hline Treinta y Tres & Uruguay & SU & $-32,97$ & $-54,08$ & Actual-1950 & AMNH 205901 \\
\hline Santiago del Estero & Argentina & EP & $-43,68$ & $-68,73$ & Actual-1950 & FHN 10529 \\
\hline Río Negro & Argentina & $\mathrm{EP}$ & $-41,13$ & $-70,67$ & Actual & FHN 10866 \\
\hline Tucumán & Argentina & $\mathrm{ChS}$ & $-26,33$ & $-65,44$ & Actual-1950 & FHN 5543 \\
\hline Canelones & Uruguay & SU & $-34,78$ & $-55,90$ & Actual & FHN 6352 \\
\hline Buenos Aires & Argentina & $\mathrm{PH}$ & $-33,89$ & $-60,57$ & Actual & FHN 8122 \\
\hline Río Negro & Argentina & $\mathrm{MB}$ & $-41,82$ & $-66,92$ & Actual-1950 & FHN 8773 \\
\hline Santa Cruz & Argentina & $\mathrm{EP}$ & $-49,58$ & $-69,50$ & Actual-1950 & FHN 9376 \\
\hline Buenos Aires & Argentina & $\mathrm{PH}$ & $-35,43$ & $-60,17$ & Actual & FHN 9752 \\
\hline La Pampa & Argentina & Esp & $-36,61$ & $-63,96$ & Actual & FHN 8568 \\
\hline Durazno & Uruguay & SU & $-33,00$ & $-56,13$ & Actual-1950 & FHN 10613 \\
\hline La Pampa & Argentina & Esp & $-38,97$ & $-64,07$ & Actual-1950 & FHN 8915 \\
\hline Santa Cruz & Argentina & $\mathrm{EP}$ & $-50,02$ & $-68,52$ & Actual-1950 & FHN 9926 \\
\hline Santiago del Estero & Argentina & $\mathrm{ChS}$ & $-27,58$ & $-64,13$ & Actual & FHN 9457 \\
\hline Neuquén & Argentina & $\mathrm{EP}$ & $-38,42$ & $-70,50$ & Actual & FHN 6381 \\
\hline Buenos Aires & Argentina & $\mathrm{PH}$ & $-36,30$ & $-61,71$ & Actual & FMNH 24354 \\
\hline Río Negro & Argentina & $\mathrm{EP}$ & $-41,37$ & $-69,81$ & Actual & FMNH 34193 \\
\hline Córdoba & Argentina & $\mathrm{ChS}$ & $-31,00$ & $-65,08$ & Actual & FMNH 21673 \\
\hline Santa Cruz & Argentina & $\mathrm{EP}$ & $-47,07$ & $-70,75$ & Actual & FMNH 124325 \\
\hline Cautin & Chile & $\mathrm{MCh}$ & $-38,80$ & $-72,75$ & Actual & FMNH 146376 \\
\hline Bio Bio & Chile & BV & $-36,83$ & $-73,05$ & Actual & FMNH 24351 \\
\hline Los Lagos & Chile & BV & $-39,85$ & $-72,40$ & Actual & FMNH 24349 \\
\hline
\end{tabular}


Continuación Tabla 7

Coyhaique alto

R. Nireguao

Balseo, jct Ríos Simpson \& Manuiales, R Aysén

Última Esperanza, North Arm Station

N San Carlos

15 mi N San Vicente de Castillos

Quebrada de los cuervos

Est. "Los Alpes" 10Km S La Lata

15 mi SW Dolores

Passo Correntino

San Cristobal

Caleta Olivia

Neuquen

Pasando San Esteban

Cerca de Trenque Lauquen

Pasando Lincoln

Depto. La Paz sobre ruta $\mathrm{N}^{\circ} 6$

Dto. Trancas, Quebrada Las Burras

Dto. Tafí del Valle, La Angostura

Dto. Burruyacú, Estancia "El cavao"

Dto. Las trancas, La Cuesta

Las Mesadas, San Pedro de Colalao

Choele Choel, Dto. Avellaneda

San Martín de los Andes

Dto. Humahuaca, Tres Cruces

Estancia "Graciana", Dto. Padín

\begin{tabular}{|c|c|c|c|c|c|c|}
\hline Aysén & Chile & $\mathrm{EP}$ & $-45,48$ & $-71,60$ & Actual-1950 & FMNH 129840 \\
\hline Aysén & Chile & $\mathrm{BV}$ & $-45,23$ & $-71,73$ & Actual & FMNH 23294 \\
\hline Aysén & Chile & $\mathrm{BV}$ & $-45,40$ & $-72,53$ & Actual & FMNH 41361 \\
\hline Magallanes & Chile & $\mathrm{EP}$ & $-52,05$ & $-70,00$ & Actual & FMNH 50767 \\
\hline Maldonado & Uruguay & SU & $-34,80$ & $-54,92$ & Actual & FMNH 29280 \\
\hline Rocha & Uruguay & SU & $-34,13$ & $-53,83$ & Actual & FMNH 29281 \\
\hline Treinta y Tres & Uruguay & SU & $-32,90$ & $-54,42$ & Actual & FMNH 29283 \\
\hline Colonia & Uruguay & SU & $-31,75$ & $-54,42$ & Actual & FMNH 29290 \\
\hline Soriano & Uruguay & SU & $-33,55$ & $-58,22$ & Actual & FMNH 29295 \\
\hline Río Negro & Uruguay & SU & $-33,28$ & $-58,30$ & Actual & FMNH 29301 \\
\hline Santa fé & Argentina & Esp & $-30,32$ & $-61,24$ & Actual-1950 & GenBank JQ979121 \\
\hline Santa Cruz & Argentina & $\mathrm{EP}$ & $-46,61$ & $-68,50$ & Actual-1950 & GenBank JQ979118 \\
\hline Neuquen & Argentina & MB & $-38,94$ & $-68,06$ & Actual-1950 & GenBank JQ979122 \\
\hline Buenos Aires & Argentina & $\mathrm{PH}$ & $-34,86$ & $-58,53$ & Actual-1950 & GenBank JQ979119 \\
\hline Buenos Aires & Argentina & $\mathrm{PH}$ & $-34,85$ & $-58,44$ & Actual-1950 & GenBank JQ979124 \\
\hline Buenos Aires & Argentina & $\mathrm{PH}$ & $-34,83$ & $-61,49$ & Actual-1950 & GenBank JQ979120 \\
\hline Entre Rios & Argentina & $\mathrm{ChH}$ & $-30,23$ & $-59,30$ & Actual-1950 & GenBank JQ979125 \\
\hline Tucumán & Argentina & YA & $-26,30$ & $-65,05$ & Actual-1950 & IML 1077 \\
\hline Tucumán & Argentina & YA & $-26,92$ & $-65,68$ & Actual-1950 & IML 1184 \\
\hline Tucumán & Argentina & $\mathrm{ChS}$ & $-26,47$ & $-64,69$ & Actual-1950 & IML 1305 \\
\hline Tucumán & Argentina & $\mathrm{ChS}$ & $-26,42$ & $-65,50$ & Actual-1950 & IML 1532 \\
\hline Tucumán & Argentina & $\mathrm{ChS}$ & $-26,26$ & $-65,44$ & Actual & IML 1534 \\
\hline Río Negro & Argentina & MB & $-39,26$ & $-65,68$ & Actual & IML 182 \\
\hline Neuquén & Argentina & $\mathrm{BV}$ & $-40,17$ & $-71,35$ & Actual & IML 185 \\
\hline Jujuy & Argentina & $\mathrm{PC}$ & $-22,92$ & $-65,58$ & Actual & IML 187 \\
\hline Catamarca & Argentina & MA & $-26,01$ & $-65,85$ & Actual & IML 436 \\
\hline
\end{tabular}


Continuación Tabla 7

Dto, Ambato

Dto. Banda, Huyapampa

Río Salamanca

Dto. Santa Rosa, Ñacuñán

Cola del dique El Cadihal, a $5 \mathrm{~km}$ al $\mathrm{S}$ de Ticucho

Nevados del Aconquija, cerca del circo glaciar.

Lago Viedma

Dto Santa María, Puesto El Cura

Sobre ruta 52. cuesta de Lipan, 15 km O Purmamarca

Rinconada, Mina pan de azúcar, camino a Herrana

Tafí del Valle, Santa Cruz, a 10km S de Tafí del Valle

Dto. Anda-Juntas, Ríos Medina y Juramento

El Tranquilo, 250km al S de Colonia Las Heras

Lago Sarmiento, Torres del Paine, Chile

Brazo Norte, 115 km N. 63 E de Punta Arenas

Rio Caike, Est. Brazo Norte

Magallanes, Laguna Seca, $30 \mathrm{~km}$ al N de Punta Arenas

Piedra Parada

Nahuel Pan

$\mathrm{A}^{\circ}$ Pescado (barda)

Ruta 40 Entrada a Gualjaina

Ruta 259 entre Esquel-Trevelin

Colan Conhue

Laguna La Zeta

Río Corintos

Laguna Aleusco

Catamarca
Santiago de Estero
Chubut
Mendoza
Tucumán
Tucumán
Santa Cruz
Córdoba
Jujuy
Jujuy
Tucumán
Salta
Santa Cruz
De Magallanes
De Magallanes
De Magallanes
De Magallanes
Chubut
Chubut
Chubut
Chubut
Chubut
Chubut
Chubut
Chubut
Chubut

Argentina MA

$-27,83$

$-66,08$ Actual

IML 439

Argentina $\mathrm{ChS}$

$-27,38$

$-64,30$ Actual-1950

$-67,42$ Actual

Argentina MB

$-34,05$

Argentina $\mathrm{ChS}$

-67,97 Actual-1950

IML 5476

Argentina YA

$-26,57$

$-26,45$

Argentina EP

Argentina $\mathrm{ChS}$

Argentina PC

Argentina PC

Argentina YA

Argentina $\mathrm{ChS}$

Argentina EP

Chile $\mathrm{BMg}$

Chile EP

Chile EP

Chile $\mathrm{BMg}$

Argentina EP

Argentina EP

Argentina EP

Argentina EP

Argentina EP

Argentina EP

Argentina EP

Argentina BV

Argentina EP
$-65,25$ Actual-1950 IML 5973

-65,72 Actual-1950 IML 6195

$-72,50$ Actual IML 6322

$-63,67$ Actual IML 642

$-65,77$ Actual IML 7150

-66,03 Actual IML 7151

$-65,68$ Actual-1950 IML 7355

-64,56 Actual-1950 IML 1627

-71,68 Actual-1950 IML 6194

$-72,68$ Actual IZP34

-70,15 Actual IZP36

$-69,55$ Actual IZP39

$-70,89$ Actual IZP35

-70,13 Actual-1950 LIEB 795

-71,19 Actual-1950 LIEB 799

-70,91 Actual-1950 LIEB 802

-71,13 Actual-1950 LIEB 810

$-71,35$ Actual-1950 LIEB 882

-69,85 Actual-1950 LIEB 798

-71,39 Actual-1950 LIEB 796

-71,39 Actual-1950 LIEB 801

$-70,42$ Actual-1950 LIEB 804 
Continuación Tabla 7

Ruta 259 entre Esquel y Trevelin

Ruta 40 Leleque. A 95km desde Esquel

Ruta 259 entre Esquel y Trevelin. A 10km Esquel

Ruta 259. Portón acceso Gendarmería

Cerro Zeballos

Ruta P71. A 3 Km rotonda Esquel-PN Los Alerces

Sobremonte, los Hoyos

Depto Mburucuyá, Manantiales

Depto Catán-Lil, Las Coloradas, Cpo. Grande

Dto Caleu, Caleu

Dto Lihuel-Calel, Ea. San Máximo

Ea. Melenik, 20km E PNPerito Moreno

\section{Picunleufú}

Villa Federal

Villa Reartes

Humahuaca

Miramar

La Laguna

Rawson

Paso Peñalva

Gra. Roca

Vichigasta

Gándara

Dto Los Andes. Los Chorrillos 4500m

Cerro Velazco

Depto Metán, La Represa

$\begin{array}{lllllll}\text { Chubut } & \text { Argentina } & \text { BV } & -42,97 & -71,40 & \text { Actual-1950 } & \text { LIEB } 797 \\ \text { Chubut } & \text { Argentina } & \text { EP } & -42,38 & -71,11 & \text { Actual-1950 } & \text { LIEB } 811 \\ \text { Chubut } & \text { Argentina } & \text { BV } & -42,98 & -71,40 & \text { Actual-1950 } & \text { LIEB } 915 \\ \text { Chubut } & \text { Argentina } & \text { EP } & -42,94 & -71,25 & \text { Actual-1950 } & \text { LIEB } 887 \\ \text { Chubut } & \text { Argentina } & \text { EP } & -42,58 & -70,33 & \text { Actual-1950 } & \text { LIEB 914 } \\ \text { Chubut } & \text { Argentina } & \text { BV } & -42,98 & -71,42 & \text { Actual-1950 } & \text { LIEB } 888 \\ \text { Córdoba } & \text { Argentina } & \text { ChS } & -31,99 & -64,37 & \text { Actual-1950 } & \text { MACN } 13297 \\ \text { Corrientes } & \text { Argentina } & \text { ChH } & -27,95 & -58,13 & \text { Actual-1950 } & \text { MACN } 13714 \\ \text { Neuquén } & \text { Argentina } & \text { EP } & -39,55 & -70,58 & \text { Actual-1950 } & \text { MACN } 14083 \\ \text { La Pampa } & \text { Argentina } & \text { Esp } & -38,25 & -63,75 & \text { Actual-1950 } & \text { MACN } 15480 \\ \text { La Pampa } & \text { Argentina } & \text { Esp } & -37,72 & -64,87 & \text { Actual-1950 } & \text { MACN } 15549 \\ \text { Santa Cruz } & \text { Argentina } & \text { EP } & -47,78 & -72,15 & \text { Actual-1950 } & \text { MACN } 16320 \\ \text { Neuquén } & \text { Argentina } & \text { MB } & -39,52 & -69,25 & \text { Actual-1950 } & \text { MACN } 17769 \\ \text { Entre Ríos } & \text { Argentina } & \text { Esp } & -30,95 & -58,80 & \text { Actual } & \text { MACN 20424 } \\ \text { Córdoba } & \text { Argentina } & \text { ChS } & -31,92 & -64,58 & \text { Actual } & \text { MACN 25.165 } \\ \text { Jujuy } & \text { Argentina } & \text { MA } & -23,20 & -65,35 & \text { Actual } & \text { MACN 26.182 } \\ \text { Buenos Aires } & \text { Argentina } & \text { PH } & -36,02 & -61,17 & \text { Actual } & \text { MACN 26.98 } \\ \text { Jujuy } & \text { Argentina } & \text { PC } & -22,45 & -65,55 & \text { Actual } & \text { MACN 27.101 } \\ \text { Chubut } & \text { Argentina } & \text { MB } & -43,30 & -65,10 & \text { Actual } & \text { MACN 28.72 } \\ \text { Río Negro } & \text { Argentina } & \text { MB } & -39,47 & -65,50 & \text { Actual } & \text { MACN 28.105 } \\ \text { La Rioja } & \text { Argentina } & \text { ChS } & -29,41 & -66,81 & \text { Actual } & \text { MACN 28.186 } \\ \text { La Rioja } & \text { Argentina } & \text { MA } & -29,48 & -67,52 & \text { Actual } & \text { MACN 29.194 } \\ \text { Buenos Aires } & \text { Argentina } & \text { PH } & -35,43 & -58,10 & \text { Actual } & \text { MACN 29.912 } \\ \text { Salta } & \text { PC } & -24,22 & -66,45 & \text { Actual } & \text { MACN } 30.101 \\ \text { La Rioja } & \text { Argentina } & \text { MA } & -28,50 & -67,02 & \text { Actual } & \text { MACN } 30.229 \\ \text { Salta } & \text { ChS } & -22,30 & -63,57 & \text { Actual } & \text { MACN } 30.392\end{array}$


Continuación Tabla 7

\begin{tabular}{l} 
Villa Unión \\
Rivadavia \\
Lago San Martín \\
El Quebrachal \\
Dragones \\
Sierra de la Ventana \\
Uspallata \\
Junín de los Andes \\
Chos Malal \\
B. Massé \\
Cochinoca \\
Victoria \\
Valle Lizoite \\
Dto Santa Victoria \\
Pilcomayo, Fortín Nuevo \\
Appeleg \\
Paso de las Niñas, Río Teuco \\
Dto Andalgalá, R. Vallecito \\
Echague \\
Criadero de Abrapampa \\
Crro Brea \\
Beazley \\
Cerca de Dehenny, antes de 9 de Julio \\
Viedma \\
Ruta provincial 5, cerca de Speluzzi \\
Norquinco \\
\hline
\end{tabular}

\begin{tabular}{|c|c|c|c|c|c|c|}
\hline La Rioja & Argentina & MA & $-29,30$ & $-68,20$ & Actual & MACN 34.330 \\
\hline Salta & Argentina & $\mathrm{ChS}$ & $-24,18$ & $-62,88$ & Actual & MACN 33.167 \\
\hline Río Negro & Argentina & $\mathrm{BMg}$ & $-48,87$ & $-72,65$ & Actual & MACN 36.137 \\
\hline Salta & Argentina & $\mathrm{ChS}$ & $-25,28$ & $-64,07$ & Actual & MACN 36.321 \\
\hline Salta & Argentina & $\mathrm{ChS}$ & $-23,25$ & $-63,35$ & Actual & MACN 36.485 \\
\hline Buenos Aires & Argentina & $\mathrm{PH}$ & $-38,06$ & $-61,98$ & Actual & MACN 36.59 \\
\hline Mendoza & Argentina & MA & $-32,58$ & $-69,33$ & Actual & MACN 37.10 \\
\hline Neuquén & Argentina & $\mathrm{EP}$ & $-39,93$ & $-71,08$ & Actual & MACN 38.224 \\
\hline Neuquén & Argentina & $\mathrm{EP}$ & $-37,38$ & $-70,27$ & Actual & MACN 38.85 \\
\hline Córdoba & Argentina & $\mathrm{ChS}$ & $-31,30$ & $-64,47$ & Actual & MACN 39.196 \\
\hline Jujuy & Argentina & $\mathrm{PC}$ & $-22,73$ & $-65,90$ & Actual & MACN 39.497 \\
\hline La Pampa & Argentina & $\mathrm{ChS}$ & $-32,22$ & $-65,45$ & Actual & MACN 39.703 \\
\hline Salta & Argentina & $\mathrm{ChS}$ & $-25,27$ & $-65,17$ & Actual & MACN 41.58 \\
\hline Salta & Argentina & YA & $-22,55$ & $-64,89$ & Actual & MACN 41.96 \\
\hline Formosa & Argentina & $\mathrm{ChS}$ & $-23,87$ & $-60,88$ & Actual & MACN 43.58 \\
\hline Chubut & Argentina & $\mathrm{EP}$ & $-44,68$ & $-70,85$ & Actual & MACN 44.5 \\
\hline Formosa & Argentina & $\mathrm{ChS}$ & $-24,92$ & $-61,00$ & Actual & MACN 47.119 \\
\hline Catamarca & Argentina & MA & $-27,58$ & $-66,47$ & Actual-1950 & MACN 50.421 \\
\hline Entre Ríos & Argentina & $\mathrm{PH}$ & $-32,40$ & $-59,27$ & Actual-1950 & MACN 51.162 \\
\hline Jujuy & Argentina & $\mathrm{PC}$ & $-22,72$ & $-65,70$ & Actual-1950 & MACN 52.89 \\
\hline Mendoza & Argentina & EA & $-34,95$ & $-69,72$ & Actual-1950 & MACN 53.43 \\
\hline San Luis & Argentina & MB & $-33,75$ & $-66,65$ & Actual-1950 & MACN 53.83 \\
\hline Buenos Aires & Argentina & $\mathrm{PH}$ & $-35,35$ & $-60,77$ & Actual-1950 & MACN 23986 \\
\hline Río Negro & Argentina & MB & $-41,10$ & $-63,32$ & Actual-1950 & MACN 23994 \\
\hline La Pampa & Argentina & $\mathrm{PH}$ & $-35,53$ & $-63,80$ & Actual-1950 & MACN 23989 \\
\hline Río Negro & Argentina & $\mathrm{EP}$ & $-41,85$ & $-70,90$ & Actual-1950 & MACN 24004 \\
\hline
\end{tabular}


Continuación Tabla 7

Sierra Pailemán

Concepción, Rincón de Luna

Leleque, Fofocahuel

Pampa de María Santísima

Pampa Castillo

Magdalena, Est El Destino

Río Salado, Samborombón

Reserva Esc Granja Esperanza, Las Colonias

Ruta 118 km S Salado Cabal, Garay

Dpto. Toay, Ea. La Florida

P. Luro, camino a balneario San Antonio

Punta Indio, ruta 11

$\mathrm{R}$ prov 56, a $5 \mathrm{~km}$ de la ciudad de Gral Madariaga

Barreto, Ea. La Magdalena

Gral Villegas

Depto. Colón, colonia Caraballo

Laguna Alsina

Gral. Alvear, R. 205, km 290

Colonia Villa Elisa

Colonia Hocker

Tapalqué, Ea. Jurado

Vuelta del Senguer, Cañada Grande

Lago Nahuel Huapi

Cristiano Muerto

Punta Piaggio

Cerro Colorado

227 Chascomús, Colonia Manantiales

\begin{tabular}{|c|c|c|c|c|c|c|}
\hline Río Negro & Argentina & MB & $-41,15$ & $-65,93$ & Actual-1950 & MACN 23992 \\
\hline Corrientes & Argentina & $\mathrm{ChH}$ & $-28,47$ & $-58,23$ & Actual-1950 & MACN 14051 \\
\hline Chubut & Argentina & $\mathrm{EP}$ & $-42,38$ & $-70,70$ & Actual-1950 & MACN 16475 \\
\hline Santa Cruz & Argentina & $\mathrm{EP}$ & $-45,95$ & $-69,20$ & Actual & MACN 29.915 \\
\hline Chubut & Argentina & $\mathrm{EP}$ & $-45,80$ & $-68,08$ & Actual & MACN 32.69 \\
\hline Buenos Aires & Argentina & $\mathrm{PH}$ & $-35,13$ & $-57,38$ & Actual & MACN 20.391 \\
\hline Buenos Aires & Argentina & $\mathrm{PH}$ & $-35,22$ & $-58,28$ & Actual-1950 & MACN 51.85 \\
\hline Santa Fé & Argentina & Esp & $-31,33$ & $-60,67$ & Actual & MSF 0.871 \\
\hline Santa Fé & Argentina & Esp & $-31,10$ & $-60,75$ & Actual & MSF 0.733 \\
\hline La Pampa & Argentina & Esp & $-36,38$ & $-65,03$ & Actual-1950 & MLP 1-II-93-1 \\
\hline Buenos Aires & Argentina & Esp & $-39,48$ & $-62,68$ & Actual-1950 & MLP 1-II-95-1 \\
\hline Buenos Aires & Argentina & $\mathrm{PH}$ & $-35,30$ & $-57,28$ & Actual-1950 & MLP 10-II-99-1 \\
\hline Buenos Aires & Argentina & $\mathrm{PH}$ & $-37,00$ & $-57,15$ & Actual-1950 & MLP 14-IX-98-8 \\
\hline Córdoba & Argentina & $\mathrm{PH}$ & $-33,35$ & $-63,32$ & Actual & MLP 1582 \\
\hline Buenos Aires & Argentina & $\mathrm{PH}$ & $-35,03$ & $-63,02$ & Actual & MLP 1727 \\
\hline Entre Ríos & Argentina & $\mathrm{PH}$ & $-32,10$ & $-58,25$ & Actual-1950 & MLP 19-XII-02-2 \\
\hline Buenos Aires & Argentina & $\mathrm{PH}$ & $-36,82$ & $-62,22$ & Actual-1950 & MLP 2-VI-60-13 \\
\hline Buenos Aires & Argentina & $\mathrm{PH}$ & $-36,05$ & $-60,02$ & Actual-1950 & MLP 3-X-94-1 \\
\hline Entre Ríos & Argentina & $\mathrm{PH}$ & $-32,17$ & $-58,40$ & Actual-1950 & MLP 5-V-99-4 \\
\hline Entre Ríos & Argentina & $\mathrm{PH}$ & $-32,08$ & $-58,33$ & Actual-1950 & MLP 5-V-99-5 \\
\hline Buenos Aires & Argentina & $\mathrm{PH}$ & $-36,35$ & $-60,02$ & Actual & MLP 5-IX-44-5 \\
\hline Chubut & Argentina & EP & $-45,00$ & $-70,29$ & Actual & MLP 6-III-36-36 \\
\hline Río Negro & Argentina & $\mathrm{EP}$ & $-40,54$ & $-70,35$ & Actual & MLP 6-III-36-37 \\
\hline Buenos Aires & Argentina & $\mathrm{PH}$ & $-38,63$ & $-59,62$ & Actual-1950 & MLP 6-III-36-38 \\
\hline Chubut & Argentina & $\mathrm{EP}$ & $-42,53$ & $-64,35$ & Actual & MLP 7-IV-43-1 \\
\hline Salta & Argentina & MA & $-25,40$ & $-66,35$ & Actual & MLP 7-X-46-1 \\
\hline Buenos Aires & Argentina & $\mathrm{PH}$ & $-35,70$ & $-58,03$ & Actual-1950 & MLP 9-X-92-5 \\
\hline
\end{tabular}


Continuación Tabla 7

$\begin{array}{ll}228 & \text { Villarino, Lag. Chasicó } \\ 229 & \text { Paso Río Mayo } \\ 230 & \text { Río Chico. Puesto } \\ 231 & \text { Stroeder, Patagones } \\ 232 & \text { Ruta 11, km 28 al N de Santa Clara del Mar } \\ 233 & \text { Arroyo Pan de Azúcar } \\ 234 & \text { Arroyo Negro } \\ 235 & \text { Itapebi, Salto Grande } \\ 236 & \text { Pozo hondo. Tambores } \\ 237 & \text { Balneario Solis } \\ 238 & \text { Arroyo Perdido } \\ 239 & \text { Espinillar } \\ 240 & \text { Balneario Jaureeuberry } \\ 241 & \text { Ruta 3 km 600 } \\ 242 & \text { Río Negro } \\ 243 & \text { 5km SE Solís de Mataofo } \\ 244 & \text { Arroyo Sauce } \\ 245 & \text { Arrocera Conti } \\ 246 & \text { Balneario Atlántico } \\ 247 & \text { Sierras del Infiernillo } \\ 248 & \text { Rincón de Perez } \\ 249 & \text { Cerro Largo, Arroyo de La Mina } \\ 250 & \text { Paso del Rey } \\ 251 & \text { Laguna Formosa, Est. La Formosa, Cerro Largo } \\ 252 & \text { Estancia Los Abuelos FYMNSA, ribera } \\ 253 & \text { Cebollatí } \\ 254 & \text { Colonia, Martin Chico } \\ & \\ 234 & \end{array}$

\begin{tabular}{|c|c|c|c|c|c|c|}
\hline Buenos Aires & Argentina & Esp & $-38,69$ & $-62,97$ & Actual-1950 & MLP 28-VII-78-1 \\
\hline Chubut & Argentina & $\mathrm{EP}$ & $-45,68$ & $-70,27$ & Actual-1950 & MLP 2-VI-60-2 \\
\hline Sta. Cruz & Argentina & $\mathrm{EP}$ & $-49,80$ & $-68,62$ & Actual & MLP 1-XII-00-5 \\
\hline Buenos Aires & Argentina & Esp & $-40,18$ & $-62,62$ & Actual & MMP 2138 \\
\hline Buenos Aires & Argentina & $\mathrm{PH}$ & $-37,83$ & $-57,50$ & Actual & MMP 4102 \\
\hline Maldonado & Uruguay & SU & $-34,83$ & $-55,13$ & Actual-1950 & MHNM 1849 \\
\hline Paysandú & Uruguay & SU & $-32,48$ & $-58,18$ & Actual-1950 & MHNM 1936 \\
\hline Salto & Uruguay & SU & $-31,30$ & $-57,70$ & Actual-1950 & MHNM 289 \\
\hline Depto Tacuarembó & Uruguay & $\mathrm{SU}$ & $-31,78$ & $-56,25$ & Actual-1950 & MHNM 290 \\
\hline Maldonado & Uruguay & SU & $-34,78$ & $-55,37$ & Actual & MHNM 291 \\
\hline Soriano & Uruguay & SU & $-33,38$ & $-57,37$ & Actual & MHNM 292 \\
\hline Salto & Uruguay & SU & $-33,47$ & $-54,20$ & Actual & MHNM 293 \\
\hline Canelones & Uruguay & SU & $-34,76$ & $-55,70$ & Actual-1950 & MHNM 294 \\
\hline Artigas & Uruguay & SU & $-30,51$ & $-57,72$ & Actual-1950 & MHNM 2957 \\
\hline Tacuarembó & Uruguay & SU & $-32,54$ & $-56,47$ & Actual & MHNM 3073 \\
\hline Maldonado & Uruguay & SU & $-34,60$ & $-55,48$ & Actual-1950 & MHNM 3200 \\
\hline Maldonado & Uruguay & SU & $-34,87$ & $-54,91$ & Actual-1950 & MHNM 3201 \\
\hline Artigas & Uruguay & SU & $-30,53$ & $-57,83$ & Actual-1950 & MHNM 3278 \\
\hline Rocha & Uruguay & SU & $-34,47$ & $-53,93$ & Actual-1950 & MHNM 3354 \\
\hline Tacuarembó & Uruguay & SU & $-31,38$ & $-56,17$ & Actual-1950 & MHNM 3415 \\
\hline Paysandú & Uruguay & SU & $-32,16$ & $-57,47$ & Actual-1950 & MHNM 3947 \\
\hline Cerro Largo & Uruguay & SU & $-34,73$ & $-55,71$ & Actual-1950 & MHNM 4742 \\
\hline San José & Uruguay & SU & $-34,53$ & $-56,80$ & Actual-1950 & MHNM 5490 \\
\hline Cerro Largo & Uruguay & SU & $-31,85$ & $-54,30$ & Actual-1950 & MHNM 6276 \\
\hline Rivera & Uruguay & SU & $-31,29$ & $-55,76$ & Actual-1950 & MHNM 6419 \\
\hline Rocha & Uruguay & SU & $-33,27$ & $-53,79$ & Actual & MHNM 976 \\
\hline Colonia & Uruguay & SU & $-34,12$ & $-58,21$ & Actual-1950 & MHNM 1850 \\
\hline
\end{tabular}


Continuación Tabla 7

\begin{tabular}{|c|c|c|c|c|c|c|c|c|}
\hline 255 & Arroyo Milán, Reboledo & Florida & Uruguay & SU & $-33,99$ & $-55,65$ & Actual & MHNM 880 \\
\hline 256 & Depto Canelones, ruta $5 \mathrm{~km} \mathrm{56,500}$ & Canelones & Uruguay & SU & $-34,47$ & $-56,28$ & Actual-1950 & MHNM 2953 \\
\hline 257 & San José, Sierra de Mahoma & San José & Uruguay & SU & $-34,08$ & $-56,89$ & Actual-1950 & MHNM 3975 \\
\hline 258 & Km 348 Panamericana Norte & Coquimbo & Chile & $\mathrm{MCh}$ & $-30,94$ & $-71,64$ & Actual & MNHNS 328 \\
\hline 259 & Valparaiso & Valparaiso & Chile & $\mathrm{MCh}$ & $-33,05$ & $-71,60$ & Actual & NMW 1004 \\
\hline 260 & Frutillar, Llanquihue & De los Lagos & Chile & $\mathrm{BV}$ & $-41,12$ & $-73,10$ & Actual & NMW 1053 \\
\hline 261 & Chasicó (La Clotilde) & Buenos Aires & Argentina & Esp & $-38,62$ & $-63,00$ & Actual-1950 & UNS 107 \\
\hline 262 & Dorrego & Buenos Aires & Argentina & $\mathrm{PH}$ & $-38,66$ & $-60,98$ & Actual-1950 & UNS 118 \\
\hline 263 & Guatrache & La Pampa & Argentina & Esp & $-37,76$ & $-63,55$ & Actual & UNS 50 \\
\hline 264 & Sierra de la Ventana - La Toma & Buenos Aires & Argentina & $\mathrm{PH}$ & $-38,07$ & $-61,91$ & Actual & UNS 70 \\
\hline 265 & PN Los Alerces (Portada Norte) & Chubut & Argentina & $\mathrm{BV}$ & $-42,57$ & $-71,63$ & Actual-1950 & UNS 113 \\
\hline 266 & Pdo. Coronel Rosales, Pehuenco & Buenos Aires & Argentina & $\mathrm{PH}$ & $-39,00$ & $-61,62$ & Actual-1950 & UNS F1 \\
\hline 267 & Pdo. Coronel Dorrego, Aparicio & Buenos Aires & Argentina & $\mathrm{PH}$ & $-38,62$ & $-60,87$ & Actual-1950 & UNS CV3 \\
\hline 268 & Pdo. Coronel Rosales, Bajo Hondo & Buenos Aires & Argentina & PH & $-38,77$ & $-61,90$ & Actual-1950 & UNS F8 \\
\hline 269 & Loma Blanca & Jujuy & Argentina & $\mathrm{PC}$ & $-22,50$ & $-66,50$ & Actual-1950 & UNS F9 \\
\hline 270 & Partido de Saavedra, Arroyo corto & Buenos Aires & Argentina & $\mathrm{PH}$ & $-37,50$ & $-62,33$ & Actual-1950 & UNS F10 \\
\hline 271 & Coranzulí & Jujuy & Argentina & $\mathrm{PC}$ & $-23,03$ & $-66,40$ & Actual-1950 & UNS F18 \\
\hline 272 & Pdo. Patagones, Carmen de Patagones & Buenos Aires & Argentina & Esp & $-40,80$ & $-62,98$ & Actual-1950 & UNS F20 \\
\hline 273 & Comodoro Rivadavia & Chubut & Argentina & $\mathrm{EP}$ & $-45,87$ & $-67,50$ & Actual-1950 & UNS A1 \\
\hline 274 & Puerto Madryn & Chubut & Argentina & MB & $-42,77$ & $-65,05$ & Actual-1950 & UNS A2 \\
\hline 275 & Rio Gallegos & Santa Cruz & Argentina & $\mathrm{EP}$ & $-50,33$ & $-69,20$ & Actual-1950 & UNS A3 \\
\hline 276 & Esperanza & Santa Cruz & Argentina & $\mathrm{EP}$ & $-51,05$ & $-70,84$ & Actual-1950 & UNS A4 \\
\hline
\end{tabular}


Tabla 8. Landmarks y semilandmarks utilizados en análisis de morfometría geométrica para estudiar segregación trófica. Véase sección 3.6.

\begin{tabular}{ll}
\hline Número de landmark & \multicolumn{1}{c}{ Cráneo vista ventral } \\
\hline 1 & Borde posterior del foramen magnum \\
2 & Borde anterior del foramen magnum \\
3 & Borde externo del cóndilo occipital \\
4 & Proceso paracondilar \\
5 & Punto más externo del proceso mastoideo \\
6 & Punto más interno de la fosa glenoidea \\
7 & Punto más externo de la fosa glenoidea \\
8 & Torus palatino \\
$9-13$ & Semilandmarks sobre el arco cigomático \\
14 & Punto más posterior del M1 \\
15 & Punto más lingual del M1 \\
16 & Punto más anterior del M1 \\
17 & Punto más lingual del Pm4 \\
18 & Punto más anterior del Pm4 \\
19 & Punto más posterior del C \\
20 & Punto más anterior del C \\
21 & Punto más externo de la serie incisiva \\
22 & Punto medio de la serie incisiva \\
\hline & \\
\hline 1 & Mandíbula vista lateral \\
2 & Ápice del proceso coronoide \\
3 & Punto más bajo del arco formado por procesos coronoides y mandibular \\
4 & Punto más posterior del cóndilo mandibular \\
$05-12$ & Punto más posterior del proceso angular \\
$13-18$ & Semilandmarks sobre la cara anterior del proceso coronoide \\
19 & Semilandmarks sobre el borde inferior del dentario \\
20 & Punto más posterior del m1 \\
22 & Punto más anterior del trigónido del m1 (sobre el paracónido) \\
23 & Punto más posterior del Pm4 \\
\hline & \\
\hline & Punto más anterior del Pm4 anterior del c \\
\hline & \\
\hline &
\end{tabular}


Tabla 9. Contribución de las variables climáticas para los dos modelos generados para

Galictis cuja. En negrita se presentan las variables con mayor contribución.

\begin{tabular}{lcccc}
\hline & \multicolumn{3}{c}{ Actual } & \multicolumn{3}{c}{$\mathbf{1 9 5 0}$} \\
\cline { 2 - 5 } Variable & Contribución & Permutación & Contribución & Permutación \\
\hline Estacionalidad To & $\mathbf{3 4 , 1}$ & $\mathbf{2 3 , 1}$ & $\mathbf{5 2 , 9}$ & $\mathbf{0 , 1}$ \\
Isotermalidad & 0,6 & 0,6 & 8,6 & 53,6 \\
$\mathrm{~T}^{\mathbf{o}}$ máxima Agosto & 17,9 & 2,2 & 1,3 & 8,5 \\
$\mathrm{~T}^{\mathbf{o}}$ media Septiembre & 10,3 & 1,3 & -- & -- \\
$\mathrm{T}^{\mathbf{o}}$ máxima Abril & 2,7 & 0,1 & -- & -- \\
$\mathrm{T}^{\mathbf{o}}$ máxima Mayo & 2,4 & 0,9 & -- & -- \\
Altitud & 2,3 & 3,8 & 4,9 & 3,3 \\
$\mathrm{~T}^{\mathbf{o}}$ máxima Febrero & 1,7 & 0,9 & -- & -- \\
Precipitación de Octubre & 1,7 & 1,4 & -- & -- \\
$\mathrm{T}^{\mathbf{o}}$ media de Junio & 1,6 & 0,1 & 4,5 & 0 \\
$\mathrm{~T}^{\mathbf{o}}$ media de Julio & 1,3 & 0,1 & 3,3 & 0 \\
$\mathrm{~T}^{\mathbf{o}}$ mínima de Septiembre & 1,2 & 0,2 & 2,5 & 0 \\
$\mathrm{~T}^{\mathbf{o}}$ máxima de Septiembre & -- & -- & 1,8 & 0 \\
$\mathrm{~T}^{\mathbf{o}}$ media de Agosto & 1 & 1,2 & 1,8 & 0 \\
$\mathrm{~T}^{\mathbf{o}}$ máxima de Julio & 1,2 & 0,1 & 1,7 & 0,5 \\
$\mathrm{~T}^{\mathbf{o}}$ media de Mayo & -- & -- & 1,6 & 0 \\
$\mathrm{~T}^{\mathbf{o}}$ mínima del mes más frío & 0,8 & 0 & 1,3 & 0 \\
$\mathrm{~T}^{\mathbf{o}}$ media del trimestre más seco & 1,5 & 3,7 & -- & -- \\
$\mathrm{T}^{\mathbf{o}}$ máxima Marzo & 1,3 & 2 & -- & -- \\
Precipitación del trimestre más frío & 1,3 & 4,4 & -- & -- \\
Total & $\mathbf{8 4 , 9}$ & -- & $\mathbf{8 6 , 2}$ & -- \\
\hline
\end{tabular}

Test de Jackknife para importancia de variables

Variable con mayor poder explicativo

Estacionalidad $\mathrm{T}^{\mathrm{o}}$

Isotermalidad

Variable con información más única

Altitud

Isotermalidad

Test de Jackknife usando ganancia de prueba

Variable con mayor poder explicativo

Estacionalidad $\mathrm{T}^{\mathrm{o}}$

Isotermalidad

Variable con información más única

$\mathrm{T}^{\mathrm{o}}$ mínima Julio

Altitud

Test de Jackknife usando AUC

Variable con mayor poder explicativo

Isotermalidad

Isotermalidad

Variable con información más única 
Tabla 10. Resultados de las pruebas umbral-dependiente para Galictis cuja, para ambos modelos generados.

\begin{tabular}{lrrrr}
\hline & \multicolumn{2}{c}{ Actual } & \multicolumn{2}{c}{$\mathbf{1 9 5 0}$} \\
\cline { 2 - 5 } Valor umbral & Área predicha & $P$-valor & Área predicha & $P$-valor \\
\hline 1 & 0,8041 & 0,0014 & 0,5412 & 0,0012 \\
5 & 0,6648 & 0,0011 & 0,4418 & 0,005 \\
10 & 0,5852 & 0,0014 & 0,3836 & 0,0091 \\
\hline
\end{tabular}


Tabla 11. Contribución de las variables climáticas para los cuatro modelos generados para Lyncodon patagonicus. En negrita se presentan las variables con mayor contribución.

\begin{tabular}{|c|c|c|c|c|c|c|c|c|}
\hline \multirow[b]{2}{*}{ Variable } & \multicolumn{2}{|c|}{ Pleistoceno-Holoceno } & \multicolumn{2}{|c|}{ Holoceno } & \multicolumn{2}{|c|}{ Actual } & \multicolumn{2}{|c|}{1950} \\
\hline & Contribución & Permutación & Contribución & Permutación & Contribución & Permutación & Contribución & Permutación \\
\hline $\mathrm{T}^{\mathrm{o}}$ media trimestre más frío & 64,1 & 45,5 & 60,3 & 58,1 & 3,8 & 1,6 & 3,6 & 5,8 \\
\hline $\mathrm{T}^{\mathrm{o}}$ mínima del mes más frío & 9,1 & 27,9 & 13,8 & 24 & 2 & 14,3 & 2,9 & 0,5 \\
\hline Estacionalidad de las precipitaciones & 7 & 2,4 & 7,7 & 0,7 & 2,5 & 1,3 & 3,2 & 1,4 \\
\hline Estacionalidad de la $\mathrm{T}^{\mathbf{o}}$ & 4,9 & $\overrightarrow{9,6}$ & 4,8 & 11,9 & 55,1 & 1,1 & 48,3 & 1,2 \\
\hline Precipitación del trimestre más seco & 2,7 & 6,5 & 2,3 & 1,2 & 0,6 & 7,9 & 0,3 & 0,1 \\
\hline Precipitación del trimestre más húmedo & 2,6 & 0,1 & 2,8 & 0,3 & 1,2 & 0,7 & --- & --- \\
\hline Isotermalidad & 2,4 & 0 & 1,6 & 0 & 0,4 & 3,8 & 0,9 & 8,3 \\
\hline Precipitación del mes más seco & 2,3 & 5,7 & --- & --- & 0,4 & 0,7 & 1,4 & 13,4 \\
\hline Precipitación anual & 1,5 & 0 & 0,7 & 0 & 0,3 & 0 & --- & --- \\
\hline Rango diurno medio & 1,5 & 0,1 & 1,6 & 0 & 0,6 & 0,3 & 1 & 0 \\
\hline $\mathrm{T}^{\mathrm{o}}$ media del trimestre más cálido & 0,9 & 0 & 0,8 & 0 & --- & --- & --- & --- \\
\hline $\mathrm{T}^{\mathrm{o}}$ media del trimestre más seco & 0,3 & 1 & 0,6 & 0,1 & 0,8 & 2,1 & 2,2 & 1,4 \\
\hline Precipitación del trimestre más frío & 0,2 & 0,4 & 2,3 & 1,7 & --- & --- & --- & --- \\
\hline Precipitación Octubre & --- & --- & --- & --- & 6,6 & 8,9 & 9,6 & 19,2 \\
\hline Altitud & --- & --- & --- & --- & 5,9 & 6,1 & 6,6 & 15,1 \\
\hline Precipitación Noviembre & --- & --- & --- & --- & 3,8 & 1,6 & 3,6 & 5,8 \\
\hline $\mathrm{T}^{\mathrm{o}}$ mínima Julio & --- & --- & --- & --- & 2,8 & 5,1 & 2 & 16,5 \\
\hline $\mathrm{T}^{\mathrm{o}}$ mínima Junio & --- & --- & --- & --- & 2,1 & 12,1 & 1 & 4 \\
\hline $\mathrm{T}^{\mathrm{o}}$ mínima Septiembre & --- & --- & --- & --- & 1,9 & 0 & 1,4 & 0 \\
\hline $\mathrm{T}^{\mathrm{o}}$ mínima Agosto & --- & --- & --- & --- & 1,4 & 3,8 & --- & --- \\
\hline Precipitación Julio & --- & --- & --- & --- & 1,1 & 1,4 & 1,1 & 0,1 \\
\hline $\mathrm{T}^{\mathrm{o}}$ máxima Febrero & --- & --- & --- & --- & 1 & 1,9 & 2,9 & 4,9 \\
\hline Precipitación Marzo & --- & --- & --- & --- & 0,9 & 0,6 & 1,1 & 0,3 \\
\hline Precipitación Febrero & --- & --- & --- & --- & 0,9 & 4,7 & 0,9 & 1,6 \\
\hline Total & $\mathbf{9 9 , 5}$ & & $\mathbf{9 9 , 3}$ & & 96,1 & & 94 & \\
\hline
\end{tabular}

\section{Test de Jackknife para importancia de}

\section{variables}

Variable con mayor poder explicativo 
Continuación Tabla 11

Variable con información no contenida en el resto

$\mathrm{T}^{\mathrm{o}}$ media del trimestre más frío

\section{Test de Jackknife usando ganancia de}

\section{prueba}

Variable con mayor poder explicativo

Variable con información no contenida en

$\mathrm{T}^{\mathrm{o}}$ mínima del mes más frío

$\mathrm{T}^{\mathrm{o}}$ mínima del mes más frío

$\mathrm{T}^{\mathrm{o}}$ mínima del mes más frío

$\mathrm{T}^{\mathrm{o}}$ mínima del mes más frío

$\mathrm{T}^{\mathrm{o}}$ mínima del mes más frío

$\mathrm{T}^{\mathrm{o}}$ mínima del mes más frío

\section{Test de Jackknife usando AUC}

Variable con información no contenida en

Estacionalidad precipitaciones
Altitud

Altitud
Estacionalidad $\mathrm{T}^{\mathbf{o}}$

Altitud

Precipitación anual Altitud
Estacionalidad $\mathrm{T}^{\circ}$

Altitud

el resto 
Tabla 12. Resultados de las pruebas umbral-dependiente para Lyncodon patagonicus, para los cuatro modelos generados.

\begin{tabular}{rrrrrrrrrr}
\hline \multirow{2}{*}{ Valor umbral } & \multicolumn{2}{c}{ Pleistoceno-Holoceno } & \multicolumn{2}{c}{ Holoceno } & \multicolumn{2}{c}{ Actual } & 1950 \\
\cline { 2 - 9 } & \multicolumn{1}{c}{ Área predicha } & $P$-valor & Área predicha & $P$-valor & Área predicha & $P$-valor & Área predicha & $P$-valor \\
\hline 1 & 0,1575 & 0,0203 & 0,1745 & 0,001 & 0,1614 & 0 & 0,1687 & 0 \\
& 5 & 0,0994 & 0,0337 & 0,1121 & 0,0009 & 0,1173 & 0 & 0,1082 & 0 \\
10 & 0,0721 & 0,0379 & 0,0821 & 0,0006 & 0,093 & 0 & 0,0786 & 0,0067 \\
\hline
\end{tabular}


Tabla 13. Contribución de las variables climáticas para los dos modelos generados para

Lontra provocax. En negrita se presentan las variables con mayor contribución.

\begin{tabular}{|c|c|c|c|c|}
\hline \multirow[b]{2}{*}{ Variable } & \multicolumn{2}{|c|}{ Actual } & \multicolumn{2}{|c|}{1950} \\
\hline & Contribución & Permutación & Contribución & Permutación \\
\hline $\mathrm{T}^{\mathrm{o}}$ media del trimestre más húmedo & 41.9 & 31.5 & 40.4 & 38.6 \\
\hline Precipitación Julio & 22.8 & 9.7 & 23.2 & 4.3 \\
\hline Precipitación Agosto & 7.3 & 6 & 10.3 & 3.1 \\
\hline Estacionalidad precipitaciones & 4.7 & 2 & 4.2 & 2.5 \\
\hline Precipitación de trimestre más seco & 3.7 & 2.8 & 3.6 & 0.2 \\
\hline Precipitación Mayo & 3.1 & 0.1 & 5.1 & 2.7 \\
\hline Altitud & 1.9 & 22.9 & 1.4 & 34.1 \\
\hline Isotermalidad & 1.6 & 6 & & \\
\hline $\mathrm{T}^{\mathrm{o}}$ mínima Noviembre & 1.3 & 0 & & \\
\hline Estacionalidad $\mathrm{T}^{\mathbf{o}}$ & 1.1 & 0 & 1.8 & 0 \\
\hline Total & 89.4 & & 90 & \\
\hline \multicolumn{5}{|c|}{ Test de Jackknife para importancia de variables } \\
\hline Variable con mayor poder explicativo & \multicolumn{2}{|c|}{$\mathrm{T}^{\mathrm{o}}$ máxima Septiembre } & \multicolumn{2}{|c|}{$\mathrm{T}^{\mathrm{o}}$ máxima Agosto } \\
\hline Variable con información más única & \multicolumn{2}{|c|}{ Altitud } & \multicolumn{2}{|c|}{ Altitud } \\
\hline \multicolumn{5}{|c|}{ Test de Jackknife usando ganancia de prueba } \\
\hline Variable con mayor poder explicativo & \multicolumn{2}{|c|}{$\mathrm{T}^{\mathrm{o}}$ máxima Septiembre } & \multicolumn{2}{|c|}{$\mathrm{T}^{\mathrm{o}}$ mínima Enero } \\
\hline Variable con información más única & \multicolumn{2}{|c|}{ Estacionalidad precipitaciones } & \multicolumn{2}{|c|}{ Altitud } \\
\hline \multicolumn{5}{|l|}{ Test de Jackknife usando AUC } \\
\hline Variable con mayor poder explicativo & \multicolumn{2}{|c|}{$\mathrm{T}^{\mathrm{o}}$ máxima Agosto } & \multicolumn{2}{|c|}{$\mathrm{T}^{\mathrm{o}}$ mínima Enero } \\
\hline Variable con información más única & \multicolumn{2}{|c|}{ Altitud } & \multicolumn{2}{|c|}{ Altitud } \\
\hline
\end{tabular}


Tabla 14. Resultados de las pruebas umbral-dependiente para Lontra provocax, para los dos modelos generados.

\begin{tabular}{rrrrr}
\hline \multirow{2}{*}{$\begin{array}{c}\text { Valor } \\
\text { umbral }\end{array}$} & \multicolumn{2}{c}{ Actual } & \multicolumn{2}{c}{$\mathbf{1 9 5 0}$} \\
\cline { 2 - 5 } & Área predicha & $P$-valor & Área predicha & $P$-valor \\
\hline 1 & 0,0798 & 0 & 0,0841 & 0 \\
5 & 0,0358 & 0 & 0,0313 & 0 \\
10 & 0,0214 & 0 & 0,0169 & 0 \\
\hline
\end{tabular}


Tabla 15. Contribución de las variables climáticas para el modelo generado para

Neovison vison. En negrita se presenta la variable con mayor contribución.

\begin{tabular}{|c|c|c|}
\hline \multirow[b]{2}{*}{ Variable } & \multicolumn{2}{|c|}{1950} \\
\hline & Contribución & Permutación \\
\hline $\mathrm{T}^{\mathrm{o}}$ media trimestre más húmedo & 26.4 & 9.2 \\
\hline $\mathrm{T}^{\circ}$ máxima Agosto & 16 & 0.1 \\
\hline $\mathrm{T}^{\circ}$ máxima Septiembre & 11.1 & 0.7 \\
\hline Isotermalidad & 10.7 & 2.5 \\
\hline $\mathrm{T}^{\mathrm{o}}$ media trimestre más seco & 5.2 & 1.3 \\
\hline Rango diurno medio $\left(\mathrm{T}^{\circ}\right)$ & 3.9 & 2 \\
\hline Estacionalidad precipitaciones & 3.3 & 3.1 \\
\hline $\mathrm{T}^{\mathrm{o}}$ máxima Octubre & 2.9 & 0.1 \\
\hline Precipitación Noviembre & 2.4 & 4.6 \\
\hline $\mathrm{T}^{\mathrm{o}}$ máxima Julio & 2.2 & 0.8 \\
\hline Estacionalidad $\mathrm{T}^{\mathrm{o}}$ & 1.6 & 3.8 \\
\hline Altitud & 1.5 & 21.1 \\
\hline Total & 87.2 & -- \\
\hline \multicolumn{3}{|c|}{ Test de Jackknife para importancia de variables } \\
\hline Variable con mayor poder explicativo & \multicolumn{2}{|c|}{$\mathrm{T}^{\circ}$ media trimestre más húmedo } \\
\hline Variable con información más única & \multicolumn{2}{|c|}{ Isotermalidad } \\
\hline \multicolumn{3}{|c|}{ Test de Jackknife usando ganancia de prueba } \\
\hline Variable con mayor poder explicativo & \multicolumn{2}{|c|}{$\mathrm{T}^{\mathrm{o}}$ media trimestre más húmedo } \\
\hline Variable con información más única & \multicolumn{2}{|c|}{ Isotermalidad } \\
\hline \multicolumn{3}{|l|}{ Test de Jackknife usando AUC } \\
\hline Variable con mayor poder explicativo & \multicolumn{2}{|c|}{$\mathrm{T}^{\mathrm{o}}$ media trimestre más húmedo } \\
\hline Variable con información más única & \multicolumn{2}{|c|}{ Altitud } \\
\hline
\end{tabular}


Tabla 16. Resultados de las pruebas umbral-dependiente para Neovison vison, para el modelo generado.

\begin{tabular}{rrr}
\hline & \multicolumn{2}{c}{$\mathbf{1 9 5 0}$} \\
\cline { 2 - 3 } Valor umbral & Área predicha & $P$-valor \\
\hline 1 & 0,0562 & 0 \\
5 & 0,0348 & 0 \\
10 & 0,0236 & 0 \\
\hline
\end{tabular}


Tabla 17. Contribución de las variables climáticas para los dos modelos generados para Conepatus chinga. En negrita se presentan las variables con mayor contribución.

\begin{tabular}{|c|c|c|c|c|}
\hline \multirow[b]{2}{*}{ Variable } & \multicolumn{2}{|c|}{ Actual } & \multicolumn{2}{|c|}{1950} \\
\hline & Contribución & Permutación & Contribución & Permutación \\
\hline $\mathrm{T}^{\mathrm{o}}$ mínima Julio & 35,3 & 3,3 & 1,9 & 1,9 \\
\hline $\mathrm{T}^{\mathrm{o}}$ máxima Mayo & -- & -- & 15,1 & 0,5 \\
\hline $\mathrm{T}^{\mathrm{o}}$ mínima Agosto & 25,2 & 17,2 & 5,7 & 5,4 \\
\hline $\mathrm{T}^{\mathrm{o}}$ media Junio & 9,4 & 0,1 & 4,2 & 0,3 \\
\hline $\mathrm{T}^{\mathrm{o}}$ media Julio & 7,6 & 0 & 10,3 & 0 \\
\hline $\mathrm{T}^{\mathrm{o}}$ mínima Junio & 3,1 & 2,4 & 1,5 & 1,8 \\
\hline $\mathrm{T}^{\mathrm{o}}$ mínima Octubre & 2,7 & 0,2 & -- & -- \\
\hline Estacionalidad $\mathrm{T}^{\mathrm{o}}$ & 1,9 & 3,5 & 1,9 & 3,6 \\
\hline Altitud & 1,2 & 2,5 & 1,3 & 6,8 \\
\hline $\mathrm{T}^{\mathbf{o}}$ máxima Julio & -- & -- & 11,6 & 0,4 \\
\hline $\mathrm{T}^{\mathrm{o}}$ media Agosto & -- & -- & 7,4 & 1,7 \\
\hline $\mathrm{T}^{\mathrm{o}}$ máxima Junio & -- & -- & 6,5 & 1,5 \\
\hline $\mathrm{T}^{\mathrm{o}}$ media del trimestre más frío & 1,1 & 0,1 & 12,5 & 0,4 \\
\hline Isotermalidad & 1 & 3,1 & 1,6 & 11 \\
\hline Precipitación del trimestre más húmedo & -- & -- & 3,6 & 0,6 \\
\hline $\mathrm{T}^{\mathrm{o}}$ media Septiembre & -- & -- & 3,3 & 0,4 \\
\hline $\mathrm{T}^{\mathrm{o}}$ mínima del mes más frío & -- & -- & 1,7 & 1,1 \\
\hline $\mathrm{T}^{\mathrm{o}}$ minima Mayo & -- & -- & 1,4 & 1,4 \\
\hline Total & $\mathbf{8 8 , 5}$ & & 91,5 & \\
\hline
\end{tabular}

Test de Jackknife para importancia de variables

Variable con mayor poder explicativo

Variable con información no contenida en el resto
$\mathrm{T}^{\mathbf{o}}$ mínima Agosto

Estacionalidad precipitaciones
$\mathrm{T}^{\mathrm{o}}$ media Agosto

Altitud 
Test de Jackknife usando ganancia de prueba

Variable con mayor poder explicativo

Variable con información no contenida en el resto

Test de Jackknife usando AUC

Variable con mayor poder explicativo

Variable con información no contenida en el resto
$\mathrm{T}^{\mathbf{o}}$ máxima Junio

Precipitación Diciembre

Isotermalidad

Precipitación Diciembre
$\mathrm{T}^{\mathbf{o}}$ media Septiembre

Precipitación Julio

Isotermalidad

Precipitación Julio 
Tabla 18. Resultados de las pruebas umbral-dependiente para Conepatus chinga, para los dos modelos generados.

\begin{tabular}{rcccc}
\hline & \multicolumn{2}{c}{ Actual } & \multicolumn{2}{c}{1950} \\
\cline { 2 - 5 } Valor umbral & Área predicha & \multicolumn{1}{c}{$P$-valor } & Área predicha & $P$-valor \\
\hline 1 & 0,7877 & 0,0001 & 0,6649 & 0 \\
5 & 0,7133 & 0,0002 & 0,5825 & 0 \\
10 & 0,6613 & 0,0013 & 0,5348 & 0,0003 \\
\hline
\end{tabular}


Tabla 19. Distancias de Procrustes (A) y $P$-valores de las distancias de Procrustes (B) entre grupos, obtenidos del test de permutaciones de cráneo ventral. En negrita se presentan los valores significativos para un $P<0,01$.

\begin{tabular}{l|r|r|r|l}
\hline \multicolumn{7}{c}{ A } \\
\hline & C. chinga & G. cuja & L. provocax & L. patagonicus \\
\hline G. cuja & 0,1027 & & & \\
\hline L. provocax & 0,1005 & 0,1037 & & \\
\hline L. patagonicus & 0,0962 & 0,0463 & 0,0962 & \\
\hline N. vison & 0,0905 & 0,0435 & 0,108 & 0,0494 \\
\hline \multicolumn{7}{|c|}{ B }
\end{tabular}

\begin{tabular}{l|r|l|l|l}
\hline & C. chinga & G. cuja & L. provocax & L. patagonicus \\
\hline G. cuja & $<\mathbf{0 , 0 0 0 1}$ & & & \\
\hline L. provocax & $<\mathbf{0 , 0 0 0 1}$ & $<\mathbf{0 , 0 0 0 1}$ & & \\
\hline L. patagonicus & $<\mathbf{0 , 0 0 0 1}$ & $<\mathbf{0 , 0 0 0 1}$ & $\mathbf{0 , 0 0 5 8}$ & \\
\hline N. vison & $<\mathbf{0 , 0 0 0 1}$ & $<\mathbf{0 , 0 0 0 1}$ & $\mathbf{0 , 0 0 3 1}$ & $<\mathbf{0 , 0 0 0 1}$ \\
\hline
\end{tabular}


Tabla 20. Distancias de Procrustes (A) y $P$-valores de las distancias de Procrustes (B) entre grupos, obtenidos del test de permutaciones de mandíbula lateral. En negrita se presentan los valores significativos para un $P<0,01$.

\begin{tabular}{l|r|r|r|r}
\hline \multicolumn{5}{c}{ A } \\
\hline C. chinga & G. cuja & L. provocax & L. patagonicus \\
\hline G. cuja & 0,1319 & & & \\
\hline L. provocax & 0,0981 & 0,0873 & & \\
\hline L. patagonicus & 0,1298 & 0,0449 & 0,0806 & \\
\hline N. vison & 0,1442 & 0,0607 & 0,0729 & \\
\hline \multicolumn{5}{|c|}{$\mathbf{B}$} \\
\hline \multicolumn{7}{|c|}{ C. chinga } & G. cuja & L. provocax & L. patagonicus \\
\hline L. prova & $<\mathbf{0 , 0 0 0 1}$ & & & \\
\hline L. patagonicus & $<\mathbf{0 , 0 0 0 1}$ & $\mathbf{0 , 0 0 0 7}$ & & \\
\hline N. vison & $<\mathbf{0 , 0 0 0 1}$ & $\mathbf{0 , 0 0 1 6}$ & $\mathbf{0 , 0 0 8 7}$ & \\
\hline
\end{tabular}


Tabla 21. $P$-valores del t-test con corrección de Bonferroni de los análisis realizados con el tamaño de centroide para cráneos, entre grupos. En negrita se presentan los valores significativos para un $P<0,01$.

\begin{tabular}{lrrrr}
\hline & C. chinga & G. cuja & L. provocax & L. patagonicus \\
\hline G. cuja & $<\mathbf{0 , 0 0 1}$ & & & \\
L. provocax & $<\mathbf{0 , 0 0 1}$ & $<\mathbf{0 , 0 0 1}$ & & \\
L. patagonicus & $<\mathbf{0 , 0 0 1}$ & $<\mathbf{0 , 0 0 1}$ & $<\mathbf{0 , 0 0 1}$ & \\
N. vison & 1 & $<\mathbf{0 , 0 0 1}$ & $<\mathbf{0 , 0 0 1}$ & $<0,001$ \\
\hline
\end{tabular}


Tabla 22. $P$-valores del t-test con corrección de Bonferroni de los análisis realizados con el tamaño de centroide para mandíbulas, entre grupos. En negrita se presentan los valores significativos para un $P<0,01$.

\begin{tabular}{lrrrr}
\hline & C. chinga & G. cuja & L. provocax & L. patagonicus \\
\hline G. cuja & 1 & & & \\
L. provocax & $<\mathbf{0 , 0 0 1}$ & $<\mathbf{0 , 0 0 1}$ & & \\
L. patagonicus & $<\mathbf{0 , 0 0 1}$ & $<\mathbf{0 , 0 0 1}$ & $<\mathbf{0 , 0 0 1}$ & \\
N. vison & $<\mathbf{0 , 0 0 1}$ & $<\mathbf{0 , 0 0 1}$ & $<\mathbf{0 , 0 0 1}$ & $<\mathbf{0 , 0 0 1}$ \\
\hline
\end{tabular}


Tabla 23. Resultado de OLS (véase Materiales y Métodos, sección 3.7.3) de tamaño de cráneo ventral y variables ambientales para Galictis cuja.

\begin{tabular}{lcc}
\hline Variable independiente & $\boldsymbol{P}$-valor & $\mathbf{R}^{\mathbf{2} a d j}$ \\
\hline Latitud & 0,321 & 0,023 \\
Longitud & 0,063 & 0,078 \\
Altitud & 0,055 & 0,083 \\
$\mathrm{~T}^{\mathbf{o}}$ media anual & 0,656 & 0,005 \\
Rango diurno medio de $\mathrm{T}^{\mathbf{o}}$ & 0,178 & 0,042 \\
Isotermalidad & 0,167 & 0,044 \\
Estacionalidad T$^{\mathbf{o}}$ & 0,741 & 0,003 \\
$\mathrm{~T}^{\mathbf{o}}$ máxima del mes más cálido & 0,912 & $<, 001$ \\
$\mathrm{~T}^{\mathbf{o}}$ mínima del mes más frío & 0,364 & 0,019 \\
Rango anual medio de To & 0,349 & 0,02 \\
$\mathrm{~T}^{\mathbf{o}}$ media del trimestre más húmedo & 0,592 & 0,007 \\
$\mathrm{~T}^{\mathbf{o}}$ media del trimestre más seco & 0,494 & 0,011 \\
$\mathrm{~T}^{\mathbf{o}}$ media del trimestre más cálido & 0,682 & 0,004 \\
$\mathrm{~T}^{\mathbf{o}}$ media del trimestre más frío & 0,82 & 0,001 \\
Precipitación anual & 0,074 & 0,072 \\
Precipitación del mes más húmedo & 0,378 & 0,018 \\
Precipitación del mes más seco & 0,121 & 0,055 \\
Estacionalidad de las precipitaciones & 0,056 & 0,082 \\
Precipitación del trimestre más húmedo & 0,467 & 0,012 \\
Precipitación del trimestre más seco & 0,139 & 0,05 \\
Precipitación del trimestre más cálido & 0,656 & 0,005 \\
Precipitación del trimestre más frío & 0,193 & 0,039 \\
NPP & 0,078 & 0,071 \\
PET $^{\mathbf{s}}$ & 0,357 & 0,02 \\
\hline
\end{tabular}


Tabla 24. Resultado de OLS (véase Materiales y Métodos, sección 3.7.3) de tamaño de mandíbula lateral y variables ambientales para Galictis cuja.

\begin{tabular}{lcc}
\hline Variable independiente & $\boldsymbol{P}$-valor & $\mathbf{R}^{\mathbf{2}} \mathbf{a d j}$ \\
\hline Latitud & 0,286 & 0,028 \\
Longitud & 0,271 & 0,03 \\
Altitud & 0,385 & 0,019 \\
$\mathrm{~T}^{\mathbf{o}}$ media anual & 0,673 & 0,004 \\
Rango diurno medio de $\mathrm{T}^{\mathbf{o}}$ & 0,414 & 0,017 \\
Isotermalidad & 0,417 & 0,017 \\
Estacionalidad To & 0,934 & $<, 001$ \\
$\mathrm{~T}^{\mathbf{o}}$ máxima del mes más cálido & 0,957 & $<, 001$ \\
$\mathrm{~T}^{\mathbf{o}}$ mínima del mes más frío & 0,665 & 0,005 \\
Rango anual medio de T & 0,557 & 0,008 \\
$\mathrm{~T}^{\mathbf{o}}$ media del trimestre más húmedo & 0,229 & 0,027 \\
$\mathrm{~T}^{\mathbf{o}}$ media del trimestre más seco & 0,743 & 0,003 \\
$\mathrm{~T}^{\mathbf{o}}$ media del trimestre más cálido & 0,743 & 0,003 \\
$\mathrm{~T}^{\mathbf{o}}$ media del trimestre más frío & 0,723 & 0,003 \\
Precipitación anual & 0,184 & 0,044 \\
Precipitación del mes más húmedo & 0,729 & 0,003 \\
Precipitación del mes más seco & 0,122 & 0,059 \\
Estacionalidad de las precipitaciones & 0,061 & 0,085 \\
Precipitación del trimestre más húmedo & 0,76 & 0,002 \\
Precipitación del trimestre más seco & 0,126 & 0,058 \\
Precipitación del trimestre más cálido & 0,719 & 0,003 \\
Precipitación del trimestre más frío & 0,099 & 0,066 \\
NPP & 0,147 & 0,052 \\
PET & 0,467 & 0,013 \\
\hline & &
\end{tabular}


Tabla 25. Parámetros estimados a partir del promedio de nueve OLS entre tamaño del centroide de cráneo de G. cuja y variables ambientales, usando AICw y variables ambientales seleccionadas (véase sección 3.7.3).

\begin{tabular}{lccc|c}
\hline Variable independiente & Coeficientes & Importancia & VIF & \multicolumn{1}{c}{$\mathbf{R}^{\mathbf{2}}$} \\
\hline Altitud & $-0,031$ & 0,533 & 1,406 & \\
$\mathrm{~T}^{\mathbf{o}}$ media anual & $-0,261$ & 0,386 & 1,22 & \\
Estacionalidad $\mathrm{T}^{\mathbf{o}}$ & 0,005 & 0,281 & 2,075 & 0,103 \\
$\mathrm{~T}^{\mathbf{o}}$ media del trimestre más seco & $-0,202$ & 0,348 & 1,397 & \\
Precipitación anual & 0,043 & 0,606 & 2,411 & \\
\hline
\end{tabular}


Tabla 26. Parámetros estimados a partir del promedio de ocho OLS entre tamaño del centroide de mandíbulas de G. cuja y variables ambientales, usando AICw y variables ambientales seleccionadas (véase sección 3.7.3).

\begin{tabular}{lccc|c}
\hline Variable independiente & Coeficientes & Importancia & VIF & \multicolumn{1}{c}{$\mathbf{R}^{\mathbf{2}}$} \\
\hline Altitud & 0,002 & 0,335 & 2,254 & \\
$\mathrm{~T}^{\mathbf{o}}$ media anual & $-0,393$ & 0,399 & 1,585 & \\
${\text { Estacionalidad } \mathrm{T}^{\mathbf{o}}}^{\mathrm{o}}$ & 0,026 & 0,347 & 2,778 & \multirow{2}{*}{0,032} \\
$\mathrm{~T}^{\mathbf{o}}$ media del trimestre más seco & 0,128 & 0,269 & 1,364 & \\
Precipitación anual & 0,08 & 0,567 & 3,319 & \\
\hline
\end{tabular}


Tabla 27. Resultados de OLS de tamaño del centroide de cráneo ventral y variables ambientales. En negrita se presentan los valores

significativos para un $P<0,01$. Un "Si” en la columna SFs indica la presencia de autocorrelación espacial en los datos y la utilización de filtros

espaciales. Se presentan además el $\mathrm{R}^{2}$ de OLS, de la variable independiente por separado, de los filtros espaciales por separado, y compartido entre la variable independiente y los filtros espaciales.

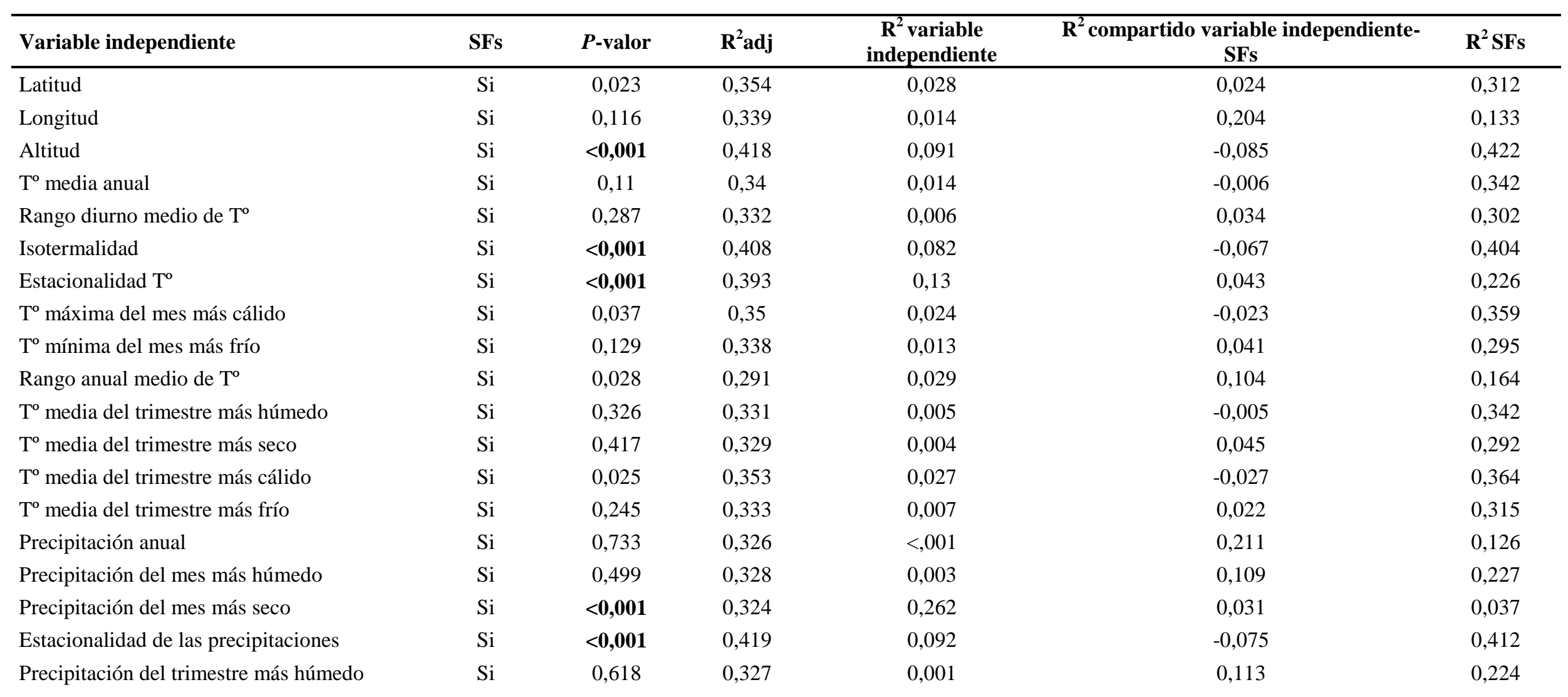


Continuación Tabla 27

\begin{tabular}{|c|c|c|c|c|c|c|}
\hline Precipitación del trimestre más seco & $\mathrm{Si}$ & $<0,001$ & 0,319 & 0,257 & 0,026 & 0,042 \\
\hline Precipitación del trimestre más cálido & $\mathrm{Si}$ & 0,813 & 0,326 & $<, 001$ & 0,07 & 0,267 \\
\hline Precipitación del trimestre más frío & $\mathrm{Si}$ & $<0,001$ & 0,32 & 0,256 & 0,016 & 0,06 \\
\hline NPP & No & $<0,001$ & 0,328 & --- & --- & --- \\
\hline PET & $\mathrm{Si}$ & 0,51 & 0,328 & 0,002 & $-0,002$ & 0,339 \\
\hline
\end{tabular}


Tabla 28. Resultados de OLS de tamaño del centroide de mandíbula lateral y variables ambientales. En negrita se presentan los valores

significativos para un $P<0,01$ Un "Si" en la columna SFs indica la presencia de autocorrelación espacial en los datos y la utilización de filtros espaciales. Se presentan además el $\mathrm{R}^{2}$ de OLS, de la variable independiente por separado, de los filtros espaciales por separado, y compartido entre la variable independiente y los filtros espaciales.

\begin{tabular}{|c|c|c|c|c|c|c|}
\hline Variable independiente & SFs & P-valor & $\mathbf{R}^{2} \mathbf{a d j}$ & $\begin{array}{c}\mathbf{R}^{2} \text { variable } \\
\text { independiente }\end{array}$ & $\begin{array}{l}\mathbf{R}^{2} \text { compartido variable independiente- } \\
\text { SFs }\end{array}$ & $\mathbf{R}^{2} \mathrm{SFs}$ \\
\hline Latitud & $\mathrm{Si}$ & 0,67 & 0,361 & 0,001 & $<, 001$ & 0,374 \\
\hline Longitud & $\mathrm{Si}$ & 0,932 & 0,334 & $<, 001$ & 0,113 & 0,241 \\
\hline Altitud & $\mathrm{Si}$ & 0,054 & 0,344 & 0,025 & $-0,024$ & 0,355 \\
\hline $\mathrm{T}^{\mathrm{o}}$ media anual & $\mathrm{Si}$ & 0,092 & 0,379 & 0,018 & $-0,018$ & 0,391 \\
\hline Rango diurno medio de $\mathrm{T}^{\mathrm{o}}$ & $\mathrm{Si}$ & 0,896 & 0,318 & $<, 001$ & 0,069 & 0,263 \\
\hline Isotermalidad & $\mathrm{Si}$ & 0,393 & 0,323 & 0,005 & 0,008 & 0,324 \\
\hline Estacionalidad $\mathrm{T}^{\mathrm{o}}$ & $\mathrm{Si}$ & 0,172 & 0,315 & 0,013 & 0,031 & 0,278 \\
\hline $\mathrm{T}^{\mathrm{o}}$ máxima del mes más cálido & $\mathrm{Si}$ & 0,025 & 0,353 & 0,034 & $-0,032$ & 0,363 \\
\hline $\mathrm{T}^{\mathrm{o}}$ mínima del mes más frío & $\mathrm{Si}$ & 0,351 & 0,324 & 0,006 & 0,031 & 0,3 \\
\hline Rango anual medio de $\mathrm{T}^{\mathrm{o}}$ & $\mathrm{Si}$ & 0,371 & 0,307 & 0,006 & 0,099 & 0,21 \\
\hline $\mathrm{T}^{\mathrm{o}}$ media del trimestre más húmedo & $\mathrm{Si}$ & 0,004 & 0,373 & 0,054 & $-0,044$ & 0,375 \\
\hline $\mathrm{T}^{\mathrm{o}}$ media del trimestre más seco & $\mathrm{Si}$ & 0,277 & 0,31 & 0,008 & 0,052 & 0,257 \\
\hline $\mathrm{T}^{\mathrm{o}}$ media del trimestre más cálido & $\mathrm{Si}$ & 0,013 & 0,36 & 0,041 & $-0,041$ & 0,373 \\
\hline $\mathrm{T}^{\mathrm{o}}$ media del trimestre más frío & $\mathrm{Si}$ & 0,548 & 0,32 & 0,003 & 0,003 & 0,328 \\
\hline Precipitación anual & $\mathrm{Si}$ & 0,648 & 0,319 & 0,001 & 0,147 & 0,185 \\
\hline Precipitación del mes más húemdo & $\mathrm{Si}$ & 0,586 & 0,32 & 0,002 & 0,048 & 0,283 \\
\hline Precipitación del mes más seco & $\mathrm{Si}$ & $<0,001$ & 0,281 & 0,265 & $-0,012$ & 0,35 \\
\hline Estacionalidad de las precipitaciones & $\mathrm{Si}$ & 0,561 & 0,32 & 0,002 & 0,065 & 0,267 \\
\hline Precipitación del trimestre más húmedo & $\mathrm{Si}$ & 0,797 & 0,318 & $<, 001$ & 0,045 & 0,287 \\
\hline
\end{tabular}


Continuación Tabla 28

\begin{tabular}{lccccc} 
Precipitación del trimestre más seco & Si & $<\mathbf{0 , 0 0 1}$ & 0,302 & 0,27 & $-0,026$ \\
Precipitación del trimestre más cálido & $\mathrm{Si}$ & 0,933 & 0,318 & $<, 001$ & 0,013 \\
Precipitación del trimestre más frío & $\mathrm{Si}$ & $\mathbf{< 0 , 0 0 1}$ & 0,285 & 0,072 \\
NPP & $\mathrm{Si}$ & $<\mathbf{0 , 0 0 1}$ & 0,293 & 0,319 \\
PET & $\mathrm{Si}$ & 0,028 & 0,351 & 0,277 & $-0,006$ \\
\hline
\end{tabular}


Tabla 29. Parámetros estimados a partir del promedio de ocho OLS entre tamaño del centroide de cráneo de $C$. chinga y variables ambientales, usando AICw y variables ambientales seleccionadas (véase sección 3.7.3)

\begin{tabular}{lccc|c}
\hline Variable independiente & Coeficientes & \multicolumn{1}{c}{ Importancia } & \multicolumn{1}{c}{ VIF } & \multicolumn{1}{c}{$\mathbf{R}^{\mathbf{2}}$} \\
\hline Altitud & 0,033 & 0,875 & 7,01 & \\
Isotermalidad & 3,673 & 0,433 & 5,334 & \\
Estacionalidad T & 0,025 & 0,524 & 5,865 & \\
$\mathrm{~T}^{\mathbf{o}}$ media del trimestre más seco & 0,123 & 0,34 & 2,3 & \\
Estacionalidad precipitaciones & 0,064 & 0,266 & 6,295 & 0,401 \\
Precipitación del trimestre más húmedo & $-0,04$ & 0,298 & 5,886 & \\
NPP & 233,14 & 1 & 5,438 & \\
PET & $-0,006$ & 0,284 & 5,516 & \\
\hline
\end{tabular}


Tabla 30. Parámetros estimados a partir del promedio de ocho OLS entre tamaño del centroide de mandíbulas de $C$. chinga y variables ambientales, usando AICw y variables ambientales seleccionadas (véase sección 3.7.3)

\begin{tabular}{lccc|c}
\hline Variable independiente & Coeficientes & \multicolumn{1}{c}{ Importancia } & \multicolumn{1}{c}{ VIF } & \multicolumn{1}{c}{$\mathbf{R}^{\mathbf{2}}$} \\
\hline Altitud & 0,026 & 0,941 & 6,446 & \\
Isotermalidad & 0,351 & 0,268 & 6,157 & \\
Estacionalidad T & 0,034 & 0,924 & 4,985 & \\
$\mathrm{~T}^{\mathbf{o}}$ media del trimestre más seco & 0,298 & 0,905 & 2122 & \multirow{2}{*}{0,323} \\
Estacionalidad precipitaciones & $-0,165$ & 0,314 & 7,235 & \\
Precipitación del trimestre más húmedo & $-0,047$ & 0,384 & 6,155 & \\
NPP & 138,547 & 1 & 5,287 & \\
PET & $-0,019$ & 0,357 & 5,419 & \\
\hline
\end{tabular}




\section{Apéndices}


Apéndice I. Lista de especímenes analizados (indicados por números de colección), ordenados por especie, institución y provincia y/o país de su localidad de registro. Para Conepatus chinga, una “(c)” representa que el material se compone de cráneo y/o mandíbula, una “(p)” representa que el material se compone de una piel; mientras que “(c+p)” indica que contenía ambos. Para el resto de las especies sólo se analizó material óseo.

\section{Conepatus chinga}

BMNH. British Museum of Natural History. Solamente (c).

Buenos Aires: 9.12.1.18.

Córdoba: 2.2.5.3

La Rioja: 19.12.7.1; 19.12.7.3.

Bolivia: 98.3.16.4.

“Estrecho de Magallanes": s.k.bb.a.

CMI. Colección de Mamíferos del IADIZA. Solamente (c).

Catamarca: 05801.

Mendoza: 03475; 05802; 05804; 05805; 05807; 05808; 05809; 05810; 05811; 05815.

FHN. Fundación de Historia Natural Félix de Azara.

Buenos Aires: 4409(p); 8122(c); 8750(c); 9752(c).

La Pampa: 8568(c+p); 8915(c).

Neuquén: 418(c); 6381(c).

Río Negro: 8773(c); 10866(c).

Santa Cruz: 9376(c); 9926(c). 
Santiago del Estero: 9457(c); 10529(c); 10531(c); 10532(c); 10803(c).

Tucumán: 5543(p).

República Oriental del Uruguay: 6352(c); 10613(c).

Sin datos: $4430(p)$.

IML. Instituto Miguel Lillo.

Catamarca: 436(p); 439(p).

Chubut: 538(p); 6322(c);

Córdoba: 642(c+p), 643(c+p); 657(c+p); 658(c+p); 659(c+p).

Entre Ríos: 4078(c).

Jujuy: 187(c+p); 5972(c); 7150(c); 7151(c).

Mendoza: 5476(c).

Neuquén: 185(p).

Río Negro: 182(c).

Salta: 183(c); 1495(c); 1627(c+p).

Santa Cruz: 6194(c).

Santiago del Estero: 528(c+p); 529(c+p).

Tucumán: 198(c); 1077(c+p); 1183(c+p); 1184(c+p); 1185(c+p);1186; 1305(c+p); 1532(c+p); $1534(\mathrm{p}) ;$ 5973(c); 6195(c); 7355(c).

IZP. Instituto Zoológico de la Patagonia. Solamente (c).

República de Chile: 34; 36; 39.

LIEB. Laboratorio de Investigaciones en Evolución y Biodiversidad. Solamente (c).

Chubut: 795; 796; 797; 798; 799; 800; 801; 802; 803; 810; 811. 
MACN. Museo Argentino de Ciencias Naturales "Bernardino Rivadavia".

Buenos Aires: 26.98(c); 36.59(p); 36.62(p); 36.63(p). 51.85(c); 20391(c); 23985(c); 23986(c); 23987(c); 23989(c); 23991(c); 29912(p).

Catamarca: 50.421(p); 50.429(c); 50.439(c).

Chaco: 30.204(p).

Chubut: 13.35(c); 28.72(c+p); 28.73(c+p); 28.74(c); 32.69(c); 32.70(c); 44.5(c); 44.6(c); 16.475(c+p).

Córdoba: 25.165(p); 39.195(c); 39.196(c); 13297(c+p).

Corrientes: 14052(p); 13714(p).

Entre Ríos: 28.21(c); 28.22(c); 49.9(c+p); 49.10(c+p); 49.15(c+p); 49.42(c+p);

20.424(p); 48.283(p); 51.162(p); 51.163(p).

Formosa: 43.58(c+p); 43.59(p); 47.119(c+p).

Jujuy: 52.89(c); 26.182(p); 27.101(p); 32.251(c); 39.497(p); 39.498(p).

La Pampa: 15480(p); 15549(c+p); 15573(c); 15574(c+p); 39.703(p); 39.709(p); 39.710(p); 39.711(p); 49.168(p); 49.171(p); 49.172(p).

La Rioja: 28.184(c+p); 28.185(c); 28.186(c+p); 30.229(p); 34.330(c+p); 34.363(p); 34.553(p); 34.564(p);

Mendoza: 37.10(p); 37.11(p); 38.85(p); 53.43(c).

Neuquén: 38.83(p); 38.84(p); 13.499(c+p); 14083(c+p); 14084(c); 14085(c+p); 17769(c+p); 34.224(p).

Río Negro: 23992(c); 23993(c); 23994(c); 23995(c); 23996(c); 23997(c); 23998(c); 23999(c); 24000(c); 24001(c); 24002(c); 24003(c); 24004(c); 24005(c); 24006(c); 28.105(p). 
Salta: 41.58(p); 41.61(p); 41.62(p); 41.96(p) 30.101(c+p); 30.102(c+p); 30.392(c+p); 30.393(c+p); 36.167(c+p); 36.321(p); 36.322(c+p); 36.323(c+p); 36.324(c+p);

36.325(p); 36.326(c+p); 36.332(c+p); 38.485(p); 36.486(p); 36.728(c+p).

San Luis: 53.82(p); 53.83(p); 29.194(c).

Santa Cruz: 23.22(c); 16320(c); 23724(c); 29.896(c); 29915(c).

"Patagonia": 3.33(c)

Sin datos: 23518(c).

MHNM. Museo de Historia Natural de Montevideo.

República Oriental del Uruguay: 289(c); 290(c); 291(c); 292(p) 293(c+p); 294(c+p); 799(p); 880(c+p); 976(p); 1312(c); 1849(c+p); 1850(c+p); 1936(c); 2953(c); 2957(c+p); 3073(p); 3177(c); 3200(c); 3201(c); 3202(c); 3210(c); 3278(c); 3282(c); 3284(c); 3341(c); 3354(c); 3415(c); 3974(c+p); 3975(c); 3976(c); 4742(p); 5487(c); 5488(c); 5490(c); 5496(c); 5497(c); 6276(c); 6403(p); 6419(c); 6438(c).

MHNN. Muséum National d'Histoire Naturelle.

Río Negro: A3150(c).

MHNSR. Museo de Historia Natural de San Rafael. Solamente (c).

La Pampa: 459.

Mendoza: 251; 706.

MLP. Museo de La Plata. 
Buenos Aires: 1.II.95.1(c); 2.VI.60.13(c); 5.IX.44.5(p); 5.IX.44.6(p); 6.III.36.38(p); 3.X.94.1(c); 8.V.59.4(c); 8.V.59.6(c); 9.X.92.5(p); 10.II.99.1(c); 14.IX.98.8(c);

28.VII.78.1(c+p); 1273(c); 1274(c); 1275(c); 1277(c); 1727(c).

Chaco: 2007(c).

Chubut: 2.VI.60.2(c); 5.III.36.36(p); 6.III.36.39(c+p); 7.IX.43.1(p); 325(c); 533(c); 534(c); 702(c); 1807(c).

Córdoba: 12-XI-41-13(p); 12-XI-41-14(p); 12-XI-41-15(p); 12-XI-41-16(p); 18.XI.41.1(p); 18.XI.41.2(p); 18.XI.41.3(p); 18.XI.41.4(p); 18.XI.41.5(p); 18.XI.41.6(p); 18.XI.41.7(p); 18.XI.41.8(p); 658(c); 1582(c).

Entre Ríos: 5.V.99.4(c); 5.V.99.5(c); 5.V.99.7(c); 8.IX.98.3(c); 19.XII.02.2(c).

La Pampa: 1.II.93.1(p); 1.II.93.2(p); 6.III.36.37(p); 8.V.95.2(p); 8.V.95.4(p); 8.V.95.5(p).

Río Negro: 2027(c); 2028(c); 2029(c).

Salta: 7.X.46.1(c+p).

Santa Cruz: 1.XII.00.4(c); 1.XII.00.5(c).

MMP. Museo Municipal de Ciencias Naturales "Lorenzo Scaglia". Solamente (c). Buenos Aires: 2138; 4102; 4125.

Santiago del Estero: 2526.

República Oriental del Uruguay: 535.

Sin datos: $54 ; 55 ; 56 ; 1391$.

MNHNS. Museo Nacional de Historia Natural de Santiago.

República de Chile: 328(c). 
NMW. Naturhistorischen Museum Wien - Mammalogy. Solamente (c).

República de Chile: 1004; 1005; 1008; 1052; 1053; 2474

SMNS. Staatliches Museum für Naturkunde Sttutgart - Mammalogy. Solamente (c).

Santa Cruz: 39681.

Santa Fe: 26335.

“Argentina, provincia central": 21873.

República de Chile: 522; 21874.

UNS. Universidad Nacional del Sur. Solamente (c).

Buenos Aires: $5 ; 11 ; 12 ; 21 ; 41 ; 44 ; 52 ; 55 ; 56 ; 66 ; 69 ; 70 ; 71 ; 72 ; 79 ; 86 ; 98 ; 107 ; 109$; $111 ; 118 ; 136 ; 224$ bis.

Chubut: 113.

La Pampa: 50.

Tucumán: 33 .

\section{Conepatus semistriatus}

MACN. Museo Argentino de Ciencias Naturales "Bernardino Rivadavia".

República del Ecuador: 31.62(c).

\section{Galictis cuja}

CMI. Colección de Mamíferos del IADIZA.

Chaco: 05803.

Mendoza: 05812; 05813; 06372. 
FHN. Fundación de Historia Natural Félix de Azara.

Buenos Aires: 2692; 4374; 9742; 9751.

Chubut: 5594.

Entre Ríos: 8299.

Formosa: 4601.

La Pampa: 10555

San Luis: 8615

Santa Cruz: 9369.

Santiago del Estero: 11067.

IML. Instituto Miguel Lillo.

La Rioja: 3734.

Salta: 7127.

Tucumán: $1043 ; 1587 ; 3728$.

LIEB. Laboratorio de Investigaciones en Evolución y Biodiversidad.

Chubut: 884; 911.

MACN. Museo Argentino de Ciencias Naturales "Bernardino Rivadavia".

Buenos Aires: $31.19 ; 184 ; 315 ; 13.075 ; 23291 ; 23659 ; 26.166$.

Chubut: $28.75 ; 13.939 ; 16520$

Córdoba: 23658; 29.191.

Jujuy: $37.84 ; 18.201 ; 31.170 ; 31.171 ; 31.200$.

La Pampa: 15584.

La Rioja: 34-331. 
Neuquén: $13.498 ; 13.501 ; 13.798$.

Río Negro: $13.963 ; 13.065 ; 23604$.

San Juan: 29795.

San Luis: 26.80 .

Tucumán: 30.95; 30.96.

República del Paraguay: 47.373.

MHNM. Museo de Historia Natural de Montevideo.

República del Uruguay: 295; 296; 955; 1158; 1246; 1923; 2548; 2690; 2696; 3233; $6412 ; 6433$.

República Federativa del Brasil: 1339.

MHNSR. Museo de Historia Natural de San Rafael.

Mendoza: 160.

MLP. Museo de La Plata.

Buenos Aires: 3.V.99.4; 8.V.59.6; 15.V.97.42; 25.IV.01.1;1705.

Entre Ríos: 1706.

Santa Cruz: 19.XII.02.21.

Santa Fe: 674; 704.

\section{Galictis vittata}

FHN. Fundación de Historia Natural Félix de Azara.

Misiones: 5723. 


\section{Lyncodon patagonicus}

CMI. Colección de Mamíferos del IADIZA.

Mendoza: 05814.

FHN. Fundación de Historia Natural Félix de Azara.

Río Negro: 5569.

IML. Instituto Miguel Lillo.

Catamarca: 655 .

Tucumán: 835.

LIEB. Laboratorio de Investigaciones en Evolución y Biodiversidad.

Chubut: 889.

MACN. Museo Argentino de Ciencias Naturales "Bernardino Rivadavia".

Chubut: 19423.

La Rioja: 31214.

MHNSR. Museo de Historia Natural de San Rafael.

Mendoza: 124; 461.

MLP. Museo de La Plata.

Chubut: 6.III.36.32.

La Pampa: 27.III.96.1. 
Río Negro: 29.XII.00.17.

\section{Lontra provocax}

MACN. Museo Argentino de Ciencias Naturales "Bernardino Rivadavia".

Santa Cruz: 20281

Tierra del Fuego: 4.402

MMP. Museo Municipal de Ciencias Naturales "Lorenzo Scaglia".

Neuquén: 141

SMNS. Staatliches Museum für Naturkunde Sttutgart - Mammalogy.

República de Chile: 5691.

\section{Neovison vison}

FHN. Fundación de Historia Natural Félix de Azara.

Tierra del Fuego: 2274; 2275.

LIEB. Laboratorio de Investigaciones en Evolución y Biodiversidad.

Chubut: 806; 807; 808; 886.

MACN. Museo Argentino de Ciencias Naturales "Bernardino Rivadavia".

Chubut: $16327 ; 17825 ; 17826$.

Buenos Aires: 19185; 19186; 19187.

MLP. Museo de La Plata.

Buenos Aires: 27.X.97.2; 27.X.97.6. 
Apéndice II. Nombre de las variables bioclimáticas (Hijmans et al., 2005a), con las traducciones usadas en este trabajo.

BIO1= Annual Mean Temperature $=$ Temperatura media annual.

BIO2= Mean Diurnal Range $=$ Rango diurno medio de temperatura.

$\mathrm{BIO}=$ Isothermality $=$ Isotermalidad.

BIO4= Temperature Seasonality $=$ Estacionalidad de la temperatura.

BIO5= Max Temperature of Warmest Month = Temperatura máxima del mes más cálido

BIO6= Min Temperature of Coldest Month = Temperatura mínima del mes más frío.

$\mathrm{BIO} 7=$ Temperature Annual Range $=$ Rango anual de temperature.

BIO8= Mean Temperature of Wettest Quarter $=$ Temperatura media del trimestre más húmedo.

BIO9= Mean Temperature of Driest Quarter $=$ Temperatura media del trimestre más seco.

$\mathrm{BIO} 10=$ Mean Temperature of Warmest Quarter $=$ Temperatura media del trimestre más cálido.

BIO11= Mean Temperature of Coldest Quarter $=$ Temperatura media del trimestre más frío.

BIO12= Annual Precipitation $=$ Precipitación annual.

BIO13= Precipitation of Wettest Month = Precipitación del mes más húmedo.

BIO14= Precipitation of Driest Month = Precipitación del mes más seco.

BIO15 = Precipitation Seasonality $=$ Estacionalidad de las precipitaciones.

BIO16= Precipitation of Wettest Quarter $=$ Precipitación del trimestre más húmedo.

BIO17= Precipitation of Driest Quarter $=$ Precipitación del trimestre más seco. 
BIO18= Precipitation of Warmest Quarter $=$ Precipitación del trimestre más cálido.

BIO19= Precipitation of Coldest Quarter $=$ Precipitación del trimestre más frío. 